\begin{abstract}
Eric A. Silk, Ph.D., 2006 A.D.

Research Advisors: $\quad$ Professor Kenneth Kiger

Department of Mechanical Engineering

Professor Jungho Kim

Department of Mechanical Engineering
\end{abstract}

Title of Ph.D.: INVESTIGATION OF ENHANCED SURFACE SPRAY COOLING

Phase change technology is a science that is continually finding new applications, from passive refrigeration cycles to semiconductor cooling. The primary heat transfer techniques associated with phase change heat transfer are pool boiling, flow boiling, and spray cooling. Of these techniques, spray cooling is the least studied and the most recent to receive attention in the scientific community. Spray cooling is capable of removing large amounts of heat between the cooled surface and the liquid, with reported heat flux capabilities of up to $1000 \mathrm{~W} / \mathrm{cm}^{2}$ for water. Many previous studies have emphasized heat flux as a function of spray parameters and test conditions. Enhanced spray cooling investigations to date have been limited to surface roughness studies. These studies concluded that surface tolerance (i.e. variations in machined surface finish) had an impact upon heat flux when using pressure atomized sprays. Analogous pool boiling studies with enhanced surfaces have shown heat flux enhancement. A spray cooling study using enhanced surfaces beyond the surface roughness range may display heat flux enhancement as well. 
In the present study, a group of extended and embedded surfaces (straight fins, cubic pin fins, pyramids, dimples and porous tunnels) have been investigated to determine the effects of enhanced surface structure on heat flux. The surface enhancements were machined on the top surface of copper heater blocks with a crosssectional area of $2.0 \mathrm{~cm}^{2}$. Measurements were also obtained on a flat surface for baseline comparison purposes. Thermal performance data was obtained under saturated (pure fluid at $101 \mathrm{kPa}$ ), nominally degassed (chamber pressure of $41.4 \mathrm{kPa}$ ) and gassy conditions (chamber with $\mathrm{N}_{2}$ gas at $101 \mathrm{kPa}$ ). The study shows that both extended and embedded structures (beyond the surface roughness range) promote heat flux enhancement for both degassed and gassy spray cooling conditions. The study also shows that straight fins provide the best utilization of surface area added for heat transfer. An Energy conservation based CHF correlation for flat surface spray cooling was also developed. CHF predictions were compared against published and non-published studies by several researchers. Results for the correlations performance show an average mean error of $\pm 17.6 \%$ with an accuracy of $\pm 30 \%$ for $88 \%$ of the data set compared against. 


\title{
INVESTIGATION OF ENHANCED SURFACE SPRAY COOLING
}

\author{
By
}

Eric A. Silk
Dissertation submitted to the Faculty of the Graduate School of the University of Maryland, College Park, in partial fulfillment of the requirements for the degree of Doctor of Philosophy of Mechanical Engineering 2006 A.D.

Advisory Committee:

Professor Kenneth Kiger

Professor Jungho Kim

Professor Marino di Marzo

Professor Reinhard Radermacher

Professor Ken $\mathrm{Yu}$ 
(C) Copyright by Eric A. Silk

2006 A.D. 


\section{DEDICATION}

To the Ancient Black Men of old (men of reknown) whose legacy on this planet has been diminished by genocide, ethnocentrism, historical revisionism, and the obliteration of their presence through domination, destruction and death: "... as it was in the beginning, so shall it be in the end". 


\section{ACKNOWLEDGEMENTS}

The author would like to thank Dr. Ken Kiger and Dr. Jungho Kim for their patience and support through this process.

The author would like to thank J.B. Dotellis and Lester Lorentz of the Laboratory for Physical Sciences for their skillful assistance in helping to make my ideas a reality. The author would also like to thank Richard Freburger of NASA Goddard Space Flight Center for his assistance and machining expertise.

The author would like to thank Paul Boudreaux, as well as Ted Swanson and Dan Butler of NASA Goddard Space Flight Center for their monetary support and encouragement throughout this process.

The author would like to thank the Dissertation Committee members for agreeing to participate in the review process.

The author would like to thank Dr. Reinhard Radermacher of the University of Maryland College Park for his promotion and guidance in aspiring for a Doctoral Degree.

The author would like to thank Dr. Emmanuel K. Glakpe of Howard University for providing a passageway into the realm of graduate school.

The author would like to thank Dr. Carsie A. Hall III and Dr. Preston Frazier for providing a living template for success in advanced degree pursuits.

Last but not least, the author would like to thank his parents and extended family for their moral support during this process. 


\section{TABLE OF CONTENTS}

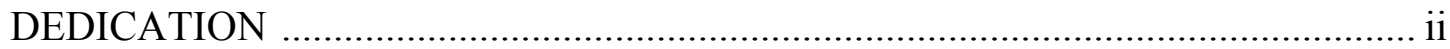

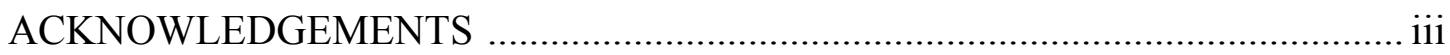

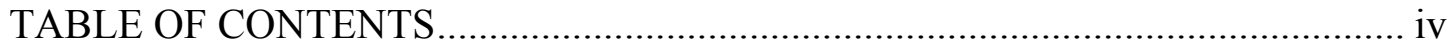

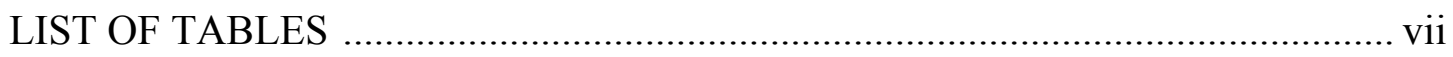

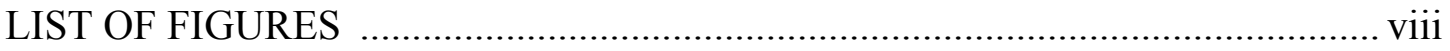

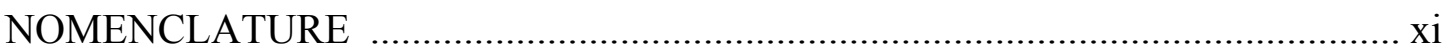

CHAPTER

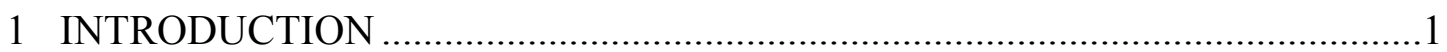

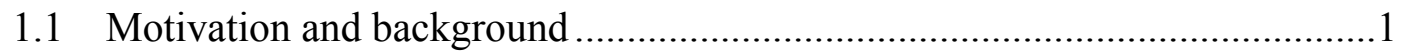

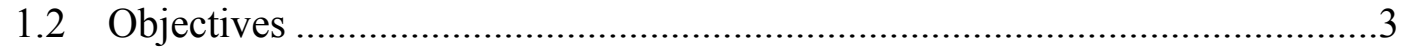

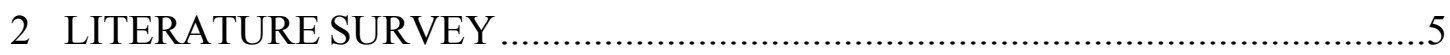

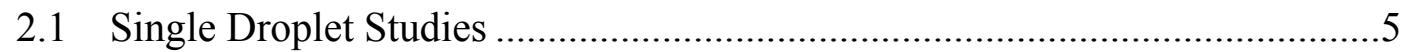

2.1.1 Heat Transfer Phenomena..............................................................5

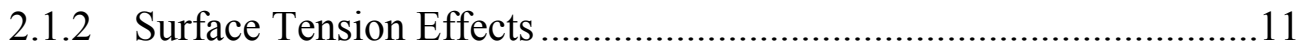

2.2 Spray Cooling Studies.................................................................................

2.2.1 Test Conditions and Spray Characteristics ………..............................14

2.2.2 Dissolved Gasses .....................................................................22

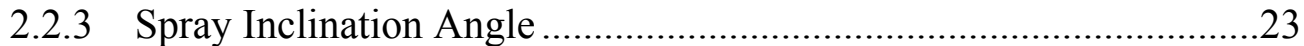

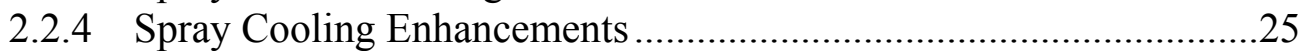

2.3 Enhanced Surface Pool Boiling Studies ....................................................27

2.4 Summary and Overview Of Present Work ....................................................

3 EXPERIMENTAL APPARATUS AND PROCEDURES ……………………........33

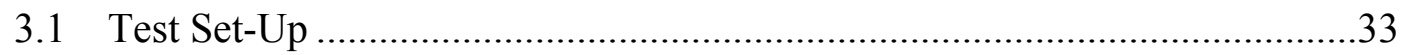

3.1.1 Laboratory for Physical Sciences (LPS) Studies ................................33

3.1.2 NASA Goddard Space Flight Center Studies .....................................37

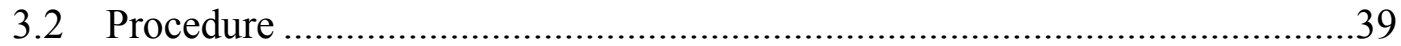

3.3 ISR Nozzle Spray Characteristics ..............................................................42

3.3.1 Effective Volumetric Flow Rate Determination ..............................42

3.3.2 Spray Droplet Measurements............................................................46

3.4 Spray Nozzle Volumetric Flux Uniformity Studies.........................................51

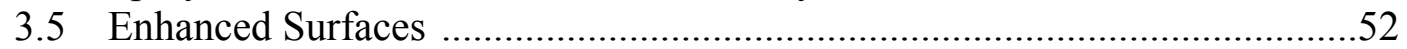




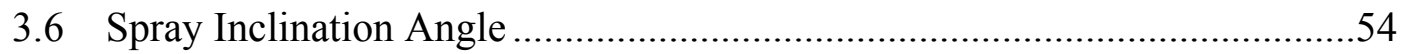

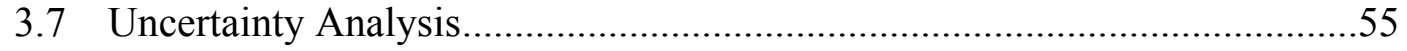

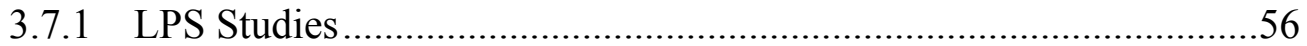

3.7.2 NASA Goddard Space Flight Center Studies ...................................57

3.7.3 Chamber Environment Heat Exchange .............................................57

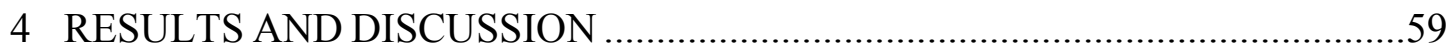

4.1 Flat Surface Variational Height and Flow Rate Studies ...............................59

4.1.1 ISR Nozzle Spray Characteristics ..................................................59

4.1.2 Spray Cooling Heat Flux Performance ………...............................64

4.2 Spray Nozzle Volumetric Flux Survey Study ………..................................70

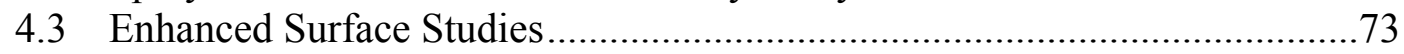

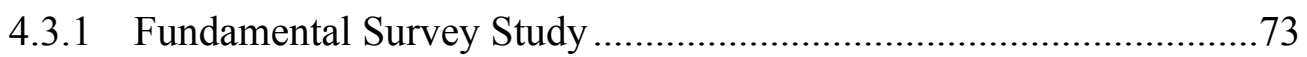

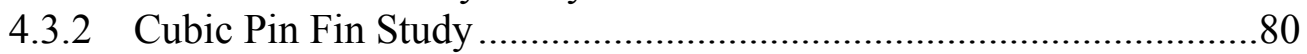

4.3.3 Compound Surface Enhancements and Embedded Structures ...........90

4.3.4 Spray Inclination Angle Impact Upon Heat Flux ……………...........99

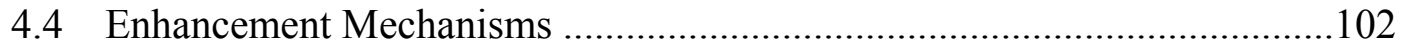

4.4.1 Structured Surface Geometries .......................................................102

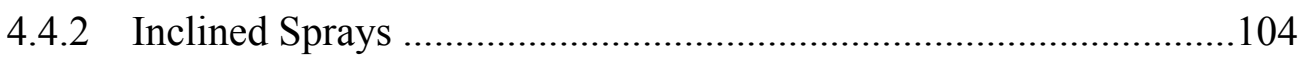

5 HEAT FLUX CORRELATION DEVELOPMENT ……………….....................107

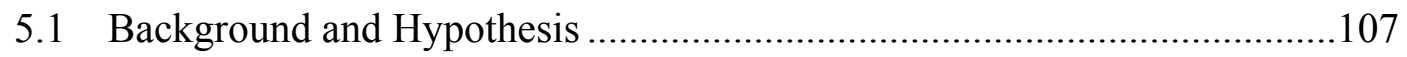

5.2 Spray Cooling Heat Transfer Process ………............................................113

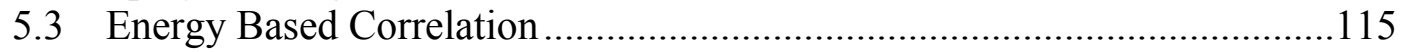

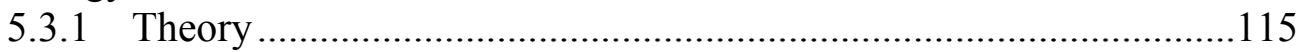

5.3.2 Fortran Code Energy Based Correlation Results and Discussion....121

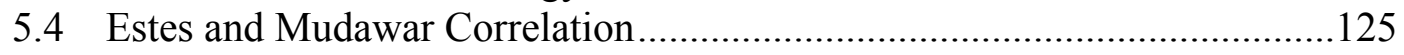

5.5 Energy Based Correlation Scope and Application........................................128

6 CONCLUSIONS AND RECOMMENDATIONS ...............................................131

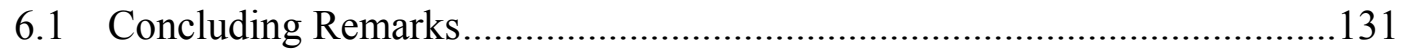

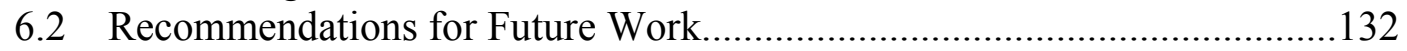

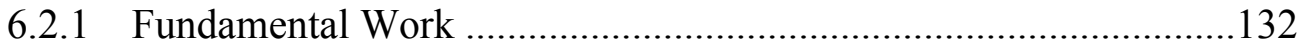

6.2.2 Theoretical Development ..........................................................134

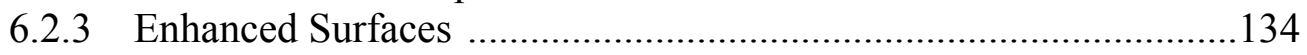

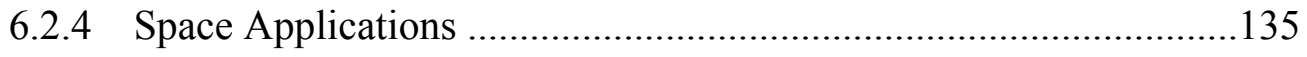

APPENDIX A: Droplet Shape Relation ……………………...........................137

APPENDIX B: Spray Cooling Flow Field Governing Equations .............................138

APPENDIX C: Test Conditions For Model Comparison Studies .............................140 


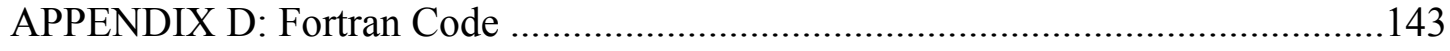

APPENDIX E: List of Publications and Presentations ..........................................146

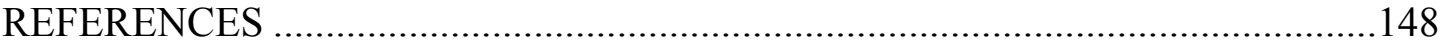




\section{LIST OF TABLES}

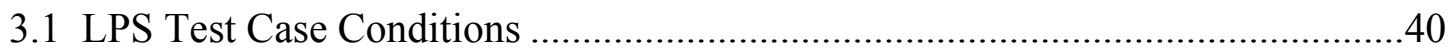

3.2 Spray Cooling Test Cases for Flat Surface Copper Block................................40

3.3 NASA GSFC Test Case Conditions ............................................................41

3.4 Volumetric Fraction Case Study Summary ................................................46

3.5 Spray Characteristics Measurement PDPA Settings.......................................47

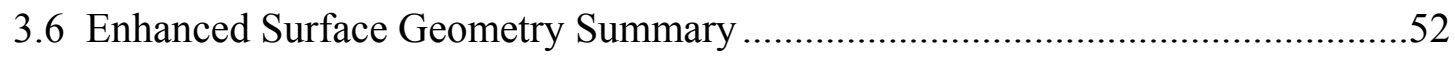

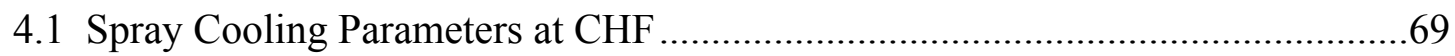

4.2 Nozzle Survey Volumetric Flux Uniformity Measurements .............................71

4.3 Summary of Enhanced Surface Data for Fundamental Study ...........................75

4.4 Summary of Cubic Pin Finned Surface Data for Variational Study .....................83

4.5 Summary of Degassed and Gassy data for Compound and Embedded surface

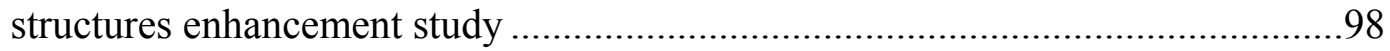

4.6 Summary of Data for Spray Inclination Angle Impact Study .........................101

5.1 Spray Cooling Parameters at Maximum Heat Flux .........................................109

5.2 Studies Used For Energy Based Nu Correlation Effort .................................120

C.1 Model Comparison Test data for Silk LPS Study …................................... 140

C.2 Model Comparison Test data for Horacek et al. (2005) Study .........................140

C.3 Model Comparison Test data for Rini et al. (2002) Study ...............................140

C.4 Model Comparison Test data for Lin and Ponnappan (2003) Study.................141

C.5 Model Comparison Test data for Puterbaugh et al. (2007) Study.....................141

C.6 Model Comparison Test data for Silk et al. (2005) GSFC Extended Studies ....141

C.7 Model Comparison Test data for Chen et al. (2002) Study ............................. 142 


\section{LIST OF FIGURES}

3.1 LPS Spray Cooling Test Rig Configuration .......................................................33

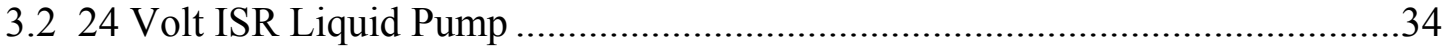

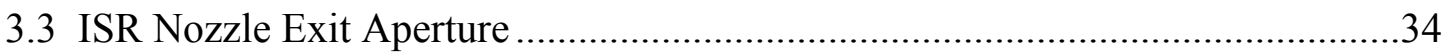

3.4 LPS Test Rig Copper Block Housing Configuration...............................................35

3.5 Heater Block TC Locations (not to scale)..........................................................36

3.6 NASA GSFC Spray Cooling Test Rig Configuration ............................................37

3.7 NASA GSFC Test Rig Copper Block Housing Schematic .....................................38

3.8 Copper Block Schematic with TC Locations (not to scale)....................................39

3.9 Example of Temperature vs. Time plot for Spray Cooling Test Data ...................41

3.10 Example of Heat Flux vs. Time plot for Spray Cooling Test Data......................42

3.11 Volumetric Over-spray Schematic...................................................................43

3.12 Uniform Volumetric Flow Rate Distribution Calculation Schematic..................44

3.13 Spray Cone close-up at variable Spray Volumetric Flow Rates; (a) $3.33 \times 10^{-7}$

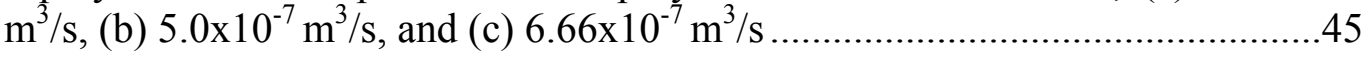

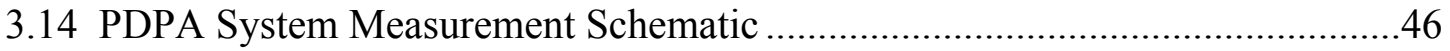

3.15 Spray Cone Measurement Planes........................................................................48

3.16 Mean Velocity and SMD distributions at $x=-3, z=20 \mathrm{~mm}$ plane, $30 \mathrm{ml} / \mathrm{min}$.....50

3.17 Mean Velocity and SMD distributions at $\mathrm{x}=0, \mathrm{z}=20 \mathrm{~mm}$ plane, $30 \mathrm{ml} / \mathrm{min}$.......50

3.18 Mean Velocity and SMD distributions at $\mathrm{x}=4, \mathrm{z}=20 \mathrm{~mm}$ plane, $30 \mathrm{ml} / \mathrm{min}$.......50

3.19 Spray Uniformity Test Schematic (not to scale) .................................................51

3.20 Surface Geometry Cross Sectional Views and Photos ……………....................53

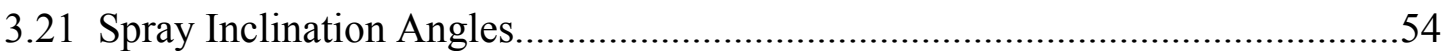

3.22 Spray Orientation Relative to the Straight Fins ………....................................55 
4.1 ISR Nozzle in $0^{\circ}$ orientation, $\dot{V}=3.33 \times 10^{-7} \mathrm{~m}^{3} / \mathrm{s}$; (a) SMD, (b) Mean Droplet Velocity .60

4.2 ISR Nozzle in $0^{\circ}$ orientation, $\dot{V}=5.0 \times 10^{-7} \mathrm{~m}^{3} / \mathrm{s}$; (a) SMD, (b) Mean Droplet Velocity .60

4.3 ISR Nozzle in $0^{\circ}$ orientation, $\dot{V}=6.66 \times 10^{-7} \mathrm{~m}^{3} / \mathrm{s}$; (a) SMD, (b) Mean Droplet Velocity 60

4.4 Comparison for $0^{\circ}$ and $90^{\circ}$ orientations; (a) SMD, (b) Mean Droplet Velocity ..62

4.5 Active $\left(\dot{q}^{\prime \prime}=59.6 \mathrm{~W} / \mathrm{cm}^{2}\right)$ vs. Non-Active heater comparison; (a) SMD, (b) Mean Droplet Velocity

4.6 Heat Flux vs. Superheat as a function of Nozzle height; (a) Nozzle height $10 \mathrm{~mm}$, (b) Nozzle height $20 \mathrm{~mm}$, (c) Nozzle height $30 \mathrm{~mm}$, (d) Nozzle height $40 \mathrm{~mm}$...65

4.7 Heat Flux vs. Superheat as a function of spray volumetric flow rate; (a) Volumetric Flow Rate $3.33 \times 10^{-7} \mathrm{~m}^{3} / \mathrm{s}$, (b) Volumetric Flow Rate $5.0 \times 10^{-7} \mathrm{~m}^{3} / \mathrm{s}$, (c) Volumetric Flow Rate $6.66 \times 10^{-7} \mathrm{~m}^{3} / \mathrm{s}$ .68

4.8 Parker Hannifin Prototype Nozzle Spray Images ................................................71

4.9 In-situ Photo of Center-Weighted Spray on Flat Surface ....................................72

4.10 Plan View of Flat Heater Surface Liquid Flows .................................................72

4.11 Heat Flux as a function of Surface Temperature for Fundamental Survey; (a) Degassed Case, (b) Gassy Case.....

4.12 Enhanced Surfaces Liquid Pooling; (a) Surface 1s at low heat flux, (b) Surface $1 \mathrm{~s}$ at intermediate heat flux, (c) Surface 1c at low heat flux, (d) Surface 1c at intermediate heat flux, (e) Surface $1 \mathrm{p}$ at low heat flux, (f) Surface $1 \mathrm{p}$ at intermediate heat flux

4.13 Heat Flux as a function of Surface Temperature for Degassed Cubic Pin Fin Study; (a) Degassed X Variation, (b) Degassed L Variation, (c) Degassed H1 Variation .82

4.14 Heat Flux as a function of Surface Temperature for Gassy Cubic Pin Fin Study;

(a) Gassy X Variation, (b) Gassy L Variation, (c) Gassy H1 Variation .85

4.15 CHF and $\xi_{2-\Phi}$ as a function of Structure Size Variation; (a) Degassed X case, (b) Gassy X case, (c) Degassed L case, (d) Gassy L case, (e) Degassed H1 case,

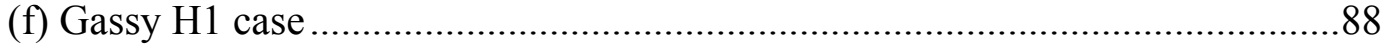


4.16 Heat flux as a function of Surface Temperature for Embedded Structure Geometries

4.17 Heat flux as a function of Surface Temperature for Straight and Cubic Pin Fin Compound Structure Geometries

4.18 Heat flux as a function of Surface Temperature for Straight and Radial Fin Geometries

4.19 Heat flux as a function of Surface Temperature and Specialty Geometry with $\mathrm{N}_{2}$ Dissolved Gasses

4.20 Heat flux as a function of Surface Temperature for Spray Inclination Angle; (a) flat surface, (b) axial straight fins $\left(\gamma=0^{\circ}\right)$, (c) transverse straight fins $\left(\gamma=90^{\circ}\right) \ldots .100$

4.21 Spray Cone Stagnation Zone Phenomena; (a) $\theta=0^{\circ}$ flat surface, (b) $\theta=30^{\circ}$ flat surface, (c) $\theta=0^{\circ},\left(\gamma=90^{\circ}\right)$ transverse straight fins, (d) $\theta=30^{\circ},\left(\gamma=90^{\circ}\right)$ transverse straight fins, (e) $\theta=0^{\circ},\left(\gamma=0^{\circ}\right)$ axial straight fins, (f) $\theta=30^{\circ},\left(\gamma=0^{\circ}\right)$ axial straight fins.

5.1 CHF as a function of centerline Droplet SMD 110

5.2 $\mathrm{CHF}$ as a function of centerline Droplet Number Flux

5.3 $\mathrm{CHF}$ as a function of centerline Droplet Number Density 111

5.4 $\mathrm{CHF}$ as a function of centerline Droplet Velocity ..... 112

5.5 Convection Coefficient as a function of centerline Droplet Velocity.

5.6 Measured vs. Predicted CHF for Perfluorocarbon Fluids Using Fortran code for determination of Constants and Powers.

5.7 Measured vs. Predicted CHF for Water and Methanol Using Fortran code for determination of Constants and Powers. 123

5.8 Liquid Volume Fraction term value as a function of exponent a 124

5.9 Measured vs. Predicted CHF for Perfluorocarbon Fluids Using Estes and Mudawar (1995) CHF correlation

5.10 Measured vs. Predicted CHF for Water and Methanol Using Estes and Mudawar (1995) CHF correlation.

6.1 Space Thermal Control Technology Temperature and Heat Flux Operational Ranges 136 


\section{NOMENCLATURE}

\begin{tabular}{|c|c|}
\hline$A$ & Area, $\mathrm{cm}^{2}$ \\
\hline$\dot{B}$ & mass vaporization rate per unit volume, $\mathrm{kg} / \mathrm{m}^{3}$ \\
\hline$C_{f}$ & friction coefficient \\
\hline $\mathrm{F}_{\mathrm{Di}}$ & drag force on a droplet class, $\mathrm{i}$ \\
\hline $\mathrm{H} 1$ & primary structure height, $\mathrm{mm}$ \\
\hline $\mathrm{H} 2$ & secondary structure height, $\mathrm{mm}$ \\
\hline$L$ & distance between successive structures, $\mathrm{mm}$ \\
\hline$\dot{N}^{\prime \prime}$ & Droplet Flux, (droplet number density $) \times($ droplet velocity) \\
\hline $\mathrm{P}$ & Pressure, $\mathrm{kPa}$ \\
\hline$R_{a}$ & Surface Roughness, $\mu \mathrm{m}$ \\
\hline$R_{f l}$ & $\frac{\left(T_{\text {surf }}-T_{l}\right)}{\dot{q}^{\prime \prime}}$, convective thermal resistance, $\mathrm{m}^{2}-\mathrm{K} / \mathrm{W}$ \\
\hline$S$ & radius of total wetted region, $\mathrm{mm}$ \\
\hline$T$ & temperature, ${ }^{\circ} \mathrm{C}$ \\
\hline$T C$ & thermocouple \\
\hline $\mathrm{U}$ & velocity, $\mathrm{m} / \mathrm{s}$ \\
\hline$\dot{V}$ & volumetric flow rate, $\mathrm{m}^{3} / \mathrm{s}$ \\
\hline$\dot{V}^{\prime \prime}$ & volumetric flux, $\mathrm{m}^{3} / \mathrm{m}^{2}-\mathrm{s}$ \\
\hline$X$ & structure feature dimension, $\mathrm{mm}$ \\
\hline$X_{t t}$ & Martinelli parameter \\
\hline$\dot{b}^{(j)}$ & mass vaporization rate of an average droplet in the $\mathrm{j}^{\text {th }}$ class \\
\hline$c_{p}$ & specific heat, $\mathrm{kJ} / \mathrm{kg}-\mathrm{K}$ \\
\hline
\end{tabular}




\begin{tabular}{|c|c|}
\hline$d 1$ & pore/dimple diameter, $\mathrm{mm}$ \\
\hline$d 2$ & tunnel diameter, $\mathrm{mm}$ \\
\hline $\bar{d}$ & average droplet diameter, $\mu \mathrm{m}$ \\
\hline$d_{32}$ & sauter mean diameter, $\mu \mathrm{m}$ \\
\hline$d_{h}$ & hydraulic diameter, $\mathrm{mm}$ \\
\hline$g_{i}$ & gravitational constant, $\mathrm{m} / \mathrm{s}^{2}$ \\
\hline$h$ & specific enthalpy, $\mathrm{kJ} / \mathrm{kg}$ \\
\hline$h_{\text {conv }}$ & convection coefficient, $\mathrm{W} / \mathrm{m}^{2}-\mathrm{K}$ \\
\hline$h_{l s}$ & liquid droplet surface enthalpy, $\mathrm{kJ} / \mathrm{kg}$ \\
\hline$h_{s}$ & gas phase surface enthalpy for liquid droplet, $\mathrm{kJ} / \mathrm{kg}$ \\
\hline$h_{x}$ & local convection coefficient, $\mathrm{W} / \mathrm{m}^{2}-\mathrm{K}$ \\
\hline$h_{f g}$ & enthalpy of vaporization, $\mathrm{kJ} / \mathrm{kg}$ \\
\hline$h_{C H F}$ & $\frac{q_{C H F}^{\prime \prime}}{\left(T_{\text {surf }}-T_{l}\right)}$ \\
\hline$k$ & thermal conductivity, $\mathrm{W} / \mathrm{m}-\mathrm{K}$ \\
\hline$l$ & nozzle to heater surface distance, $\mathrm{mm}$ \\
\hline$\dot{m}$ & mass flow rate, $\mathrm{kg} / \mathrm{s}$ \\
\hline$n^{(j)}$ & number density of droplets in the $\mathrm{j}^{\text {th }}$ class, droplets $/ \mathrm{m}^{3}$ \\
\hline$p$ & structure pitch, mm \\
\hline$\dot{q}$ & heat exchange, $\mathrm{W}$ \\
\hline$\dot{q}_{l}^{(j)}$ & conductive heat flux from gas interface to droplet interior, $\mathrm{W} / \mathrm{m}^{2}$ \\
\hline$\dot{q}^{\prime \prime}$ & heat flux (energy per unit area), W/cm² \\
\hline
\end{tabular}




\begin{tabular}{|c|c|}
\hline$t$ & time, $\mathrm{s}$ \\
\hline$u$ & local velocity, $\mathrm{m} / \mathrm{s}$ \\
\hline$x$ & thermocouple distance, $\mathrm{mm}$ \\
\hline$x_{j}$ & spatial position coordinate, $\mathrm{m}$ \\
\hline y & coordinate normal to heater surface at center of wetted region, $\mathrm{mm}$ \\
\hline $\mathrm{z} 1$ & pore/dimple depth into structure, $\mathrm{mm}$ \\
\hline$\Delta \mathrm{P}$ & pressure across nozzle, $\mathrm{kPa}$ \\
\hline$\Delta \mathrm{T}$ & temperature difference, ${ }^{\circ} \mathrm{C}$ \\
\hline$\Gamma$ & weighted volume flux for concentric ring, $\%$ \\
\hline$\delta \dot{q}^{\prime \prime}$ & error in heat flux, $\mathrm{W} / \mathrm{m}^{2}$ \\
\hline$\delta_{i j}$ & Kronecker Delta \\
\hline$\delta_{k}$ & error in conductivity, $\mathrm{W} / \mathrm{m}-\mathrm{K}$ \\
\hline$\delta_{\Delta T}$ & error in thermocouple temperature difference, ${ }^{\circ} \mathrm{C}$ \\
\hline$\delta_{x}$ & error in thermocouple location, $\mathrm{mm}$ \\
\hline$J a$ & $\frac{c_{p}\left(T_{\text {sat }}-T_{l}\right)}{h_{f g}}$ \\
\hline$J a_{\text {aug }}$ & $\frac{c_{p}\left(T_{\text {surf }}-T_{l}\right)}{h_{f g}}$ \\
\hline$N u$ & $\frac{h_{\text {conv }} d_{h}}{k}$ \\
\hline $\operatorname{Pr}$ & $\frac{\mu_{l} c_{p}}{k}$ \\
\hline$R e$ & $\frac{\rho_{l} U d_{h}}{\mu_{l}}$ \\
\hline
\end{tabular}




$$
\begin{array}{ll}
\text { St } & \frac{h_{c o n v}}{\rho_{l} c_{p} U} \\
S u & \left(\frac{\rho_{l}}{\rho_{v}}\right)\left(\frac{c_{p} \Delta T_{\text {sub }}}{h_{f g}}\right) \\
\text { We } & \frac{\rho_{l} U^{2} d_{32}}{\sigma} \\
W e_{s p} & \text { Spray Weber number, } \frac{\rho_{l} \dot{V}^{\prime \prime} d_{32}}{\sigma}
\end{array}
$$

\section{GREEK SYMBOLS}

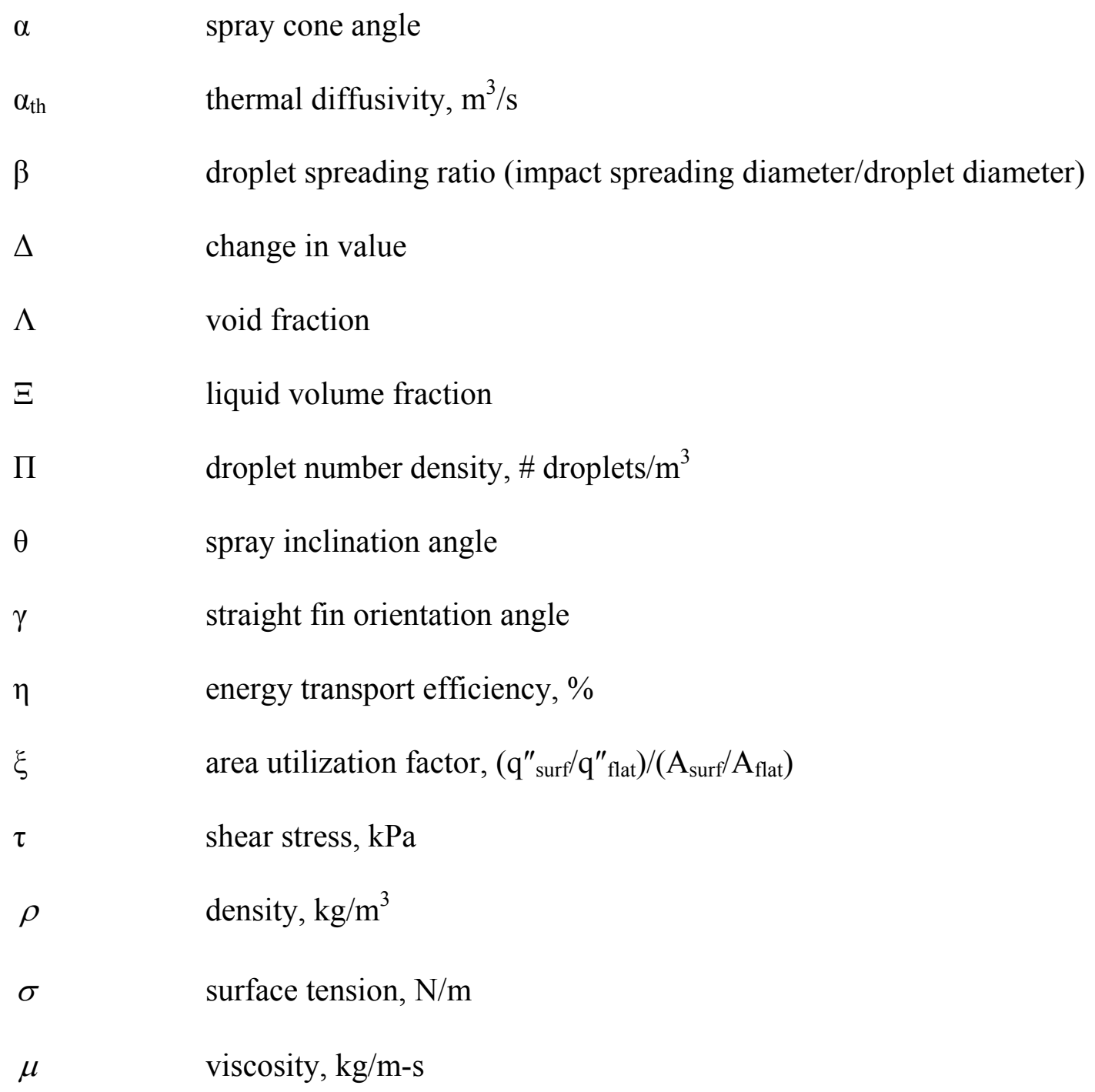




\section{SUBSCRIPTS}

\begin{tabular}{|c|c|}
\hline $\mathrm{CHF}$ & critical heat flux \\
\hline$M H F$ & minimum heat flux \\
\hline conv & convection \\
\hline eff & effective value \\
\hline flat & flat surface \\
\hline$i$ & concentric ring \\
\hline$k$ & conductivity \\
\hline$l$ & liquid \\
\hline $\max$ & maximum \\
\hline sat & saturation conditions \\
\hline$s p$ & spray \\
\hline sub & subcooling \\
\hline sup & superheat \\
\hline surf & surface \\
\hline$T$ & temperature \\
\hline$x$ & thermocouple distance \\
\hline $1-\Phi$ & single phase \\
\hline $2-\Phi$ & multiphase \\
\hline
\end{tabular}




\section{CHAPTER 1}

\section{INTRODUCTION}

\subsection{Motivation and Background}

Since its inception, the electronics industry has always evolved its contemporary technologies into smaller, faster performing versions. Decreasing size and increasing performance speed for electronics components is achieved at the expense of increasing thermal dissipation. A corresponding evolution in thermal management techniques is critical to their successful performance. High power electronics in use today based on technologies such as Insulated Gate Bipolar Transistors (IGBT's), Metal-Oxide Semiconductor Field-Effect Transistors (MOSFET's), and MOSControlled Thyristors (MCT's), as well as Laser-Diode Arrays (LDA's), and Multichip modules (MCM's) can generate waste heat upwards of $1500 \mathrm{~W} / \mathrm{cm}^{2}$ (Sehmbey et al., 1995a). Because of limitations in heat exchange surface area inherent to each of these devices, high heat flux cooling techniques are required for their thermal management. Traditional thermal control technologies (single phase convection, boiling, and flow boiling) have limited heat flux removal capabilities. Spray cooling can provide high heat fluxes in excess of $100 \mathrm{~W} / \mathrm{cm}^{2}$ using fluorinerts and over 1000 $\mathrm{W} / \mathrm{cm}^{2}$ with water while allowing tight temperature control at low coolant fluid flow rates. It is a proven flight technology that has been demonstrated through the Space Shuttle's open loop Flash Evaporator System (FES). Provided closed system issues such as scavenging excess liquid and vapor can be adequately resolved, spray cooling presents one of the most appealing heat transfer techniques for the thermal 
management needs of future high heat flux terrestrial and extra-terrestrial applications.

Previous studies pertaining to spray cooling heat transfer have parametrically examined the effect of secondary gas atomizers vs. pressure atomizers (Yang et al., 1993; Sehmbey et al., 1995a), mass flux of ejected fluid (Yang et al., 1996b; Estes and Mudawar, 1995), spray velocity (Sehmbey et al., 1992; Chen et al., 2002), surface impact velocity (Healy et al., 1998; Sawyer et al., 1997; Chen et al., 2002), micro-scale surface roughness (Bernadin and Mudawar, 1999; Sehmbey et al., 1992; Sehmbey et al., 1995; Pais et al., 1992), ejected fluid temperature (Mudawar and Estes, 1996), chamber environmental conditions (Mudawar and Estes, 1996), and spray footprint optimization on the effective heat flux across the heat exchange surface (Mudawar and Estes, 1996). Other topics researched to date include surfactant addition (Qiao and Chandra, 1997; Qiao and Chandra, 1998), secondary nucleation (Mesler, 1993; Sehmbey et al., 1995; Rini et al. 2002), dissolved gas effects (Milke et al., 1997; Lin and Ponnappan, 2003; Horacek et al., 2005), and the impact of spray inclination angles on heat flux (Shedd and Pautsch, 2005; Mudawar and Estes, 1996; Kearns et al., 2002; Schwarzkopf et al., 2004). Studies that have examined enhanced surfaces have usually done so from the perspective of surface roughness.

Sehmbey et al. (1995) reported an increase in convection coefficient and heat flux for pressure atomized sprays as the heater surface roughness was increased. The surface roughness is understood to be proportional to the nucleation site density (the rougher the surface, the higher the number of possible nucleation sites). The authors 
did not investigate alternative approaches to increasing heat flux via heater surface enhancement.

Spray cooling is considered a multiphase convective process. One technique commonly used to promote heat transfer in convective processes is surface enhancements (structured surfaces larger than the surface roughness scale). The heat exchange area addition associated with the use of enhanced surfaces provides an increase in heat transfer. One manner in which surface enhancements may be implemented is via extended/embedded surfaces. Since spray cooling is a convective process, enhanced surface spray cooling should provide an increase in heat transfer compared to the reference flat surface case. However, further investigation is required to validate this assumption. Furthermore, a detailed understanding of the phenomena occurring at the interfaces for both flat and enhanced surfaces (liquid/vapor and solid/liquid) as well as within the liquid film may lead to future heat transfer enhancements when using this technique.

\subsection{Objectives}

The primary objective of the current work is to examine the effects of structured surface geometries that are much larger than the liquid film thickness on spray cooling heat flux performance. Extended and embedded surfaces were tested to determine heat flux as a function of surface geometry. This is the first systematic study that illustrates that enhanced surfaces can provide significantly larger heat transfer relative to smooth surfaces. In addition, spray angle inclination was investigated as a heat transfer enhancement technique as well. Spray axis inclination 
angles studied were made for angles between $0^{\circ}$ and $45^{\circ}$. A flat surface spray cooling CHF model was also developed and compared to experimental studies by several different researchers for validation. 


\section{CHAPTER 2}

\section{LITERATURE SURVEY}

\subsection{Single Droplet Studies}

\subsubsection{Heat Transfer Phenomena}

A thorough understanding of the phenomena involved in spray cooling has yet to be attained. Nonetheless, the first step towards defining and understanding an emerging technology is to examine that technology given ideal conditions without the many complexities that might distract the researcher from identifying the important fundamental components of the problem. A spray may be considered a multi-droplet array of liquid. As such, the behavior concerning the fluid dynamics for each individual droplet while traveling to the surface, as well as the heat transfer phenomena experienced upon impinging the heat exchange surface, can be considered similar to that for a single droplet provided that certain spray density and surface conditions are met (Sawyer et al., 1997; Qiao and Chandra, 1997; Fukai et al., 1994; Halvorson et al., 1994; Healy et al., 1998; Pautsch and Cohen, 1999; Lee et al., 2000). Several of the assumptions incorporated into spray cooling research to date have been founded on results from single droplet studies. However, a direct analogy in behavior when transitioning from single droplet studies to spray studies falls short for the following reasons:

i) Due to the increase in volume flux when using a multi-droplet system, one might extrapolate that the vapor efflux from the heated surface is increased and the flow field dynamics are more strongly coupled to the 
heat transfer at the liquid/vapor interface (Pais et al., 1992; Yang et al., 1993).

ii) Due to pooling at the heat exchange surface, if nucleate boiling occurs, then bubble growth phenomena on the heater surface and in the liquid film will be fundamentally different than droplet nucleation on a dry surface (Estes and Mudawar, 1995).

iii) Due to pooling, the droplet impingement surface is elastic as opposed to rigid. Droplet dynamics at impact will be fundamentally different (Fukai et al., 1993; Pasandideh-Fard et al., 1995).

The majority of single droplet studies have been aimed at finding the critical heat flux as a function of test configuration parameters. In the study by Halvorson et al. (1994), CHF data was obtained for a horizontal, upward facing heater experiencing a mono-dispersed stream of droplets. The droplets were comprised of distilled water and had diameters ranging 2.3-3.8 mm. Droplets produced by three different needle gage sizes were subjected to free-fall. The droplet frequency ranged from 2-15 Hz. The travel distance and impact velocity were approximately $9 \mathrm{~cm}$ and $1.3 \mathrm{~m} / \mathrm{s}$, respectively. At heat fluxes below $\mathrm{CHF}$, the droplets appeared to spread uniformly over the surface and evaporate. As CHF was approached, the center portion of the liquid film experienced nucleate boiling while the outer region continued to experience evaporation. It was found that all CHF values occurred within a superheat range of $25-45^{\circ} \mathrm{C}$. Furthermore, the superheat temperature tended to increase with increases in both droplet diameter and impact frequency. It was observed that the 
smaller droplets resulted in higher heat fluxes. This was attributed to the fact that the smaller drops produced thinner films on the heat exchange surface. The assumption of a heat flux increase due to decreasing film thickness is also supported in the work of Mesler and Mailen (1977). Halvorson et al.'s (1994) study also showed that an increase in heat flux from the surface can be obtained by subcooling the working fluid. The authors attributed this to sensible heating of the droplet upon impact. The surface averaged CHF (heat transfer over the entire heater surface area) was found to be virtually independent of droplet frequency and size for a fixed flow rate. Adjusted CHF (heat transfer over the wetted area) values ranged from $100 \mathrm{~W} / \mathrm{cm}^{2}$ to 320 $\mathrm{W} / \mathrm{cm}^{2}$. Heat flux was modeled as a function of the droplet thickness on the heated surface. The authors found that heat flux models based on thin films (Toda, 1973) underpredicted the cooling experienced with the thick films actually tested.

Sawyer et al. (1997) performed a similar study with distilled water that examined the impact of droplet diameter, frequency, and velocity on CHF. The droplet sizes used in this study were approximately $1.5-2.7 \mathrm{~mm}$ in diameter. Droplet generation was performed via an audio speaker coil mounted to the dropper assembly. The speaker coil was used to vibrate the assembly and forcibly break off the droplets before the weight of the droplets alone overcame the surface tension forces. The droplet stream created by the assembly was metered to a desired frequency using a selector wheel. Experiments were conducted spanning from low superheat up to CHF. Impact velocities ranged $2.4-4.6 \mathrm{~m} / \mathrm{s}$ and We values spanned 170 to 730 . The study showed that increasing frequency and mass flux helped to increase the adjusted CHF while increasing the velocity decreased this value. The decrease in CHF when droplet 
velocity increased was contrary to expected trends. As in the study by Halvorson et al. (1994), one would expect a higher heat flux due to increased thinning of the droplet on the surface. The authors suggest that higher impact velocities affect the uniformity and stability of the liquid film formed by the droplet, however no mention is given to the possibility of droplet fracture which could also decrease heat transfer. The authors were also able to develop an empirical relation for the CHF values using the non-dimensional representation of the adjusted CHF. The correlation had a prediction accuracy of $\pm 22 \%$ relative to the experimental results in the study. This gave the model a confidence level of $96 \%$ for the experimental data compared against.

In the work of Healy et al. (1998), this correlation was applied to studies that varied test parameters such as pressure and We. Droplet deposition for the range of We considered in the study of Sawyer et al. (1997) usually resulted in fragmentation upon impact. For surfaces heated beyond the Leidenfrost point, droplets broke apart upon impact above $\mathrm{We} \approx 70$. The studies by Halvorson et al. (1994) and Halvorson (1993) present experimental data for low We and pressure values ranging 0.2-2.0 atm. That data was compared to data generated with the correlation by Sawyer et al. (1997), and found lacking in accuracy. Thus a new correlation was developed, that proved to have a $95 \%$ confidence level for predictions with an error of $\pm 20 \%$ relative to the experimental data from both experiments surveyed.

In the study by di Marzo and Evans (1987), an analytical model was developed for total evaporation time of a droplet. The model was formulated via a heat balance between the droplet and the heated surface utilizing the Chilton-Colburn analogy 
(Chilton and Colburn, 1934) and the convective heat transfer equation. The wetting parameter $(\beta)$, which is the ratio of the wetted area radius on the heater surface to the droplet radius, was also incorporated into this relation (via the droplet shape relation as shown in Appendix A). The authors defined a new quantity termed the volume of influence in order to aid in the determination of useful correlations between the magnitude of the cooling effect and the droplet evaporation phenomena. The volume of influence is defined as the region where the temperature variation with respect to the steady state conduction temperature distribution prior to droplet deposition exceeds the maximum possible temperature difference in the system by $10 \%$. Volume of influence into the heater block and wetting parameter were determined experimentally. It was found that the evaporation time varied linearly with the volume of influence. Various surface materials were studied (copper, carbon, steel and aluminum). Evaporation time decreased with increasing initial surface temperatures and decreased for smaller droplets. However, evaporative heat flux increased with increasing initial solid temperature.

In the follow-up study by di Marzo and Evans (1989), an analytical model for the droplet shape (non-dimensional thickness of the droplet) upon impact was developed. This parameter was a function of the spreading ratio $(\beta)$ only. An analytical model for the evaporation time of the droplet was also developed using the assumption of uniform temperature in the solid. A key component to this development was the coupling of the mass transfer and heat transfer at the liquid/vapor interface using the Chilton-Colburn analogy (Chilton and Colburn, 1934). This was done to arrive at a relation for the local heat flux at the interface. The relation for instantaneous rate of 
evaporation developed by di Marzo and Evans (1987) was also implemented. Temporal and spatial studies were performed over the lifetime of the droplet. It was found that the heat flux at the edge of the droplet can be three times that of the spatially averaged heat flux at the beginning of evaporation. The computational models showed reasonable agreement with experimental results over the entire lifetime of the liquid droplet.

In the study by Lee et al. (2000a), a quartz wafer substrate with 96 individually controlled heaters was used to map the surface heat flux while simultaneously recording the droplet diameter and contact angle using a digital video camera. PF5060 was used as the working fluid. Droplets were generated using a glass nozzle. Approximate droplet diameter sizes were $0.82 \mathrm{~mm}$, with impact velocities of approximately $0.31 \mathrm{~m} / \mathrm{s}$. The surface temperatures used were in the low and intermediate superheat ranges. These surface temperatures were $65^{\circ} \mathrm{C}$, and $75^{\circ} \mathrm{C}$ for the low superheat cases while the intermediate superheat case was $85^{\circ} \mathrm{C}$ (approximately $9^{\circ} \mathrm{C}, 19^{\circ} \mathrm{C}$, and $29^{\circ} \mathrm{C}$ superheat, respectively). Time resolved heat fluxes over the droplet contact area were calculated and compared to the energy required for phase change. It was found that heat flux oscillations just after impact were strongly coupled with the initial droplet oscillations. Furthermore, the spreading ratio was calculated from the splat diameter. The measured wall heat flux was found to be larger than the expected heat flux when modeling transient conduction through the droplet. For the intermediate heat transfer case, nucleate boiling was observed only during the first portion of vaporization. A heat flux model was not developed. 
In the continuation study by Lee et al. (2000b), the time varying heat transfer coefficient for the lifetime of the droplet was examined in more detail. As in the first study, low and intermediate superheat cases were examined. This work reviewed the thermal resistances as well. As the liquid evaporates, the thickness decreases, thereby decreasing the resistance of the liquid. This is in agreement with the conclusions regarding the impact of film thickness upon heat transfer reported by Halvorson et al. (1994) and Mesler and Mailen (1977). The fluid thickness decrease results in the thermal circuit being dominated by vapor resistance at the liquid/vapor interface. This determination was also made in the work of di Marzo and Evans (1993) where it was found that the heat transfer coefficient remained fairly constant over the evaporation time.

\subsubsection{Surface Tension Effects}

Some researchers have sought alternative means of increasing heat transfer by reducing the working fluid's surface tension. The premise behind the strategy is that a low surface tension liquid will be highly wetting and will more readily spread across the surface. Increasing the spreading ratio (high $\beta$ values) results in thinner liquid films and higher heat fluxes. One way this is fostered is by addition of a surfactant at various levels of concentration. The effect of surfactant addition is often quantified via visualization techniques emphasizing the liquid/solid contact angle and contact diameter.

Chandra et al. (1996) studied liquid/solid contact angles for distilled water droplets with varying concentrations of Sodium Dodecyl Surfactant (SDS). The study 
was limited to the evaporation regime, where surface temperatures are limited to values close to or below the saturation temperature of the liquid. Concentration values ranged from 100-1000 ppm (parts per million) surfactant to water. Droplet diameters were on the order of $2.05 \mathrm{~mm}$ and surface temperatures ranged $60^{\circ} \mathrm{C} \leq \mathrm{T}_{\text {surf }} \leq 110^{\circ} \mathrm{C}$. Their study showed that surfactant addition tended to increase droplet spreading upon impingement of the surface. As the droplet spread more, the thickness became smaller, thereby creating higher heat transfer rates. The heat transfer area also increased. Droplet contact angles studied varied between $90^{\circ}$ and $20^{\circ}$. Within this contact angle window, droplet evaporation time reduced by $50 \%$, and surface cooling increased by $110 \%$. Convective and radiative heat transfer to the droplet were not considered.

Qiao and Chandra (1997) performed a similar experiment and extended their results into the boiling regime. SDS surfactant was added to pure water in concentration levels ranging from 100-1000 ppm. The surfactant inclusive studies were compared to that of pure water. The heated surface temperature ranged from $60^{\circ} \mathrm{C} \leq \mathrm{T}_{\text {surf }} \leq 340^{\circ} \mathrm{C}$. Real-time photography showed the surfactant to reduce the liquid/solid contact angle of droplets at temperatures below the boiling point of water. Once again, this increased the contact area and heat transfer. The result was a reduction of evaporation time. For the nucleate boiling case, the surfactant promoted nucleation of bubbles and caused foaming. Increased heat transfer was associated with enhanced nucleation and not surface tension reduction or a decrease in the liquid/solid contact angle. The Leidenfrost temperature was increased and evaporation time increased for the transition region. 
Pasandideh-Fard et al. (1995) studied the effect of surfactant addition on droplet dynamics. Concentrations of SDS varied from 0-1000 ppm. Droplet diameter and impact velocity were constant at approximately $2.05 \mathrm{~mm}$ and $1.05 \mathrm{~m} / \mathrm{s}$, respectively. The ejector height was $50 \mathrm{~mm}$. Photographic techniques were incorporated for visualization of the liquid/solid contact diameters and angles. In general, when droplets are deposited upon a rigid surface, they spread radially and then recoil back towards the center. Surfactant addition to pure water not only increased spread diameter (which was expected) but also reduced recoil height. An analytical model was developed to predict maximum droplet diameter after impact. Data generated with this model compared well with experimental results. A numerical model for droplet deformation was also developed. This model accurately predicted droplet spreading and equilibrium shape, yet over-predicted contact diameters during recoil. For We $>>\mathrm{Re}^{1 / 2}$, capillary effects were found to be negligible.

When examining spray cooling, it is important to note that it is an extension of single droplet cooling. As mentioned previously, however, there are some inherent differences. The primary differences relate to droplet impingement phenomena and heat transfer mechanisms. In each of the single droplet studies reviewed, the droplet impacted a rigid surface. Furthermore, the primary heat transfer mechanism associated with the single droplet studies was phase change. This is not always the case for spray applications. Nonetheless, the general topics surrounding the heat transfer phenomena remain the same. Furthermore, many of the principles observed through analysis of the single droplet studies also apply to spray cooling and can be seen in several studies performed to date. 


\subsection{Spray Cooling Studies}

\subsubsection{Test Conditions and Spray Characteristics}

One of the founding works in spray cooling was that of Toda (1972), who attempted to gain an understanding of the heat transfer phenomena associated with thin liquid films deposited on high temperature surfaces. Optical observations were made for mist cooling of two flat, circular heaters of different sizes (40 mm and 15 $\mathrm{mm}$ in diameter). The mist was generated via a high pressure jet nozzle with a single orifice. Water was used as the working fluid. The nozzle to heater distance was 10 $\mathrm{cm}$. Mass flux through the nozzle spanned $40 \mathrm{~kg} / \mathrm{cm}^{2}-150 \mathrm{~kg} / \mathrm{cm}^{2}$. Heater surface temperatures were measured using thermocouples. Flow rates, velocities, and droplet sizes were varied for the tests. The large heater surface showed the heat transfer phenomena to be dominated by secondary flow on the surface caused by nonevaporated liquid. This was not observed in the single droplet studies. As a result, general conclusions were drawn based on the small heater tests. It was determined that a liquid film formed on the surface at the time of droplet impact. At the initial time of formation, heat was transferred through the film via conduction. Three distinct heat transfer regimes were observed and described. These were the low temperature, transitional, and high temperature regimes. In the low temperature regime, liquid evaporated at the liquid/vapor interface. Nucleate boiling was observed when liquid films became thicker with excess non-evaporated liquid. However, this did not affect the heat transfer greatly. In the high temperature regime, film boiling with dry-out occurred. In the transitional regime, a combination of evaporation from the low temperature regime and thin film boiling from the high temperature regime 
co-existed. Peak heat flux was found to have little variation with changes in the amount of subcooling.

In the second study by Toda (1973), the mist cooling investigation was extended. Thin film formation for each of the heat flux regimes was quantitatively studied. Heat flux as a function of superheat and the thin film thickness were reported. Thermal models were also developed for the thin film in each temperature regime. Two heater surfaces comprised of copper and stainless steel were tested with water and glycerin as the working fluids. Both were $30 \mathrm{~mm}$ in diameter. Liquid droplet velocity was measured quantitatively by strobe flash photography. A splat thickness correlation was developed that applied to both the water and glycerin solution. This correlation was only applicable within a certain We and stability number range. The heat transfer mechanism was further examined. Sprayed liquid drops were considered a statistical group of varying diameter sizes which follow a Gaussian distribution. The logprobability equation was applied as the distribution function. The primary determination made by the author was that heat was initially transferred to the droplets via conduction. The author also introduced the concept of critical film thickness. While film thickness was discussed in the work by Halvorson et al. (1994), the notion of a critical film thickness was not explicitly stated. A full analytical model for the vapor layer and the liquid film thickness were developed. Theoretical time averaged heat flux relations were also developed for each of the three regimes. These were compared to experimental data from the first study. The theoretical models agreed well with the experimental data for the water case up through the Leidenfrost point (MHF). It was found that for larger average droplet diameters $(\bar{d})$, the 
transitional heat flux regime occurs at approximately the same superheat as in the case of pool boiling. However for small $\bar{d}$, the transitional regime shifts towards higher temperatures.

Ghodbane and Holman (1991) conducted spray cooling heat transfer studies with horizontal sprays on vertical heater surfaces $(15.24 \mathrm{~cm} \times 15.24 \mathrm{~cm}$ and $7.62 \mathrm{~cm} \mathrm{x}$ $7.62 \mathrm{~cm})$. Subcooled Freon-113 was used as the working fluid. The spray nozzles had three different orifice sizes $(0.063 \mathrm{~cm}, 0.159 \mathrm{~cm}$, and $0.238 \mathrm{~cm})$. Tests were performed with both full cone circular and square footprint spray nozzles. Flow rates were varied between 5.0 and $126 \mathrm{~cm}^{3} / \mathrm{s}$. The effect of mass flux, droplet velocity, droplet diameter, and nozzle to heater surface distance upon heat flux were reported. The authors determined that We had a large effect upon the spray cooling heat transfer process. They also developed a heat transfer correlation as a function of We, $\mathrm{Ja}, \mathrm{h}_{\mathrm{fg}}, \mu_{\mathrm{l}}$, and nozzle to heater surface distance. Error statistics on predictions were not reported.

The correlation by Ghodbane and Holman (1991) showed good accuracy, however there were limitations in the droplet velocity and diameter size range applicable for use with the correlation. The appropriate range for droplet velocities and diameters was $5.0 \mathrm{~m} / \mathrm{s}$ to $28.0 \mathrm{~m} / \mathrm{s}$ and $210 \mu \mathrm{m}$ to $980 \mu \mathrm{m}$ respectively. Holman and Kendall (1993) revisited the work by Ghodbane and Holman (1991) with the aim of extending the applicable size range for both droplet velocities and diameters. This was achieved by correlating the data from the previous study with new constant coefficients and powers on the non-dimensional parameters used. Holman and Kendall (1993) achieved a new form of the correlation initially developed by 
Ghodbane and Holman (1991) which was applicable to Freon-113 spray conditions having droplet diameters between $96 \mu \mathrm{m}$ and $980 \mu \mathrm{m}$. Error statistics on predictions were not reported in this study.

The work by Sehmbey et al. (1995a) provides an overview of spray cooling. It discusses the reasons for selecting spray cooling as a thermal management technique as well as a comparison of its effectiveness using two different types of sprays. The first type is a pressure atomized spray where liquid is atomized by the pressure differential across the nozzle, while the second type is a secondary gas (air in their study) assisted spray where a high velocity gas is used to atomize the liquid stream into a fine mist. Spray cooling curves were presented for both techniques. Heat flux and convection coefficient values were comparable in both cases, however, the pressure atomized spray required liquid flow rates 10 times that of the air atomized spray in order to achieve similar heat removal capacities. The shortcoming with the air atomized sprays was that they introduced non-condensible gasses (NCG) into the fluid system. When operating in a closed system, this can result in lower heat exchange capability within the condenser. Other secondary gasses and their impact upon heat transfer were not explored. Other than fluid properties, the authors state that the most important parameters affecting heat transfer are surface conditions and spray velocity. The heat transfer coefficient increased for smooth surfaces $\left(R_{a}<0.1\right.$ $\mu \mathrm{m})$ for air atomized sprays. The opposite was true for pressure atomized sprays. At low flow rates (i.e mist flow), the CHF and convection coefficient are controlled by liquid supply while at high flow rates (full sprays), changes are somewhat negligible. In the high flow rate case, the flooding limit for the surface is almost always 
exceeded. Thus heat transfer is negligible to slight changes in flow rate. In air atomized sprays, the influence of liquid velocity upon CHF is negligible for low density sprays (flow rates $<4.5 \mathrm{~kg} / \mathrm{m}^{2} \mathrm{~s}$ for water). Most of the liquid evaporates at CHF, thus increasing the velocity does not change the CHF.

Yang et al. (1993), conducted a study in which heat flux values were measured using a gas atomizing nozzle with air and steam as the secondary gases. The effect of atomizing pressure and liquid flow rate were studied. Droplet size and velocity, liquid film thickness and flatness were measured using a Phase Doppler Particle Analyzer (PDPA), Fresnel diffraction, and holographic techniques respectively. The heater test surface had a roughness of $\left(R_{a}<0.28 \mu \mathrm{m}\right)$. Droplet diameters ranged $12.4 \mu \mathrm{m}-17.3$ $\mu \mathrm{m}$. Droplet velocities spanned $25.6 \mathrm{~m} / \mathrm{s}-57.3 \mathrm{~m} / \mathrm{s}$. The film thickness measured varied between 85-235 $\mu \mathrm{m}$. Test results showed that for the same liquid and secondary gas flow rate, air yielded higher heat fluxes than steam. However, the temperatures of the air and steam were not reported. For a given air pressure and flow rate, the heat flux increased with increasing liquid flow rate. The same was found for a constant water flow rate with increasing air flow rate. For all water flow rates, increasing the air flow rate only increased the CHF to an optimum point beyond which further increases in air flow yielded no further increases in CHF.

In the work by Yang et al. (1996b), the effects of liquid and secondary gas flow upon spray cooling were examined using air and distilled water. Spray droplet size and velocity were measured using PDPA. Droplet sizes ranged 10-18 $\mu \mathrm{m}$ and droplet velocities ranged $25-58 \mathrm{~m} / \mathrm{s}$. Increases in either air or water flow rate with the other held constant increased the heat flux. The authors found that for similar test section 
pressures, the convection coefficient for spray cooling was four times that of the case of simple pool boiling. Using the thin film nucleate boiling correlation developed by Nishikawa and Fidgety (1990), the authors developed their own correlation through substitution of the liquid volume flux for an equation having functional dependence upon the liquid film thickness (Yang et al., 1996a). The Nu correlation was based on a constant heat flux boundary condition and a water flow rate of $1.0 \mathrm{l} / \mathrm{hr}$. The correlation predicted the experimental results for various air pressures tested to within $\pm 4 \%$ relative error.

Estes and Mudawar (1995) conducted correlation studies for the Sauter Mean Diameter (SMD) and CHF for FC-72, FC-87, and water. The effects of volumetric flux, spray nozzle type and subcooling upon CHF were also studied. It was found that sprays with high volumetric fluxes (i.e. as well as high $\mathrm{We}_{\mathrm{sp}}$ ) only showed a slight increase in the slope of the heat flux curve between the single phase and multiphase regimes. This agreed with the conclusions of Sehmbey et al. (1995a) who found that the slight increase is due to a suppression of nucleate boiling and reduced evaporation efficiency. This phenomena has not been reported in other works. In general, suppression of nucleate boiling is the product of film thinning. Low volumetric flux sprays display a pronounced increase in the boiling curve due to higher evaporation efficiency. In general, CHF increased with flow rate and was larger for nozzles that produced smaller drops. SMD for conical sprays was dependent upon orifice diameter as well as We and Re based on the flow conditions at the orifice prior to break-up. They also showed experimentally that $\eta_{2-\Phi}$ is a function of $\mathrm{We}_{\mathrm{sp}}$. A CHF correlation based on $\mathrm{We}_{\mathrm{sp}}, \mathrm{Su}, \rho_{\mathrm{l}} / \rho_{\mathrm{v}}, \dot{V}^{\prime \prime}$, and $\mathrm{h}_{\mathrm{fg}}$ was developed for full cone sprays spanning 
different nozzle sizes as well as variable amounts of subcooling and flow rates. The correlation was shown to have a mean absolute error of $12.6 \%$.

The work by Nishio and Kim (1998) emphasized the rebound motion in spray cooling when operating at heat fluxes approaching CHF. The working fluids used for the study were water and ethanol. The water droplets' sizes ranged $0.88-3.53 \mathrm{~mm}$ and the velocities spanned $0.89-1.9 \mathrm{~m} / \mathrm{s}$. Droplet sizes and velocities for the ethanol used were $1.51-2.54 \mathrm{~mm}$ and $1.23-1.80 \mathrm{~m} / \mathrm{s}$ respectively. It was determined that the heat flux upon impact was proportional to the sensible heating required to increase the droplet temperature to the saturation temperature, and was independent of velocity, diameter, and subcooling. Rebound motion was distributed uniformly between a height of zero and the full distance to the nozzle. Two and three dimensional heat flux models were developed and reported. These were the proportionality constant model and the 3-D heat transfer model. They showed a prediction accuracy of $\pm 25 \%$ relative to the experimental data. A droplet fragmentation threshold was not reported.

Rini et al. (2002) conducted an investigation into bubble behavior in nucleate boiling heat transfer for saturated FC-72. The authors compared heat flux data for pool boiling and spray cooling using the same heater (synthetic diamond $1.0 \mathrm{~cm} \times 1.0$ cm) at $1.0 \mathrm{~atm}$. Droplet flux $\left(\dot{N}^{\prime \prime}\right)$ was also varied. Their study revealed a $50 \%$ increase in heat flux when using spray cooling due primarily to secondary nucleation via puncturing of the liquid film and vapor entrainment at the liquid/vapor interface.

Chen et al. (2002) conducted a study investigating the effect of spray characteristics on CHF using gassy water sprayed onto a copper heater with a surface area of $1.0 \mathrm{~cm}^{2}(1.0 \mathrm{~cm} \times 1.0 \mathrm{~cm})$. More than twenty full cone nozzles from three 
different manufacturers (Hago, Bete, and Delavan) were used for the spray cooling tests. Each nozzle had uniform spray characteristics. The spray characteristics of interest were $\mathrm{U}$ (droplet velocity), $\mathrm{d}_{32}$ (SMD), and $\dot{N}^{\prime \prime}$ (droplet flux). The spray characteristics were measured using a Dantec PDPA system. The authors experimentally showed that the velocity was the spray characteristic with the most dominant effect upon heat flux.

Mudawar and Estes (1996) examined the effect of spray volumetric flux on CHF through optimization of the spray impact area on the heater surface. A pressure atomizer was used to develop the spray. The working fluids were degassed FC-72 and FC-87. CHF was experimentally measured at the same liquid flow rate at various nozzle to heater distances. The heater surface was square $(12.7 \mathrm{~mm} \times 12.7 \mathrm{~mm})$ and was made of oxygen free copper. In each test case, the authors found that there was an optimum nozzle to heater distance at which the CHF was maximized given a certain volumetric flux. This occurred when the circular spray footprint was exactly inscribed within the perimeter of the heater. As was the case in the studies by Halvorson et al. (1994) and Estes and Mudawar (1995), subcooling of the fluid also increased CHF monotonically. A new correlation was developed to more accurately incorporate overspray conditions in predicted CHF values for different size nozzles over varying ranges of flow rate and subcooling.

Sehmbey et al. (1995b) researched the use of cryogenic $\mathrm{LN}_{2}$ spray cooling for temperature control of power electronics. The experimental study utilized pressure atomized spray generated with nozzles of varying sizes. The heater surface was made of oxygen free copper and had a surface roughness of $R_{a}=0.15 \mu \mathrm{m}$. Heat flux was 
reported as a function of mass flow rate, nozzle orifice (and droplet size), and superheat. Tests were performed with the supply fluid conditioned to $78 \mathrm{~K}$. The heat transfer coefficient and CHF increased with mass flow rate for each individual nozzle. The convection coefficient and CHF were found to be dependent on the orifice used. The authors did not associate an optimum convection coefficient with the surface flooding limit or nozzle to heater surface distance. Nominal values for each of these increased as the orifice size decreased. The maximum heat flux observed was $165 \mathrm{~W} / \mathrm{cm}^{2}$ at a superheat of $16 \mathrm{~K}$.

\subsubsection{Dissolved Gasses}

Milke et al. (1997) analyzed the effect of dissolved gases on evaporative cooling for water sprays. Their results were compared to those of a previous study using degassed water. The surface was radiantly heated prior to and throughout the spraying process. A range of initial surface temperatures and water mass fluxes were studied. Both the gassed and the degassed water studies showed exponential cooling from the initial surface temperature to the steady state temperature. For the test configuration used, dissolved gasses enhanced the cooling process by reducing incoming radiant energy. This contradicts the conclusions reported by Sehmbey et al. (1995a) pertaining to NCG's. However, their study did not incorporate radiation into their observations.

Lin and Ponnappan (2003) conducted spray cooling measurements using a multinozzle array with and without dissolved air in the working fluid. Four different working fluids were tested (FC-87, FC-72, methanol, and water). The heat exchange 
surface was made of copper and had a total surface area of $2.0 \mathrm{~cm}^{2}(1.0 \mathrm{~cm} \times 2.0 \mathrm{~cm})$. The study showed that the test cases without air had significantly lower superheat (i.e. better thermal performance) than the air dissolved case for heat fluxes $<70 \mathrm{~W} / \mathrm{cm}^{2}$. However, above $70 \mathrm{~W} / \mathrm{cm}^{2}$ the air dissolved case had higher flux at comparable superheat levels.

Horacek et al. (2005) conducted a detailed investigation into the effects of dissolved gasses on spray cooling heat flux. Distilled FC-72 was used as the working fluid. The heater surface was a microheater array with a total area of $0.49 \mathrm{~cm}^{2}(7.0$ $\mathrm{mm} \times 7.0 \mathrm{~mm}$ ). The array consisted of 96 heaters, each nominally $700 \mu \mathrm{m}$ in size. Five experimental cases were tested using variable thermal subcooling and gas concentrations in the pumped fluid system. The authors experimentally showed in the gas dissolved cases that the presence of the non-condensible gas caused a shift in the saturation temperature of the liquid and increased the subcooling of the liquid being sprayed onto the heater surface. The resultant effect was an enhancement in heat flux.

\subsubsection{Spray Inclination Angle}

Previous investigations with the spray axis inclined relative to the heater surface normal have typically emphasized their impact upon heat flux via removal of residual liquid on the heater surface. Shedd and Pautsch (2005) investigated spray cooling performance using multi-nozzle arrays with different nozzle patterns. The heater

surface used was a $70 \times 70 \mathrm{~mm}^{2}$ MCM board populated with test dies (each die was square with a side measure of $15 \mathrm{~mm}$ ) developed by IBM. The working fluid used was FC-72. The authors experimentally showed that the nozzles that used the fluid 
most efficiently for removal of thermal energy provided the lowest heat transfer. The highest heat transfer was observed when phase change was avoided in the spray process. The multi-nozzle arrays used were inherently inefficient due to interaction between neighboring sprays. However, the authors identified inclined sprays as a technique to assist with fluid drainage and mitigation of heat flux degradation due to the multi-nozzle configuration. The authors also stated that inclined sprays also provide orientation-independent heat flux performance.

In the study by Mudawar and Estes (1996), heat flux as a function of cone angle and nozzle height for a given flow rate were examined. The heater test surface was square $\left(12.7 \times 12.7 \mathrm{~mm}^{2}\right)$ while the nozzle used had a circular spray footprint. The working fluids were FC-72 and FC-87. As previously mentioned, the authors determined that $\mathrm{CHF}$ was a function of volumetric flow distribution on the heater surface and the optimum was attained when the spray cone footprint was inscribed within the perimeter of the heater surface.

Kearns et al. (2002) studied spray cooling of a row of heaters inside a narrow channel. A total of nine heaters were used, each with an area of $38.1 \mathrm{~mm}^{2}$. The channel length, width, and height were $400 \mathrm{~mm}, 265 \mathrm{~mm}$, and $255 \mathrm{~mm}$ respectively. Fluid was sprayed into the channel at one end by a single full cone nozzle with a cone angle of $55^{\circ}$. The configuration was designed to simulate the confined conditions inside a row of circuit boards. The working fluid was PF-5060 at $101 \mathrm{kPa}$. Maximum heat dissipation $(60 \mathrm{~W})$ occurred on the heater closest to the nozzle, while the minimum dissipation $(20 \mathrm{~W})$ occurred on the heater farthest away. The authors 
concluded that this was due to the proximity of the leading heater relative to the nozzle as well as the impingement angle on its leading edge.

Schwarzkopf et al. (2004) studied the effect of spray inclination angle on spray cooling using a single atomizer. The heated surface consisted of a thermal test chip with multiple heater modules, each of which contained an embedded temperature sensor. The heated surface was mounted in an upside down (heater normal facing downwards) configuration. The fluid was sprayed upward onto the heated surface. Spray angles varied between $0^{\circ}$ and $60^{\circ}$ (spray axis measured relative to the heater normal) with the orifice kept at a constant radius of $1.4 \mathrm{~cm}$ from the heated surface. The working fluid used was PF-5060 at $101 \mathrm{kPa}$. The authors showed that CHF was $\approx$ $63 \mathrm{~W} / \mathrm{cm}^{2}$ for inclination angles between $0^{\circ}$ and $40^{\circ}$. CHF began to decrease rapidly for spray inclination angles greater than $40^{\circ}$.

\subsubsection{Spray Cooling Enhancements}

Qiao and Chandra (1998) studied spray cooling enhancement by surfactant addition. An aqeous solution of $100 \mathrm{ppm}$ SDS was tested and compared to that of pure water for varying velocities and mass fluxes. Photography was used to analyze droplets during testing. It was found that the surfactant helped enhance heat transfer for all cases studied by promoting bubble nucleation and foaming. The temperature for the onset of nucleation reduced from $118^{\circ} \mathrm{C}$ to $103^{\circ} \mathrm{C}$. Heat transfer during transition boiling was reduced slightly because the liquid-solid contact angle was decreased by the surfactant. 
While the Space Shuttle's FES used cyclic water spray cooling of enhanced surfaces (Triangular grooves) to cool freon based heat exchangers (Nason et al., 1985; O'Connor et al., 1997), work in the area of spray cooling with enhanced surfaces has been very limited. Most previous studies that have examined enhanced surfaces have done so primarily from the perspective of surface roughness. Sehmbey et al. (1995a) and Pais et al. (1992) studied the effects of surface roughness on heat transfer when using spray cooling. In the study by Pais et al. (1992), the surface roughness values studied were 22, 14 and $0.3 \mu \mathrm{m}$. The studies were performed up to CHF. No Leidenfrost data was reported. The contact surface was copper with an area of 1.0 $\mathrm{cm}^{2}$. An air-atomizing nozzle was used with deionized water as the working fluid. Tests were conducted at a nozzle to heater distance of $23 \mathrm{~mm}$. The droplet size distribution spanned 7-28 $\mu \mathrm{m}$. Liquid and air flow rate ranged 1.0-0.1 1/h and 0.1-0.4 1/s respectively. Data was obtained up to the CHF value for all surface tolerances. It was found that the $0.3 \mu \mathrm{m}$ rough surface achieved higher heat fluxes over the temperature domain sampled. This surface had a peak heat flux of $1250 \mathrm{~W} / \mathrm{cm}^{2}$. Furthermore, the onset of nucleate boiling is experienced at lower superheat values for this tolerance. The authors attributed the heat transfer enhancement to early bubble departure from the surface and nucleate boiling. The review by Mesler (1993) challenged the ability to quantify this enhancement by early bubble departure as opposed to secondary nucleation. Pais et al. (1992) insisted that secondary nucleation has a primary role as a heat transfer mechanism only if the surface finish is smooth. 


\subsection{Enhanced Surface Pool Boiling Studies}

Pool boiling has received much attention regarding heat flux enhancement applications. These applications have been implemented through surfaces specifically designed to increase nucleation site density and/or addition of surface area available for nucleation. Enhancements such as paints and porous structures may be considered as providing heat flux enhancement through increased nucleation sites. Structured surface geometries (macro, micro and submicron-scale) provide heat flux enhancement through both. Each of these techniques have been shown to enhance heat transfer for certain applications.

Scurlock (1995) conducted an overview of saturated boiling heat transfer characteristics for plasma sprayed surfaces using four different cryogenic working fluids. The working fluids tested were liquid nitrogen, argon, oxygen and R-12. The plasma coating consisted of a mixture of Aluminum (with 10\% Silicon) powder and polyester. Various coating thicknesses between $0.13 \mathrm{~mm}$ and $1.32 \mathrm{~mm}$ were made. The heat exchange surfaces used were all $50 \mathrm{~mm} \times 50 \mathrm{~mm}$ in area. Superheats tested for each case ranged between $0 \mathrm{~K}$ and $12 \mathrm{~K}$. For each working fluid, there existed an optimum coating thickness whereby the convection coefficient was maximized and the heat transfer increased. The heat flux increase for liquid nitrogen (with $\Delta \mathrm{T}_{\text {surf }}=2$ $\mathrm{K}$ ) was from $0.3 \mathrm{~W} / \mathrm{cm}^{2}$ to $20 \mathrm{~W} / \mathrm{cm}^{2}$. The heat flux increase for R-12 (with $\Delta \mathrm{T}_{\text {surf }}=5$ K) was from $0.5 \mathrm{~W} / \mathrm{cm}^{2}$ to $30 \mathrm{~W} / \mathrm{cm}^{2}$. In general, the increases observed were about 30 to 70 times that of the values obtained using the smooth surface.

Hsieh and Weng (1997) also studied the impact of coated surfaces (via porosity and coating thickness) upon heat transfer. Results were compared to those for a 
smooth surface. The enhancement surfaces used for their test articles incorporated three different types of coatings. These were plasma spraying (with $\mathrm{Cu}$ and $\mathrm{Mo}$ ), flame spraying (with $\mathrm{Al}$ and $\mathrm{Zn}$ ), and pitted coatings using a sandblast technique. In each case the coated surface material was $\mathrm{Cu}$. The fluids used were R-134a and R407c. Similar to Scurlock (1995), the authors concluded that there was an optimum surface roughness for heat transfer enhancement. The pitted coating surfaces performed the best and showed maximum heat transfer coefficient increase factors ranging 1.5 to 2.5 (for given heat fluxes spanning $1.3 \mathrm{~kW} / \mathrm{m}^{2}$ to $25 \mathrm{~kW} / \mathrm{m}^{2}$ ). The authors also stated that refrigerant properties appeared to have a significant influence on the performance of the surface.

O'Connor and You (1995) applied silver flakes (via a painting technique) to a Lexan heater to enhance boiling heat transfer. FC-72 was used as the test fluid. The final surface contained multilayered silver flake micro-structures that created a total layer thickness of $25 \mu \mathrm{m}$. Cavity feature size on the surface was approximately 1.0 $\mu \mathrm{m}$. Heat flux results for the painted surface were compared to those of a non-painted heater surface of the same size. The painted surface showed lower incipience superheats $\left(3^{\circ} \mathrm{C}\right.$ to $\left.8.5^{\circ} \mathrm{C}\right)$. This was $70 \%$ to $85 \%$ lower than those observed for the non-painted surface. CHF for the enhanced surface was $109 \%\left(30 \mathrm{~W} / \mathrm{m}^{2}\right)$ greater than that tested for the non-painted surface. The authors attributed this increase to the surface micro-structure and its influence on boiling heat transfer characteristics.

Honda et al. (2002) investigated FC-72 boiling on silicon chips with micro-pinfins, submicron-scale roughness and a combination surface utilizing both enhancements. The square pins had dimensions of $50 \times 50 \times 60 \mu \mathrm{m}^{3}$, while the 
submicron-scale roughened surface had a Root Mean Square (RMS) roughness between 25 and $32 \mathrm{~nm}$. Heat flux, as well as the effects of subcooling and dissolved gasses for these surfaces was reported. The submicron-scale roughened surface displayed higher heat transfer than the micron-pin-finned surface at low heat flux values. The opposite was observed for high heat flux. The combination surface displayed the highest heat transfer of all the surfaces with a CHF value of 1.8 to 2.3 times larger than the analogous smooth surface case. CHF varied linearly with subcooling for all chips. The boiling incipience temperature decreased for all the dissolved gas cases resulting in larger heat flux values in the low heat flux regime ( $\leq$ $\left.15 \mathrm{~W} / \mathrm{cm}^{2}\right)$.

Chien and Webb (1998a) investigated the effects of structured tunnel dimensions upon nucleate boiling convection coefficients for heat fluxes ranging between 2 $\mathrm{kW} / \mathrm{m}^{2}$ and $70 \mathrm{~kW} / \mathrm{m}^{2}$. Tests were performed on a $19.1 \mathrm{~mm}$ diameter horizontal tube using R-11 and R-123 as working fluids. Tunnel pitch, height, width, and base radius were the primary dimensions studied. The authors found that fins shorter than $0.9 \mathrm{~mm}$ produced significant increases in the convection coefficient when the fin count increased from 1378 fins $/ \mathrm{m}$ to 1575 fins $/ \mathrm{m}$. They also found that using a rectangular fin base helped to increase evaporation by retaining more liquid. Increasing fin height had little effect upon the convection coefficient. Fin pitch was also observed to have little significance.

The continuation study by Chien and Webb (1998b) emphasized the impact of pore diameter and pitch upon nucleate boiling of R-11 and R-123. The pore diameters studied were $0.12 \mathrm{~mm}, 0.18 \mathrm{~mm}, 0.23 \mathrm{~mm}$, and $0.28 \mathrm{~mm}$. Pitch dimensions used were 
$1.5 \mathrm{~mm}$ and $3.0 \mathrm{~mm}$. The heat fluxes for this study ranged between $2 \mathrm{~kW} / \mathrm{m}^{2}$ and 70 $\mathrm{kW} / \mathrm{m}^{2}$. The authors found that the liquid supply rate to the tunnel was a function of the pore diameter. They concluded that as the pore diameter increased, the tunnel dryout heat flux increased as well. However, the large pore surfaces exposed to low heat fluxes $\left(\leq 35 \mathrm{~kW} / \mathrm{m}^{2}\right)$ produced flooding and thereby lowered the convection coefficient. Smaller pores could not provide sufficient liquid into the tunnel when exposed to high heat flux. This case also produced low convection coefficients.

Rainey et al. (1997) conducted a flow boiling study on plain and micro-porous coated surfaces. The working fluid used was FC-72. Two copper heaters were used, each with a $1.0 \mathrm{~cm}^{2}(10 \mathrm{~mm} \times 10 \mathrm{~mm})$ heat exchange surface area. One was highly polished, while the other was micro-porous coated. The coated surface had a fine porous structure with cavity feature sizes ranging 0.1 to $1.0 \mu \mathrm{m}$ and $50 \mu \mathrm{m}$ thick. The coating material used was Aluminum/Brushable Ceramic epoxy/Methyl-EthylKetone. During testing, both surfaces were mounted to the bottom of a horizontal flow channel. Channel velocities tested ranged $0.5 \mathrm{~m} / \mathrm{s}$ to $4.0 \mathrm{~m} / \mathrm{s}$. Subcooling was on the order of $4 \mathrm{~K}$ to $20 \mathrm{~K}$. Nucleate boiling on the smooth surface was shown to be highly dependent on flow velocity (which ranged between $0-0.5 \mathrm{~m} / \mathrm{s}$ ) and subcooling up to $4 \mathrm{~K}$. The micro-porous surface (vs. the smooth surface) showed enhancement factors up to 1.5 with the exception of the high heat flux regime. Above $50 \mathrm{~W} / \mathrm{cm}^{2}$, the micro-porous surface actually provided worse heat transfer performance than the smooth surface. The authors theorized this was due to the limiting conductive resistance inherent to the porous coating. CHF values appeared to increase with increasing fluid velocity for the smooth surface. The micro-porous surface displayed 
an increase as well, however the enhancement effectiveness upon CHF for this surface decreased linearly with increased velocity.

\subsection{Summary And Overview Of Present Study}

Given the spray cooling enhanced surface studies reviewed here, the study by Pais et al. (1992) is of particular interest. In this work, it was reported that for gas atomizing nozzles, heat flux decreases with increasing surface roughness. However, this work, as well as the work of Sehmbey et al. (1995a), report that the opposite trend is observed with liquid atomizing nozzles. The pool boiling works of Scurlock (1995), Hsieh and Weng (1997), and O'Connor and You (1995), all showed surface coatings enhance heat transfer by a nominal factor (1.5). Convection coefficients were also enhanced in these studies. The work of Honda et al. (2002) showed an increase in heat transfer by factors ranging from 1.8 to 2.3 when using submicronscale enhanced surfaces.

Underlying the enhancements witnessed in each of these studies is the concept that the nucleation site density increases with roughness and/or addition of structured surfaces (micro and submicron scale) which ultimately enhance the heat transfer. The heat transfer mechanism associated with the pool boiling studies was phase change. Thus the enhancement promoted increased nucleation (i.e. phase change). All of the spray cooling studies examined here were primarily concerned with heat flux optimization and enhancement via variation of the spray cooling parameters. This was investigated through variation in working fluids, spray characteristics, phase change conditions, and heat transfer enhancements. In the afore-mentioned enhancement 
studies (Pais et al., 1992; Sehmbey et al., 1992; Sehmbey et al. 1995a; Mesler, 1993), heat flux as a function of surface roughness was investigated and shown to provide a heat flux enhancement under certain conditions. The spray cooling process, unlike pool boiling, consists of both single and multiphase heat transfer. Since the process is multiphase and has displayed heat flux enhancement due to surface roughness conditions, structured surface enhancement techniques such as those referenced in the afore-mentioned pool boiling studies may also provide enhanced heat transfer. A spray cooling study investigating variable extended/embedded surface geometries (macro scale) and their impact to heat transfer may prove beneficial in attaining higher heat fluxes (as observed in the case of pool boiling) than smooth surfaces at comparable thermodynamic conditions and spray characteristics. 


\section{CHAPTER 3}

\section{EXPERIMENTAL APPARATUS AND PROCEDURES}

\subsection{Test Set-Up}

\subsubsection{Laboratory for Physical Sciences (LPS) Studies}

The LPS experiments were conducted using a closed fluid loop system. The test rig (schematic shown in Fig. 3.1) consists of an environmental chamber, liquid pump, flow meter, and temperature bath for set-point control of the supply line temperature. The chamber is equipped with a vacuum port, as well as temperature (T-type stainless steel sheathed thermocouple) and pressure sensors. Temperature and pressure sensors were also placed in the liquid line upstream of the nozzle for fluid and supply line temperature and pressure measurement. The spray chamber was made of an aluminum shell and lid with a stainless steel base. It was $22.86 \mathrm{~cm}$ in height with an

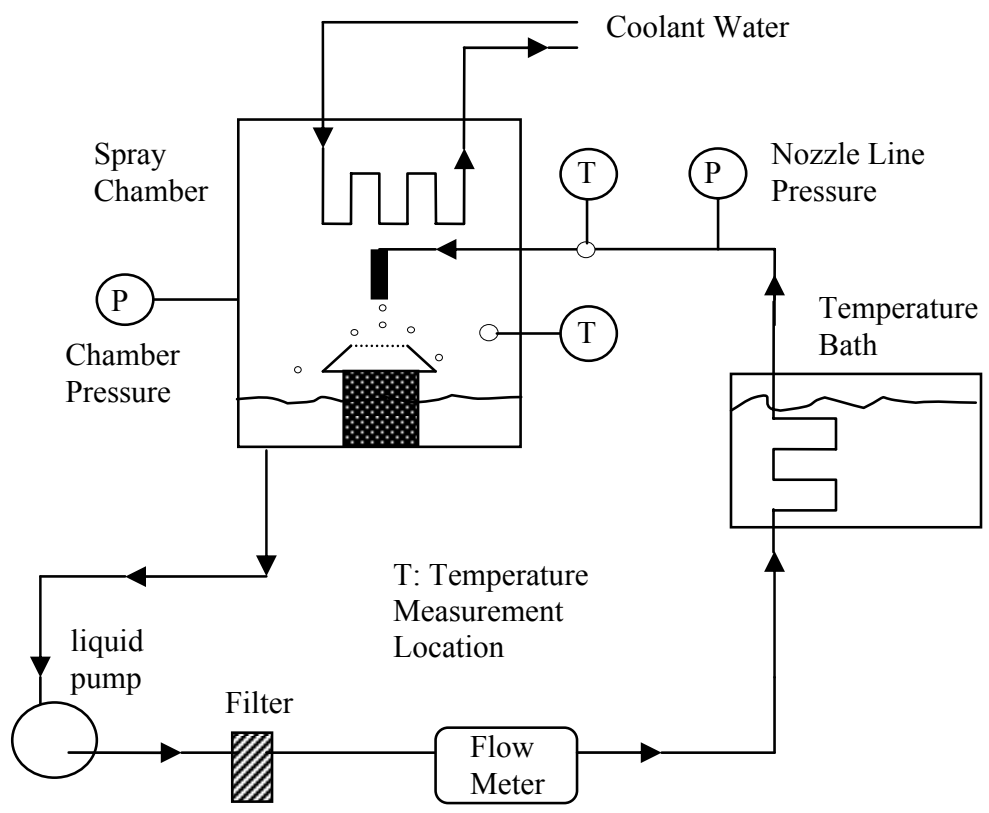

Fig. 3.1 LPS Spray Cooling Test Rig Configuration 
interior diameter of $25.4 \mathrm{~cm}$ (volume of $11,326.7 \mathrm{~cm}^{3}$ ). Four quartz windows were included to allow visualization and investigation into the spray characteristics. Both the nozzle and pump used were supplied courtesy of ISR (Isothermal Systems Research Incorporated). The pump was a $24 \mathrm{~V}$ liquid pump (shown in Fig. 3.2) with a refrigerant cooling coil mounted to its housing. Some cooling of the fluid was

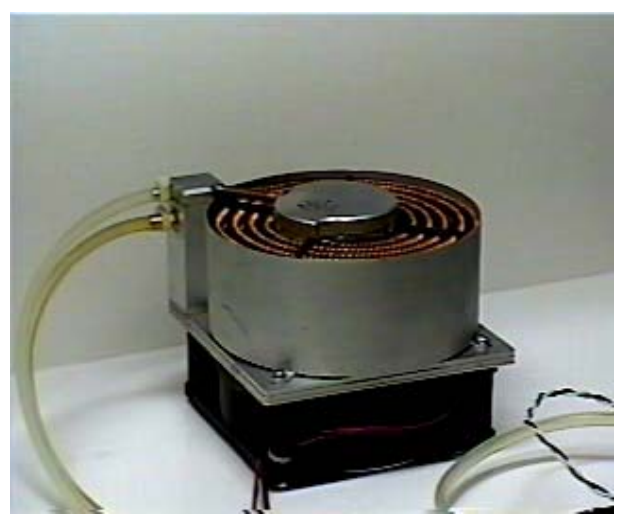

Fig. 3.2 24 Volt ISR Liquid Pump

provided by a fan mounted at the base of the pump. The nozzle was a differential pressure atomizer. It had an exit aperture diameter of $0.2 \mathrm{~mm}$ (see Fig. 3.3), which was measured using a high power microscope and a fiducial. During testing, the

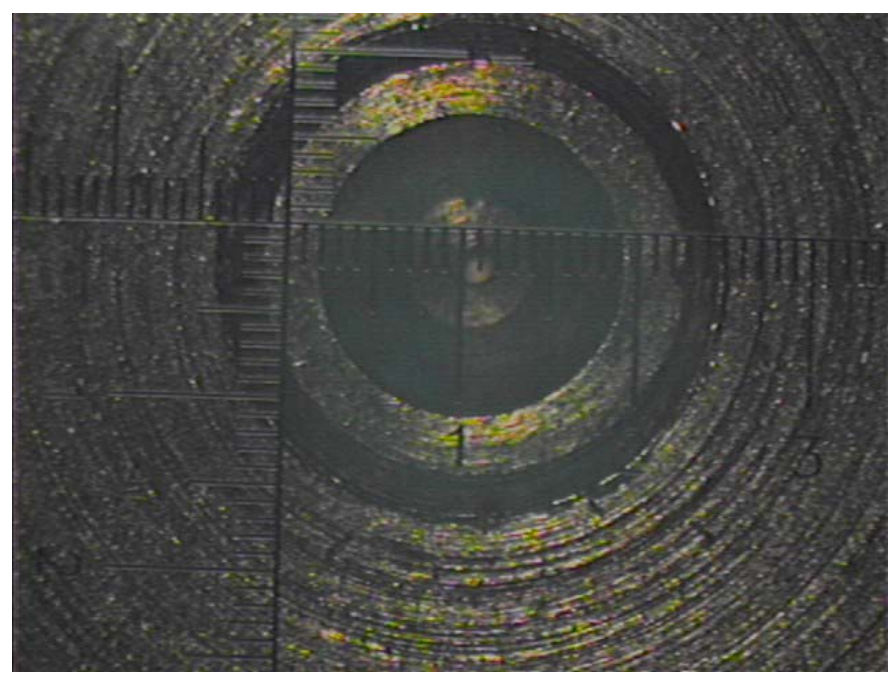

Fig. 3.3 ISR Nozzle Exit Aperture 
nozzle was mounted to a holder capable of rotation $\left(0^{\circ}-90^{\circ} \mathrm{CCW}\right)$ and both lateral and vertical translation with respect to the heater surface. The test article was placed in the chamber and separated from the pooled liquid and excess liquid path by a stainless steel shell and an alumina bisque ceramic flange (see Fig. 3.4). The upper necking of the copper block was fixed to the ceramic flange using a bead of epoxy along the inner heater/flange boundary. The bottom of the ceramic was grooved so it could be mated to the top chamfer of the stainless steel housing. The copper heater (shown in Fig. 3.5) was attached to the baseplate with a teflon gasket placed between the baseplate and itself to seal off the fluid path to the interior of the housing and ultimately the copper block. Three T-type thermocouples were mounted in the upper

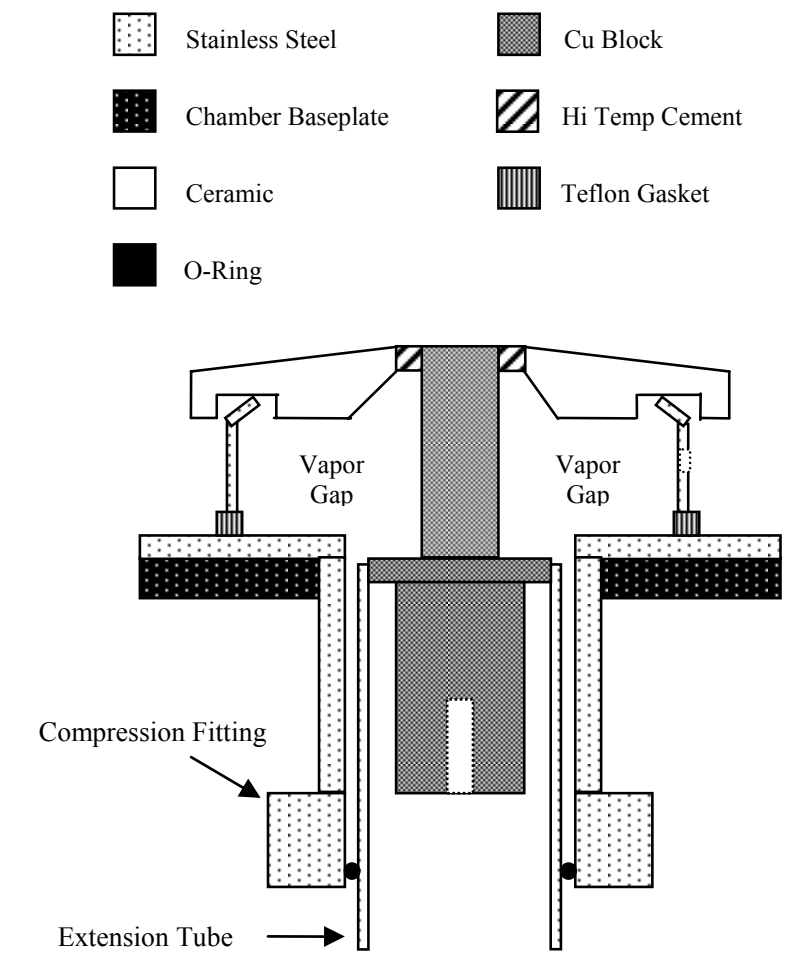

Fig. 3.4 LPS Test Rig Copper Block Housing Configuration 


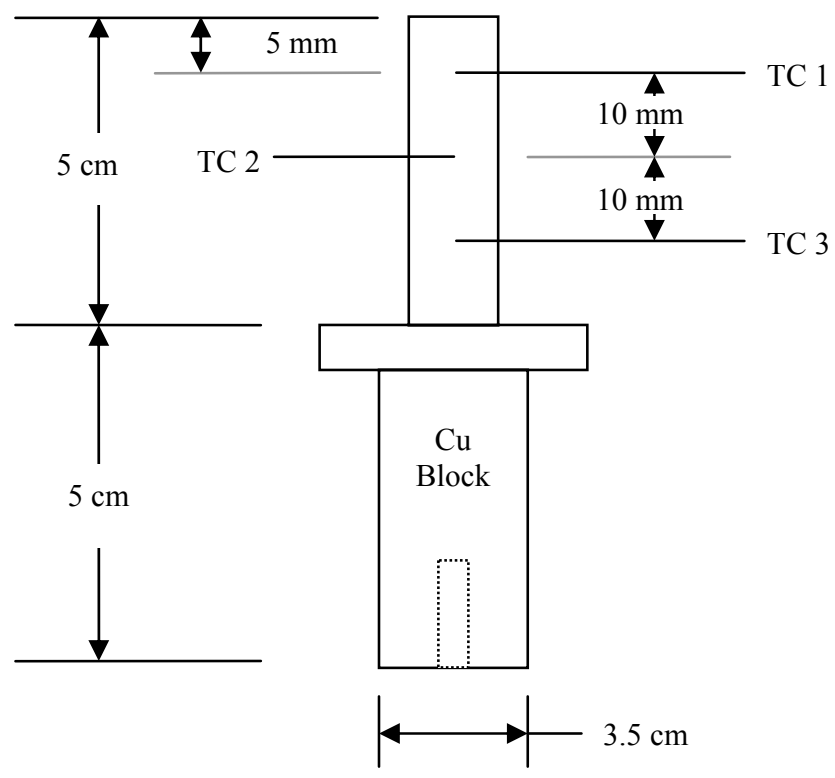

Fig. 3.5 Heater Block TC Locations (not to scale)

necking of the copper block along the center line axis. These were used to calculate the heat flux. Since the thermocouple locations and the temperature at these respective locations was konwn, Fourier's Law for Conduction was used to calculate the heat flux. Surface temperature was linearly extrapolated from the thermocouples closest to the surface.

The data acquisition system used for the tests consisted of a National Instruments DAQCard-6062E, a 58 Pin E series multi-pin connector and a Toshiba Satellite 1905 Series laptop. The DAQCard-6062E was a multi-function analog, digital, and timing I/O card for computers equipped with Type II PCMCIA slots. This card featured a 12-bit ADC (analog to digital converter), two 12-bit DACs (digital to analog converters), and two 24-bit counter/timers for timing I/O. Temperature and voltage measurements (specifically for the flow meter) were recorded by the computer via the pin-connector and DAQCard. The controller software used was LabView 6.0. 


\subsubsection{NASA Goddard Space Flight Center Studies}

The enhanced surface experiments were conducted within a closed fluid loop. The test rig (schematic shown in Fig. 3.6) consisted of a test chamber, pump, flow meter, micro-filter, and a condenser. Chamber temperature and pressure were measured using a T-type thermocouple and a pressure sensor. Temperature and pressure sensors were also placed in the liquid line directly upstream of the nozzle to measure liquid supply line temperature and the pressure across the nozzle.

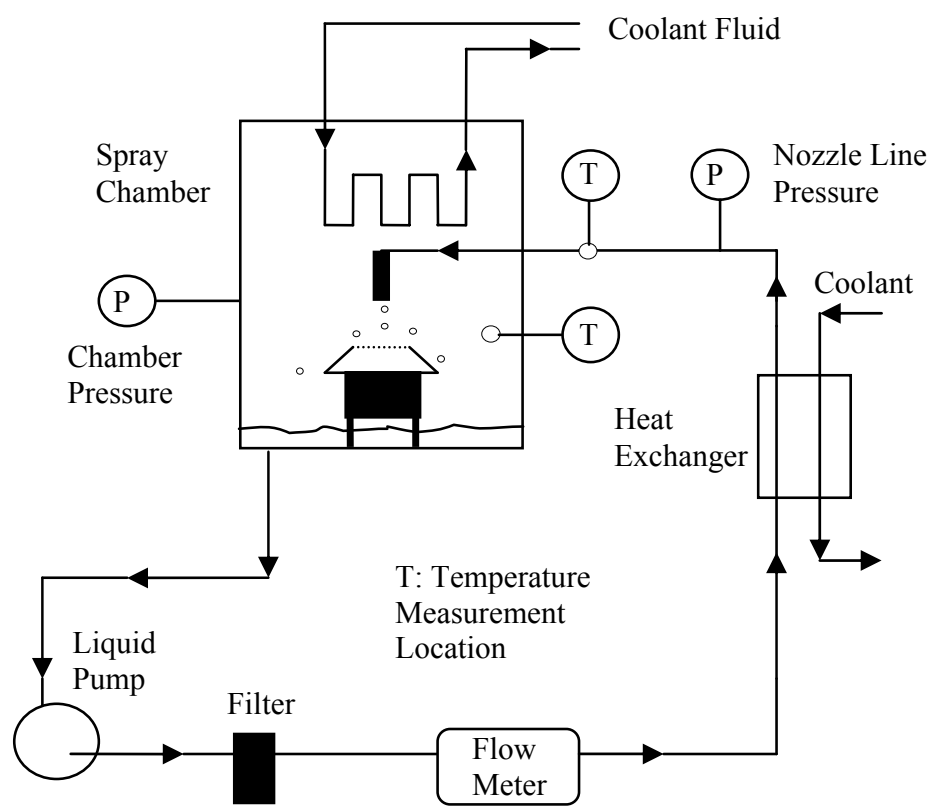

Fig. 3.6 NASA GSFC Spray Cooling Test Rig Configuration

The test surfaces were fabricated on the top surface of oxygen-free high conductivity copper blocks with a uniform undercoat of nickel ( $2.54 \mu \mathrm{m}$ thickness), followed by a final coat of gold (1.27 $\mu$ m thickness). Heat was supplied to the test surfaces using a $500 \mathrm{~W}$ cartridge heater. The heater assembly was placed within the interior of the chamber, but was separated from the excess liquid by an enclosure consisting of a polycarbonate housing and an alumina bisque ceramic top flange (Fig. 
3.7). The upper section of the heater block was epoxied to the flange. Temperatures in the heater blocks were sampled using five T-type thermocouples mounted in the neck of each block (shown in Fig. 3.8). The heat flux was calculated using Fourier's Law of conduction assuming steady state conduction through the upper neck of the block (i.e. 1-D). The reported heat flux was obtained by averaging the heat flux computed from neighboring thermocouple pairs. Surface temperature was determined by linear extrapolation of the temperatures indicated by TC1 and TC2.

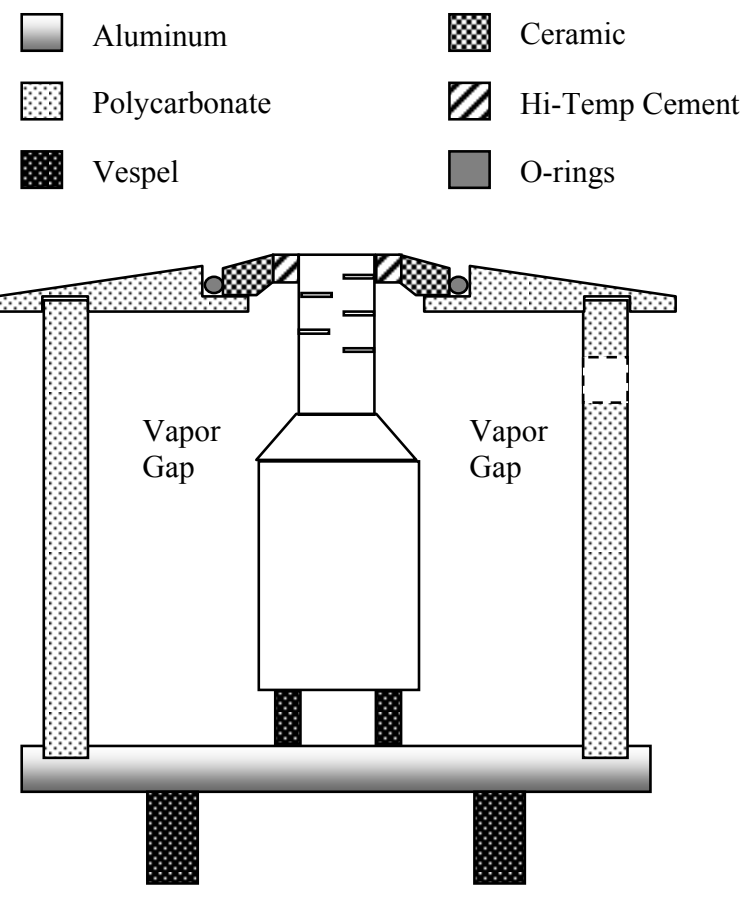

Fig. 3.7 NASA GSFC Test Rig Copper Block Housing Schematic 


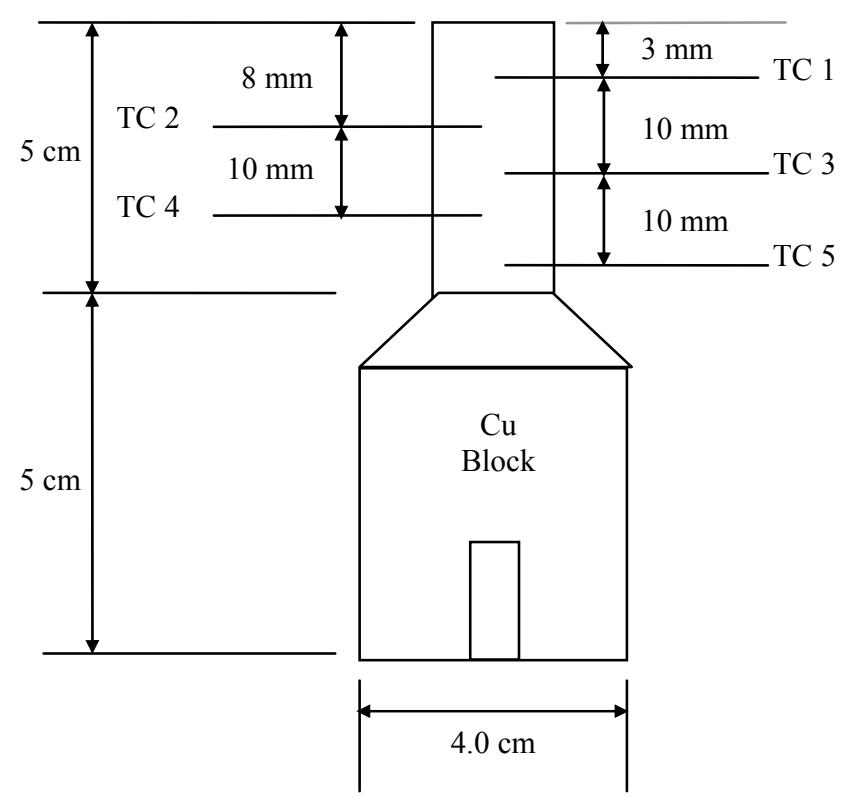

Fig. 3.8 Copper Block Schematic with TC Locations (not to scale)

\subsection{Procedure}

In each of the studies, prior to experimentation the test rig was charged with the working fluid (PF-5060) and degassed at room temperature by repeatedly pulling vacuum on the chamber until the appropriate saturation pressure was attained. For the LPS studies, once the working fluid was degassed, the chamber was heated to saturation conditions at $101 \mathrm{kPa}$. Test conditions are shown in Table 3.1. All of the LPS tests were conducted at this saturation pressure. Heat flux and spray characterization measurements were obtained. For the heat flux measurements, data was acquired at four different nozzle-to-heater surface distances and three different spray volumetric flow rates. These are shown in Table 3.2. Heat was input to the copper block via a $200 \mathrm{~W}$ cartridge heater mounted in its base. Voltage to the cartridge heater was supplied via variac. 
Table 3.1 LPS Test Case Conditions

\begin{tabular}{|c|c|}
\hline \multicolumn{2}{|c|}{ Spray Cooling Parameters } \\
\hline Parameters & Values \\
\hline $\mathrm{P}_{\text {sat }}$ & $101 \mathrm{kPa}$ \\
\hline $\mathrm{T}_{\text {sat }}$ & $56^{\circ} \mathrm{C}$ \\
\hline $\mathrm{T}_{1}$ & $23.5^{\circ} \mathrm{C}$ \\
\hline $\mathrm{h}_{\mathrm{fg}}$ & $76 \mathrm{~kJ} / \mathrm{kg}$ \\
\hline
\end{tabular}

Table 3.2 Spray Cooling Test Cases for Flat Surface Copper Block

\begin{tabular}{|c|c|c|c|c|c|}
\hline \multirow{2}{*}{$\begin{array}{c}\text { Test Matrix } \\
\text { Case Numbers }\end{array}$} & \multicolumn{4}{|c|}{$\begin{array}{c}\text { Nozzle to Heat Exchange Surface } \\
\text { Height }\end{array}$} \\
\cline { 2 - 6 } & $40 \mathrm{~mm}$ & $30 \mathrm{~mm}$ & $20 \mathrm{~mm}$ & $10 \mathrm{~mm}$ \\
\hline \multirow{2}{*}{} & $\begin{array}{c}3.33 \times 10^{-7} \mathrm{~m}^{3} / \mathrm{s} \\
\left(20 \mathrm{ml} / \mathrm{min}^{2}\right.\end{array}$ & 1 & 4 & 7 & 10 \\
\cline { 2 - 6 } & $\begin{array}{c}5.0 \times 10^{-7} \mathrm{~m}^{3} / \mathrm{s} \\
\left(30 \mathrm{ml} / \mathrm{min}^{2}\right.\end{array}$ & 2 & 5 & 8 & 11 \\
\cline { 2 - 6 } & $\begin{array}{c}6.66 \times 10^{-7} \mathrm{~m}^{3} / \mathrm{s} \\
(40 \mathrm{ml} / \mathrm{min})\end{array}$ & 3 & 6 & 9 & 12 \\
\hline
\end{tabular}

In the NASA Goddard Space Flight Center (NASA GSFC) degassed case studies, the spray chamber and fluid loop were charged with PF-5060 and a vacuum was repeatedly applied to the chamber until a pressure of $41.4 \mathrm{kPa} \quad(470 \mathrm{ppm}$ gas concentration) was reached. For the gassy case, the chamber was backfilled to 101 $\mathrm{kPa}$ using $\mathrm{N}_{2}$ gas ( $99.9 \%$ purity). The gas concentration for this case was $3821 \mathrm{ppm}$. The chamber was allowed to attain equilibrium prior to conducting the tests. Test conditions for both the gassy and degassed cases are shown in Table 3.3. All of the NASA GSFC tests were run at constant chamber pressure, liquid flow rate (200 $\mathrm{ml} / \mathrm{min}$ ) and constant nozzle height above the heater surface. Heat was input to the copper block via a $500 \mathrm{~W}$ cartridge heater mounted in its base. Power was supplied to the cartridge heater in increments of $10 \mathrm{~W}$ using a programmable power supply. 
Table 3.3 NASA GSFC Test Case Conditions

\begin{tabular}{|c|c|c|}
\hline \multicolumn{3}{|c|}{ Spray Cooling Parameters } \\
\hline Parameters & Degassed Case & Gassy Case \\
\hline $\mathrm{P}_{\text {sat }}$ & $41.4 \mathrm{kPa}$ & $101 \mathrm{kPa}$ \\
\hline $\mathrm{T}_{\mathrm{sat}}$ & $31^{\circ} \mathrm{C}$ & $56^{\circ} \mathrm{C}$ \\
\hline $\mathrm{T}_{1}$ & $20.5^{\circ} \mathrm{C}$ & $20.5^{\circ} \mathrm{C}$ \\
\hline $\mathrm{h}_{\mathrm{fg}}$ & $92 \mathrm{~kJ} / \mathrm{kg}$ & $76 \mathrm{~kJ} / \mathrm{kg}$ \\
\hline Gas Content & $470 \mathrm{ppm}$ & $3821 \mathrm{ppm}$ \\
\hline
\end{tabular}

In each of the studies (i.e. LPS and NASA GSFC) steady state was achieved at each power level, and data was acquired before application of the next successive heat load. Upon dry-out at the heater surface, power to the cartridge heater was turned off. Experimentation was resumed at the next test case once the block cooled to ambient temperature. Figs. 3.9 and 3.10 are example plots of the collected test data for the LPS studies at a nozzle-to-heater surface distance of $10 \mathrm{~mm}$ and a spray volumetric flow rate of $30 \mathrm{ml} / \mathrm{min}$. Q1 and Q2 are the heat fluxes estimated using

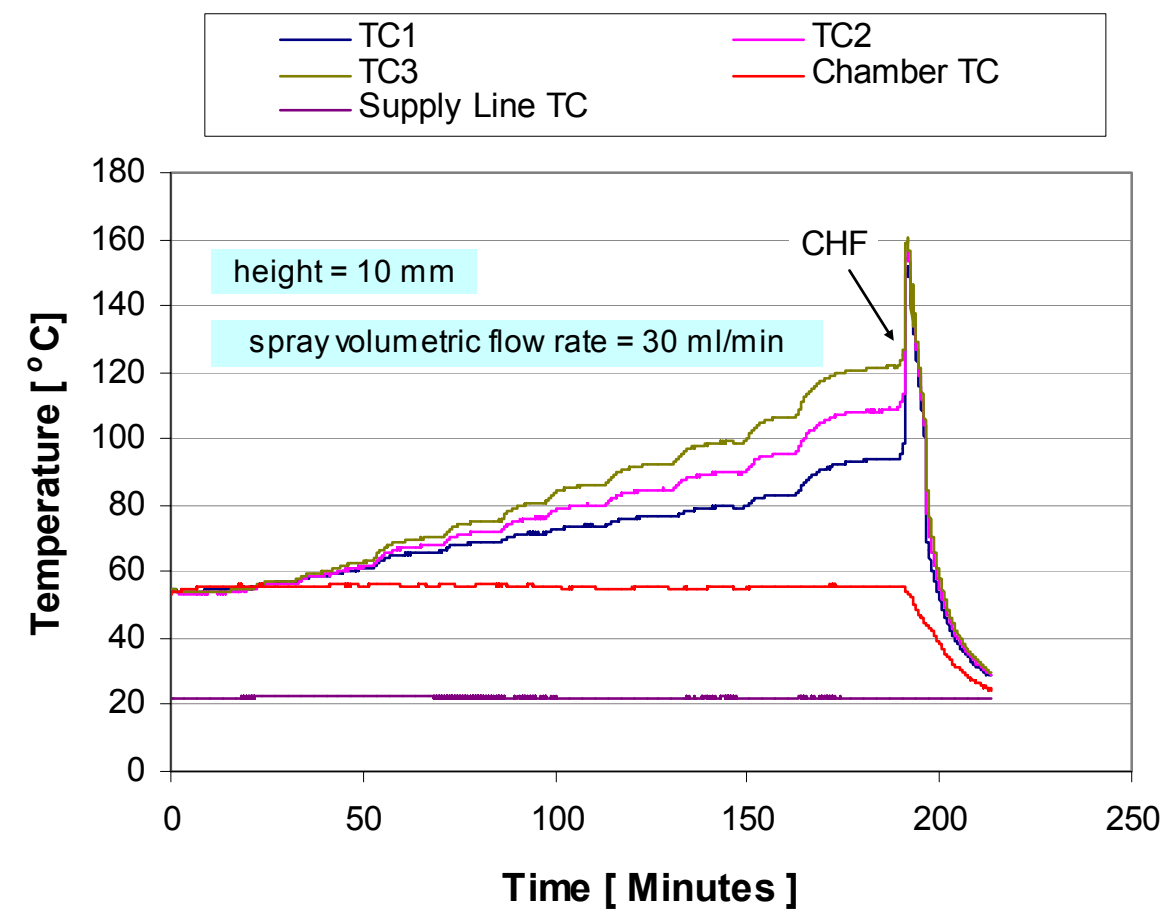

Fig. 3.9 Example of Temperature vs. Time plot for Spray Cooling Test Data 


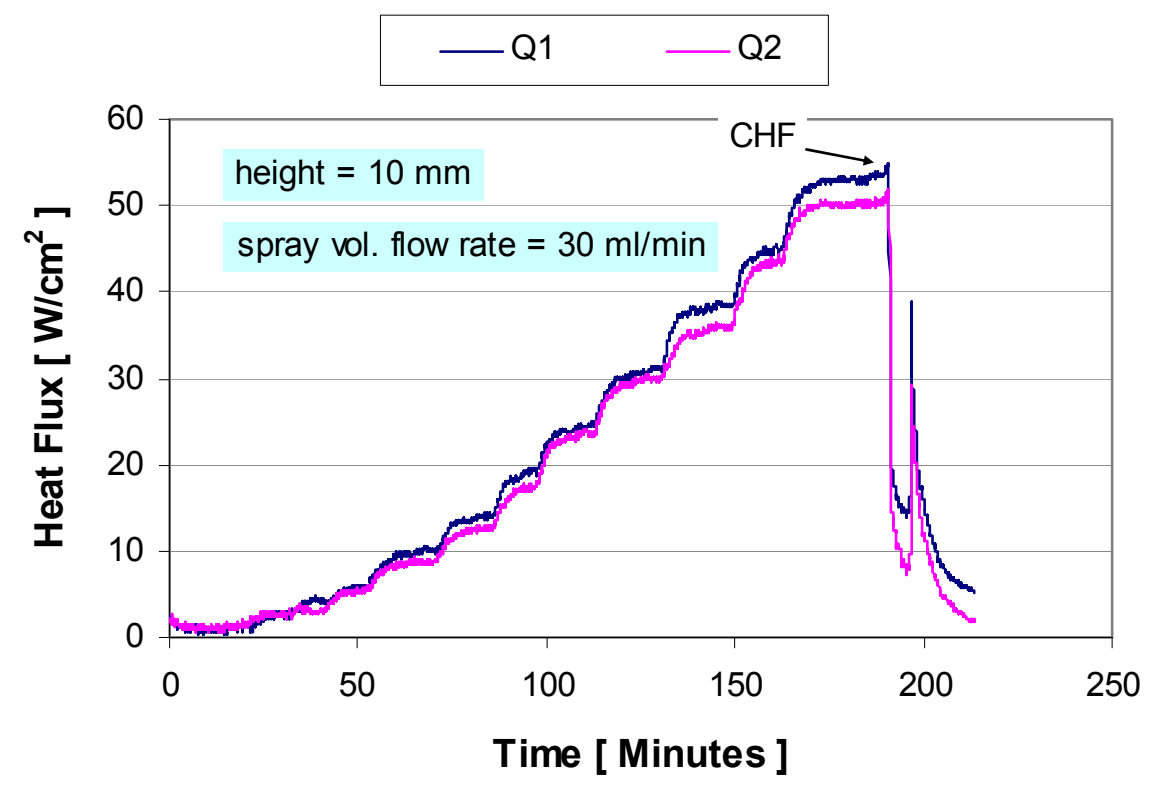

Fig. 3.10 Example of Heat Flux vs. Time plot for Spray Cooling Test Data

different combinations of thermocouples within the heater. Steady state is exemplified by constant temperature for the copper block thermocouples and constant heat fluxes. Dry-out was detected by a rapid increase in surface temperature coinciding with a rapid decrease in heat flux. Transition to the Leidenfrost point ensued immediately afterward.

\subsection{ISR Nozzle Spray Characteristics}

\subsubsection{Effective Volumetric Flow Rate Determination}

Review of the heat flux data for the LPS studies identified two important factors which are worthy of examination. These are the effective volumetric flow rate impacting the heater surface and the spray droplet characteristics. The effective volumetric flow rate is a function of the spray cone angle and the nozzle to heater distance. For the spray used in the LPS studies, the liquid will eject from the nozzle in 
conical fashion. The perimeter at which the spray cone impinges the heater surface is important because this impacts the amount of over-spray (liquid landing outside of the perimeter of the heater surface). See Fig. 3.11 for a schematic.

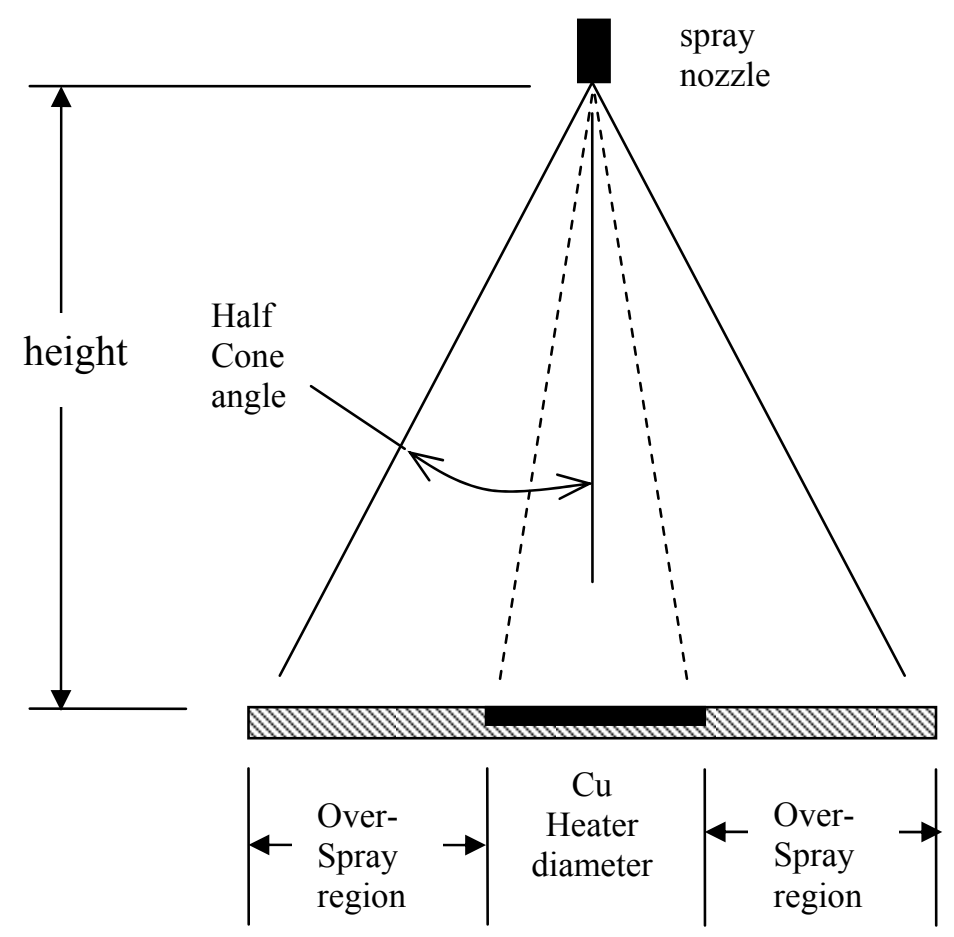

Fig. 3.11 Volumetric Over-spray Schematic

Since the cone angle is changing with the spray volumetric flow rate used, the amount of over-spray will be dependent upon the height of the nozzle and the spray volumetric flow rate. The effective volumetric flow rate impinging the heater surface can either be determined experimentally or geometrically if the cone angle is known. The experimental approach incorporates the use of hollow inserts of the same cross sectional area as the heater placed at the top of a fluid collector. Due to the size of the LPS chamber the geometrical approach was used. 
Mudawar and Estes (1996) developed a geometric relation (shown in eqn 3.1) for the fraction of the spray volumetric flow rate impacting a heater surface when experi-

$$
\frac{\dot{V}_{i}}{\dot{V}_{s p}}=\frac{1}{1-\cos (\alpha / 2)} \cdot\left[1-\frac{1}{\sqrt{1+\left(\frac{r}{l}\right)^{2}}}\right]
$$

encing over-spray. The relation treats the spray nozzle tip as a point source for the total spray volumetric flow rate. Using this approach, the spray is assumed to have a uniform distribution over any spherical surface (at the leading edge of the spray) centered at the spray orifice (see Fig. 3.12). This relation is applicable as long as the target radius is less than the spray cone radius at the point of impact of the spray [i.e. $\mathrm{r}<l \cdot \tan (\alpha / 2)]$. Beyond this condition, fractions greater than unity will be obtained and all of the spray volume is impinging the heater surface. For a detailed derivation, see the work by Mudawar and Estes (1996).

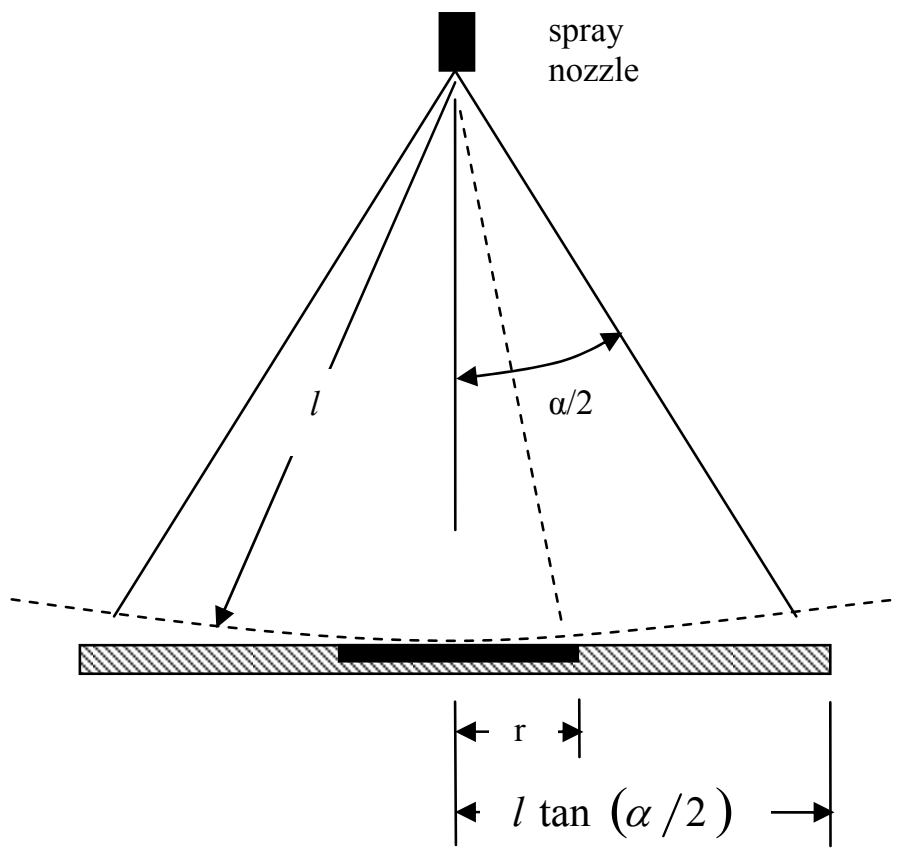

Fig. 3.12 Uniform Volumetric Flow Rate Distribution Calculation Schematic 
The cone angles were determined by taking video footage of the spray cone at each of the spray volumetric flow rates while under standard test conditions (degassed PF-5060 at $101 \mathrm{kPa}$ ). As shown in Figs. 3.13a through 3.13c, the cone angle actually decreased when the spray volumetric flow rate was increased. Given the dimensions of the spray cone contour, the cone angle was determined using simple geometry. Table 3.4 shows a listing of each of the cases along with their respective cone angle and calculated volumetric flux across the heater surface. For the $20 \mathrm{~mm}$ and the 10 mm nozzle height cases, all of the spray impacted the heater surface. These results will be revisited in chapter 4 . The uniform spray assumption applied to the ISR nozzles used is addressed in the following section.

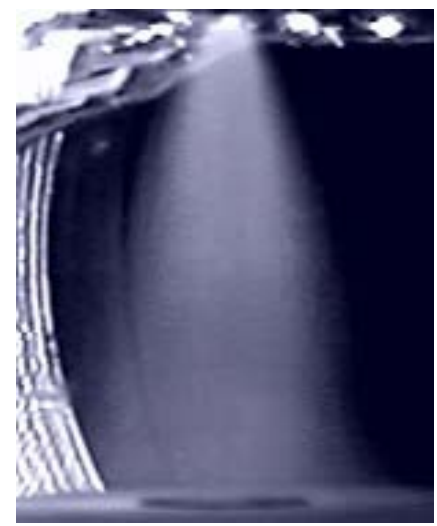

(a) $3.33 \times 10^{-7} \mathrm{~m}^{3} / \mathrm{s}$

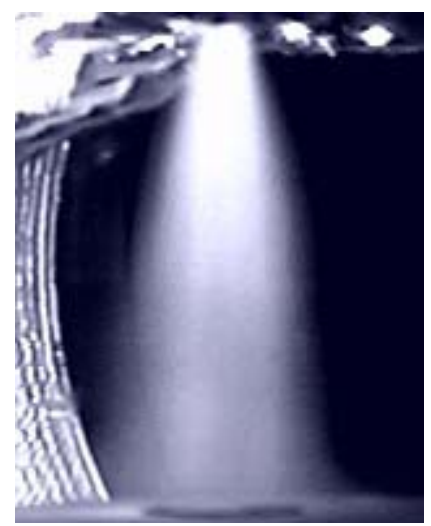

(b) $5.0 \times 10^{-7} \mathrm{~m}^{3} / \mathrm{s}$

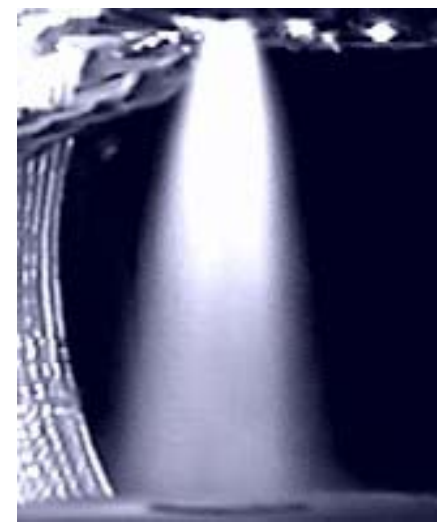

(c) $6.66 \times 10^{-7} \mathrm{~m}^{3} / \mathrm{s}$

Fig. 3.13 Spray Cone close-up at variable Spray Volumetric Flow Rates 
Table 3.4 Volumetric Fraction Case Study Summary

\begin{tabular}{|c|c|c|c|c|c|}
\hline $\begin{array}{c}\text { Case } \\
\text { Number }\end{array}$ & $\begin{array}{c}\text { Nozzle } \\
\text { Height } \\
(\mathrm{mm})\end{array}$ & $\begin{array}{c}\text { Spray } \\
\text { Volumetric } \\
\text { Flow Rate } \\
(\mathrm{ml} / \mathrm{min})\end{array}$ & $\begin{array}{c}\text { Cone Angle } \\
\alpha \\
(\text { Degrees })\end{array}$ & $\begin{array}{c}\text { Volumetric } \\
\text { Fraction }\end{array}$ & $\begin{array}{c}\dot{V}^{\prime \prime} \\
\left(\mathrm{m}^{3} / \mathrm{m}^{2} \mathrm{~s}\right)\end{array}$ \\
\hline 1 & 40 & 20 & 30.0 & 0.28 & 0.0009 \\
\hline 2 & 40 & 30 & 27.0 & 0.36 & 0.0018 \\
\hline 3 & 40 & 40 & 26.0 & 0.39 & 0.0026 \\
\hline 4 & 30 & 20 & 30.0 & 0.50 & 0.0017 \\
\hline 5 & 30 & 30 & 27.0 & 0.63 & 0.0032 \\
\hline 6 & 30 & 40 & 26.0 & 0.68 & 0.0045 \\
\hline 7 & 20 & 20 & 30.0 & 1.00 & 0.0033 \\
\hline 8 & 20 & 30 & 27.0 & 1.00 & 0.0050 \\
\hline 9 & 20 & 40 & 26.0 & 1.00 & 0.0067 \\
\hline 10 & 10 & 20 & 30.0 & 1.00 & 0.0033 \\
\hline 11 & 10 & 30 & 27.0 & 1.00 & 0.0050 \\
\hline 12 & 10 & 40 & 26.0 & 1.00 & 0.0067 \\
\hline
\end{tabular}

\subsubsection{Spray Droplet Measurements}

The spray characterization measurements were conducted using a Dantec PDPA (Phase Doppler Particle Analyzer). The PDPA system determines spray characteristics via photo-detection of scattered light. The system (schematic shown in Fig. 3.14) consists of an emitter, one or more detector receivers, a laser, a signal

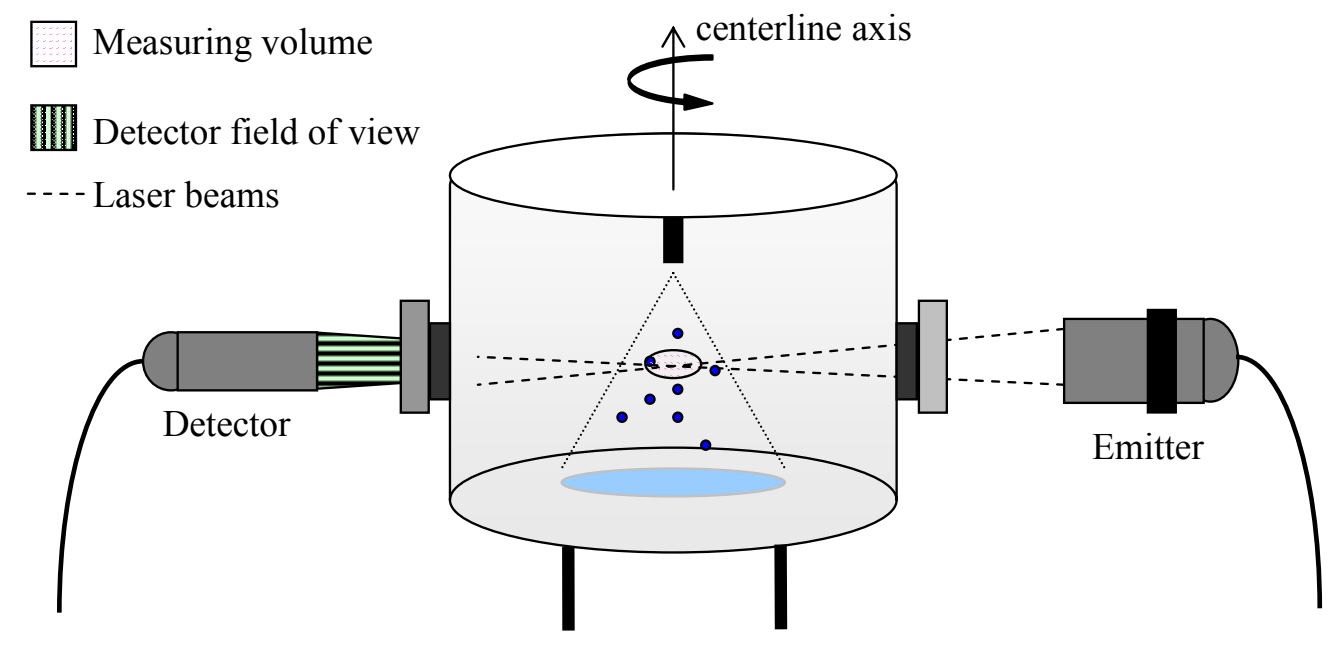

Fig. 3.14 PDPA System Measurement Schematic 
processor and a computer. A beam of laser light is split into two separate beams that intersect each other at a given angle (dependent upon the beam separation distance and focal length of the lens used). The beams are coherent to one another in the volume of their intersection and create fringe patterns. Particles traversing through this volume (shown in the schematic as the rose oval in the spray cone) create scattered light incident upon the photo-detector. The oscillation intensity of the scattered light corresponds to particles passing through the fringes and has a frequency that is proportional to the velocity of the component at right angles to the fringes. The particles traversing the measuring volume also create doppler bursts received by the detector. The phase of the burst corresponds to the size of the particle. Table 3.5 lists PDPA settings used. The scattering angle is the angle of the detector position measured relative to the plane created by the split laser beams coming from the emitter. In this study, measurements were taken using a single detector.

At each of the volumetric flow rates, SMD and mean velocity distributions were measured in the spray cone. Two different studies were performed. The first was dedicated to the characterization of the spray. In these tests, measurements were taken in a straight line path at four different planes of known distance from the nozzle (see

Table 3.5 Spray Characteristics Measurement PDPA Settings

\begin{tabular}{|c|c|c|c|}
\hline \multicolumn{2}{|c|}{ Transmitter Optics } & \multicolumn{2}{c|}{ Receiver Optics } \\
\hline Parameter & Setting & Parameter & Setting \\
\hline Focal Length & $310 \mathrm{~mm}$ & Focal Length & $310 \mathrm{~mm}$ \\
\hline Beam Diameter & $1.35 \mathrm{~mm}$ & Scattering Mode & $1^{\text {st }}$ Order Refraction \\
\hline Beam Spacing & $40.0 \mathrm{~mm}$ & Scattering Angle & $70^{\circ}$ \\
\hline Frequency Shift & $40 \mathrm{MHz}$ & Polarization & Parallel \\
\hline High Voltage & $1000 \mathrm{~V}$ & Aperture Mask & A \\
\hline & & Relative Index & 1.251 \\
\hline
\end{tabular}




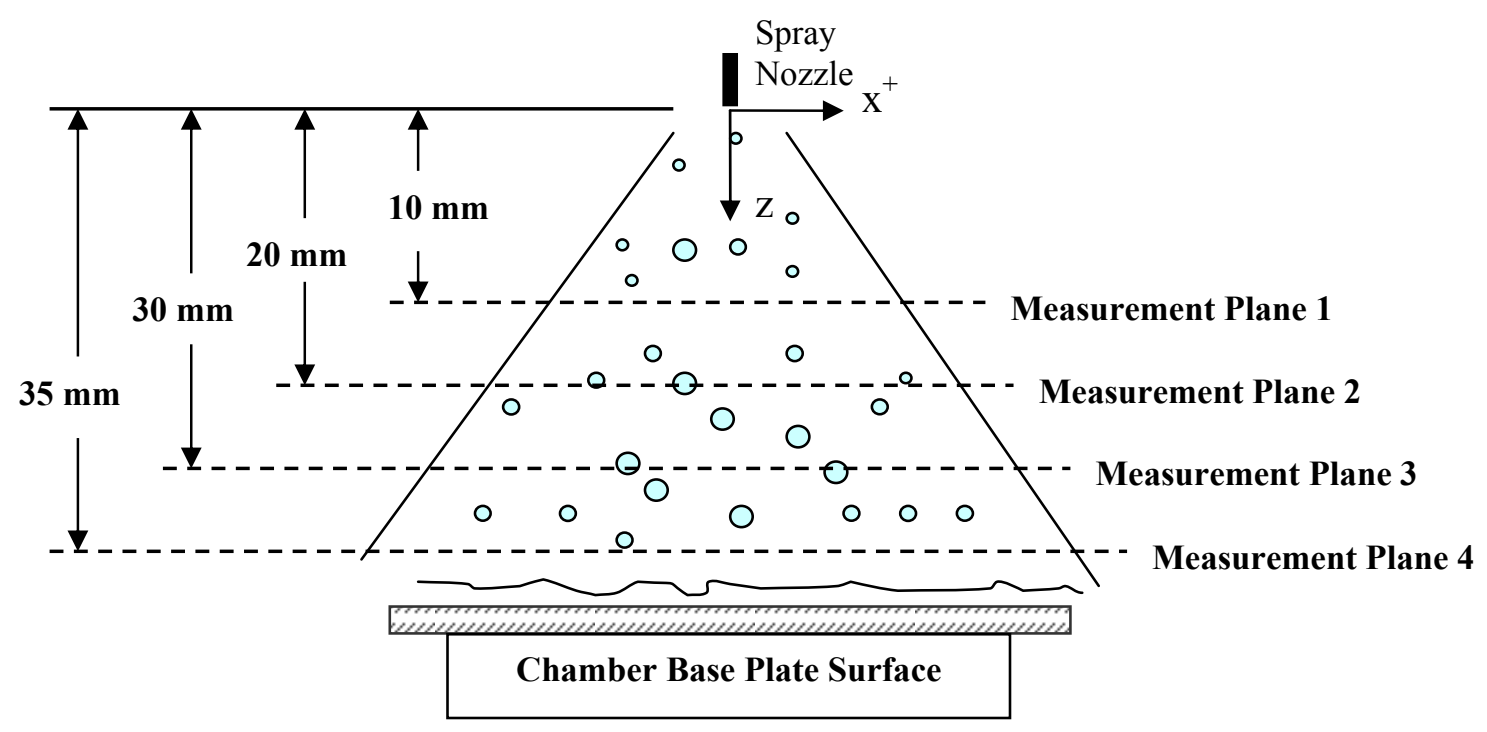

Fig. 3.15 Spray Cone Measurement Planes

Fig. 3.15). This test is referenced as the $0^{\circ}$ orientation case. The nozzle was then rotated $90^{\circ}$ (in-plane $\mathrm{CCW}$ ) and the test was repeated.

The goal of taking the spray measurements with and without the nozzle rotated by $90^{\circ}$ about the nozzle axis $\left(90^{\circ}\right.$ orientation case) was to determine the uniformity of the spray and test the assumption of axisymmetry. The second study was aimed at determining the effect of an active heater upon the spray characteristics that might be impacted by vapor generation and blockage of the spray. Measurements were taken at $35 \mathrm{~mm}$ from the nozzle tip (i.e. $5 \mathrm{~mm}$ above the heater surface). The $0^{\circ}$ orientation was used for the active heater test and later compared to the $0^{\circ}$ orientation non-active heater case. This study was only conducted for the $20 \mathrm{ml} / \mathrm{min}$ volumetric flow rate. Since the PDPA system cannot detect vapor, the impact of the vapor efflux upon the spray during heater activation could only be measured as a function of droplet velocity immediately prior to impact. The premise of the study is that any significant impact upon the spray due to heater activation and vapor efflux will decrease droplet 
velocities below those of the non-active heater mode (baseline study). Lower velocities make the droplets more susceptible to vapor efflux. Given the flow rates studied in this work, the $20 \mathrm{ml} / \mathrm{min}$ volumetric flow rate produced the lowest ejection velocity for the droplets. The combination of the nozzle height $(40 \mathrm{~mm}$ from the heater surface) and the flow rate used create the lowest possible impact velocities for all the cases studied. This implies that if the vapor efflux were to affect the inbound droplets, the largest effect would be experienced by this case, providing an upper limit to the maximum possible expected impact. Thus, it is a bounding case for determination of whether or not an active heater impacts the spray for all of the cases tested. In the heated case, the heat flux $\left(\approx 59.6 \mathrm{~W} / \mathrm{cm}^{2}\right)$ was set to the maximum value (shown as case 12 in Table 3.4) attained in the previous testing. Testing for both studie $\left(0^{\circ}\right.$ and $90^{\circ}$ cases $)$ were performed in PF-5060 vapor at $101 \mathrm{kPa}$. All PDPA measurement data collected and presented here is subject to the following criteria regarding the definition of the spray cone edges.

i) (Level 1 criteria) Determination of the spray cone edge for each nozzle-toheater distance was based on the spray cone data rate. Edges on either side of the centerline axis (for a given measurement plane) were specified as occurring at the point in which the data rate reduced to $10 \%$ of the maximum data rate recorded in plane. The maximum data rate location consistently held with the centerline axis for the $0^{\circ}$ orientation cases.

ii) (Level 2 criteria) Determination of the spray cone edge was based on the number of samples detected at the respective measurement location. The spray cones' edges were defined as occurring at the point where the sample size 
decreased to $\approx 20 \%$ of the sample size at the centerline axis for a given measurement plane. An example of the reduction in samples taken at the cone edge can be seen in the histogram plots for SMD (shown in Figs. 3.16 through 3.18). The centerline axis is taken as $x=0$ in these figures. Visual inspection of the PDPA's measurement volume with respect to the spray cones edge showed the reduction location to occur at the point in which the laser beam's measurement volume began to step outside of the visible spray cone itself.
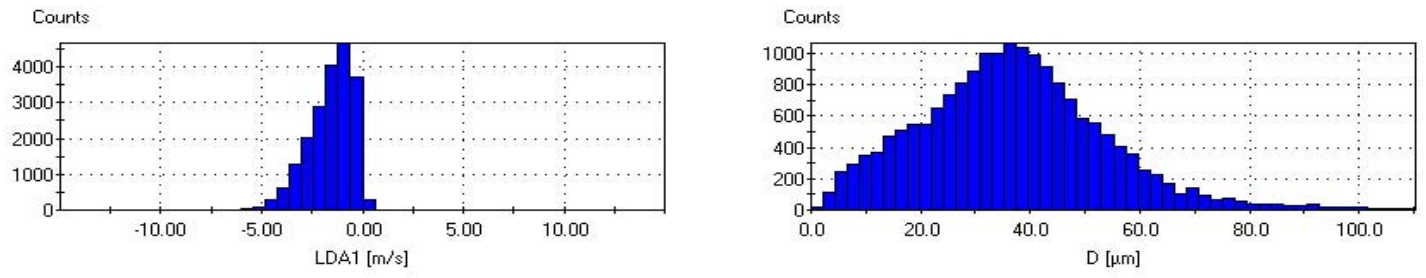

Project: PF5060_30mpm_Odegrees_e - Pos: $-5.00 ; 15.00 ; 0.00$ - Date/Time: 12:31:09 AM

Fig. 3.16 Mean Velocity and SMD distributions at $\mathrm{x}=-3, \mathrm{z}=20 \mathrm{~mm}$ plane, $30 \mathrm{ml} / \mathrm{min}$
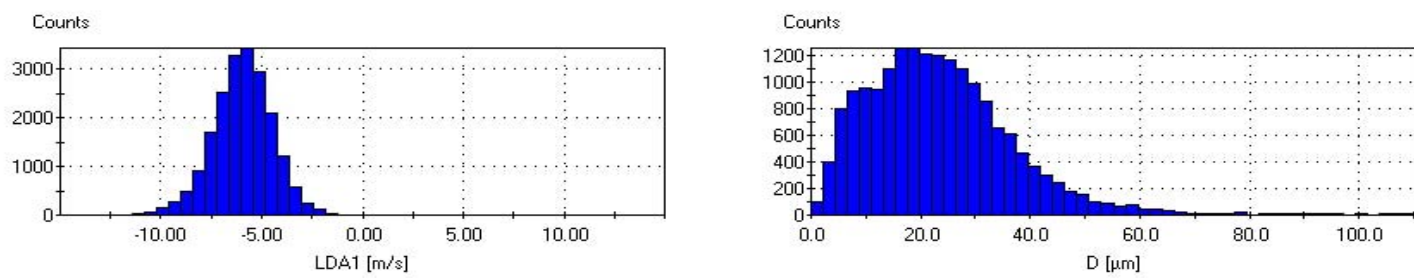

Project: PF5060_30mpm_0degrees_e - Pos: $-2.00 ; 15.00 ; 0.00$ - Date/Time: 12:31:36 AM

Fig. 3.17 Mean Velocity and SMD distributions at $\mathrm{x}=0, \mathrm{z}=20 \mathrm{~mm}$ plane, $30 \mathrm{ml} / \mathrm{min}$
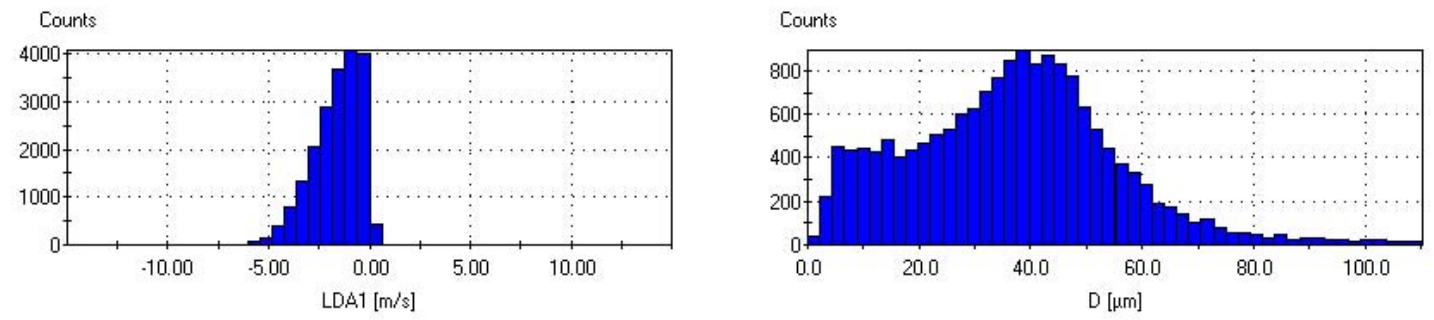

Project: PF5060_30mpm_0degrees_e - Pos: $2.00 ; 15.00 ; 0.00$ - Date/Time: 12:32:11 AM

Fig. 3.18 Mean Velocity and SMD distributions at $\mathrm{x}=4, \mathrm{z}=20 \mathrm{~mm}$ plane, $30 \mathrm{ml} / \mathrm{min}$ 
All points classified as outside the spray cone according to these criteria were omitted from the data presented in this document. Results from the spray characteristic measurements are presented and discussed in chapter 4 .

\subsection{Spray Nozzle Volumetric Flux Uniformity Study}

The PDPA droplet characteristics measurements detailed for the ISR nozzle used in the LPS studies led to the determination that the ISR nozzle had non-uniform spray characteristics. In response to this determination, a search for a uniform spray nozzle was initiated. Prior to performing the enhanced surface studies, seven nozzles from five different nozzle manufacturers were obtained and tested for volumetric flux uniformity. Spray nozzle uniformity for a coverage area equal to that of the heat exchange surface was measured using stainless steel tubes of different inner diameter, a graduated cylinder, and a stopwatch. The largest tube had an inner diameter approx-

\begin{tabular}{|c|c|c|}
\hline Section & $\begin{array}{c}\text { Area } \\
\left(\mathbf{c m}^{\mathbf{2}}\right)\end{array}$ & $\begin{array}{c}\text { Area } \\
(\mathbf{\%})\end{array}$ \\
\hline $\mathrm{A}_{1}$ & 0.33 & 17.5 \\
\hline $\mathrm{A}_{2}$ & 0.38 & 20 \\
\hline $\mathrm{A}_{3}$ & 0.54 & 28.5 \\
\hline $\mathrm{A}_{4}$ & 0.64 & 34 \\
\hline
\end{tabular}

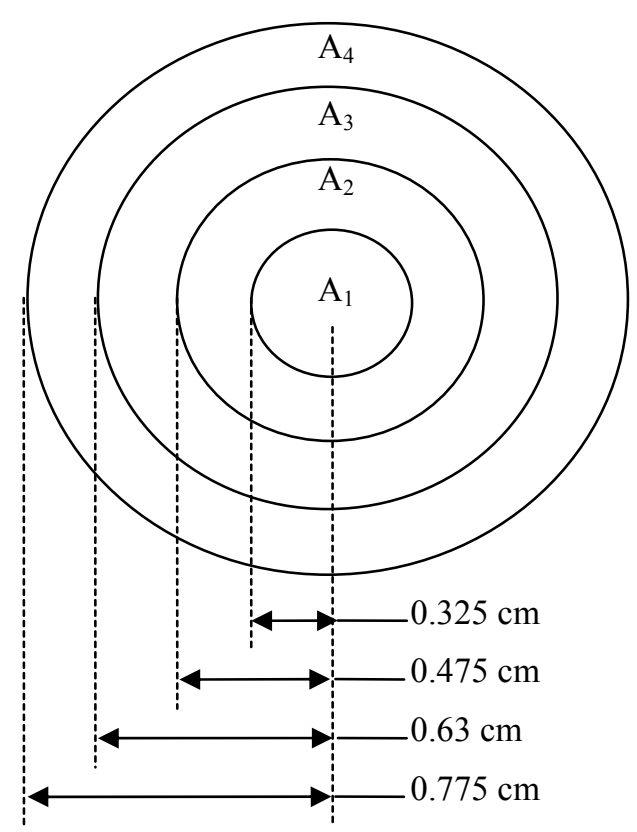

Fig. 3.19 Spray Uniformity Test Schematic (not to scale) 
imately the same diameter as the heated surface. The spray uniformity test schematic along with the concentric cylinder ring section $\left(\mathrm{A}_{1}\right.$ through $\left.\mathrm{A}_{4}\right)$ areas and percentages of total area are shown in Fig. 3.19. Results are discussed in chapter 4.

\subsection{Enhanced Surfaces}

The feature geometry dimensions of each surface tested are summarized in Table 3.6. The heater block labeled $1 \mathrm{f}$ corresponds to the flat surface (no fins present). For the extended surfaces with Cartesian fin arrangements, X, L and H1 are the structure feature width, separation distance, and height respectively. The separation distance for the pyramid (1p) surfaces' structures was zero (i.e, $L=0$ ) because the structures were positioned immediately next to one another. Schematics and photographs of the enhanced surfaces are shown in Fig. 3.20. The cross-sectional view shown for the

Table 3.6 Enhanced Surface Geometry Summary

\begin{tabular}{|c|c|c|c|c|c|c|c|}
\hline \multirow{2}{*}{ Surface } & \multicolumn{7}{|c|}{ Dimensions in (mm) } \\
\cline { 2 - 8 } & $\mathbf{X}$ & $\mathbf{L}$ & H1 & H2 & d1 & d2 & $\mathbf{z 1}$ \\
\hline Flat Surface (1f) & 0 & 0 & 0 & -- & -- & -- & -- \\
\hline Straight Fins (1s) & 1.0 & 1.0 & 1.0 & -- & -- & -- & -- \\
\hline Cubic Pin Fins (1c) & 1.0 & 1.0 & 1.0 & -- & -- & -- & -- \\
\hline Pyramid Fins (1p) & 1.0 & 0.0 & 1.0 & -- & -- & -- & -- \\
\hline Cubic Pin Fins (2c) & 1.5 & 1.0 & 1.0 & -- & -- & -- & -- \\
\hline Cubic Pin Fins (3c) & 2.0 & 1.0 & 1.0 & -- & -- & -- & -- \\
\hline Cubic Pin Fins (4c) & 1.0 & 1.5 & 1.0 & -- & -- & -- & -- \\
\hline Cubic Pin Fins (5c) & 1.0 & 2.0 & 1.0 & -- & -- & -- & -- \\
\hline Cubic Pin Fins (6c) & 1.0 & 1.0 & 1.5 & -- & -- & -- & -- \\
\hline Cubic Pin Fins (7c) & 1.0 & 1.0 & 2.0 & -- & -- & -- & -- \\
\hline Thin Straight Fins (1s t) & 0.5 & 0.5 & 1.0 & -- & -- & -- & -- \\
\hline Straight fins w/Cubics (1sc) & 1.0 & 1.0 & 0.5 & 0.5 & -- & -- & -- \\
\hline Dimples (1d) & -- & 1.0 & -- & -- & 0.5 & -- & 0.5 \\
\hline Straight Fins w/Dimples (1sd) & 1.0 & 1.0 & 1.0 & -- & 0.5 & -- & 0.5 \\
\hline Radial Fins (1r) & -- & 0.5 & 1.0 & -- & -- & -- & -- \\
\hline Porous Tunnels (1pt) & -- & -- & -- & -- & 1.0 & 1.0 & 0.5 \\
\hline
\end{tabular}




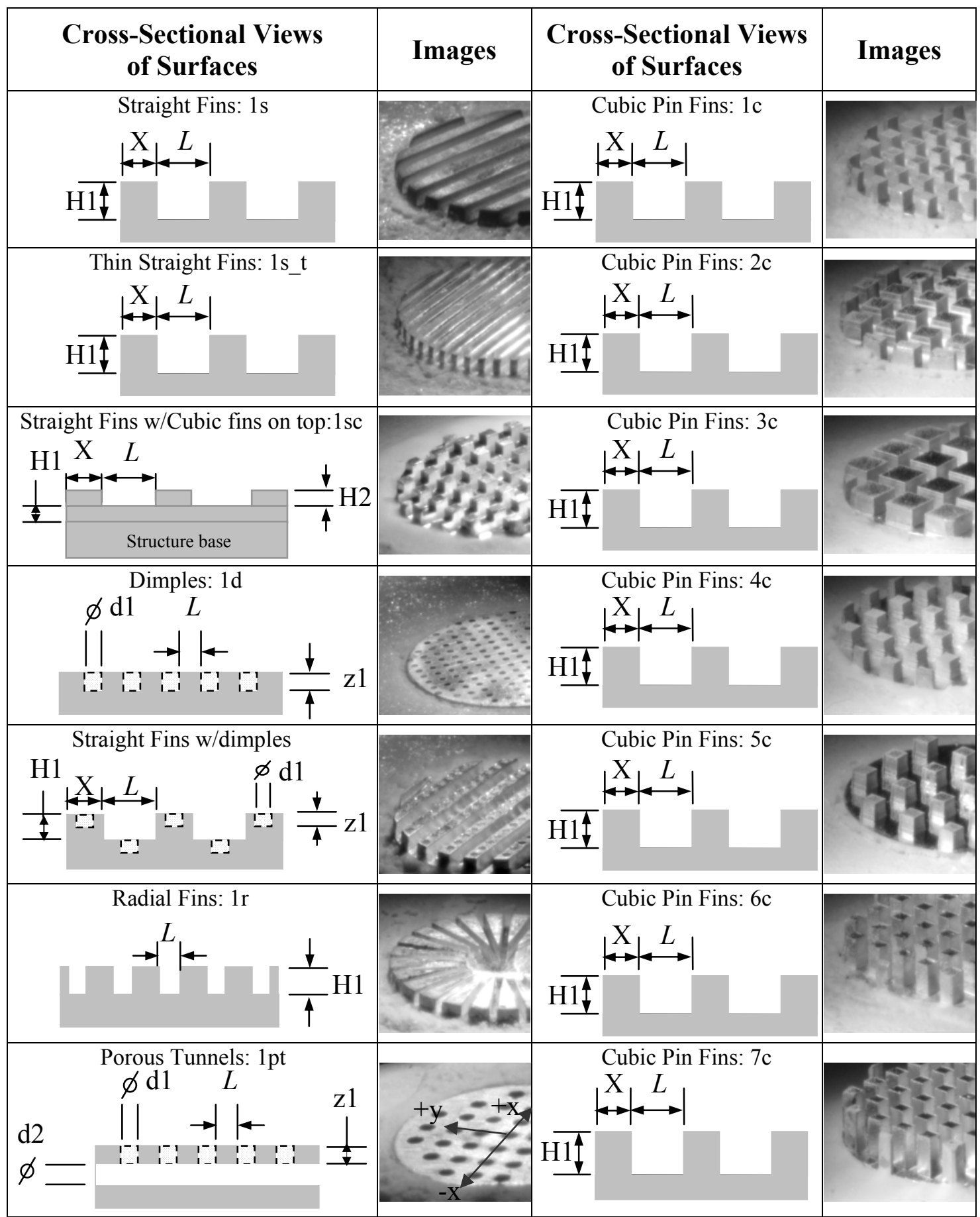

Fig. 3.20 Surface Geometry Cross Sectional Views and Photos

radial fin surface (1r) highlights the channel dimensions. These channels were positioned on the top of the surface every $15^{\circ}$ in the azimuthal direction. The axes 
shown in the porous tunnel surface (1pt) picture are for reference regarding the subsurface structure geometry. The tunnels were aligned along the $\mathrm{x}$ axis (i.e. extended along a constant $y$ value). The centerline of each tunnel was positioned beneath a row of pores drilled normal to the surface. Each tunnel extended through the entire cross section of the copper block. The perimeter of that cross section (including the areas immediately circumscribing the perimeter of the tunnel outlets) was insulated with epoxy. This limited liquid contact to the top surface, the pore interior, and the interior of the tunnels.

\subsection{Spray Inclination Angle}

Spray inclination angles $(\theta)$ were defined as the angle between the spray axis and the normal to the heated surface (Fig. 3.21). The four angles tested in this study were

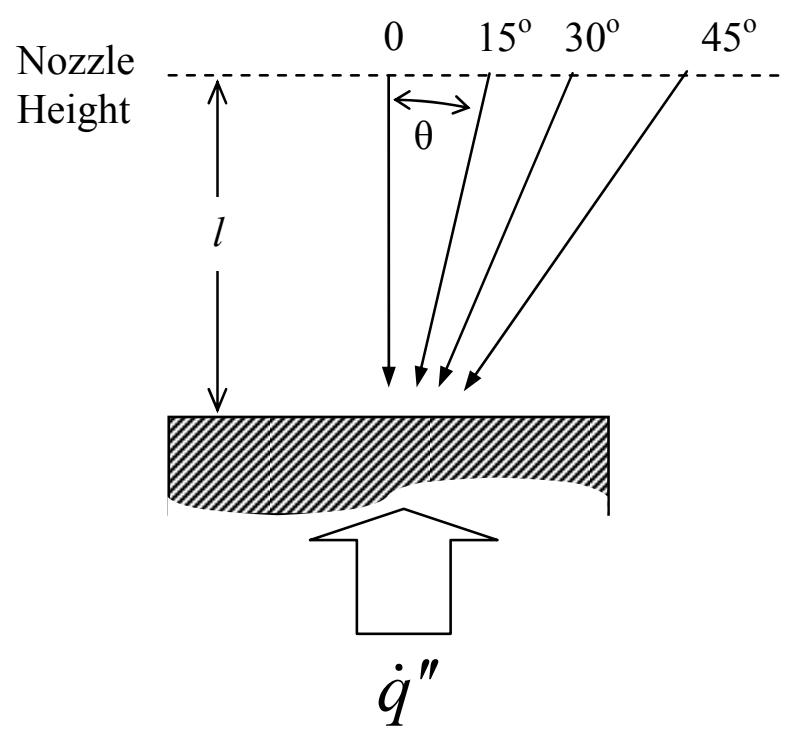

Fig. 3.21 Spray Inclination Angles

$\theta=0^{\circ}$ (vertical), $15^{\circ}, 30^{\circ}$, and $45^{\circ}$. When spraying onto the straight fin surface at an angle other than $\theta=0^{\circ}$, the fin orientation relative to the spray axis must also be 
defined. Two orientations were tested in this study (Fig. 3.22); $\gamma=0^{\circ}$ (axial orientation) and $\gamma=90^{\circ}$ (transverse orientation). The nozzle manifold height $(l)$ was held constant for each of the tests. Delrin spacers were fabricated and used to accurately position the nozzle relative to the heater surface. A spray angle of $\theta=0^{\circ}$ was used for each surface in the initial surface structure geometry survey.

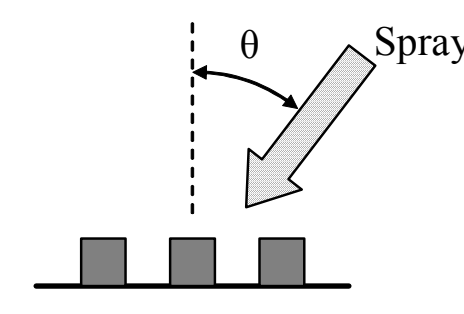

Transverse Orientation

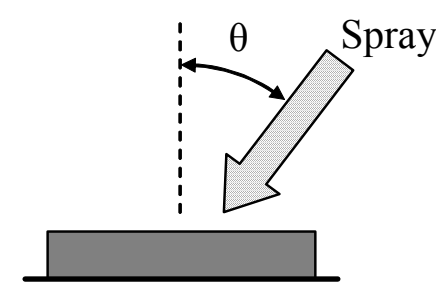

Axial Orientation

\section{SIDE VIEW}

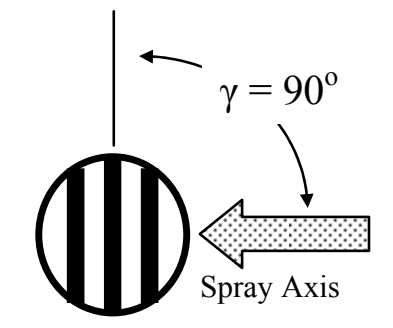

Transverse Orientation

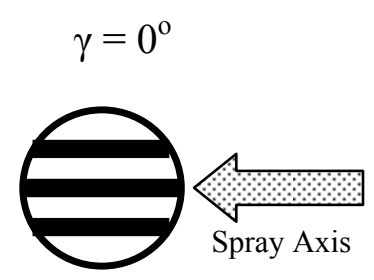

Axial Orientation

TOP VIEW

Fig. 3.22 Spray Orientation Relative to the Straight Fins

\subsection{Uncertainty Analysis}

The primary measure of interest for these experiments is the heat flux. The heat flux presented for each of the studies was taken as the average of the sum of multiple heat flux measurements in the heater block. Total error for the reported heat flux was calculated in the same manner. The heat flux calculation for a single measurement has three sources of error: the thermal conductivity of the heater block, the error in the 
positioning of the thermocouple locations, and the error in the temperature measured. Each of these were used for standard error analysis of the calculated heat flux. The error for an individual heat flux measurement was calculated using equation 3.2.

$$
\delta \dot{q}^{\prime \prime}= \pm \sqrt{\left(\frac{\partial \dot{q}^{\prime \prime}}{\partial x} \delta_{x}\right)^{2}+\left(\frac{\partial \dot{q}^{\prime \prime}}{\partial k} \delta_{k}\right)^{2}+\left(\frac{\partial \dot{q}^{\prime \prime}}{\partial(\Delta T)} \delta_{\Delta T}\right)^{2}}
$$

The thermal conductivity value used was $389 \mathrm{~W} / \mathrm{m}-\mathrm{K}$ with $\pm 4 \mathrm{~W} / \mathrm{m}-\mathrm{K}$ error (taken from the CRC handbook of Thermophysical and Thermo-chemical Data). Since this value is fixed for each experimental case, variations between the calculated error for different individual experiments are highly dependent upon the thermocouple locations and the temperature difference between these respective measurement locations. Furthermore, the error for an individual experiment will be highly dependent upon the accuracy included in the determination of the thermocouple locations. The error in the thermocouple location for each individual experiment was determined to be the difference between the diameter of the mounting holes and the thermocouple bead width.

\subsubsection{LPS Studies}

After being mounted to the heater block, the thermocouples were calibrated over a temperature range of $20^{\circ} \mathrm{C}$ to $90^{\circ} \mathrm{C}$ using a temperature bath, mercury thermometer and the data acquisition system. The DAQCard-6062E provided its own CJC (Cold Junction Compensation) value for reference. The offset between the actual temperature measured using the thermometer and the temperature sensed with the thermocouples was recorded for the temperature range spanned. Based on this data, a 
user supplied CJC value was selected for the acquisition system which gave each thermocouple an error of $\pm 0.5^{\circ} \mathrm{C}$ over the calibrated temperature range. Uncertainty in the heat flux measurement was calculated to be $\pm 11.8 \%$ at $16.9 \mathrm{~W} / \mathrm{cm}^{2}$. Pressures were measured within $\pm 3 \mathrm{kPa}$. The flow meter used was calibrated with the aid of a graduated cylinder and a stopwatch. Measurements taken had an error of \pm 0.5 $\mathrm{ml} / \mathrm{min}$.

\subsubsection{NASA Goddard Space Flight Center Studies}

The error in the thermocouple location was determined to be $\pm 0.56 \mathrm{~mm}$. Error in the thermocouple measurements was determined to be $\pm 0.5^{\circ} \mathrm{C}$. The uncertainty in the heat flux was determined to be $\pm 5.6 \%$ at $80 \mathrm{~W} / \mathrm{cm}^{2}$. The heat flux demonstrated repeatability within $1 \%$ for multiple tests under identical conditions. Pressures were measured within $\pm 3 \mathrm{kPa}$, while flow rates and volume flux measurements had errors of $\pm 1 \mathrm{ml} / \mathrm{min}$ and $\pm 8.33 \times 10^{-5} \mathrm{~m}^{3} / \mathrm{m}^{2} \mathrm{~s}$ respectively.

\subsubsection{Chamber Environment Heat Exchange}

In each test case, heat exchange (not including the spray) from the copper block to the surrounding chamber environment is assumed to include both conduction into the high temperature cement at the top of the heater block, as well as convective heat exchange between the heater block and the chamber's ambient gas. Analytical calculations showed that the summation of heat losses within the upper portion of the copper block to the high temperature cement and from the heater block to the ambient 
gas (assuming free convection) was less than $2 \%$ of the total heat input at $\mathrm{CHF}$ for each of the test cases. 


\section{CHAPTER 4}

\section{RESULTS AND DISCUSSION}

\subsection{Flat Surface Variational Height and Volumetric Flow Rate Studies}

\subsubsection{ISR Nozzle Spray Characteristics}

Figs. 4.1 through 4.3 are plots for the Sauter Mean Diameter (SMD) and mean droplet velocity distribution samples at respective liquid flow rates of $3.33 \times 10^{-7} \mathrm{~m}^{3} / \mathrm{s}$, $5.0 \times 10^{-7} \mathrm{~m}^{3} / \mathrm{s}$, and $6.66 \times 10^{-7} \mathrm{~m}^{3} / \mathrm{s}$. Fig. 4.1 a shows that as the distance from the nozzle increased, the SMD increased as well. The SMD increase along the centerline axis was approximately $8 \mu \mathrm{m}$ (i.e. $41 \mu \mathrm{m}$ at $10 \mathrm{~mm}$ and $48 \mu \mathrm{m}$ at $35 \mathrm{~mm}$ from the nozzle). There was also a variation (laterally) in SMD across the spray cone in each measurement plane. The maximum variation occurred in the $35 \mathrm{~mm}$ measurement plane which has a delta of $20 \mu \mathrm{m}$ between the centerline value and the edge value. The centerline and edge location for the $10 \mathrm{~mm}$ plane had a maximum difference of $11 \mu \mathrm{m}$. The mean droplet velocity distribution (Fig. 4.1b) showed that the distribution peak values occurred along the centerline axis. The nominal peak value also corresponded directly to the measurement distance from the nozzle. The peak velocities decreased as the distance from the nozzle increased. Regardless of the distance from the nozzle, the distribution plot showed that the velocities decreased significantly as the spray cone edge was approached. The maximum droplet velocity attained for this flow rate $\left(3.33 \times 10^{-7} \mathrm{~m}^{3} / \mathrm{s}\right)$ was $5.74 \mathrm{~m} / \mathrm{s}$.

Figs. 4.2a and 4.2b show the SMD and mean droplet velocity distribution samples for a flow rate of $5.0 \times 10^{-7} \mathrm{~m}^{3} / \mathrm{s}$. In this data set, the SMDs also increased as the distance from the nozzle increased. SMD values along the centerline axis increased 


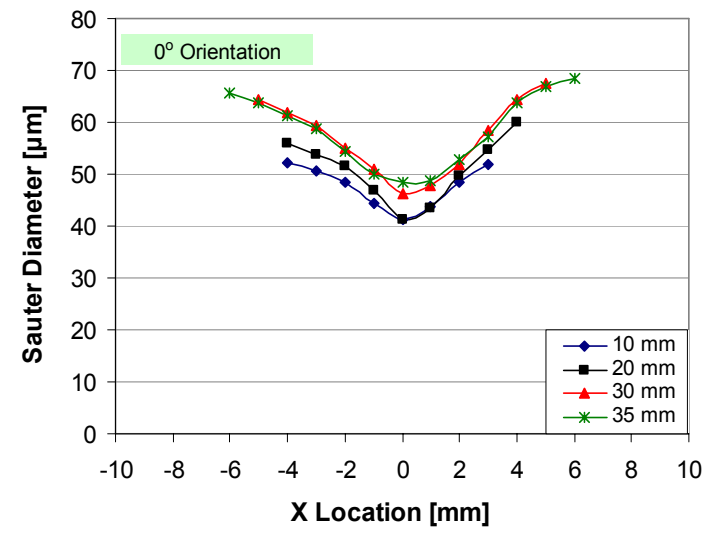

(a)

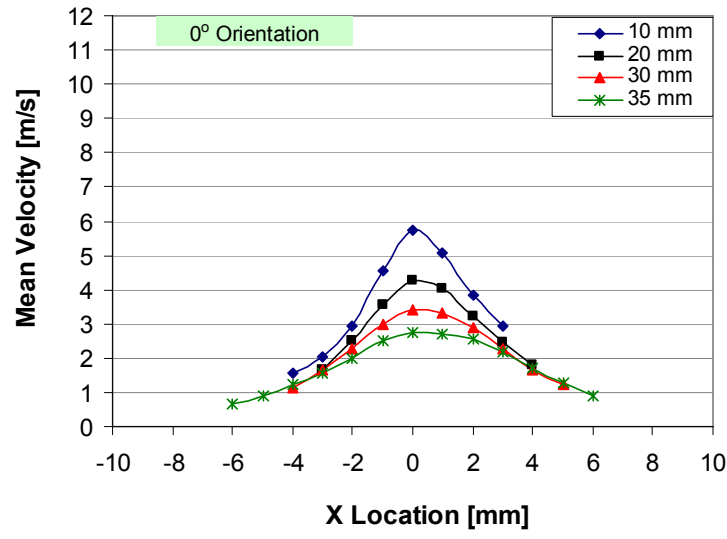

(b)

Fig. 4.1 ISR Nozzle in $0^{\circ}$ orientation, $\dot{V}=3.33 \times 10^{-7} \mathrm{~m}^{3} / \mathrm{s}$; (a) SMD,

(b) Mean Droplet Velocity

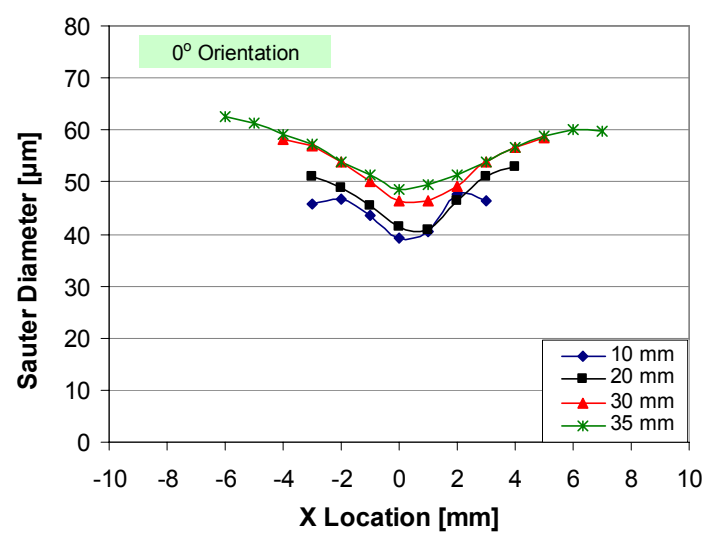

(a)

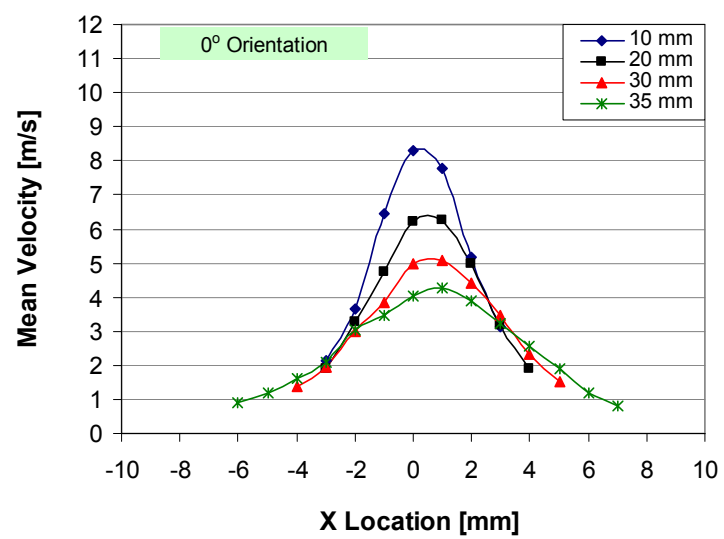

(b)

Fig. 4.2 ISR Nozzle in $0^{\circ}$ orientation, $\dot{V}=5.0 \times 10^{-7} \mathrm{~m}^{3} / \mathrm{s}$; (a) SMD, (b) Mean Droplet Velocity

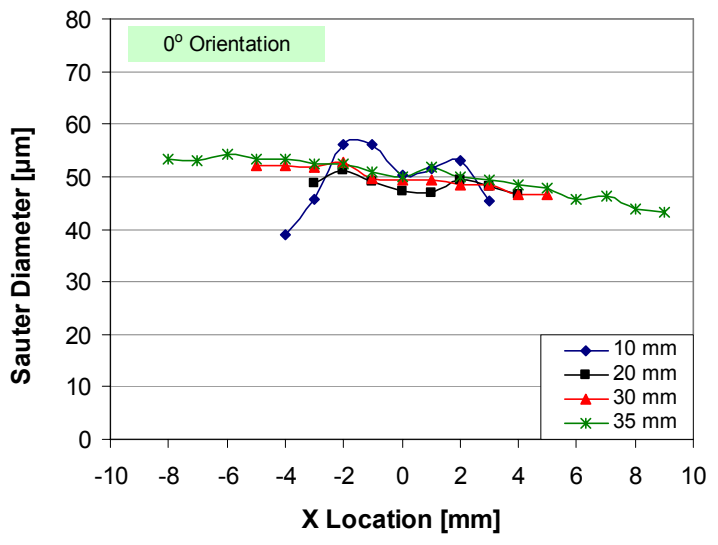

(a)

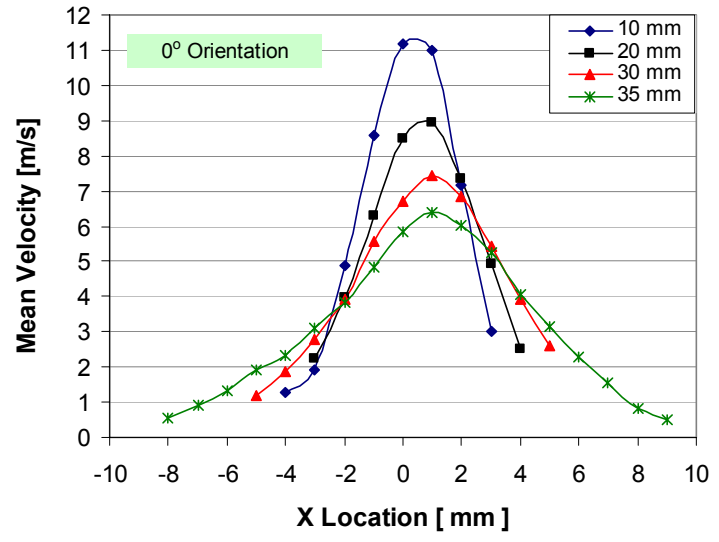

(b)

Fig. 4.3 ISR Nozzle in $0^{\circ}$ orientation, $\dot{V}=6.66 \times 10^{-7} \mathrm{~m}^{3} / \mathrm{s}$; (a) SMD,

(b) Mean Droplet Velocity 
from $39.2 \mu \mathrm{m}$ at $10 \mathrm{~mm}$ to $49.5 \mu \mathrm{m}$ at $35 \mathrm{~mm}$ from the nozzle. The $35 \mathrm{~mm}$ measurement plane and the $30 \mathrm{~mm}$ measurement plane both had a variation of $13 \mu \mathrm{m}$ between the centerline axis and the edge value. This was the maximum difference observed for this volumetric flow rate. The difference between the centerline and edge value for the $10 \mathrm{~mm}$ plane was $7 \mu \mathrm{m}$. The mean droplet velocity distribution plot (Fig. 4.2b) showed the distribution peak values to be highly dependent upon the measurement distance from the nozzle. The maximum droplet velocity for this flow rate (as seen in Fig. $4.2 \mathrm{~b}$ ) was $8.3 \mathrm{~m} / \mathrm{s}$.

The SMD distribution values (shown in Fig. 4.3a) for the $6.66 \times 10^{-7} \mathrm{~m}^{3} / \mathrm{s}$ flow rate case were distinctly different from those of the previous two cases (Figs. 4.1a and 4.2a). The values at the $20 \mathrm{~mm}, 30 \mathrm{~mm}$ and $40 \mathrm{~mm}$ measurement planes were nearly identical, with the values slightly decreasing from left to right across the spray cone measurement planes. The $10 \mathrm{~mm}$ measurement plane displayed a decrease in the SMDs at the centerline. Nonetheless, droplet velocities still peaked at the centerline and decreased with increasing nozzle-to-heater distance (shown in Fig. 4.3b). The maximum droplet velocity for this flow rate was $11.2 \mathrm{~m} / \mathrm{s}$.

Figs. 4.1 and 4.2 clearly showed the largest droplets in each measurement plane occurring near the outer edges of the spray. Since the liquid supply line temperature $\left(\mathrm{T}_{1}=23.5^{\circ} \mathrm{C}\right)$ was subcooled relative to the test conditions in the chamber (i.e. $\mathrm{T}_{\mathrm{sat}}=56^{\circ} \mathrm{C}$ ), droplet evaporation during transit to the heater surface is not expected. The increase in droplet SMD may have been due to droplet coalescence during dispersion or orifice defects. Droplet coalescence is typically observed in dense sprays. Since the PDPA measurements were performed using a single axis (i.e. one 
detector), the droplet number density for the spray was not determined experimentally and could not be used in the determination of the sprays as either sparse or dense. However, sparse sprays typically have a liquid volume fraction $<1 \%$ (Sadhal et al., 1996). Liquid volume fractions (discussed in detail in chapter 5) were less than $1 \%$ for each of these test cases. Thus if droplet coalescence occurred, it was due to localized density variations in the spray which may have been caused by orifice defects.

The parabolic profile for the SMD and mean droplet velocity distribution plots in Figs. 4.1 through 4.3 suggested that the spray characteristics were non-uniform. The centerline peaks in the mean droplet velocity plots reflect jet like behavior for the spray nozzle. However, before the determination that the ISR nozzle is non-uniform can be concluded, planar measurements had to be taken. As mentioned previously, the nozzle was rotated $90^{\circ} \mathrm{CCW}$ and the tests conducted in the $0^{\circ}$ orientation were repeated for purposes of checking the spray cone uniformity. The results showed that there were some non-uniformities present in the spray cone. Figs. $4.4 \mathrm{a}$ and $4.4 \mathrm{~b}$ are

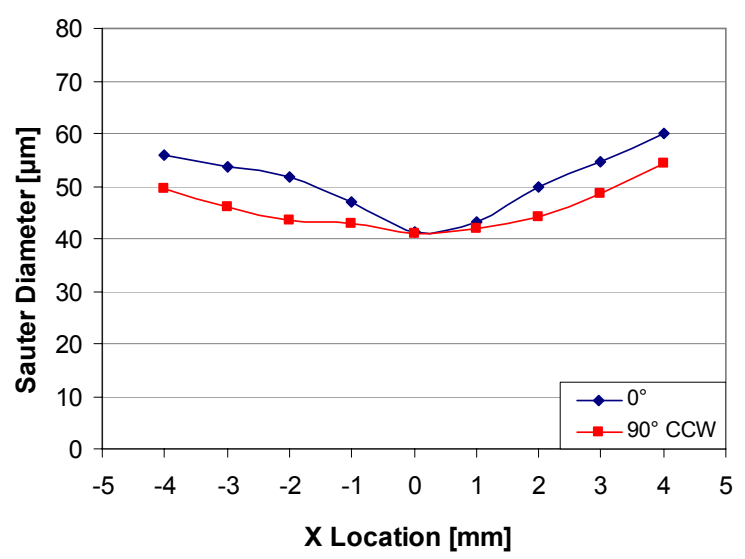

(a) SMD

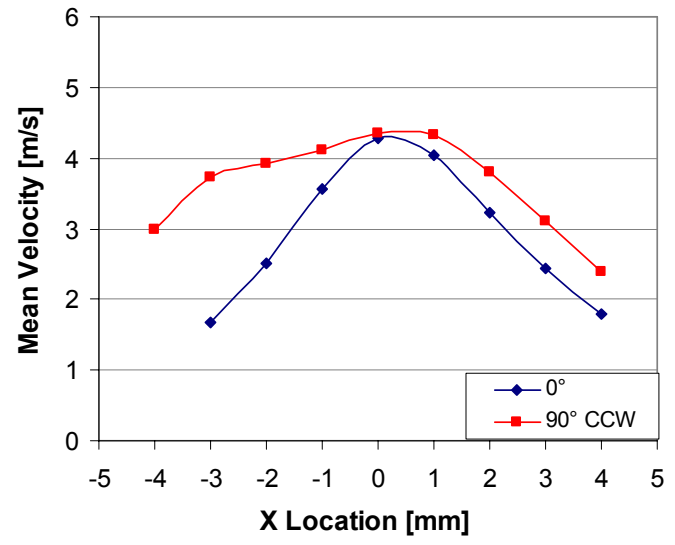

(b) Mean Droplet Velocity

Fig. 4.4 Comparison for $0^{\circ}$ and $90^{\circ}$ orientations; (a) SMD, (b) Mean Droplet Velocity 
example plots of the SMD and mean droplet velocity distribution at $0^{\circ}$ and $90^{\circ}$ for the $20 \mathrm{~mm}$ measurement plane and a volumetric flow rate of $3.33 \times 10^{-7} \mathrm{~m}^{3} / \mathrm{s}$. While the centerline SMD values presented in Fig. $4.4 \mathrm{a}$ are the same, the $90^{\circ}$ orientation data has values consistently lower than that of the $0^{\circ}$ orientation across the measurement plane. For the measurement locations presented, the maximum in-plane difference in SMD is $8 \mu \mathrm{m}$. The centerline mean droplet velocities (shown in Fig. 4.4b) are approximately the same for both orientations. However, the planar variation in the values left of the centerline axis for the $90^{\circ}$ orientation are noticeably larger than those for the $0^{\circ}$ orientation. Furthermore, the measurements for the $90^{\circ}$ orientation are asymmetric. It appears that there is a wider dispersion of droplets in the $90^{\circ}$ orientation at comparable liquid flow rates and measurement planes. The discrepancies shown (Figs. 4.4a and 4.4b) between the two orientations for both the SMD and the mean droplet velocity distributions held for all volumetric flow rates and measurement planes. This, coupled with the centerline peaks from Figs. 4.1 through Fig. 4.4 (which contain some characteristics of liquid jets), reflect nonuniform behavior. While the source of these effects is unknown at this time, the spray may be concluded as being non-uniform. Thus, usage of the Muduwar and Estes relation (eqn. 3.1) to determine volumetric flow rate impacting the heater surface in these studies idealizes the flow distribution across the heater surface.

All of the afore-mentioned spray characteristic results were measured without the heater activated (i.e. no heat supplied to the heater surface). The validity of the data and its pertinence to the heat flux is dependent upon whether or not the heater has an 


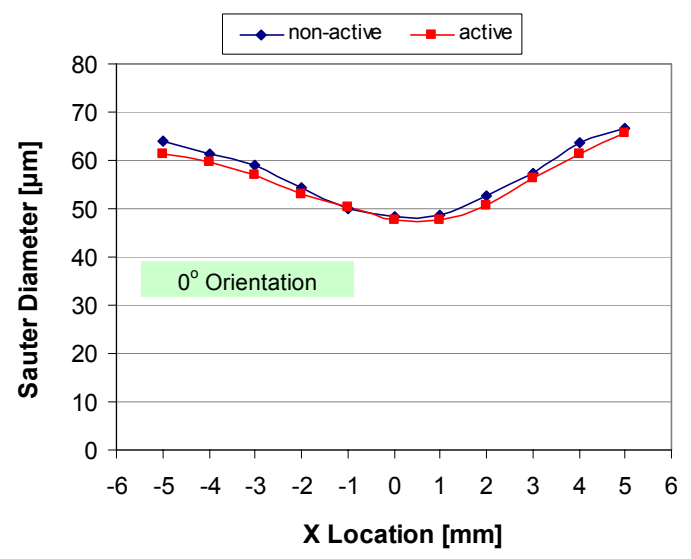

(a) SMD

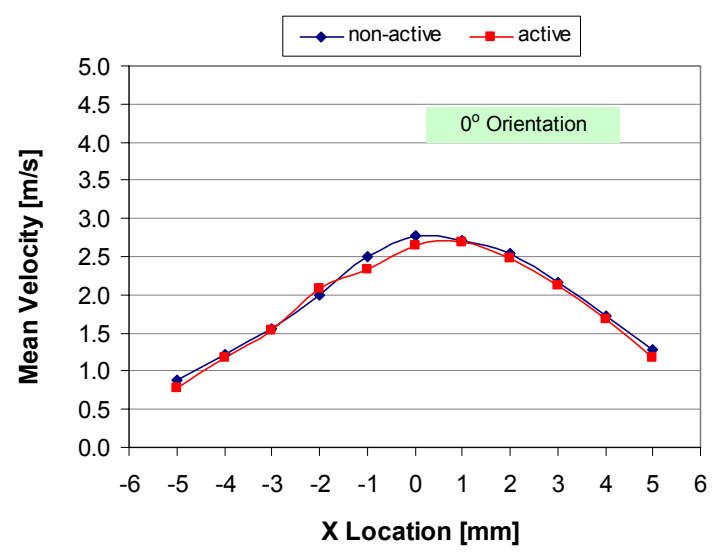

(b) Mean Droplet Velocity

Fig. 4.5 Active $\left(\dot{q}^{\prime \prime}=59.6 \mathrm{~W} / \mathrm{cm}^{2}\right)$ vs. Non-Active heater comparison; (a) SMD, (b) Mean Droplet Velocity

impact upon the spray characteristic results when in operation. Figs. $4.5 \mathrm{a}$ and $4.5 \mathrm{~b}$ compare plots of SMD and mean droplet velocity distribution at $0^{\circ}$ nozzle orientation with and without the heater activated. Both plots were taken at the measurement plane closest to the heater surface $(35 \mathrm{~mm})$. The case selected was case 1 (as shown in Table 3.2). Both the SMD and mean droplet velocity distribution values for the comparisons are in excellent agreement. As mentioned previously, this configuration is considered to be the case where heater effects are most prevalent. It can be concluded that the heater activation has negligible impact upon the spray and its characteristics for the heat flux ranges presented in this portion of the study.

\subsubsection{Spray Cooling Heat Flux Performance}

Twelve different spray cooling cases were tested in the LPS studies. The parameters varied for the test cases run were the nozzle-to-heater distance and the spray volumetric flow rate (as shown in Table 3.2). The saturation conditions for each 


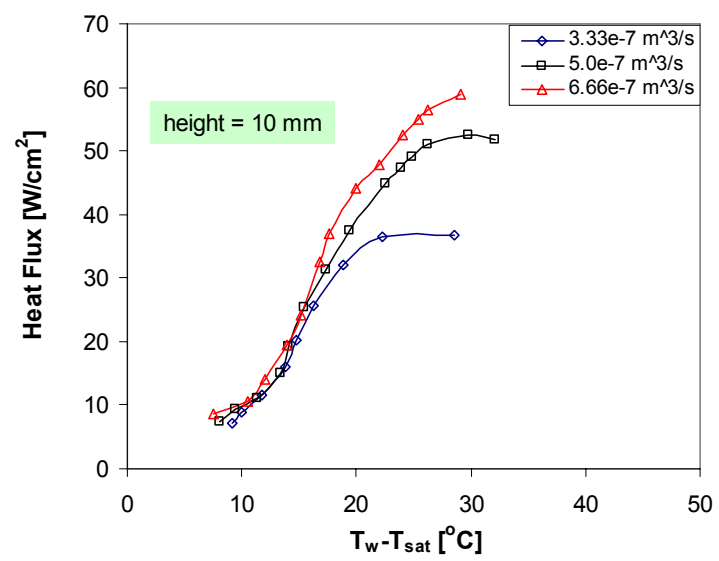

(a) Nozzle height $10 \mathrm{~mm}$

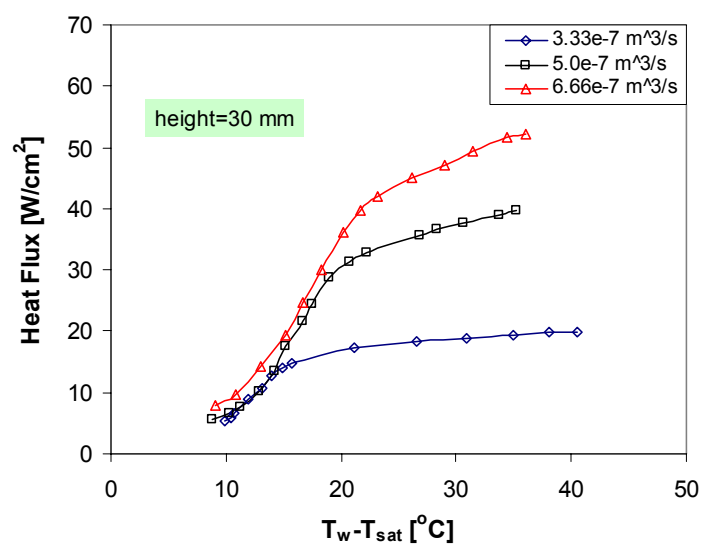

(c) Nozzle height $30 \mathrm{~mm}$

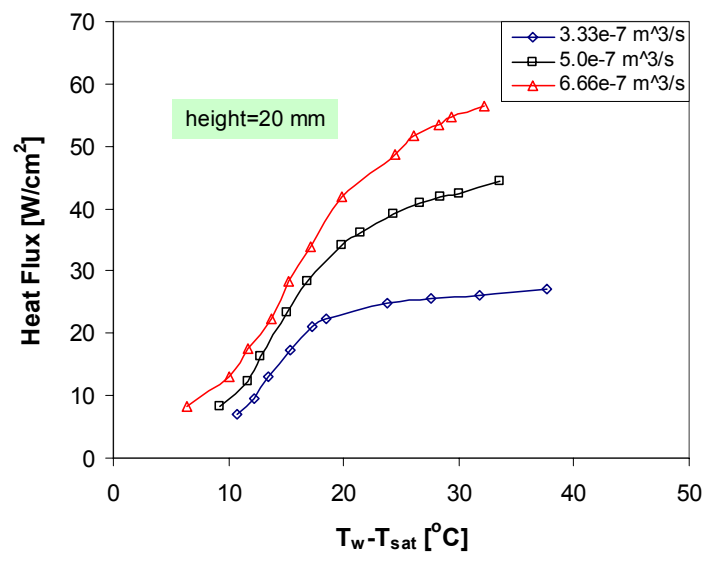

(b) Nozzle height $20 \mathrm{~mm}$

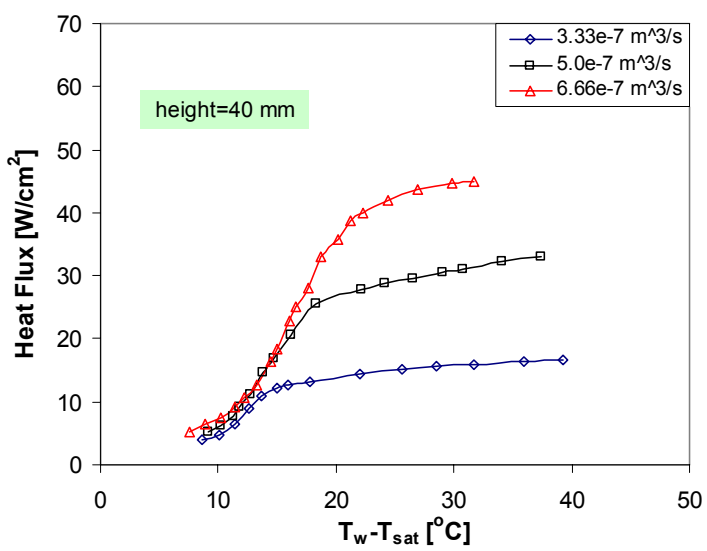

(d) Nozzle height $40 \mathrm{~mm}$

Fig. 4.6 Heat Flux vs. Superheat as a function of Nozzle height; (a) Nozzle height 10 $\mathrm{mm}$, (b) Nozzle height $20 \mathrm{~mm}$, (c) Nozzle height $30 \mathrm{~mm}$, (d) Nozzle height $40 \mathrm{~mm}$

of the tests were held constant throughout the experiments $\left(\mathrm{T}_{\mathrm{sat}}=56^{\circ} \mathrm{C}\right)$ by heating of the test chamber. Figs. 4.6a through $4.6 \mathrm{~d}$ show heat flux as a function of superheat at three volumetric flow rates for each of the heights tested.

The spray cooling curves for each of the plots show that the heat flux increases as the spray volumetric flow rate is increased. The maximum heat flux for each flow rate increases as the nozzle-to-heater distance decreased. The sensitivity of the heat flux to 
the superheat is enhanced by placing the nozzle closer to the heater surface. This is shown by the slope of the curves at the onset of nucleate boiling. Fig. 4.6a has the steepest slope in the multiphase regime where nucleate boiling effects become pronounced. Fig. 4.6d has only a slight slope. Mudawar and Estes (1996) showed that CHF could be optimized by positioning of the spray cone such that it immediately inscribed the heater surface. Based on the height criteria for optimum heat flux performance as defined by Mudawar and Estes (1996), the $20 \mathrm{~mm}$ nozzle height was the closest to the optimum height for the spray cone angle generated with the flow rates tested. Furthermore, the $\dot{V}=6.66 \times 10^{-7} \mathrm{~m}^{3} / \mathrm{s}$ flow rate case was the closest to having its spray cone footprint completely inscribed within the perimeter of the heater surface. As shown in Fig. 3.13 and Table 3.4, the cone angle increased with decreasing flow rate. This created an over spray condition for the $20 \mathrm{~mm}$ height tests. Thus the separation of the heat flux curves and their decrease in heat flux with decreasing flow rate (shown in Fig. 4.6b) can be attributed to over-spray. The other heights have either significant under or over-spray such that distinctions in the single phase regime are not pronounced.

While each of the test cases had approximately $30^{\circ} \mathrm{C}$ subcooling, the heat flux curves show very little single phase convection. This is characteristic of sparse sprays at low liquid flow rates. Nonetheless, some sensible heating of the droplets during transit to the heater surface may also be occurring. There was extensive superheating prior to CHF (shown in Figs. 4.6b through 4.6d). It can be concluded that this is a result of either lower droplet impact velocities or less volume contacting the heater surface as the nozzle-to-heater distance is increased. The PDPA measurements 
showed that the droplet velocities were of moderate magnitude $(3 \mathrm{~m} / \mathrm{s}$ to $11 \mathrm{~m} / \mathrm{s})$. Decreased droplet impact velocities corresponded with increased nozzle-to-heater distance. Since over-spray occurred at the larger distances (see Fig. 3.11), the extensive superheating can be attributed to both less liquid volume contacting the heater surface as well as lower droplet velocities.

Figs. $4.7 \mathrm{a}$ through $4.7 \mathrm{c}$ show heat flux as a function of superheat at various heights for a given spray volumetric flow rate tested. These plots clearly show that for a given spray volumetric flow rate, as the height is decreased, the heat flux increases. This is due to the combined effects of more liquid flux onto the heater surface as well as higher droplet velocities at impact. The spread in the spray cooling curves above a superheat of $15^{\circ} \mathrm{C}$ also decreases as the spray volumetric flow rate is increased. Since flow rate variations in sparse sprays have a greater impact upon heat flux, the small spread in the heat flux curves (shown in Fig. 4.7c) suggests that the spray becomes more dense as the flow rate increases.

The heat flux data previously shown is presented as a function of the spray volumetric flow rate. To obtain a better understanding of the results, the effective volumetric flow rate impinging the heater surface, as well as the evaporation efficiency must be incorporated into the discussion. The volumetric flow rates (including under and over-spray) were calculated using Eq. (3.1). The multiphase evaporation efficiency $\left(\eta_{2-\Phi}\right)$ is defined as:

$$
\eta_{2-\phi}=\frac{\dot{q}_{C H F}^{\prime \prime}}{\dot{q}_{\text {ideal }}^{\prime \prime}}
$$




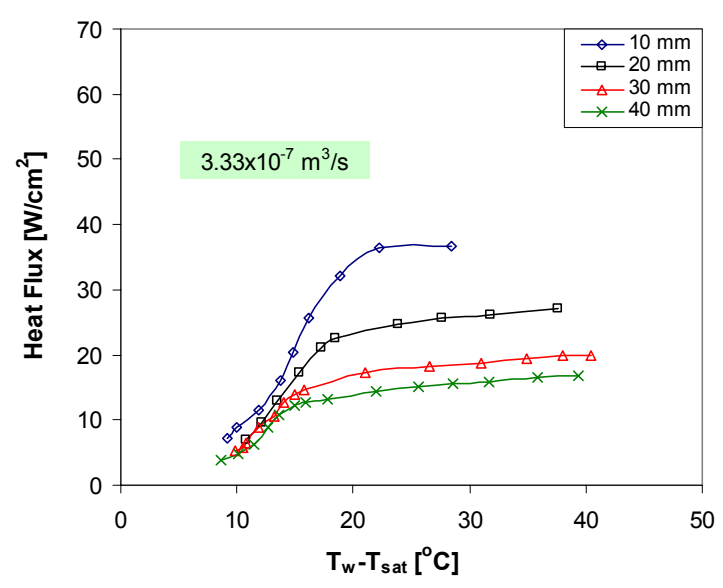

(a) Volumetric Flow Rate $3.33 \times 10^{-7} \mathrm{~m}^{3} / \mathrm{s}$

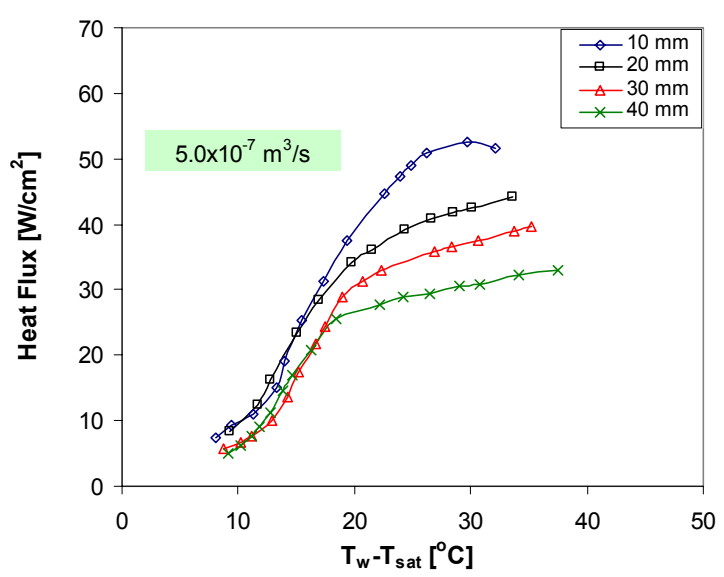

(b) Volumetric Flow Rate $5.0 \times 10^{-7} \mathrm{~m}^{3} / \mathrm{s}$

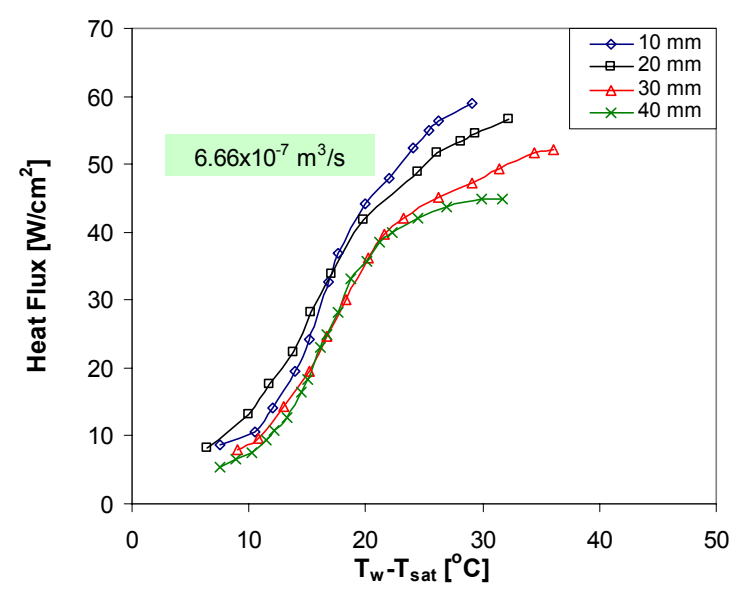

(c) Volumetric Flow Rate $6.66 \times 10^{-7} \mathrm{~m}^{3} / \mathrm{s}$

Fig. 4.7 Heat Flux vs. Superheat as a function of spray volumetric flow rate; (a) Volumetric Flow Rate $3.33 \times 10^{-7} \mathrm{~m}^{3} / \mathrm{s}$, (b) Volumetric Flow Rate $5.0 \times 10^{-7} \mathrm{~m}^{3} / \mathrm{s}$, (c) Volumetric Flow Rate $6.66 \times 10^{-7} \mathrm{~m}^{3} / \mathrm{s}$

where $\dot{q}_{C H F}^{\prime \prime}$ is the heat flux at CHF for a particular test case number. The denominator is based on the theoretical maximum amount of heat exchange possible were all of the liquid to evaporate:

$$
\dot{q}_{\text {ideal }}^{\prime \prime}=\rho_{l} \dot{V}_{e f f}^{\prime \prime}\left[c_{p}\left(T_{\text {sat }}-T_{l}\right)+h_{f g}\right]
$$


where $\dot{V}_{e f f}^{\prime \prime}$ is the effective volumetric flux on the heater surface. Equation 4.1 is then expressed as:

$$
\eta_{2-\phi}=\frac{\dot{q}_{C H F}^{\prime \prime}}{\rho_{l} \dot{V}_{e f f}^{\prime \prime}\left[c_{p}\left(T_{s a t}-T_{l}\right)+h_{f g}\right]}
$$

Table 4.1 lists the effective volumetric fluxes and evaporation efficiencies at CHF for each of the LPS flat surface cases studied. While the heat flux optimization work by Muduwar and Estes (1996) utilized a square heater surface, the same principle can be applied to the circular heater surface of the present study. For the measured spray cone angles (shown in Table 3.4) and the heater surface area used, the optimum height can be calculated to be between $20 \mathrm{~mm}$ to $23 \mathrm{~mm}$.

The high efficiencies for cases 1 through 3 indicate that almost all of the liquid hitting the surface is evaporated. This is reflective of a low density (sparse) spray (Sehmbey et al., 1995). Cases 7 through 12 show 60\% evaporation efficiency at best. This implies that excess liquid is on the heater surface. For the data shown in Table

Table 4.1 Spray Cooling Parameters at CHF

\begin{tabular}{|c|c|c|c|c|c|c|}
\hline $\begin{array}{c}\text { Case } \\
\text { Number }\end{array}$ & $\begin{array}{c}\text { Nozzle } \\
\text { Height } \\
(\mathrm{mm})\end{array}$ & $\begin{array}{c}\text { Liquid } \\
\text { Volumetric } \\
\text { Flow Rate } \\
(\mathrm{m} 1 / \mathrm{min})\end{array}$ & $\begin{array}{c}\dot{V}^{\prime \prime} \\
\left(10^{3} \mathrm{~m}^{3} / \mathrm{m}^{2} \mathrm{~s}\right)\end{array}$ & $\begin{array}{c}\dot{q}_{C H F}^{\prime \prime} \\
\left(\mathrm{W} / \mathrm{cm}^{2}\right)\end{array}$ & $\begin{array}{c}\eta_{2-\Phi} \\
(0 \text { to } 1.0)\end{array}$ & $\begin{array}{c}\mathrm{h}_{\text {conv }} \\
\left(\mathrm{W} / \mathrm{m}^{2} \mathrm{~K}\right)\end{array}$ \\
\hline 1 & 40 & 20 & 0.94 & 16.9 & 0.96 & 2338.6 \\
\hline 2 & 40 & 30 & 1.80 & 33.3 & 0.99 & 4730.5 \\
\hline 3 & 40 & 40 & 2.59 & 45.4 & 0.94 & 7021.2 \\
\hline 4 & 30 & 20 & 1.65 & 20.2 & 0.65 & 2744.9 \\
\hline 5 & 30 & 30 & 3.16 & 40.1 & 0.68 & 5880.8 \\
\hline 6 & 30 & 40 & 4.55 & 52.6 & 0.62 & 7620.6 \\
\hline 7 & 20 & 20 & 3.33 & 27.5 & 0.44 & 3888.8 \\
\hline 8 & 20 & 30 & 5.00 & 44.8 & 0.48 & 6724.0 \\
\hline 9 & 20 & 40 & 6.67 & 57.1 & 0.46 & 8754.6 \\
\hline 10 & 10 & 20 & 3.33 & 37.2 & 0.60 & 6044.8 \\
\hline 11 & 10 & 30 & 5.00 & 52.2 & 0.56 & 8025.4 \\
\hline 12 & 10 & 40 & 6.67 & 59.6 & 0.48 & 9600.9 \\
\hline
\end{tabular}


4.1 , there is a nominal $40 \%$ reduction in evaporation efficiency between the $40 \mathrm{~mm}$ (cases 1 through 3) and $10 \mathrm{~mm}$ (cases 10 through 12) height studies. Nonetheless, the convection coefficient and the heat flux increased with the increase in the volumetric flux. Chen et al. (2002) showed that the dominant spray characteristic is the droplet velocity. The cases with the lower nozzle heights have higher droplet impact velocities. The decrease in $\eta_{2-\Phi}$ also suggests that single phase effects become more dominant to the heat transfer process at these heights. The relative importance of each of these factors upon heat flux is unknown at this time.

\subsection{Spray Nozzle Volumetric Flux Survey Study}

Local volume flux between concentric cylinders, and the local volume flux between concentric cylinders normalized by the volume flux averaged over the entire heater surface $(\Gamma)$ for the nozzles tested is shown in Table 4.2. A $\Gamma$ value of unity indicates that the local volume flux is identical to the total volume flux averaged across the entire heater surface. All of the nozzles tested (with the exception of the Parker Hannifin prototype nozzle) displayed a hollow cone spray volumetric flux pattern beginning and extending to various radial distances from the spray's centerline axis. Hollow cone sprays have been shown to cause earlier dry-out than full cone and center weighted sprays. Due to the hollow cone volumetric flux patterns observed in the Hago, Delavan, Danfoss, and Spraying Systems nozzles, none of these nozzles were selected for use in the enhanced surface heat flux performance testing. As an alternative, the Parker Hannifin (P-H) prototype spray nozzle (plate \#7) 
Table 4.2 Nozzle Survey Volumetric Flux Uniformity Measurements

\begin{tabular}{|c|c|c|c|c|c|c|c|c|c|}
\hline \multirow{2}{*}{ Spray Nozzle } & \multirow{2}{*}{$\begin{array}{c}\text { Test } \\
\dot{V} \\
\left(\mathrm{~m}^{3} / \mathrm{s}\right) \\
\end{array}$} & \multicolumn{4}{|c|}{$\dot{V}^{\prime \prime}\left(\mathrm{m}^{3} / \mathrm{m}^{2} \mathrm{~s}\right)$} & \multicolumn{4}{|c|}{$\Gamma_{\mathrm{i}}$} \\
\hline & & $\mathrm{A}_{1}$ & $\mathrm{~A}_{2}$ & $\mathrm{~A}_{3}$ & $\mathrm{~A}_{4}$ & $\mathrm{~A}_{1}$ & $\mathrm{~A}_{2}$ & $\mathrm{~A}_{3}$ & $\mathrm{~A}_{4}$ \\
\hline Hago M3 & 0.010 & 0.001 & 0.006 & 0.014 & 0.007 & 0.1 & 0.8 & 1.9 & 0.9 \\
\hline Delavan $3.25 \mathrm{CT} 70^{\circ} \mathrm{B}$ & 0.009 & 0.000 & 0.001 & 0.011 & 0.011 & 0.0 & 0.2 & 1.5 & 1.5 \\
\hline Danfoss $2.7560^{\circ} \mathrm{AB}$ & 0.008 & 0.000 & 0.001 & 0.004 & 0.007 & 0.0 & 0.2 & 1.0 & 2.0 \\
\hline Danfoss $2.7570^{\circ} \mathrm{AS}$ & 0.007 & 0.000 & 0.002 & 0.005 & 0.007 & 0.1 & 0.5 & 1.1 & 1.6 \\
\hline Spraying Systems 0.3 & 0.016 & 0.004 & 0.009 & 0.016 & 0.012 & 0.3 & 0.8 & 1.4 & 1.1 \\
\hline Hago $4.50 \mathrm{P} 70^{\circ}$ & 0.010 & 0.000 & 0.000 & 0.002 & 0.007 & 0.1 & 0.1 & 0.5 & 2.4 \\
\hline P-H plate \#7 & 0.016 & 0.026 & 0.024 & 0.007 & 0.005 & 2.0 & 1.8 & 0.6 & 0.4 \\
\hline
\end{tabular}

was used for each of these tests.

The Parker Hannifin nozzle consisted of a 2x2 array of pressure swirl atomizers with a spacing of $6 \mathrm{~mm}$ (see Fig. 4.8). The outer ring $\left(\mathrm{A}_{4}\right)$ is seen to capture only $40 \%$ of the average volumetric flux. The volume flux gradually increases towards the center of the spray. The center ring $\left(A_{1}\right)$ has twice as much volume flux as the average flux. The volume flux variation indicates that the spray may be considered a non-uniform, center-biased spray (see Fig. 4.9). Although the volume flux appears qualitatively similar to that of a single-nozzle full-cone spray at nozzle-to-heater surface distances which are large compared to the nozzle spacing, an important

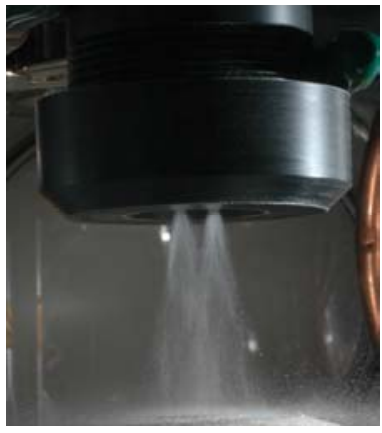

(a) Side View

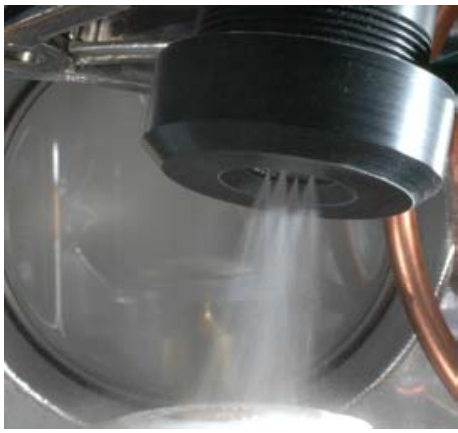

(b) Diagonal View

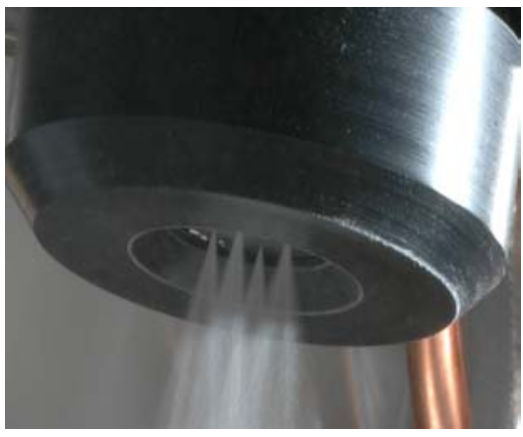

(c) Diagonal View Close-Up

Fig. 4.8 Parker Hannifin Prototype Nozzle Spray Images 


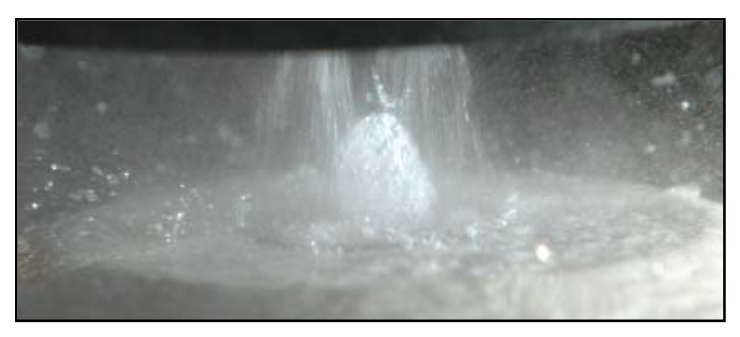

Fig. 4.9 In-situ Photo of Center-Weighted Spray on Flat Surface

difference exists. Due to the use of multiple nozzles, a non-radial momentum and mass flux is generated on the impingement surface in the region between the nozzles (see Fig. 4.10). This can result in the accumulation of liquid on the surface, especially

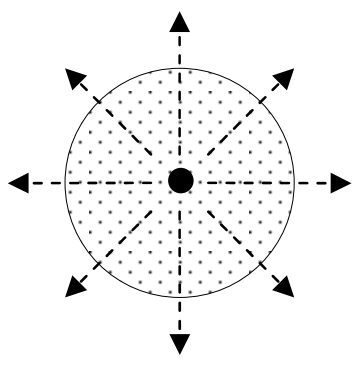

Single Nozzle

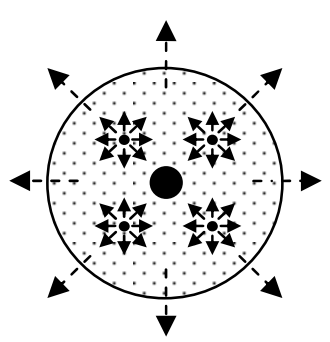

Multi-Nozzle Array (not to scale)

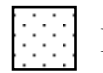

Heater surface

- Stagnation zone region

Fig. 4.10 Plan View of Flat Heater Surface Liquid flows

when the standoff height is small relative to the nozzle spacing. Volume flux measurements were also obtained for each of the inclined sprays investigated, using the largest tube from the concentric cylinder measurements. Spray characteristics such as droplet size, velocity and spray density were not obtained in this study. 


\subsection{Enhanced Surface Studies}

\subsubsection{Fundamental Survey Study}

Spray cooling has been observed to be a convective boiling process that is largely dominated by single phase convection (Silk et al., 2005a,b). The enhanced structures used in this study can be considered finned heat sinks. Addition of finned heat sinks to convectively cooled surfaces is known to decrease the single phase convective thermal resistance $\left(\mathrm{R}_{\mathrm{fl}}\right)$ to heat transfer (Krause and Bar-Cohen, 1995) by increasing the total wetted surface area. If the heat flux were to scale with the total wetted surface area, then it would be expected that the pyramid surface $\left(\mathrm{A}_{\text {surf, } 1 \mathrm{p}}=4.5 \mathrm{~cm}^{2}\right)$ would have the highest heat flux, followed by the cubic pin finned and straight finned surfaces $\left(A_{\text {surf }, 1 \mathrm{c}}=A_{\text {surf }, 1 \mathrm{~s}}=4.0 \mathrm{~cm}^{2}\right)$.

The spray cooling curves for the fundamental enhanced geometry survey are shown in Fig. 4.11. All heat flux data are based on the projected area of $2.0 \mathrm{~cm}^{2}$, instead of the wetted surface area. Table 4.3 summarizes the total wetted surface area $\left(\mathrm{A}_{\text {surf }}\right), \mathrm{CHF}, \mathrm{CHF}$ enhancement relative to the flat surface, area utilization factor $(\xi)$, surface temperature at $\mathrm{CHF}$ for each of the blocks tested, and the evaporation efficiency as defined in Eq. 4.1. The area utilization factor (AUF) is defined as the ratio of the heat flux enhancement to the proportional increase in wetted surface area $(\xi)$. It is shown in eqn. 4.4. The AUF was determined for both the single phase regime

$$
A U F=\frac{\dot{q}_{C H F}^{\prime \prime} / \dot{q}_{C H F, f l a t}^{\prime \prime}}{A_{\text {surf }} / A_{\text {surf }, \text { flat }}}
$$

$\left(\xi_{1-\phi}\right)$ and the multiphase regime $\left(\xi_{2-\phi}\right)$ at $\mathrm{CHF}$. 


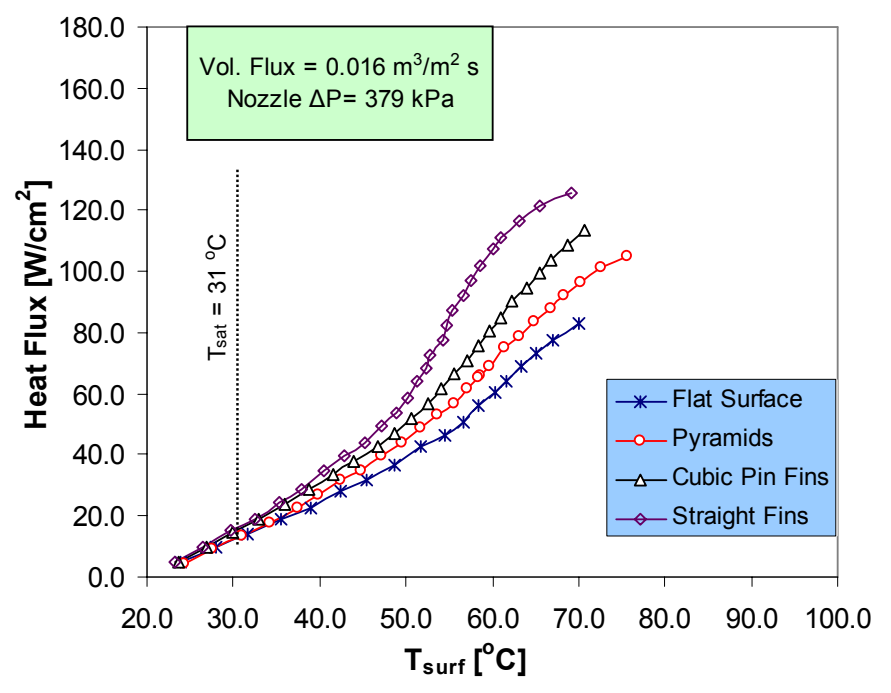

(a) Degassed Case

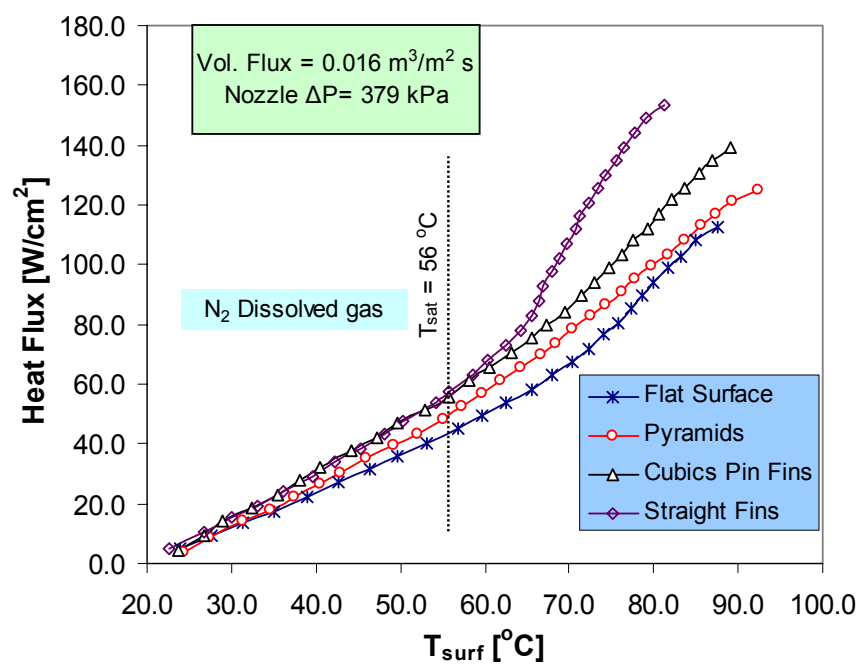

(b) Gassy Case

Fig. 4.11 Heat Flux as a function of Surface Temperature for Fundamental Survey; (a) Degassed Case, (b) Gassy Case 
Table 4.3 Summary of Enhanced Surface Data for Fundamental Study

\begin{tabular}{|c|c|c|c|c|c|c|c|c|}
\hline \multicolumn{9}{|c|}{ Degassed Case, $\mathrm{T}_{\text {sat }}=31.0^{\circ} \mathrm{C}$} \\
\hline \multirow{2}{*}{ Geometry } & \multirow{2}{*}{ Surface } & \multirow{2}{*}{$\begin{array}{r}A_{\text {surf }} \\
\left(\mathrm{cm}^{2}\right)\end{array}$} & \multirow{2}{*}{$\begin{array}{c}\dot{q}_{C H F}^{\prime \prime} \\
\left(\mathrm{W} / \mathrm{cm}^{2}\right)\end{array}$} & \multirow{2}{*}{$\begin{array}{c}\text { CHF } \\
\text { Enhancement } \\
\text { (relative to } \\
\text { Flat Surface } \\
\text { CHF) } \\
(\%)\end{array}$} & \multicolumn{2}{|c|}{$\begin{array}{c}\text { Area } \\
\text { Utilization } \\
\text { Factor } \\
\end{array}$} & \multirow{2}{*}{$\begin{array}{l}\mathrm{T}_{\max } \\
\left({ }^{\circ} \mathrm{C}\right)\end{array}$} & \multirow{2}{*}{$\begin{array}{l}\eta_{2-\Phi} \\
(\%)\end{array}$} \\
\hline & & & & & $* \xi_{1-\Phi}$ & $\xi_{2-\Phi}$ & & \\
\hline Flat & $\ddagger_{1 \mathrm{f}}$ & 2.0 & 80 & 0 & $-\cdots$ & $-\cdots$ & 70.0 & 29 \\
\hline Cubic Pin Fins & $1 \mathrm{c}$ & 4.0 & 114 & 43 & 0.52 & 0.73 & 70.6 & 41 \\
\hline Straight Fins & $1 \mathrm{~s}$ & 4.0 & 126 & 58 & 0.60 & 0.79 & 69.1 & 46 \\
\hline Pyramid & $1 p$ & 4.5 & 105 & 31 & 0.32 & 0.58 & 75.6 & 38 \\
\hline \multicolumn{9}{|c|}{ Gassy Case, $T_{\text {sat }}=56.0^{\circ} \mathrm{C}$} \\
\hline Flat & ${ }^{\dagger} 1 \mathrm{f}$ & 2.0 & 106 & 0 & --- & $-\cdots$ & 87.7 & 36 \\
\hline Cubic Pin Fins & $1 \mathrm{c}$ & 4.0 & 139 & 31 & 0.71 & 0.65 & 89.1 & 47 \\
\hline Straight Fins & $1 \mathrm{~s}$ & 4.0 & 156 & 47 & 0.71 & 0.73 & 86.7 & 53 \\
\hline Pyramid & $1 p$ & 4.5 & 125 & 18 & 0.53 & 0.52 & 92.3 & 42 \\
\hline
\end{tabular}

$\$$ indicates that the Area Utilization Factor is not applicable because area addition has not occurred.

* single phase enhancement factor ratios were taken with heat flux values at the end of the single phase regime

Degassed Case. In the single phase regime, the heat transfer was dominated by single phase convection at low heat flux $\left(<45 \mathrm{~W} / \mathrm{cm}^{2}\right)$ as indicated by a linear relationship between the heat flux and the wall-to-spray temperature difference for all four geometries (see Fig. 4.11a). Performance of the enhanced surfaces all exceeded that of the flat surface. The straight finned surface had the smallest convective thermal resistance (indicated by the largest slope), followed by larger thermal resistances for the cubic pin finned and the pyramid surfaces. The single phase AUF $\left(\xi_{1-\Phi}\right)$ shown in Table 4.3 indicated similar trends.

Each of the enhanced surfaces transitioned into the multiphase regime at lower temperatures than for the flat surface (see Fig. 4.11a), as indicated by the decrease in temperature of the point where the curve undergoes a distinct increase in slope. This may be due to an increase in the number of potential nucleation sites due to increased 
wetted area, or a longer residence time as the liquid traveled over the structure. Suppression of nucleation sites is known to occur during forced convection boiling heat transfer due to a thinning of the thermal boundary layer (Potash et al., 1972). However, a decrease of the liquid velocity due to increased flow resistance by the structures may diminish such effects in spray cooling. Liquid pooling or lower liquid velocities may have occurred on these parts of the fins that were shaded from the impinging droplets, allowing nucleation to occur more easily.

Heat flux performance in the multiphase regimes for the enhanced surfaces was consistently higher than on the flat surface. The straight finned surface had the highest heat transfer performance, followed by the cubic pin fins and the pyramids. The multiphase AUF $\left(\xi_{2-\Phi}\right)$ showed similar trends. CHF for the pyramids, cubic pin finned, and straight finned surfaces were greater than for the flat surface by approximately 24,33 , and $46 \mathrm{~W} / \mathrm{cm}^{2}$ (58\% increase for straight fins) respectively. The temperatures at which $\mathrm{CHF}$ occurred were within an $8^{\circ} \mathrm{C}$ range. The enhanced surfaces also had noticeably higher evaporation efficiency than the flat surface (see Table 4.3).

Fluid pooling occurred in the center of the heater surface for each test due to film drainage blocking effects caused by the multi-nozzle configuration used. It was most pronounced in the single phase regime, at low heat flux. For the cubic pin finned and straight finned surfaces, the amount of liquid pooling slowly began to diminish in the early part of the multiphase heat flux regime (see Fig. 4.12). At high heat flux (>60 $\mathrm{W} / \mathrm{cm}^{2}$ ), pooling was greatly reduced, yet still visible. Pooling on the pyramid surface 


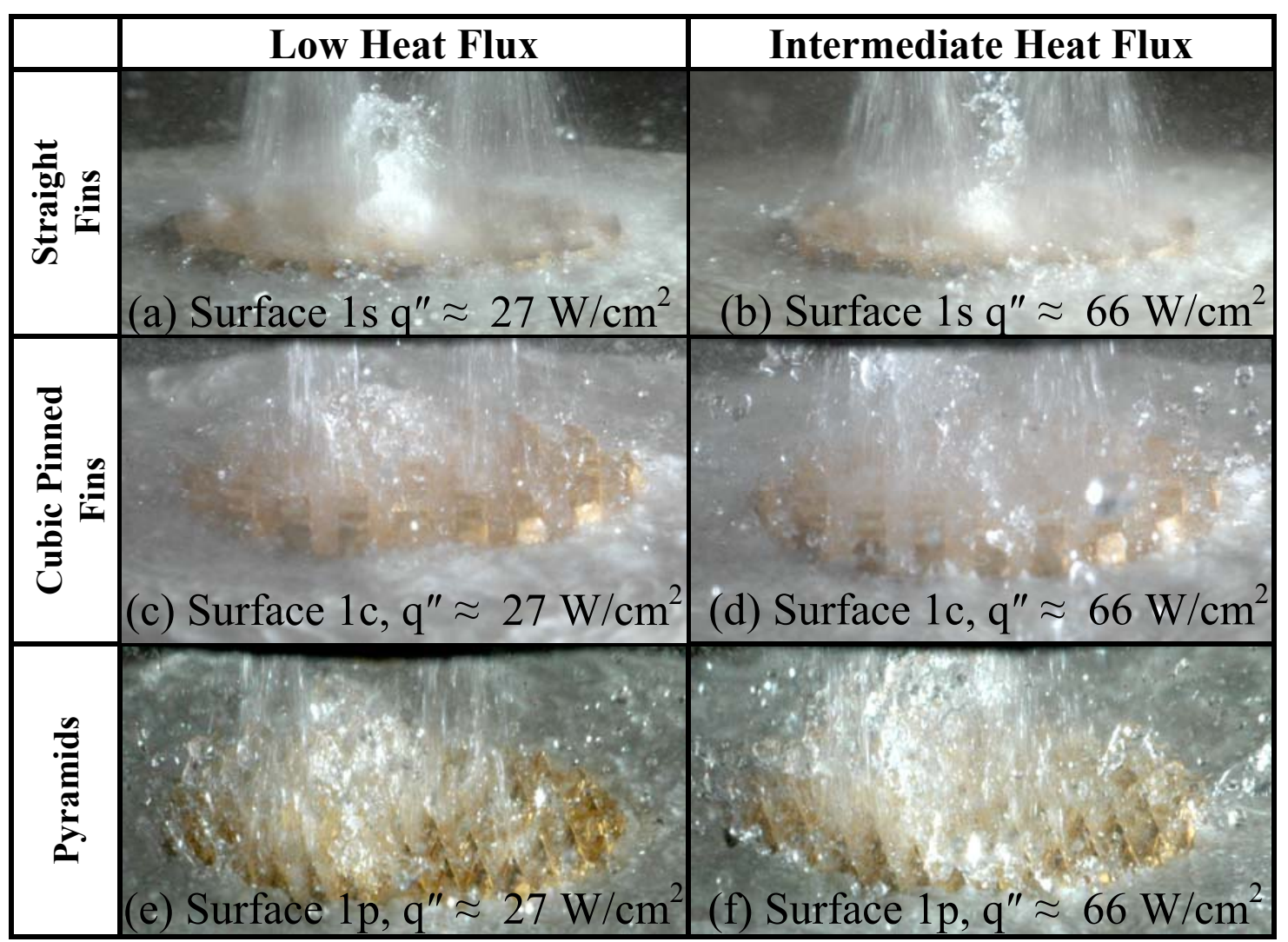

Fig. 4.12 Enhanced Surface Liquid Pooling; (a) Surface 1s at low heat flux, (b) Surface 1s at intermediate heat flux, (c) Surface 1c at low heat flux, (d) Surface 1c at intermediate heat flux, (e) Surface $1 p$ at low heat flux, (f) Surface $1 p$ at intermediate heat flux

appeared relatively unchanged for all heat fluxes throughout the spray cooling curve during testing.

Gassy Case. The gassy study (Fig. 4.11b) yielded similar results in that each of the enhanced surfaces outperformed the flat surface. In the single phase regime, the heat transfer is once again dominated by single phase convection at low heat flux $(<55$ $\mathrm{W} / \mathrm{cm}^{2}$ ). Performance rankings for the convective thermal resistances were the same as in the degassed case (pyramids had the highest thermal resistance followed by cubic pinned fins and the lowest was for the straight fins). This is exemplified 
through the gassy case single phase AUF $\left(\xi_{1-\Phi}\right)$ values shown in Table 4.3. The nominal values for the AUF are slightly higher than in the degassed case. However, the ranking (lowest to highest) for the surfaces using $\xi_{1-\Phi}$ as the criteria is the same as in the degassed case.

Transition to the multiphase regime occurs at similar temperatures $\left(\approx 57^{\circ} \mathrm{C}\right)$ for each of the surfaces. The results indicate that the straight fins again reached the highest heat flux with a CHF of $156 \mathrm{~W} / \mathrm{cm}^{2}$ followed by the cubic pin fins (139 $\left.\mathrm{W} / \mathrm{cm}^{2}\right)$ and the pyramids $\left(125 \mathrm{~W} / \mathrm{cm}^{2}\right)$. The pyramids and cubic pin finned surfaces were able to sustain slightly higher surface temperatures near dry-out. However, the surface temperature at which $\mathrm{CHF}$ occurred for each of the cases was within $6^{\circ} \mathrm{C}$. Evaporation efficiencies $\left(\eta_{2-\Phi}\right)$ increase when dissolved gasses are present (this corresponds to the increase in CHF observed). However, the dissolved gasses produce a decrease in nominal $\xi_{2-\Phi}$ and an increase in the $\xi_{1-\Phi}$ values. Furthermore, the $\xi_{2-\Phi}$ values are greater than, or approximately equal to, the values for $\xi_{1-\Phi}$. This was not observed in the degassed case. The combination of these effects implies that the dissolved gasses promote heat flux enhancement primarily through single phase effects.

Enhancement Effects. To obtain a better understanding of the results, the total wetted surface area and the efficiency with which it is utilized should be considered. The data indicates that the heat transfer does not scale directly with the total wetted surface area in any of the heat flux regimes (both the straight fins and cubic pin fins outperformed the pyramids which had the largest surface area). Previous pool boiling studies have suggested that the heat flux is directly related to liquid management on 
the heater surface (Chien and Webb, 1998). Liquid management is highly influenced by the type of surface structures used as well as their dimensions. The greatest insight into surface structure effects can be gained by comparing the straight finned and cubic pin finned surfaces. Although the cubic pin fins and straight fins had the same total wetted surface area, there was a significant difference in the heat transfer performance. The difference must be a result of either liquid management on the heater surface, the efficiency with which the wetted area is utilized, or a combination of both.

On a surface temperature basis (as shown in Fig. 4.11b), the dissolved gasses delayed the transition from the single phase to multiphase heat flux regime. This allowed for higher surface temperatures to be reached prior to dry-out. However, from a superheat perspective, the temperature at which transition occurred decreased with the addition of dissolved gasses. In the study by Honda et al. (2002), the dissolved gas case showed better heat transfer characteristics in the low heat flux regime. Heat transfer performance was comparable in the high heat flux regime. Each of the surfaces in the dissolved gas study (with exception of the straight finned surface) showed a marginal increase in the surface temperature at CHF. All of the enhanced surfaces investigated had better heat transfer performance in the multiphase high heat flux regime. In the study by Pais et al. (1992) it was reported that for gas assist atomizing nozzles, heat flux decreases with increasing surface roughness. That work, as well as the work of Sehmbey et al. (1995a), report that the opposite trend is experienced with liquid atomizing nozzles. This work shows that heat flux can also be increased by using structured surface geometries under dissolved gas test conditions. 
Lin and Ponnappan (2003) concluded that non-condensible gasses enhanced heat transfer due to increased film spreading initiated by a reduction in the partial vapor pressure within the liquid film vicinity. While this theory may apply to the flat surface, the structured surfaces present different wetting characteristics due to their respective geometries. As such, film thinning (as well as pooling) is highly dependent upon geometry and liquid management on the surface. Furthermore, since liquid pooling was observed throughout all the tests, it is concluded that film thinning had little impact upon heat transfer enhancement in the gassy case.

\subsubsection{Cubic Pin Fin Study}

The fundamental study detailed in section 4.3.1 shows that heat flux does not scale with the total wetted surface area when using enhanced surfaces. Under the premise that heat flux is directly related to liquid management on the heater surface (Chien and Webb, 1998) and liquid management is highly influenced by the surface structures and their dimensions, (heat flux to wetted surface area scalability) conclusions regarding heat transfer enhancement cannot be made since the fundamental study investigated different surface geometries. A more appropriate study for the determination of heat flux to wetted surface area scalability when using structured surfaces should include the comparison of similar geometric structures of different sizes. Thus a second survey study was initiated with cubic pin fins as the feature geometry. The cubic pin finned surfaces tested each had pin fins of different sizes (see Fig. 3.20). Structure width (X), separation distance (L), and height (H1) were varied under degassed and gassy conditions. The variations were implemented 
in $0.5 \mathrm{~mm}$ increments between $1.0 \mathrm{~mm}$ and $2.0 \mathrm{~mm}$. The increments were relative to the structure dimensions for surface $1 \mathrm{c}$.

Heat flux as a function of structure width (X), separation distance (L), and height (H1) for the nominally degassed case is shown respectively in Figs. 4.13a through 4.13c. For the gassy case, the results are shown in Figs. 4.14a through 4.14c, respectively. The calculated heat flux is based on the projected area of $2.0 \mathrm{~cm}^{2}$ for all cases.

Degassed Case. In the degassed case, the heat transfer variation for all surfaces is linear in the single phase regime. For the $\mathrm{X}$ variation study (Fig. 4.13a), each of the enhanced surface cases agreed within the experimental uncertainty throughout the single phase regime. Multiphase effects became pronounced (denoted by the increase in slope of the heat flux curves) around $\mathrm{T}_{\text {surf }} \approx 52^{\circ} \mathrm{C}$ for the $\mathrm{X}$ and $\mathrm{L}$ variations (Figs. 4.13a and 4.13b). Case $1 \mathrm{c}$ attained the highest heat flux $\left(117 \mathrm{~W} / \mathrm{cm}^{2}\right)$. CHF for cases $3 \mathrm{c}$ and $2 \mathrm{c}$ were $103 \mathrm{~W} / \mathrm{cm}^{2}$ and $104 \mathrm{~W} / \mathrm{cm}^{2}$ respectively. Surface $2 \mathrm{c}$ had the largest $\xi_{1-\Phi}$ value. Table 4.4 gives a summary of the total wetted surface area, CHF, heat flux enhancement relative to the flat surface at CHF, AUF, surface temperature at CHF and multiphase efficiency for each of the blocks tested for the degassed and gassy case. Surface $1 \mathrm{c}$ had the largest $\xi_{2-\Phi}$ value for the $\mathrm{X}$ variation.

The L variation study (Fig. 4.13b) also showed agreement to within the experimental uncertainty for the single phase regime as well as through transition to the multiphase regime. Each of the enhanced surfaces had higher heat fluxes than the flat surface. Case $5 \mathrm{c}$ had the largest single phase AUF value $\left(\xi_{1-\Phi}=0.80\right)$ for the $\mathrm{L}$ 


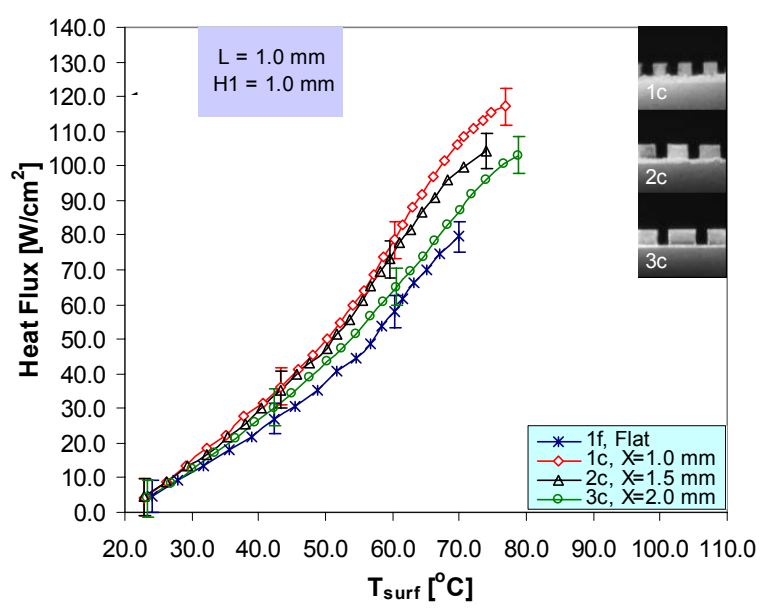

(a) Degassed X Variation

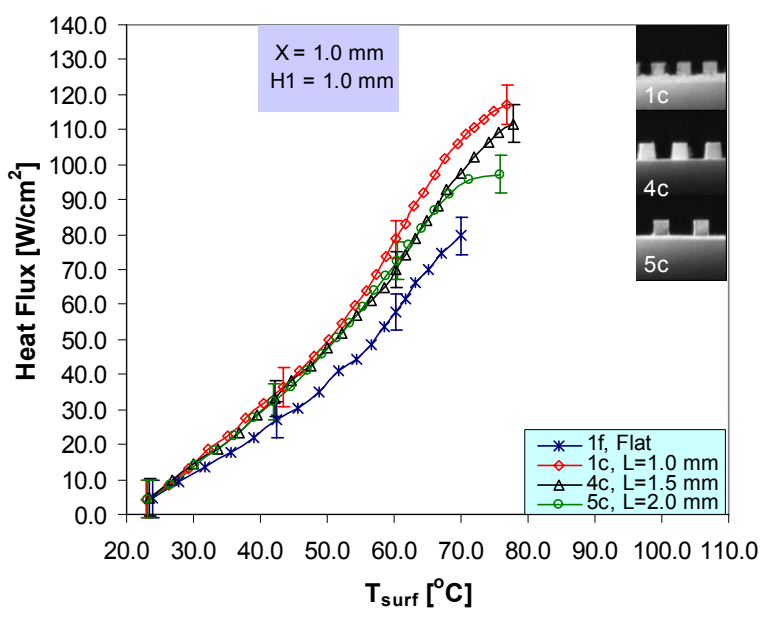

(b) Degassed L Variation

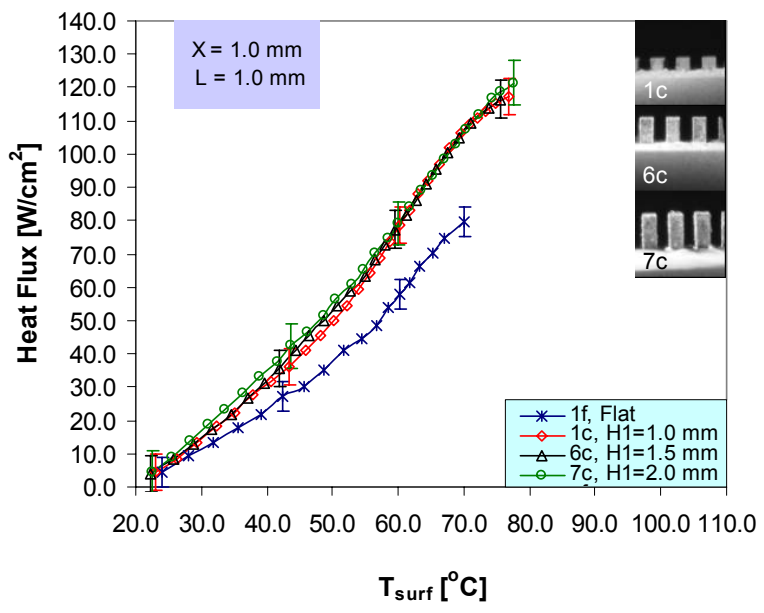

(c) Degassed H1 Variation

Fig. 4.13 Heat Flux as a function of Surface Temperature for Degassed Cubic Pin Fin Study; (a) Degassed X Variation, (b) Degassed L Variation, (c) Degassed H1 Variation 
Table 4.4 Summary of Cubic Pin Finned Surface Data for Variational Study

\begin{tabular}{|c|c|c|c|c|c|c|c|}
\hline \multicolumn{8}{|c|}{ Degassed Case, $\mathrm{T}_{\text {sat }}=31.0^{\circ} \mathrm{C}$} \\
\hline \multirow{2}{*}{ Surface } & \multirow{2}{*}{$\begin{array}{l}A_{\text {surf }} \\
\left(\mathrm{cm}^{2}\right)\end{array}$} & \multirow{2}{*}{$\begin{array}{c}\dot{q}_{C H F}^{\prime \prime} \\
\left(\mathrm{W} / \mathrm{cm}^{2}\right)\end{array}$} & \multirow{2}{*}{$\begin{array}{c}\text { CHF } \\
\text { Enhancement } \\
\text { (relative to Flat } \\
\text { Surface CHF) } \\
(\%)\end{array}$} & \multicolumn{2}{|c|}{$\begin{array}{c}\text { Area } \\
\text { Utilization } \\
\text { Factor }\end{array}$} & \multirow{2}{*}{$\begin{array}{l}\mathrm{T}_{\max } \\
\left({ }^{\circ} \mathrm{C}\right)\end{array}$} & \multirow{2}{*}{$\begin{array}{l}\eta_{2-\Phi} \\
(\%)\end{array}$} \\
\hline & & & & $* \xi_{1-\Phi}$ & $\xi_{2-\Phi}$ & & \\
\hline$\$ 1 \mathrm{f}$ & 2.0 & 80 & 0 & --- & $-\ldots$ & 70.0 & 29 \\
\hline $1 \mathrm{c}$ & 4.0 & 117 & 46 & 0.58 & 0.73 & 76.8 & 44 \\
\hline $2 c$ & 3.9 & 104 & 30 & 0.60 & 0.67 & 73.9 & 39 \\
\hline $3 c$ & 3.8 & 103 & 29 & 0.56 & 0.68 & 78.8 & 38 \\
\hline $4 c$ & 3.3 & 112 & 40 & 0.70 & 0.85 & 77.9 & 42 \\
\hline $5 c$ & 2.9 & 97 & 21 & 0.80 & 0.84 & 75.9 & 36 \\
\hline $6 c$ & 5.0 & 116 & 45 & 0.60 & 0.58 & 75.5 & 43 \\
\hline $7 \mathrm{c}$ & 6.0 & 121 & 51 & 0.49 & 0.50 & 77.7 & 44 \\
\hline \multicolumn{8}{|c|}{ Gassy Case, $T_{\text {sat }}=56.0^{\circ} \mathrm{C}$} \\
\hline${ }^{\ddagger} 1 \mathrm{f}$ & 2.0 & 107 & 0 & --- & $\ldots$ & 87.5 & 36 \\
\hline $1 \mathrm{c}$ & 4.0 & 145 & 36 & 0.76 & 0.68 & 93.3 & 49 \\
\hline $2 c$ & 3.9 & 132 & 23 & 0.51 & 0.63 & 90.7 & 45 \\
\hline $3 c$ & 3.8 & 132 & 23 & 0.48 & 0.65 & 98.3 & 45 \\
\hline $4 c$ & 3.3 & 142 & 33 & 0.74 & 0.80 & 97.0 & 48 \\
\hline $5 \mathrm{c}$ & 2.9 & 123 & 15 & 0.84 & 0.79 & 86.8 & 42 \\
\hline $6 \mathrm{c}$ & 5.0 & 145 & 36 & 0.46 & 0.54 & 94.3 & 49 \\
\hline $7 \mathrm{c}$ & 6.0 & 149 & 39 & 0.39 & 0.46 & 97.6 & 51 \\
\hline
\end{tabular}

$\$$ indicates that the Area Utilization Factor is not applicable because area addition has not occurred.

* single phase enhancement factor ratios were taken with heat flux values at the end of the single phase regime

variation and each of the surfaces tested. Multiphase effects become pronounced around $\mathrm{T}_{\text {surf }} \approx 52^{\circ} \mathrm{C}$ where separation between the cases begins in the spray cooling curves. Above this temperature, case 1c began to exhibit higher heat fluxes than cases $4 \mathrm{c}$ and $5 \mathrm{c}$. Cases $4 \mathrm{c}$ and $5 \mathrm{c}$ agreed well until high heat flux is reached $\left(\mathrm{T}_{\text {surf }} \approx 68^{\circ} \mathrm{C}\right)$. CHF for cases $1 \mathrm{c}$ and $4 \mathrm{c}$ were different by only $5 \mathrm{~W} / \mathrm{cm}^{2}$ (see Table 4.4 for actual values). Case $5 \mathrm{c}$ had the lowest $\mathrm{CHF}$ value $\left(97 \mathrm{~W} / \mathrm{cm}^{2}\right)$ for both this variation and all of the enhanced surfaces tested. However, $\xi_{2-\Phi}$ indicated that surface $5 \mathrm{c}$ has the second highest AUF (i.e. 0.84) for all surfaces tested. Case $4 \mathrm{c}$ had the highest $\xi_{2-\Phi}$ $(0.85)$ 
The tests conducted to study the effects of H1 variation (Fig. 4.13c), show that there was little difference amongst the three cases for the range of values tested. Similar to the other cases, the onset of multiphase effects occurs at approximately $\mathrm{T}_{\text {surf }} \approx 55^{\circ} \mathrm{C}$. All values agreed within the experimental uncertainty throughout the spray cooling curve. The maximum surface temperature occurred within a range of $2^{\circ} \mathrm{C}$ for each case, with CHF spanning a range of $5 \mathrm{~W} / \mathrm{cm}^{2}$ (shown in Table 4.4). Case $7 \mathrm{c}$ had the highest CHF $\left(121 \mathrm{~W} / \mathrm{cm}^{2}\right)$. The fact that the height variation had little impact upon the heat flux implied that the AUF values decreased in both the single and multiphase regime with area addition. Visual observations during testing showed that the fin height was noticeably higher than the film thickness on the heater surface. The low AUF values are corroborated by this fact since much of the area added was not utilized for heat exchange with the excess liquid on the heater surface. Case $7 \mathrm{c}$ had the lowest single and multiphase AUF values $\left(\xi_{1-\Phi}=0.49, \xi_{2-\Phi}=0.5\right)$ for both the H1 variation and the other surfaces tested.

Gassy Case. The X variation for the gassy case (Fig. 4.14a) showed similar enhancement behavior to the nominally degassed case. Each of the cases agreed within the experimental uncertainty until transition to the multiphase regime. Similar to the nominally degassed X variation (Fig. 4.13a), 3c performed lower than the other two (1c and 2c) for all surface temperatures. CHF for case $3 \mathrm{c}$ was $132 \mathrm{~W} / \mathrm{cm}^{2}$, compared to $145 \mathrm{~W} / \mathrm{cm}^{2}$ for case $1 \mathrm{c}$ (shown in Table 4.4). The $\xi_{1-\Phi}$ and $\xi_{2-\Phi}$ AUF values also were the highest for case $1 \mathrm{c}\left(\xi_{1-\Phi}=0.76, \xi_{2-\Phi}=0.68\right)$.

The L variation (Fig. 4.14b) cases (4c and 5c) agreed within the experimental uncertainty throughout the single phase regime at low heat flux $\left(\mathrm{T}_{\text {surf }} \leq 65^{\circ} \mathrm{C}\right)$ and 


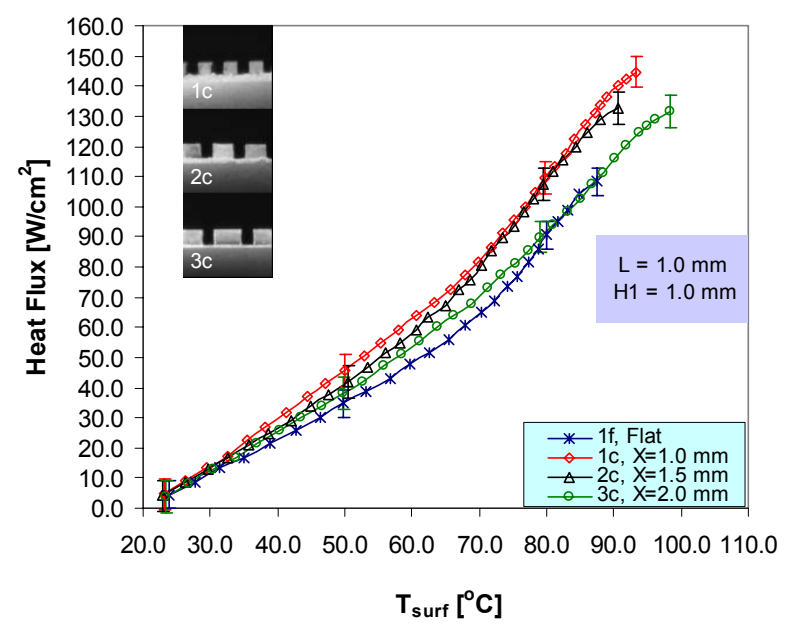

(a) Gassy X Variation

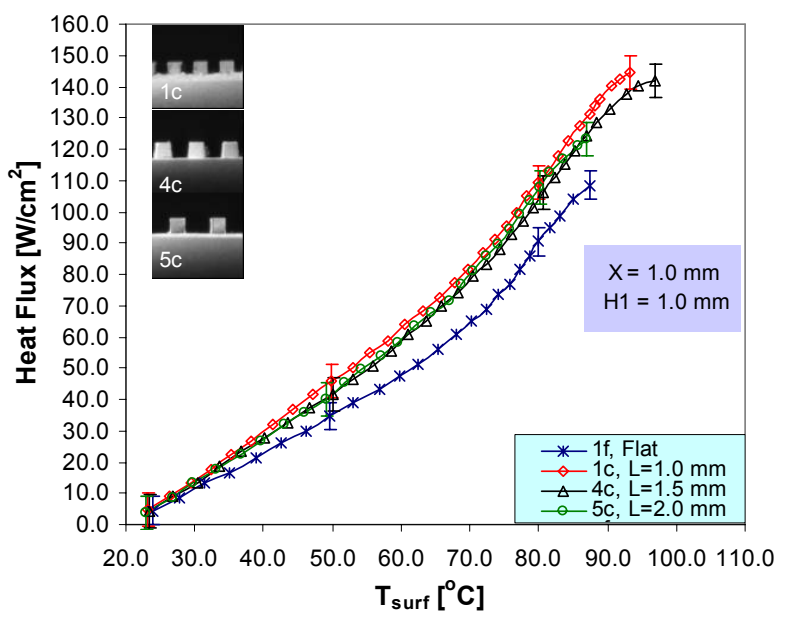

(b) Gassy L Variation

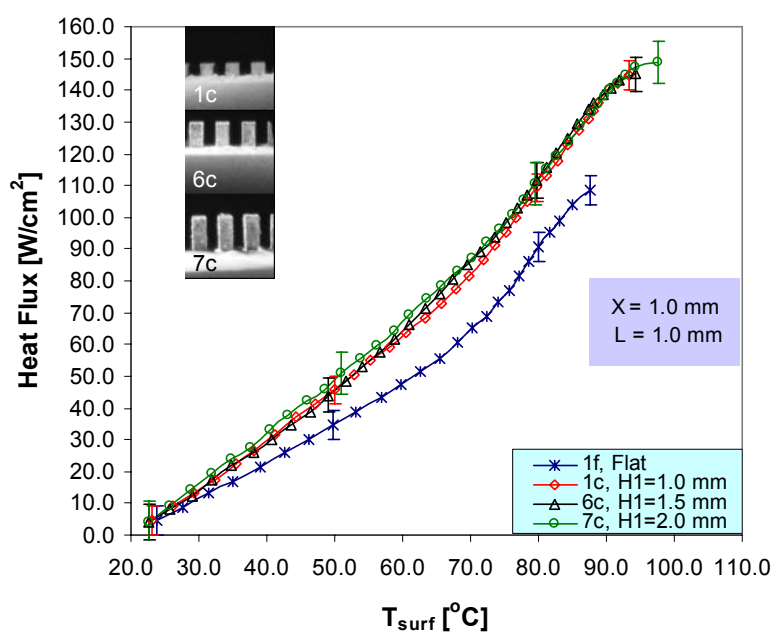

(c) Gassy H1 Variation

Fig. 4.14 Heat Flux as a function of Surface Temperature for Gassy Cubic Pin Fin Study; (a) Gassy X Variation, (b) Gassy L Variation, (c) Gassy H1 Variation 
during transition to the multiphase heat flux regime $\left(65^{\circ} \mathrm{C} \leq \mathrm{T}_{\text {surf }} \leq 80^{\circ} \mathrm{C}\right)$. Upon entering the high heat flux portion of the multiphase regime, case $5 \mathrm{c}$ reached $\mathrm{CHF}$ at $123 \mathrm{~W} / \mathrm{cm}^{2}$ (lower surface temperature than cases $4 \mathrm{c}$ and $1 \mathrm{c}$ ). This also occurred in the nominally degassed study. The ranking for the $\xi_{1-\Phi}$ values showed case $5 \mathrm{c}$ was the highest $\left(\xi_{1-\Phi}=0.84\right)$ with $1 \mathrm{c}$ the second highest $\left(\xi_{1-\Phi}=0.76\right)$ and case $4 \mathrm{c}$ ranked the lowest $\left(\xi_{1-\Phi}=0.74\right)$. The highest $\mathrm{CHF}$ values occurred for cases $1 \mathrm{c}\left(145 \mathrm{~W} / \mathrm{cm}^{2}\right)$ and $4 \mathrm{c}\left(142 \mathrm{~W} / \mathrm{cm}^{2}\right)$. Similar to the degassed case, the highest $\xi_{2-\Phi}(0.8)$ value occurred for case $4 c$.

The H1 variation (Fig. 4.14c) showed good agreement for cases 1c, 6c, and 7c throughout the entire surface temperature domain, similar to the behavior observed for the degassed case (Fig. $4.13 \mathrm{c})$. CHF for case $7 \mathrm{c}\left(149 \mathrm{~W} / \mathrm{cm}^{2}\right)$ was only $4 \mathrm{~W} / \mathrm{cm}^{2}$ higher than CHF for cases $1 \mathrm{c}\left(145 \mathrm{~W} / \mathrm{cm}^{2}\right)$ and $6 \mathrm{c}\left(145 \mathrm{~W} / \mathrm{cm}^{2}\right)$. Single phase and multiphase AUF values decreased with increasing wetted surface area. This indicated that addition of heater surface area beyond a certain length is not effective (i.e. cases 6c and 7c). Similar to the degassed case, single and multiphase AUF values decreased significantly for surfaces $6 \mathrm{c}$ and $7 \mathrm{c}$. The highest AUF values occurred for surface 1c $\left(\xi_{1-\Phi}=0.76, \xi_{2-\Phi}=0.68\right)$ in this variation.

The AUF was previously presented as a metric for determination of the effectiveness of heat transfer for the area added (relative to the projected surface area) when using an enhanced surface. CHF enhancements provide additional heat flux performance margin for the item being cooled. Heat flux performance margin presents increased performance capabilities and is often used as a design metric. However, AUF can also be used as a design tool. Given the option of selecting from 
multiple geometries, the AUF may be used in conjunction with the CHF enhancement to determine which surface has the best comparative heat flux performance. Minimizing the time required to fabricate structured geometries while providing pronounced heat flux enhancement may be considered a cost effective approach to increasing heat flux performance margin. Fig. 4.15 shows CHF enhancement and $\xi_{2-\Phi}$ as a function of structure size for each of the variations in both the degassed and gassy cases. The plots for the $\mathrm{X}$ variation (Figs. $4.15 \mathrm{a}$ and $4.15 \mathrm{~b}$ ) show a decrease in the CHF with increasing $X$ value until $1.5 \mathrm{~mm}$. Beyond $\mathrm{X}=1.5 \mathrm{~mm}$ the CHF enhancement is fairly constant. Little change was observed in the AUF values for the $\mathrm{X}$ value range tested. The $\mathrm{L}$ variation plots (Figs. $4.15 \mathrm{c}$ and $4.15 \mathrm{~d}$ ) show a decrease in CHF enhancement as the $\mathrm{L}$ values increased. AUF values increased with increasing $\mathrm{L}$ until $\mathrm{L}=1.5 \mathrm{~mm}$. Beyond this value, AUF was fairly constant. The H1 variation plots are shown in Figs. 4.15e and 4.15f. Fig. 4.15e shows the curves intersecting at the 2.0 $\mathrm{mm}$ height. Both of these plots show AUF steadily decreasing and CHF enhancement having a slight increase with increasing H1 values. For the geometries tested, surface $1 \mathrm{c}$ has the best combined performance.

Comparison of the individual test cases (Figs. 4.13 and 4.14) show that differences in heat flux in the single and multiphase heat flux regimes are predominantly within the experimental uncertainty. Differences in heat flux having a magnitude greater than the experimental uncertainty are present in the transition from the single to the multiphase regime as well as at high heat flux near CHF for the $\mathrm{X}$ and $\mathrm{L}$ variation studies. This is shown in Table 4.4 by comparing CHF for cases $1 \mathrm{c}$, $2 \mathrm{c}$ and $3 \mathrm{c}$, as well as comparing $1 \mathrm{c}$ with $4 \mathrm{c}$ and $5 \mathrm{c}$. 


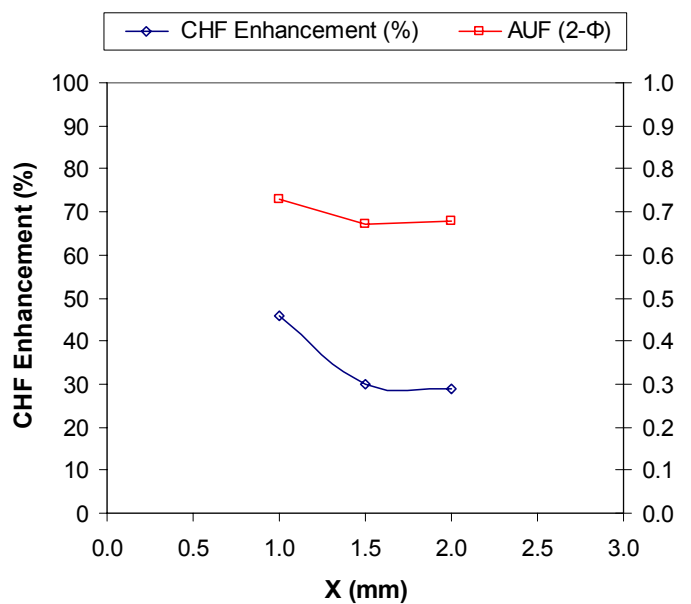

(a) Degassed X case

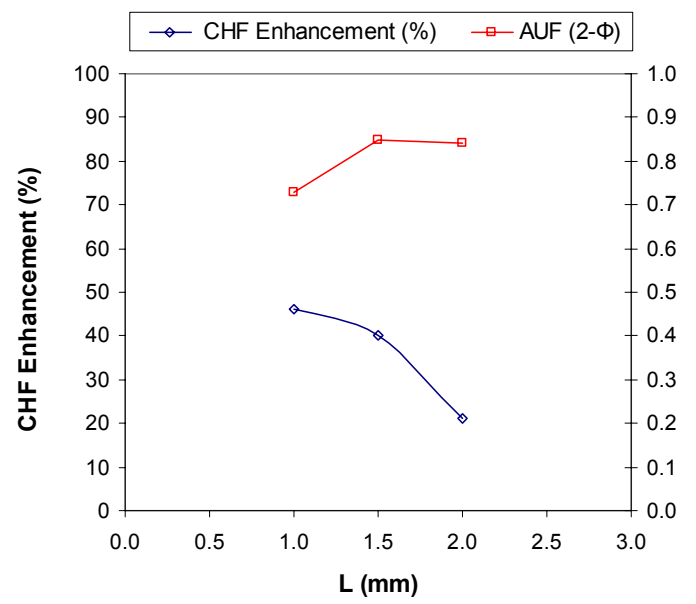

(c) Degassed L case

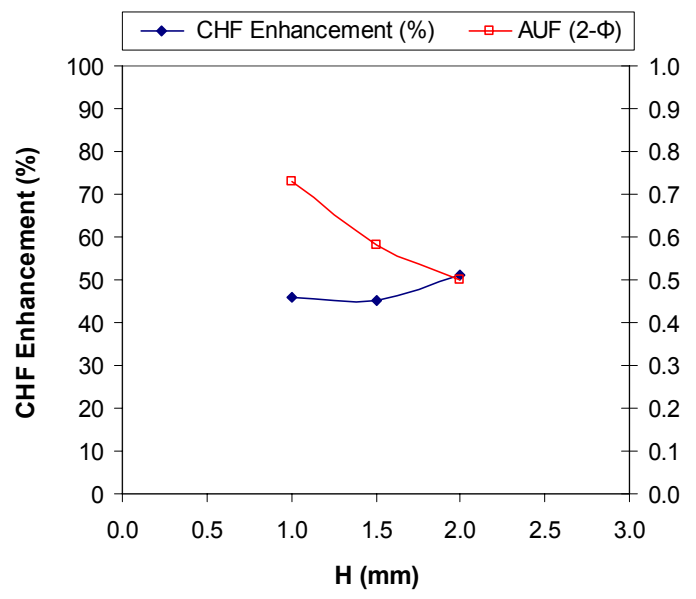

(e) Degassed H1 case

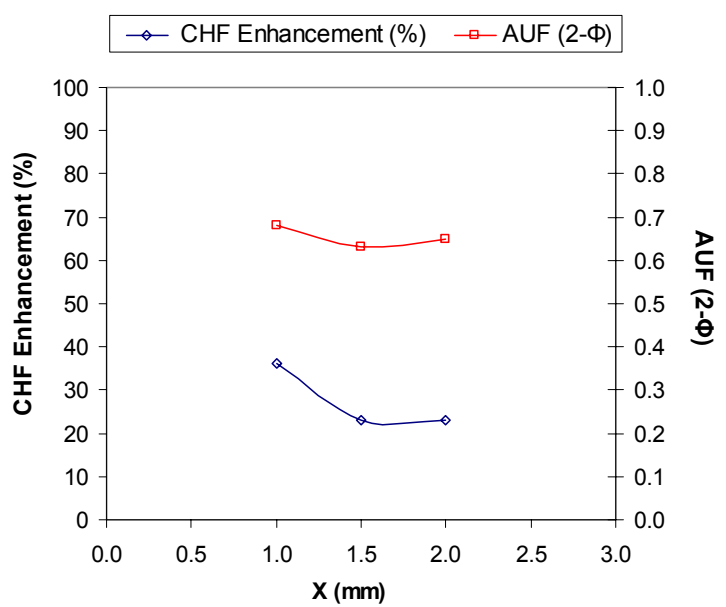

(b) Gassy X case

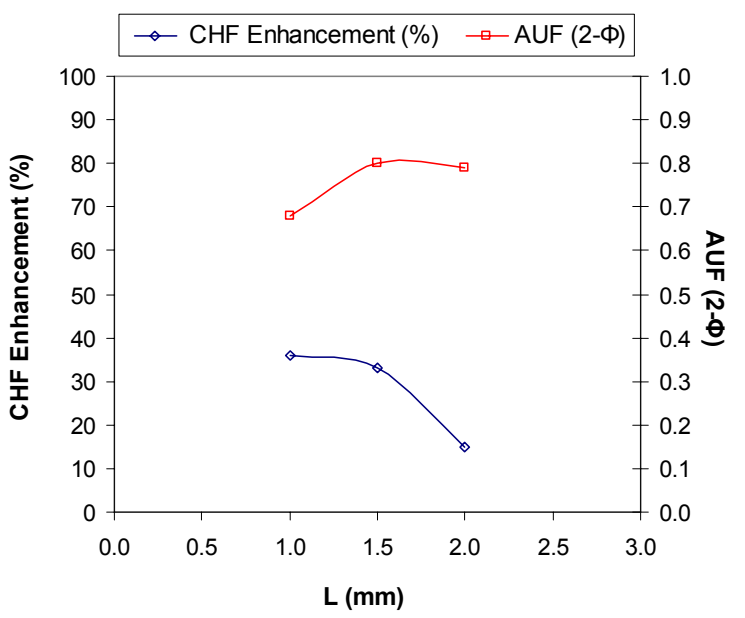

(d) Gassy L case

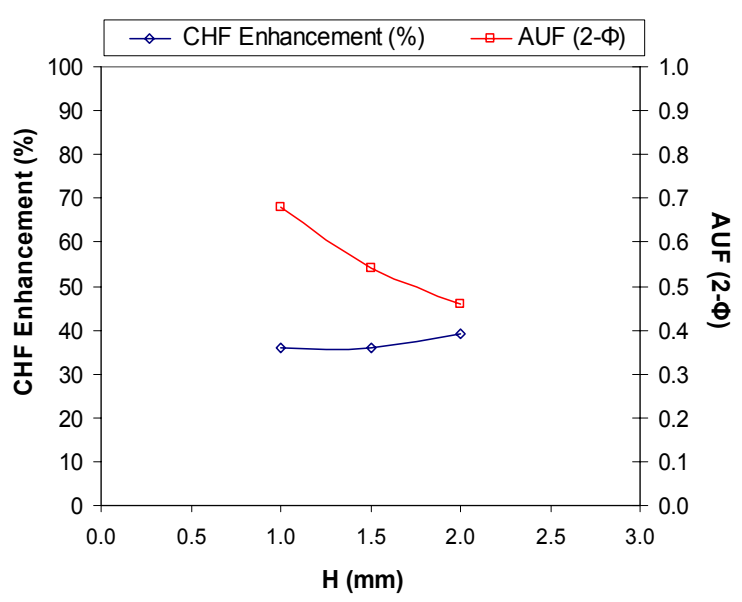

(f) Gassy H1 case

Fig. 4.15 CHF and $\xi_{2-\Phi}$ as a function of Structure Size Variation; (a) Degassed X case, (b) Gassy X case, (c) Degassed L case, (d) Gassy L case, (e) Degassed H1 case, (f) Gassy H1 case 
For the $\mathrm{X}$ and $\mathrm{L}$ variations, increases in $\mathrm{A}_{\text {surf }}$ appear to correspond to increases in CHF for both the degassed and gassy cases. However, the AUF values indicate that surfaces $4 \mathrm{c}$ and $5 \mathrm{c}$ most effectively use the surface area for both the degassed and gassy variation studies. The $\mathrm{H} 1$ variation studies (Figs. $4.13 \mathrm{c}$ and $4.14 \mathrm{c}$ ), showed very little variation $(\leq 4 \%)$ for the heights tested throughout the surface temperature domain.

As in the fundamental study, dissolved gasses delayed the transition between the single phase and multiphase heat flux regimes. As mentioned previously, Lin and Ponnappan (2003) concluded that non-condensible gasses enhanced heat transfer due to increased film spreading initiated by a reduction in the partial vapor pressure at the liquid surface. Horacek et al. (2005) found that the presence of gas resulted in subcooled liquid being sprayed onto the surface. This delayed the temperature at which multiphase effects became pronounced as well as the temperature at which CHF occurred. Spray cooling of enhanced surfaces is expected to thicken the liquid film due to pooling of liquid around the individual structures. Film thinning is not expected to impact the heat flux.

The limited spread in the single phase regime for the heat flux curves $(\mathrm{X}$ and $\mathrm{L}$ variations) suggest that the increments selected for the geometric dimensions in each of the size variations may have been too small to capture changes in each of the heat flux regimes. Furthermore, the agreement of all the spray cooling curves in the H1 variation for both the degassed and gassy cases imply that the optimum fin height (with respect to heat flux) may have been reached for the test cases studied. However, review of this data also suggests that the range for the heights tested may have been 
too small. At this point in time, it is unknown whether or not increasing or decreasing the cubic pin fin height would result in a heat flux increase or decrease. Nonetheless, the primary insight gained from the surfaces tested is that the heat flux does not scale with the total wetted surface area for neither similar nor dissimilar structures.

\subsubsection{Compound Surface Enhancements and Embedded Structures}

The fundamental study showed that spray cooling of extended surface structures such as cubic pin fins, straight fins, and pyramids results in a corresponding heat flux enhancement. However, practical engineering applications having limited nozzle to surface clearance height may be problematic regarding the application of extended surface structures. Given the numerous surface enhancement techniques available (i.e. tunnels, pitted coatings, and dimples to name a few), review of the fundamental study shows that is was fairly limited in scope with respect to the different types of surfaces tested. One question which can be posed as a follow-up to the fundamental study is whether or not comparable heat flux enhancements can be achieved using embedded structures and/or compound surface enhancements. The study reported here extends the initial investigation to include embedded structures and compound extended surface enhancements. Spray cooling heat flux as a function of geometry and structure arrangement is reported for six new geometries. Heat flux comparison between each of these geometries as well as comparison to some geometries tested in the fundamental study (i.e. cubic pin fins and straight fins) was performed. The new surfaces tested include thin straight fins (1s_t), straight fins with cubic pin fins on top (1sc), surface dimples (1d), straight fins with surface dimples in the fins and on the 
base (1sd), radial fins (1r), and porous tunnels (1pt). See Fig. 3.20 for detailed pictures.

\section{Embedded Structures (Dimpled and Porous Structures)}

Fig. 4.16 shows heat flux as a function of surface temperature and embedded structure geometry under nominally degassed conditions. The heat transfer variation for all of the surfaces is linear in the single phase heat flux regime. Multiphase effects become pronounced around $\mathrm{T}_{\text {surf }} \approx 50^{\circ} \mathrm{C}$ for the porous tunnel (1pt) surface. This is denoted by the increase in slope of the heat flux curves. For the flat (1f) and dimpled surfaces (1d), multiphase effects do not become pronounced until $\mathrm{T}_{\text {surf }} \approx 55^{\circ} \mathrm{C}$. Both of the embedded structures had a significant increase in CHF relative to the flat surface case indicating that heat flux enhancement may be attained with spray cooling

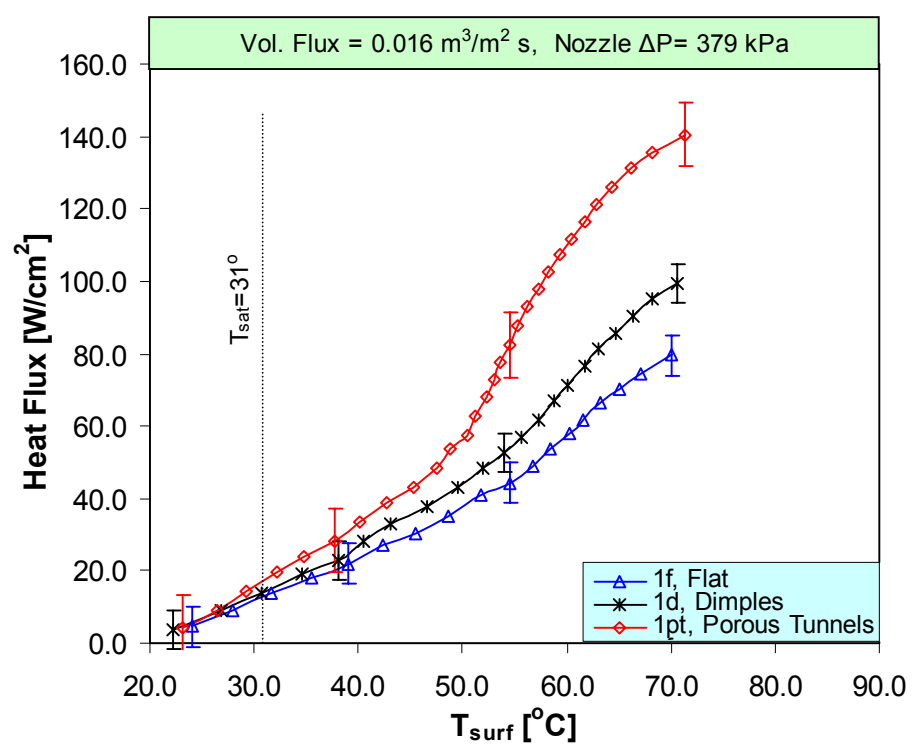

Fig. 4.16 Heat flux as a function of Surface Temperature for Embedded Structure Geometries 
using both extended and embedded structure geometries. The porous tunnels (1pt) had the highest CHF $\left(140 \mathrm{~W} / \mathrm{cm}^{2}\right)$ of the surfaces tested in this case. However, it had the lowest single and multiphase AUF values $\left(\xi_{1-\Phi}=0.41, \xi_{2-\Phi}=0.47\right)$.

\section{Straight Fins vs. Cubic Pin Fins}

Fig. 4.17 shows heat flux as a function of surface temperature and extended surface fin geometry under nominally degassed conditions. The straight and cubic pin fin data, previously reported in section 4.3.1, is also reported here for comparison to surfaces $1 \mathrm{sc}$ and $1 \mathrm{sd}$. Heat transfer variation for all surfaces is linear in the single phase heat flux regime. Multiphase effects become observable around $\mathrm{T}_{\text {surf }} \approx 40^{\circ} \mathrm{C}$ and pronounced around $\mathrm{T}_{\text {surf }} \approx 48^{\circ} \mathrm{C}$ for surface $1 \mathrm{~s}$. In the multiphase regime, the spray cooling curves for surfaces $1 \mathrm{~s}$ and $1 \mathrm{sd}$ begin to separate with surface $1 \mathrm{~s}$ performing noticeably better (beyond the range of experimental uncertainty) than

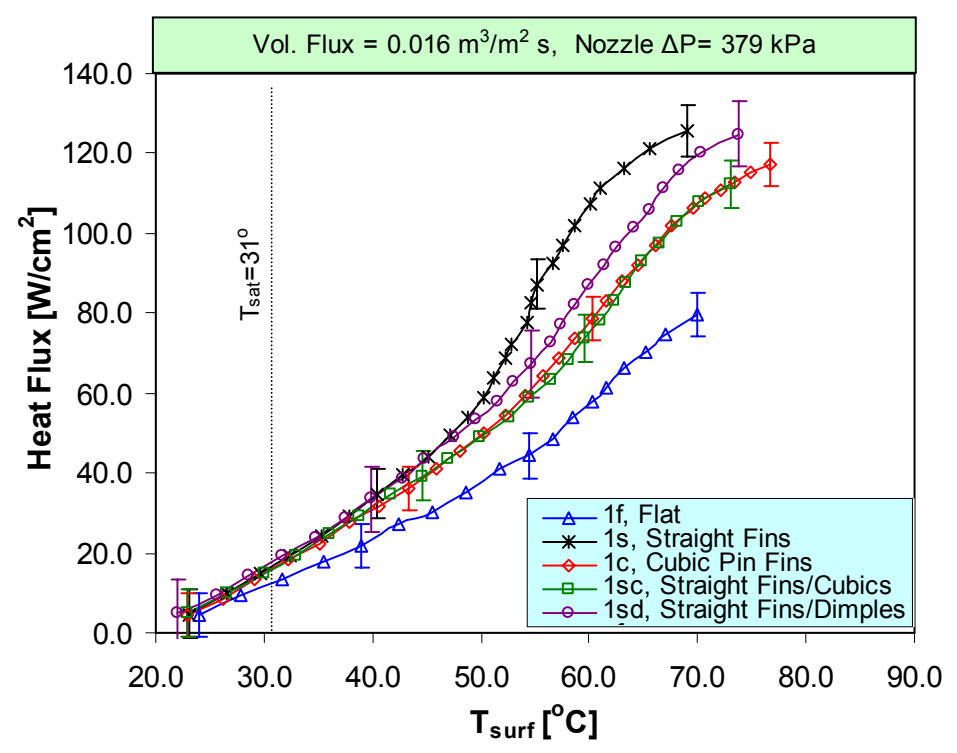

Fig. 4.17 Heat flux as a function of Surface Temperature for Straight and Cubic Pin Fin Compound Structure Geometries. 
surface $1 \mathrm{sd}$. Nonetheless, both of these surfaces approach the same nominal CHF value. Surfaces 1c and 1sc are nearly identical (well within the experimental uncertainty) in heat flux performance throughout the single and multiphase heat flux regimes. Both surfaces transition to the multiphase regime around $\mathrm{T}_{\text {surf }} \approx 52^{\circ} \mathrm{C}$. The highest CHF was attained with the straight fin and straight fin w/dimples surfaces $\left(126 \mathrm{~W} / \mathrm{cm}^{2}\right.$ and $125 \mathrm{~W} / \mathrm{cm}^{2}$ respectively). The highest single phase and multiphase AUF values were attained with surface $1 \mathrm{~s}\left(\xi_{1-\Phi}=0.60, \xi_{2-\Phi}=0.79\right)$. Surfaces $1 \mathrm{c}$ and $1 \mathrm{sc}$ attained CHF values of $117 \mathrm{~W} / \mathrm{cm}^{2}$ and $112 \mathrm{~W} / \mathrm{cm}^{2}$ respectively.

The results of the fundamental enhanced surface structure spray cooling study were non-intuitive. It was clearly shown that the straight fin (1s) surface had significantly better heat flux performance than the cubic pin fin (1c) surface even though the area increase relative to the flat surface $\left(2.0 \mathrm{~cm}^{2}\right)$ was the same (the total area exposed to the liquid for both surfaces was $4.0 \mathrm{~cm}^{2}$ ). This implied that liquid management on the 1s surface promoted better heat transfer than the 1c surface.

Further investigation into the differences in heat flux performance between the two geometries (1s and 1c) can be investigated using one of two methodologies. The first is through visualization. However, this is problematic since the large spray density obscures the surface (see Fig. 4.12). The second is through heat flux testing using surfaces specially designed to provide more insight into heat flux performance as a function of geometry. The second approach was used in this investigation in the form of surface $1 \mathrm{sc}$.

The difference in structure geometry between surface 1s and 1c is the cutaway volumes (cubes) prevalent on the 1c surface. The surface area on the top of the fins in 
the $1 \mathrm{~s}$ case is transplanted to the base of the structure when volumetric sections are removed from the straight fins to create cubic pin fins. Surface 1sc is a special geometry which is a hybrid between the two surfaces. Surface 1 sc has continuous sidewall area at the base of the structure (similar to the straight fins) up to a height of $0.5 \mathrm{~mm}$. Above that height, surface $1 \mathrm{sc}$ is similar to surface $1 \mathrm{c}$. The heat flux data in Fig. 4.17 shows that surface $1 \mathrm{sc}$ has similar heat flux performance to surface 1c. This may imply that the heat flux enhancement observed with surface $1 \mathrm{~s}$ is associated with heat transfer along the upper sidewall area of the straight fins (i.e. $0.5 \mathrm{~mm}<\mathrm{H} \leq 1.0$ $\mathrm{mm}$ ) and the top of the fin surfaces. However, due to combined effects in the process which are not completely understood, this determination is not definitive. We can only conclude that one factor involved in the larger heat flux enhancement observed in the straight fins is due to more upper sidewall and top surface area than the cubic pinned fin case.

\section{Radial vs. Straight Fins}

Fig. 4.18 shows heat flux as a function of surface temperature and straight fin geometry under nominally degassed conditions. Multiphase effects become pronounced for each of the enhanced surfaces around $\mathrm{T}_{\text {surf }} \approx 50^{\circ} \mathrm{C}$. However, the thin straight fin surface $\left(1 \mathrm{~s} \_t\right)$ has a much more linear spray cooling curve than both the radial fins (surface 1r) and the straight fins (surface 1s). Surfaces 1s and 1r show fair agreement in the multiphase regime until $\mathrm{T}_{\text {surf }} \approx 60^{\circ} \mathrm{C}$. At this point they both transition to high heat flux while approaching CHF. The highest CHF $\left(144 \mathrm{~W} / \mathrm{cm}^{2}\right)$ was attained with surface 1s_t. Surface $1 \mathrm{r}$ had a CHF of $136 \mathrm{~W} / \mathrm{cm}^{2}$ and surface $1 \mathrm{~s}$ 
(as previously reported in section 4.3.1) had a CHF of $126 \mathrm{~W} / \mathrm{cm}^{2}$. The highest single and multiphase AUF values were attained with surface $1 \mathrm{~s}$. These were $\xi_{1-\Phi}=0.6$ and $\xi_{2-\Phi}=0.79$.

Investigation of spray cooled radial fins presents a different fin approach and geometry in comparison to previously investigated structures (sections 4.3.1 and 4.3.2). The $2 \times 2$ Parker Hannifin spray manifold used for these studies creates a stagnation zone in the center of the heat exchange surface (see Fig. 4.9). Droplets that do not rebound off of the surface become entrained in the liquid flow on the heater

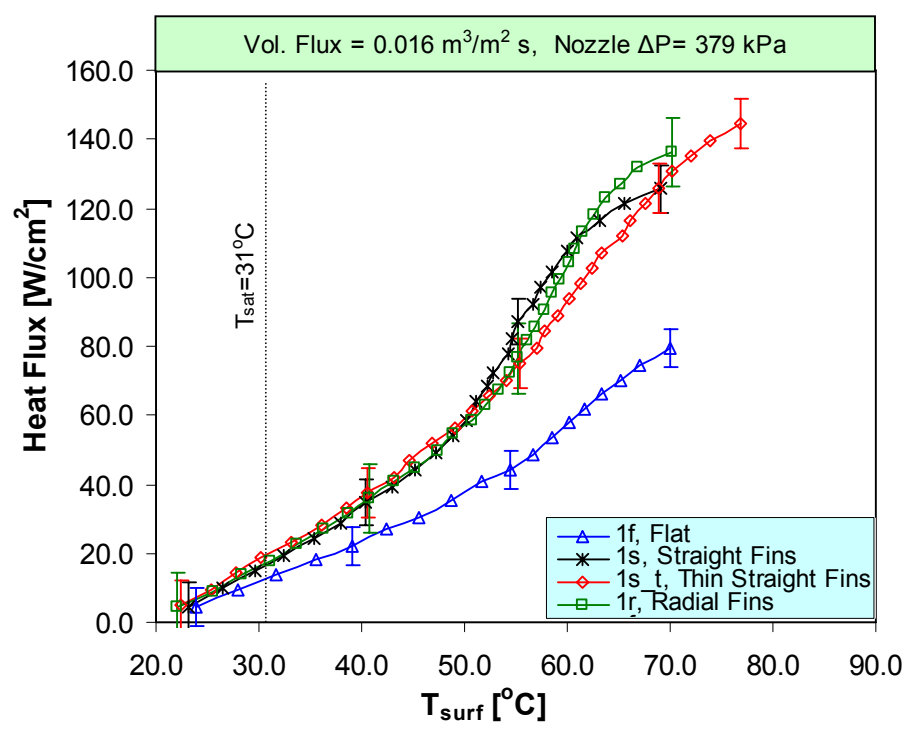

Fig. 4.18 Heat flux as a function of Surface Temperature for Straight and Radial Fin Geometries

surface. This flow moves radially outward from the stagnation zone as it is convected from the heater surface (see Fig. 4.10). Structures tested prior to this study (including many structures in this study) had fin arrangements based on Cartesian coordinates. Nonetheless, the flow across the surface (outside of the stagnation zone) is in the radial direction. The use of Cartesian based fin arrangements with a radial flow 
essentially creates conditions where the fins are mis-aligned with the surface flow. Thus, spray cooling with radial fins may be considered aligned fin spray cooling.

The difference between the extended surface enhanced structures and the flat surface is the fin side wall area. The nominal area addition between the extended structure and the flat surface may be attributed to the sidewall area. The channels created by the extended structures (and their respective geometries) are of importance regarding the total area available and aid in determining the mechanisms of heat transfer enhancement for these structures. Surfaces 1s_t and 1r are similar in that they have the same channel aspect ratio $\mathrm{X} / \mathrm{H}=0.5 \mathrm{~mm} / 1.0 \mathrm{~mm}$. However, the total surface areas are different due to differences in the channel length and the number of channels in the radial case. While the nominal heat flux values are greater for $1 \mathrm{~s} \_t$, the $\xi_{2-\Phi}$ value is only 0.6 whereas for the $1 \mathrm{r}$ surface it is 0.74 (degassed case). For the gassy case the $\xi_{2-\Phi}$ values decrease to 0.53 and 0.69 respectively. This implies that radial fins are more efficient for the spray nozzle used.

Case 1s_t was created by reducing the previously used fin width and separation distance for case 1s by a factor of two. Compared to surface 1s, surface 1s_t has twice the sidewall area $\left(4.0 \mathrm{~cm}^{2}\right)$ and twice the fin count while maintaining the same total surface area for the top of the fins and the same total base area between fins. Thus area addition relative to surface $1 \mathrm{~s}$ is through the fin sidewalls. The nominal increase in heat flux between surfaces $1 \mathrm{~s}$ and $1 \mathrm{~s} \_\mathrm{t}$ shows diminishing returns on the heat flux with the addition of sidewall area. 


\section{Dissolved Gas Study}

Similar to the previous studies, the addition of dissolved gasses provided additional enhancement. Spray cooling performance with dissolved gasses for each of the new geometries presented in this study are shown in Fig. 4.19. The porous tunnel (1pt) and radial fin (1r) surfaces were the first to transition into the multiphase regime around $\mathrm{T}_{\text {surf }} \approx 65^{\circ} \mathrm{C}$. The thin straight fins $\left(1 \mathrm{~s} \_t\right)$ and straight fins with dimples $(1 \mathrm{sd})$ surfaces show pronounced multiphase effects around $\mathrm{T}_{\text {surf }} \approx 70^{\circ} \mathrm{C}$. The straight fins with cubics (1sc), dimples (1d), and flat surfaces (1f) each transitioned to the multiphase regime around $\mathrm{T}_{\text {surf }} \approx 75^{\circ} \mathrm{C}$. The radial fins (1r) and porous tunnels (1pt) agreed well throughout each of the heat flux regimes. The thin straight fins $\left(1 \mathrm{~s} \_t\right)$ and

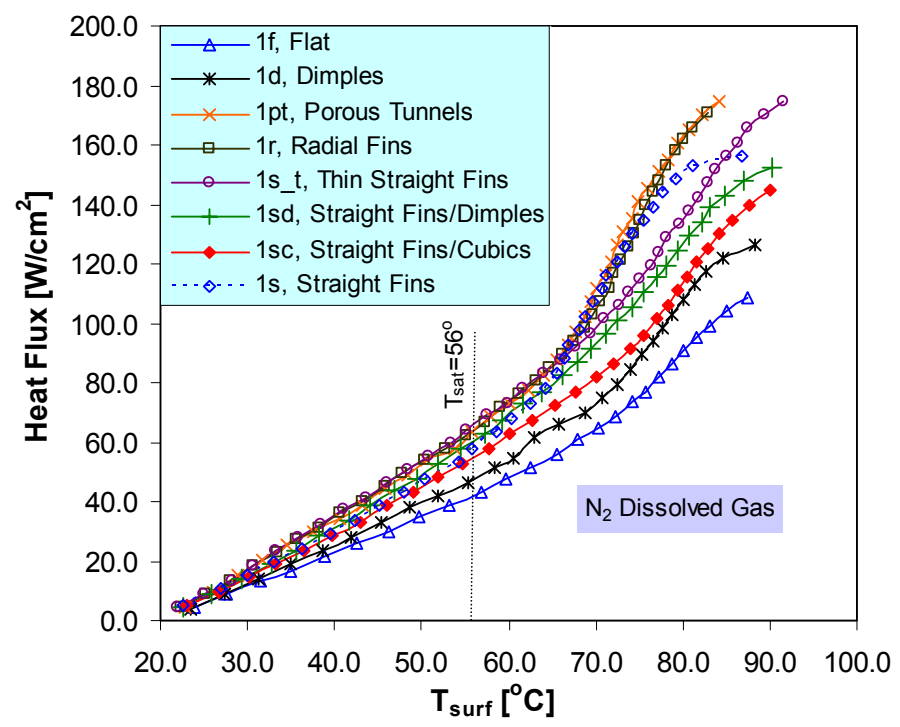

Fig. 4.19 Heat flux as a function of Surface Temperature and Specialty Geometry with $\mathrm{N}_{2}$ Dissolved Gasses

the straight fins with dimples (1sd) agreed well before their transition to high heat flux at $\mathrm{T}_{\text {surf }} \approx 83^{\circ} \mathrm{C}$. The dimples (1d) and the straight fins with cubics (1sc) agreed well within the multiphase regime. However, they diverge as they approach CHF. 
The straight fins with dimples (1sd) and the straight fins with cubics (1sc) converged as they approached CHF. The porous tunnels $(1 \mathrm{pt})$ and the thin straight fins $\left(1 \mathrm{~s} \_\mathrm{t}\right)$ both attained a CHF of $175 \mathrm{~W} / \mathrm{cm}^{2}$. This was the highest CHF attained by any of the surfaces in the gassy case. The radial fins (1r) had the second highest CHF of 171 $\mathrm{W} / \mathrm{cm}^{2}$ which is within the experimental uncertainty of the data collected. A comprehensive summary of the degassed and gassy data including the total wetted surface area, CHF, heat flux enhancement at CHF relative to the flat surface, AUF, surface temperature at CHF and multiphase efficiency for each of the blocks tested

Table 4.5 Summary of Degassed and Gassy data for Compound and Embedded surface structures enhancement study

\begin{tabular}{|c|c|c|c|c|c|c|c|}
\hline \multicolumn{8}{|c|}{ Degassed Case, $\mathrm{T}_{\text {sat }}=31.0^{\circ} \mathrm{C}$} \\
\hline \multirow{2}{*}{ Surface } & \multirow{2}{*}{$\begin{array}{c}A_{\text {surf }} \\
\left(\mathrm{cm}^{2}\right)\end{array}$} & \multirow{2}{*}{$\begin{array}{c}\dot{q}_{C H F}^{\prime \prime} \\
\left(\mathrm{W} / \mathrm{cm}^{2}\right)\end{array}$} & \multirow{2}{*}{$\begin{array}{c}\text { CHF } \\
\text { Enhancement } \\
\text { (relative to } \\
\text { Flat Surface } \\
\text { CHF) } \\
(\%)\end{array}$} & \multicolumn{2}{|c|}{$\begin{array}{c}\text { Area } \\
\text { Utilization } \\
\text { Factor }\end{array}$} & \multirow{2}{*}{$\begin{array}{l}\mathrm{T}_{\text {max }} \\
\left({ }^{\circ} \mathrm{C}\right)\end{array}$} & \multirow{2}{*}{$\begin{array}{l}\eta_{2-\Phi} \\
(\%)\end{array}$} \\
\hline & & & & $* \xi_{1-\Phi}$ & $\xi_{2-\Phi}$ & & \\
\hline *1f & 2.0 & 80 & 0 & --- & $-\ldots$ & 70.0 & 29 \\
\hline $1 \mathrm{~s}$ & 4.0 & 126 & 58 & 0.60 & 0.79 & 69.1 & 46 \\
\hline $1 \mathrm{c}$ & 4.0 & 117 & 46 & 0.58 & 0.73 & 76.8 & 43 \\
\hline $1 \mathrm{sc}$ & 4.0 & 112 & 40 & 0.58 & 0.70 & 73.1 & 41 \\
\hline $1 \mathrm{sd}$ & 5.2 & 125 & 56 & 0.46 & 0.60 & 73.8 & 45 \\
\hline $1 \mathrm{~s} \mathrm{t}$ & 6.0 & 144 & 80 & 0.40 & 0.60 & 76.9 & 52 \\
\hline $1 \mathrm{r}$ & 4.6 & 136 & 70 & 0.52 & 0.74 & 70.2 & 49 \\
\hline $1 d$ & 3.2 & 99 & 24 & 0.48 & 0.77 & 70.6 & 36 \\
\hline $1 \mathrm{pt}$ & 7.5 & 140 & 75 & 0.41 & 0.47 & 71.4 & 51 \\
\hline \multicolumn{8}{|c|}{ Gassy Case, $T_{\text {sat }}=56.0^{\circ} \mathrm{C}$} \\
\hline$\ddagger 1 \mathrm{f}$ & 2.0 & 107 & 0 & --- & --- & 87.5 & 36 \\
\hline $1 \mathrm{~s}$ & 4.0 & 156 & 46 & 0.71 & 0.72 & 86.7 & 52 \\
\hline $1 \mathrm{c}$ & 4.0 & 145 & 36 & 0.76 & 0.68 & 93.3 & 48 \\
\hline $1 \mathrm{sc}$ & 4.0 & 145 & 36 & 0.67 & 0.68 & 89.9 & 48 \\
\hline $1 \mathrm{sd}$ & 5.2 & 153 & 43 & 0.68 & 0.54 & 90.2 & 51 \\
\hline $1 \mathrm{~s} \mathrm{t}$ & 6.0 & 175 & 64 & 0.53 & 0.53 & 91.5 & 58 \\
\hline $1 \mathrm{r}$ & 4.6 & 171 & 60 & 0.69 & 0.69 & 82.9 & 57 \\
\hline $1 \mathrm{~d}$ & 3.2 & 126 & 18 & 0.71 & 0.73 & 88.3 & 42 \\
\hline $1 \mathrm{pt}$ & 7.5 & 175 & 64 & 0.42 & 0.43 & 84.2 & 58 \\
\hline
\end{tabular}

$\$$ indicates that the Area Utilization Factor is not applicable because area addition has not occurred.

* single phase enhancement factor ratios were taken with heat flux values at the end of the single phase regime 
is shown in Table 4.5. This study found that CHF for the thin straight fin (1s_t) and porous tunnel $(1 \mathrm{pt})$ surfaces was nearly the same in the degassed $\left(\approx 142 \mathrm{~W} / \mathrm{cm}^{2}\right)$ and gassy $\left(\approx 175 \mathrm{~W} / \mathrm{cm}^{2}\right)$ cases. Furthermore, each of these outperformed the other surfaces in both the degassed and gassy cases.

\subsubsection{Spray Inclination Angle Impact Upon Heat Flux}

Flat Surface. Spray cooling curves for the flat surface (1f) are shown in Fig. 4.20a. Heat flux as a function of surface temperature and spray angle for the straight finned surface in the $\gamma=0^{\circ}$ and $\gamma=90^{\circ}$ orientations are shown in Figs. 4.20b and 4.20c. Fig. 4.20a shows that the heat flux increased as the spray angle increased from $\theta=0^{\circ}$ for the flat surface. The highest CHF of $98 \mathrm{~W} / \mathrm{cm}^{2}\left(23 \%\right.$ enhancement relative to $\left.\theta=0^{\circ}\right)$ occurred for $\theta=15^{\circ}$. The $\theta=45^{\circ}$ case showed good agreement with the $\theta=0^{\circ}$ case in the single phase regime $\left(\mathrm{T}_{\text {surf }} \leq 55^{\circ} \mathrm{C}\right)$. However, heat flux performance for the $\theta \geq$ $15^{\circ}$ cases agreed within the experimental uncertainty in all heat flux regimes. The maximum surface temperature reached for $\theta=15^{\circ}$ was approximately the same as for $\theta=0^{\circ}\left(\mathrm{T}_{\text {surf }} \approx 70^{\circ} \mathrm{C}\right)$ while the other cases reached a surface temperature value of $\approx 67^{\circ} \mathrm{C}$. A summary of the data tabulated for both the flat and straight finned surfaces at each of the $\theta$ angles tested is shown in Table 4.6

Straight Finned Surface. Results of the straight fin $\gamma=0^{\circ}$ study are shown in Fig. 4.20b. The heat flux curves for the $\theta=0^{\circ}, 15^{\circ}, 30^{\circ}$, and $45^{\circ}$ cases agreed within the experimental uncertainty. Surprisingly, this indicated that the spray inclination angle has little influence on the straight finned surface heat flux. All cases had a CHF value 


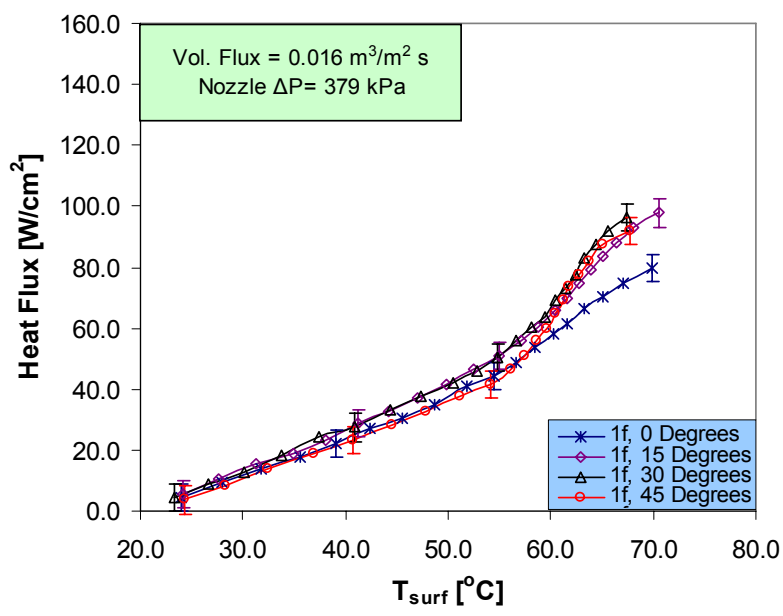

(a) flat surface

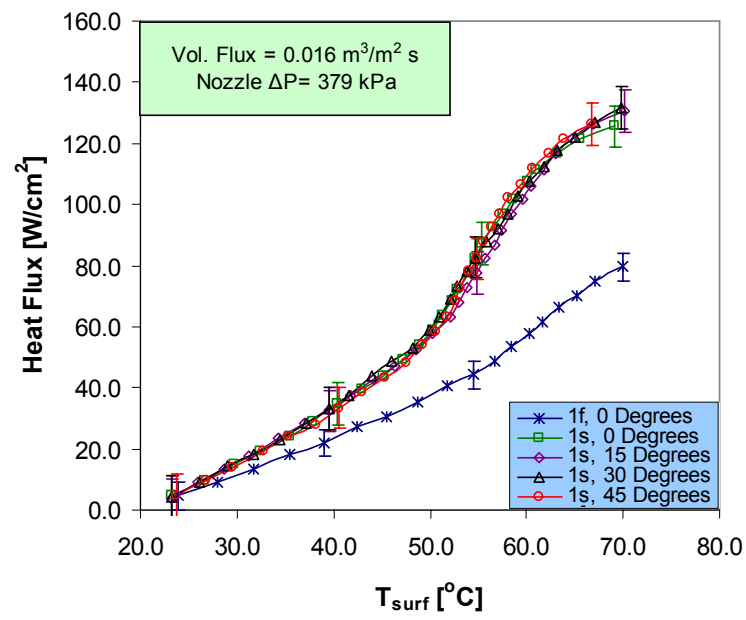

(b) axial straight fins $\left(\gamma=0^{\circ}\right)$

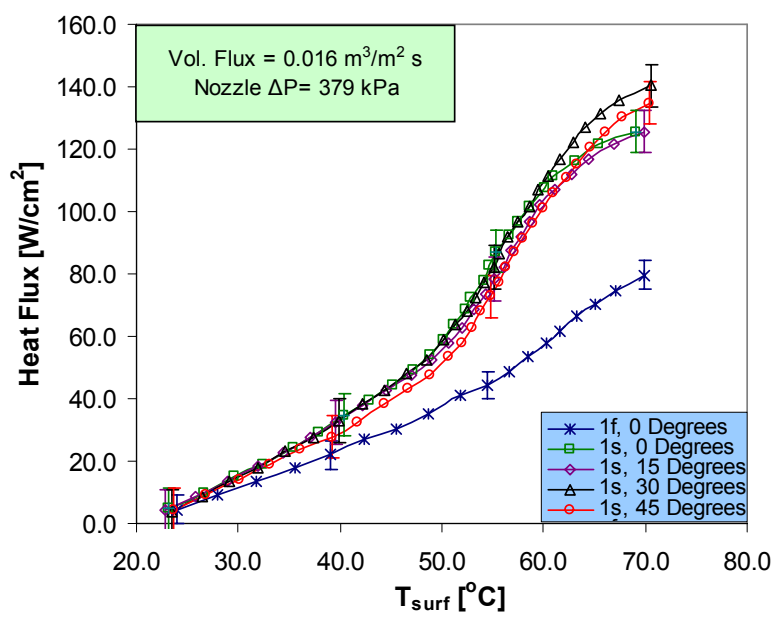

(c) transverse straight fins $\left(\gamma=90^{\circ}\right)$

Fig. 4.20 Heat flux as a function of Surface Temperature for Spray Inclination Angle;

(a) flat surface, (b) axial straight fins $\left(\gamma=0^{\circ}\right)$, (c) transverse straight fins $\left(\gamma=90^{\circ}\right)$ 
of approximately $132 \mathrm{~W} / \mathrm{cm}^{2}$. Results of the straight fin $\gamma=90^{\circ}$ study are shown in Fig. $4.20 \mathrm{c}$, and indicate that spray inclination angle has little effect on spray cooling for this orientation as well. The highest CHF occurred for $\theta=30^{\circ}\left(140 \mathrm{~W} / \mathrm{cm}^{2}\right)$ with heat flux enhancements of $11 \%$ relative to the $\theta=0^{\circ}$ case and $75 \%$ relative to the $\theta=0^{\circ}$ flat surface case. The $45^{\circ}$ case had a CHF value $\left(135 \mathrm{~W} / \mathrm{cm}^{2}\right)$ slightly lower than the $30^{\circ}$ case. The $\theta=15^{\circ}$ case had the same CHF as the $0^{\circ}$ case $\left(126 \mathrm{~W} / \mathrm{cm}^{2}\right)$. The heat fluxes for each of the straight fin cases agreed within the experimental uncertainty in both the single phase and multiphase regimes. Separation of the curves did not occur until just before CHF. CHF for $\theta=30^{\circ}$ was higher than the $\theta=0^{\circ}$ and $\theta=15^{\circ}$ cases.

Table 4.6 Summary of Data for Spray Inclination Angle Impact Study

\begin{tabular}{|c|c|c|c|c|c|c|c|c|c|c|}
\hline \multirow{2}{*}{$\begin{array}{l}\stackrel{2}{E} \\
\stackrel{0}{0} \\
\stackrel{0}{0} \\
0\end{array}$} & \multirow{2}{*}{ 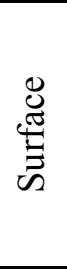 } & \multirow{2}{*}{$\begin{array}{l}A_{\text {surf }} \\
\left(\mathrm{cm}^{2}\right)\end{array}$} & \multirow{2}{*}{$\gamma$} & \multirow{2}{*}{$\theta$} & \multirow{2}{*}{$\begin{array}{c}\dot{q}_{C H F}^{\prime \prime} \\
\left(\mathrm{W} / \mathrm{cm}^{2}\right)\end{array}$} & \multirow{2}{*}{$\begin{array}{c}\text { CHF } \\
\text { Enhancement } \\
\text { (relative to } \\
\text { Flat Surface } \\
\text { CHF at } \theta=0^{\circ} \text { ) } \\
(\%) \\
\end{array}$} & \multicolumn{2}{|c|}{$\begin{array}{c}\text { Area } \\
\text { Utilization } \\
\text { Factor } \\
\end{array}$} & \multirow{2}{*}{$\begin{array}{l}\mathrm{T}_{\max } \\
\left({ }^{\circ} \mathrm{C}\right)\end{array}$} & \multirow{2}{*}{$\begin{array}{l}\eta_{2-\Phi} \\
(\%)\end{array}$} \\
\hline & & & & & & & $* \xi_{1-\Phi}$ & $\xi_{2-\Phi}$ & & \\
\hline \multicolumn{11}{|c|}{ Spray Angle Study } \\
\hline Flat & $\$ 1 \mathrm{f}$ & 2.0 & $-\cdots$ & $0^{\circ}$ & 80 & 0 & $\overline{---}$ & --- & 70.0 & 29 \\
\hline Flat & ${ }^{\ddagger} 1 \mathrm{f}$ & 2.0 & $-\cdots$ & $15^{\circ}$ & 98 & 23 & $-\ldots$ & $-\cdots$ & 70.5 & 36 \\
\hline Flat & $\$ 1 \mathrm{f}$ & 2.0 & $-\cdots$ & $30^{\circ}$ & 96 & 20 & $-\cdots$ & -- & 67.4 & 35 \\
\hline Flat & $\$ 1 \mathrm{f}$ & 2.0 & $-\cdots$ & $45^{\circ}$ & 92 & 15 & $-\cdots$ & $-\cdots$ & 67.8 & 33 \\
\hline Flat & ${ }^{* 1 \mathrm{f}}$ & 2.0 & $\cdots$ & $0^{\circ}$ & 80 & 0 & - & $\cdots$ & 70.0 & 29 \\
\hline Fins $^{\S}$ & $1 \mathrm{~s}$ & 4.0 & $-\cdots$ & $0^{\circ}$ & 126 & 58 & 0.60 & 0.79 & 69.1 & 46 \\
\hline Fins $^{\S}$ & $1 \mathrm{~s}$ & 4.0 & $0^{\circ}$ & $15^{\circ}$ & 131 & 64 & 0.60 & 0.82 & 70.0 & 48 \\
\hline Fins $^{\S}$ & $1 \mathrm{~s}$ & 4.0 & $0^{\circ}$ & $30^{\circ}$ & 132 & 65 & 0.60 & 0.83 & 69.8 & 48 \\
\hline Fins $^{\S}$ & $1 \mathrm{~s}$ & 4.0 & $\overline{0^{\circ}}$ & $45^{\circ}$ & 126 & 58 & 0.60 & 0.79 & 66.7 & 46 \\
\hline Fins $^{\S}$ & $1 \mathrm{~s}$ & 4.0 & $90^{\circ}$ & $15^{\circ}$ & 126 & 58 & 0.60 & 0.79 & 69.9 & 46 \\
\hline Fins $^{\S}$ & $1 \mathrm{~s}$ & 4.0 & $90^{\circ}$ & $30^{\circ}$ & 140 & 75 & 0.60 & 0.88 & 70.5 & 51 \\
\hline Fins $^{\S}$ & $1 \mathrm{~s}$ & 4.0 & $90^{\circ}$ & $45^{\circ}$ & 135 & 69 & 0.52 & 0.84 & 70.3 & 49 \\
\hline
\end{tabular}

$\$$ indicates that the Area Utilization Factor is not applicable because area addition has not occurred.

* single phase enhancement factor ratios were taken with heat flux values at the end of the single phase regime

$\S$ straight fins used for these tests 


\subsection{Enhancement Mechanisms}

\subsubsection{Structured Surface Geometries}

Due to the highly complicated nature of the spray/surface interaction and the inability to make local heat transfer and film characteristics measurements on enhanced surfaces, a definitive explanation of the observed results cannot currently be given. Even on smooth surfaces, the mechanisms by which heat is removed during spray cooling is not well understood. One proposed mechanism is that the spray produces a thin film on the surface through which conduction occurs. The thinner the film, the higher the heat transfer (Yang et al., 1993; Yang et al., 1996; Pais et al., 1992). Another proposed mechanism is that in which boiling is thought to occur in the liquid film itself (secondary nucleation). The growing bubbles, however, are punctured by the incoming droplets before they can grow to appreciable size. The growth and collapse of many small, rapidly growing bubbles has been proposed as the dominant heat transfer mechanism (Rini et al., 2002). Other researchers have found that the heat transfer scales directly with the length of the three-phase contact line (Horacek et al., 2005; Horacek et al., 2006), implying that the mechanism may be governed by transient conduction into a highly disrupted film or by evaporation at the contact line (Potash et al., 1972).

The efficiency with which the added surface area is used is strongly dependent on the enhanced structure geometry. This can be quantified by the AUF as presented in Tables 4.3 through 4.5. For all cases, AUF values smaller than unity were observed, indicating the heat transfer does not scale in proportion to the wetted surface area. In the single and multiphase regime, surfaces $5 \mathrm{c}$ and $4 \mathrm{c}$ respectively had the highest 
AUF values of all surfaces tested. However, the straight fins and porous tunnels attained the highest heat fluxes.

Some of the methods by which the addition of enhanced surfaces affects the thermophysics of spray evaporation are worthy of discussion. The addition of enhanced surface geometries greatly modifies the nature of the fluid/solid contact. The relative increase in wetted surface area can be expected to increase frictional resistance thereby retarding the fluid motion and promoting longer liquid residence time on the heater. The increase in liquid residence time on the heater surface can allow for more heat exchange through increased sensible heating of the liquid. It can also increase the multiphase contribution by providing many more nucleation sites, and allow activation of these nucleation sites at lower wall temperatures. If enhanced surfaces affected the thermophysics in only these two ways, then the cubic pin finned surface would be expected to have higher heat transfer than the straight finned surface. The fact that the highest heat flux and AUF value occurred for the straight finned case, however, suggests that other factors affect the heat transfer.

For a convectively dominated process, the heat transfer is determined by the heat transfer coefficient, the wetted area, and the surface-to-fluid temperature difference. Since the temperature difference $\left(T_{\text {surf }}-T_{1}\right)$ and the wetted area of the cubic pin finned surface and the straight finned surface were identical, differences in the heat transfer performance between these surfaces must be due to differences in the heat transfer coefficient. The heat transfer coefficient for the straight finned surface might be expected to be higher than for the cubic pin finned surface based on the following reasoning. If it is assumed that all liquid sprayed onto the surface flows between the 
structures before leaving the surface, then the cubic pin finned surface has twice the cross-sectional area available to drain the fluid compared to the straight finned surface. The liquid velocities on the straight finned surface would then be expected to be twice as high, resulting in a larger heat transfer coefficient.

\subsubsection{Inclined Sprays}

The increase in heat transfer with inclination angle observed in the current results is not consistent with those of previous studies which indicated minimal impact of inclination angle (Schwarzkopf et al., 2004). The reason for this might be attributed to the particular spray nozzle used in this study. As mentioned earlier, the 2x2 Parker Hannifin spray manifold used for these studies created a stagnation zone in the center of the heated surface, resulting in the accumulation of an unsteady liquid pool in the center of the heater surface for $\theta=0^{\circ}$ on both the flat and straight fin surfaces (Fig. 4.21). As heat fluxes increased towards CHF, the amount of accumulated liquid visibly diminished. For the inclined sprays $\left(\theta=15^{\circ}, 30^{\circ}\right.$ and $\left.45^{\circ}\right)$, pooling was not noticed in any of the heat flux regimes, indicating that the inclined sprays promoted better liquid drainage from the heated surface through elimination of the stagnation zone, and may have been the reason for the increased heat transfer in the flat surface case.

As the inclination angle was increased, the volumetric flux of liquid impacting the surface decreased as a result of overspray. This might be expected to cause a decrease in heat transfer. Volume flux measurements were obtained at each of the inclination angles tested (detailed in sections 3.3.2 and 3.6). The measurements showed that the 


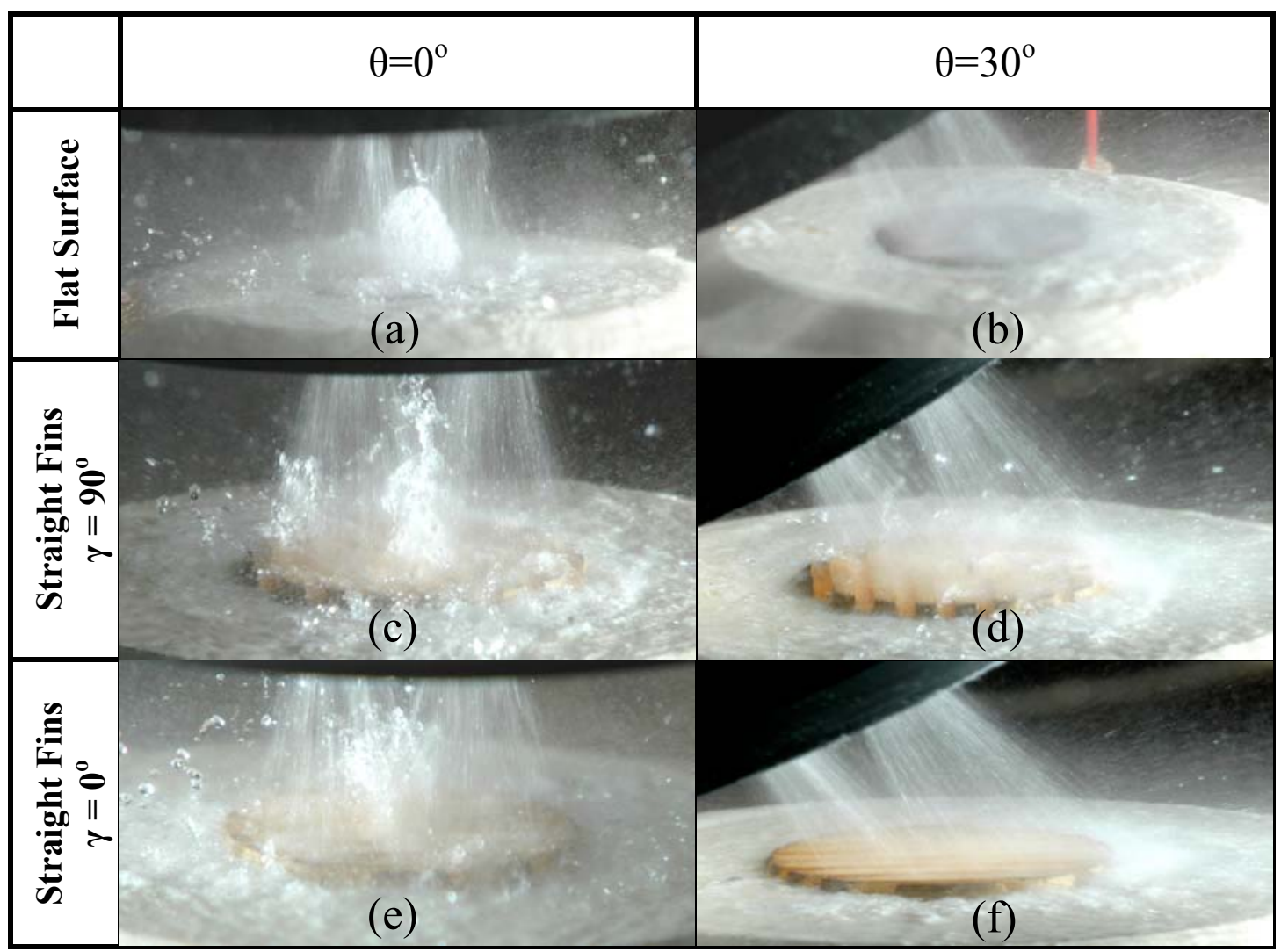

Fig. 4.21 Spray Cone Stagnation Zone Phenomena; (a) $\theta=0^{\circ}$ flat surface, (b) $\theta=30^{\circ}$ flat surface, (c) $\theta=0^{\circ},\left(\gamma=90^{\circ}\right)$ transverse straight fins, (d) $\theta=30^{\circ},\left(\gamma=90^{\circ}\right)$ transverse straight fins, (e) $\theta=0^{\circ},\left(\gamma=0^{\circ}\right)$ axial straight fins, (f) $\theta=30^{\circ},\left(\gamma=0^{\circ}\right)$ axial straight fins

liquid captured at the $\theta=15^{\circ}$ inclination was approximately equal (within $2 \%$ ) to that captured at $\theta=0^{\circ}$. The liquid captured at the $\theta=30^{\circ}$ and $\theta=45^{\circ}$ inclination, however, were reduced by $8 \%$ and $15 \%$, respectively. Since flat surface CHF values for the inclined sprays showed better performance relative to the $\theta=0^{\circ}$ case, and the CHF values for the straight finned surface cases were comparable for all angles, it may be possible that keeping the volumetric flux constant as the inclination angle increased would have provided even higher enhancement. The result of these observations have implications when multi-nozzle arrays are used to cool large surfaces, where an 
inclined spray axis can be used to produce a net momentum flux to sweep any stagnant pooled regions off the surface. 


\section{CHAPTER 5}

\section{HEAT FLUX CORRELATION DEVELOPMENT}

\subsection{Background and Hypothesis}

Spray cooling is considered a highly experimental technology in the scientific community. A firm understanding of the heat transfer mechanisms (and heat flux enhancement) associated with the process is not understood at this time. This lack of understanding of the process has also limited the development of empirical and analytical models with which to accurately predict heat flux and/or CHF across experimental conditions and test platforms. Predictive methodologies for enhanced surface spray cooling are not addressed in this document, but are considered a potential future outgrowth of the current work (see Chapter 6). Before enhanced surface models and correlations can be developed, accurate flat surface models and correlations must be developed. The goal of the present chapter is to develop a flat surface $\mathrm{CHF}$ correlation based on fundamental heat transfer/thermodynamics principles and lessons learned by previous authors about the spray cooling process. The chapter includes a review of the impact of spray characteristics for data collected with the ISR nozzle, the correlation development, results from application of the correlation to the experimental data of various researchers, as well as a comparison to the predictive capability of the CHF correlation previously developed by Estes and Mudawar (1995).

In section 4.1.2 it was shown that the volumetric flow rate has a significant effect upon heat flux. The study by Chen et al. (2002) showed that the volumetric flow rate in uniform sprays (and ultimately the volumetric flux) is comprised of three primary 
spray characteristics. These are the droplet velocity (U), droplet size (as represented by the Sauter Mean Diameter or SMD), and droplet number flux $\left(\dot{N}^{\prime \prime}\right)$. SMD is the diameter of a sphere with the same volume to surface ratio as the entire spray. In the presentation of empirical results, it is standard practice to assume that the spray behaves as if it consists of equal sized drops which have a diameter equal to the SMD (Sadhal et al., 1996). The relationship defining the functional dependence of the volumetric flux and the afore-mentioned spray characteristics is defined in eqn. 5.1 (Chen et al., 2002).

$$
\dot{V} \approx \Pi U A_{\text {surf }}\left(\frac{\pi}{6}\right) d_{32}^{3}
$$

The droplet number flux may be further reduced as shown in eqn. 5.2 where $\Pi$ is the droplet number density.

$$
\dot{N}^{\prime \prime}=\Pi U
$$

Under the assumption that the volumetric flux is a function of SMD, droplet velocity, and droplet number flux, the heat flux data presented in section 4.1.2 may also be considered as highly dependent upon each of these spray characteristics. However, for a thorough assessment of each parameters' influence upon overall heat flux, a review of the flat surface experimental results (i.e. LPS data) as a function of the primary spray characteristics is required. A study aimed at definitively determining the effect of these spray characteristics would ideally vary and analyze each spray parameter individually while maintaining the other two constant. That approach was used in the study by Chen et al. (2002). While such a detailed study was not conducted in this work, some general determinations can be made from the data obtained. For purposes of comparison between the individual cases, the characteristic 
values measured at the spray centerline have been selected as representative of the spray cone phenomena for each case. Table 5.1 is a summary of the volumetric flux, centerline spray characteristics, and experimental convection coefficient at CHF for

Table 5.1 Spray Cooling Parameters at Maximum Heat Flux

\begin{tabular}{|c|c|c|c|c|c|c|}
\hline Case \# & $\begin{array}{c}\text { Height } \\
(\mathrm{mm})\end{array}$ & $\begin{array}{c}\dot{V}^{\prime \prime} \\
\left(\mathrm{m}^{3} / \mathrm{m}^{2} \mathrm{~s}\right)\end{array}$ & $\begin{array}{c}\text { SMD } \\
(\mu \mathrm{m})\end{array}$ & $\begin{array}{c}\text { Mean } \\
\text { Velocity } \\
(\mathrm{m} / \mathrm{s})\end{array}$ & $\begin{array}{c}\dot{N}^{\prime \prime} \\
\left(1 / \mathrm{cm}^{2} \mathrm{~s} \mathrm{x} 10^{6}\right)\end{array}$ & $\begin{array}{c}\mathrm{h}_{\text {conv }} \\
\left(\mathrm{W} / \mathrm{m}^{2} \mathrm{~K}\right)\end{array}$ \\
\hline 1 & 40 & 0.00094 & 48.3 & 2.77 & 1.59 & 2338.7 \\
\hline 2 & 40 & 0.00180 & 48.5 & 4.28 & 3.01 & 4730.5 \\
\hline 3 & 40 & 0.00259 & 51.8 & 6.38 & 3.56 & 7021.2 \\
\hline 4 & 30 & 0.00165 & 46.2 & 3.42 & 3.20 & 2745.0 \\
\hline 5 & 30 & 0.00316 & 46.4 & 4.99 & 6.05 & 5880.8 \\
\hline 6 & 30 & 0.00455 & 49.4 & 7.44 & 7.21 & 7620.6 \\
\hline 7 & 20 & 0.00333 & 41.4 & 4.28 & 8.97 & 3888.9 \\
\hline 8 & 20 & 0.00500 & 41.3 & 6.23 & 13.56 & 6724.1 \\
\hline 9 & 20 & 0.00667 & 46.9 & 8.96 & 12.34 & 8754.6 \\
\hline 10 & 10 & 0.00333 & 41.3 & 5.74 & 9.04 & 6044.9 \\
\hline 11 & 10 & 0.00500 & 39.2 & 8.3 & 15.85 & 8025.5 \\
\hline 12 & 10 & 0.00667 & 50.4 & 11.19 & 9.95 & 9601.0 \\
\hline
\end{tabular}

each of the LPS test cases. CHF as a function of the centerline droplet SMDs for each of the test cases is shown in Fig. 5.1. The centerline SMD values vary between 39.2 and $52 \mu \mathrm{m}$ over the complete range of heat fluxes reported. Since the heat fluxes show a continual increase with decreasing nozzle-to-heater distance, and the SMD values fall within a narrow band of $\pm 7 \mu \mathrm{m}$, it can be concluded that the SMD has little correlation with heat flux for the range of values considered. The droplet number flux was calculated using eqn. 5.1. Fig. 5.2 is a plot of CHF as a function of the droplet number flux for the values shown in Table 5.1. The droplet number flux increases as the nozzle-to-heater distance decreases. Thus the CHF values increase with larger 


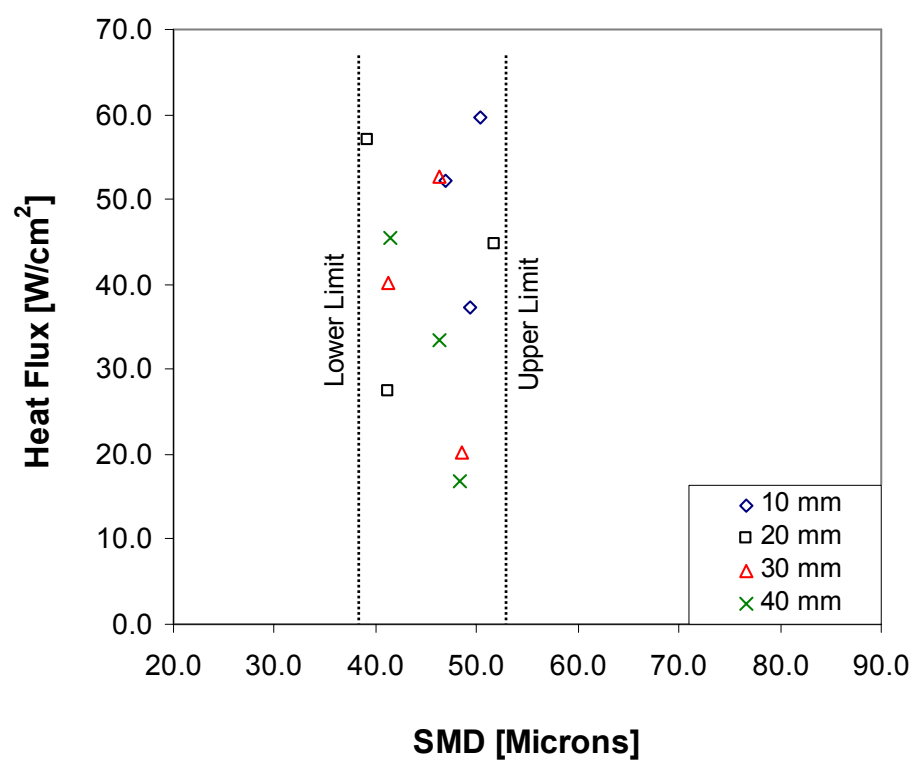

Fig. 5.1 CHF as a function of centerline Droplet SMD

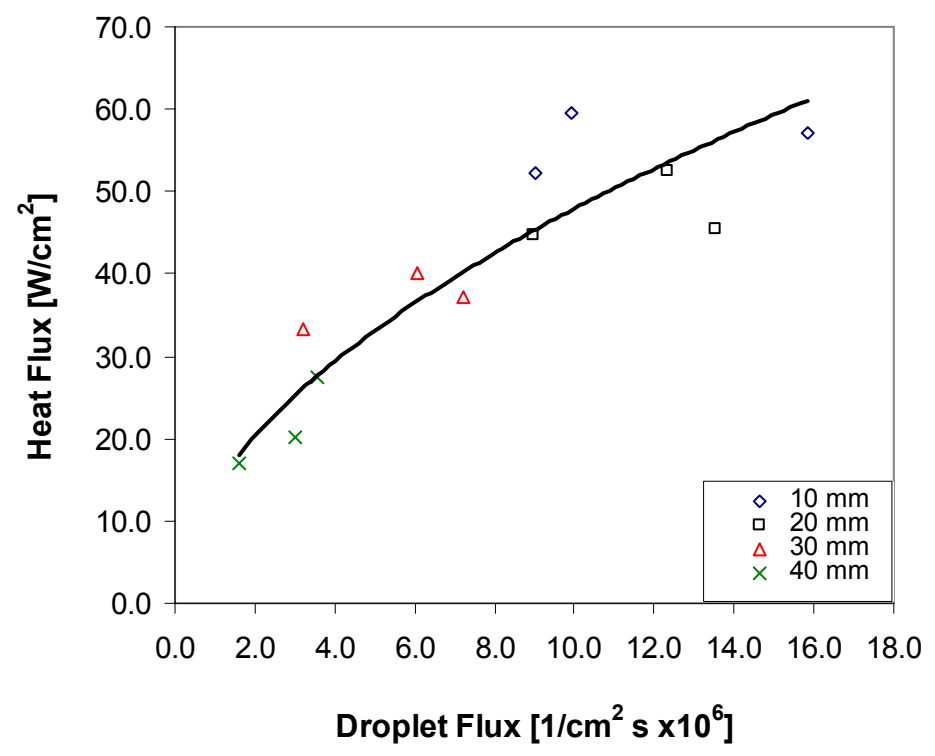

Fig. 5.2 CHF as a function of centerline Droplet Number Flux

droplet number fluxes. While the heat flux values for the individual height cases overlap, they do not directly correlate with the droplet number flux because it includes the droplet velocity. The observed correlation shown may be due to the droplet velocity. The same inconsistencies were observed in the convection coefficient values (plot not 
shown) at CHF relative to the droplet number flux. A better assessment may be made by reviewing heat flux performance as a function of the velocity and droplet number density.

Fig. 5.3 is a plot of CHF as a function of droplet number density. Similar to the droplet number flux (shown in Fig. 5.2), CHF shows some correlation with the droplet number density. However, there is significant scatter in the data at the lower nozzle-to-heater distances $(10 \mathrm{~mm}$ and $20 \mathrm{~mm})$. Fig. 5.4 is a plot of CHF as a function of the centerline droplet velocity for the test cases listed in Table 5.1. The heat flux is shown to vary strongly with the velocity, demonstrating an approximate quadratic dependence. Fig. 5.5 is a plot of the convection coefficient as a function of the droplet centerline velocity. The convection coefficient also appears to have a second order dependence to the centerline droplet velocity.

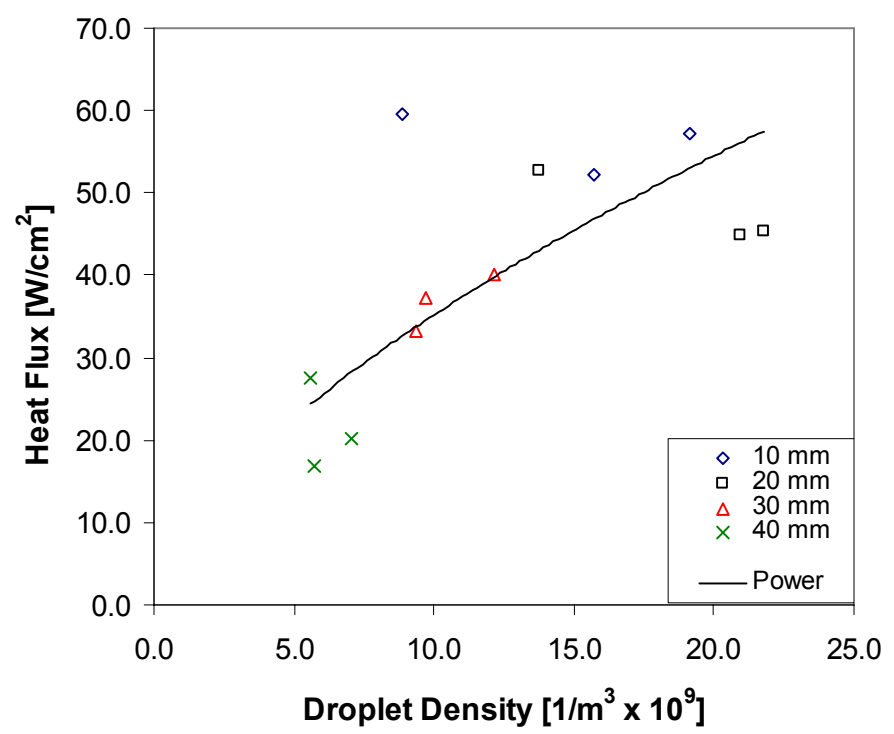

Fig. 5.3 CHF as a function of centerline Droplet Number Density 


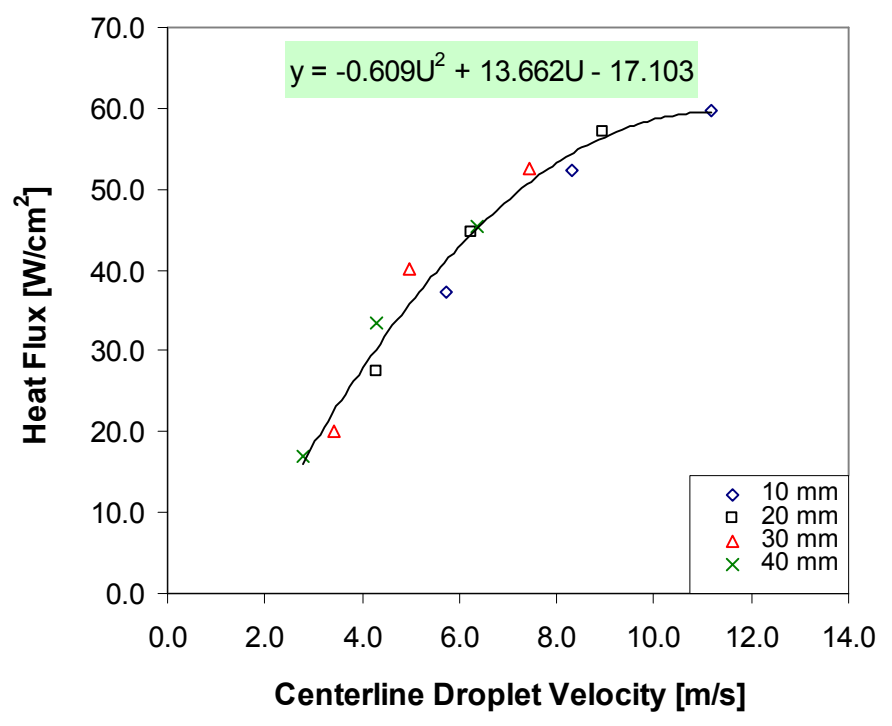

Fig. 5.4 CHF as a function of centerline Droplet Velocity

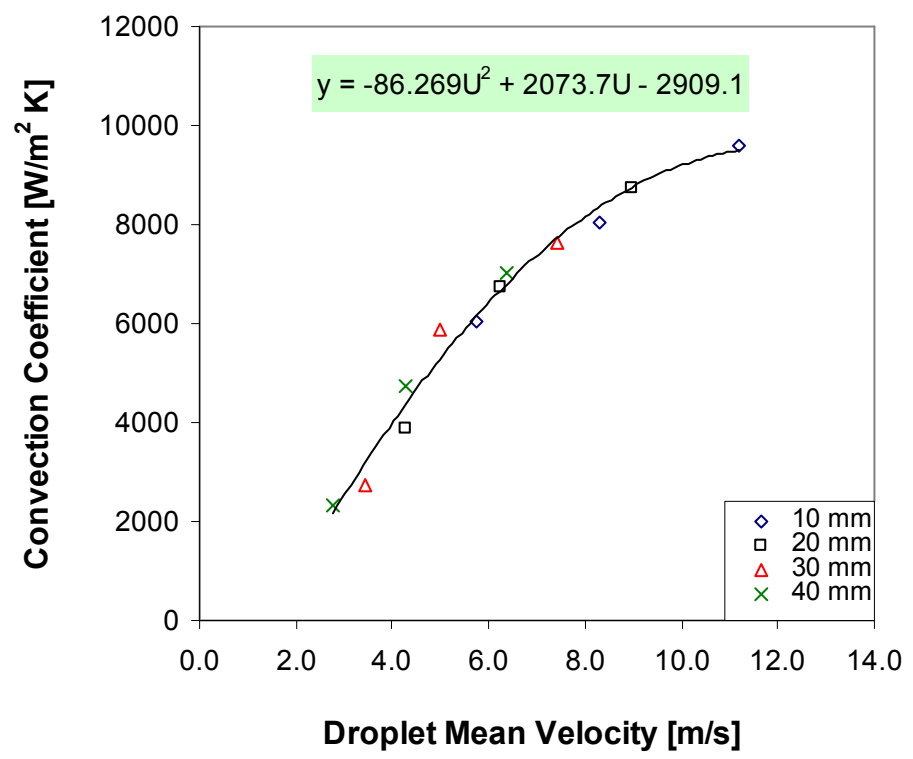

Fig. 5.5 Convection Coefficient as a function of centerline Droplet Velocity

While the spray used for the LPS experiments was not uniform, the centerline axis spray characteristic values selected and plotted in Figs. 5.1 through 5.5 may be considered representative of the spray and lead to the conclusion that the droplet velocity has a dominant effect upon heat flux, whereas the droplet number flux is somewhat 
less significant in this study. SMD has very little effect upon heat flux based on the LPS data set. These conclusions agree with those of the study by Chen et al. (2002) who also concluded that droplet velocity is the most dominant spray characteristic. This conclusion also has extended implications upon spray cooling heat transfer modeling. As stated in section 4.1.2, spray cooling is considered a convective boiling process and should be subject to predictive analysis techniques demonstrated to be applicable for traditional convective processes. One such technique is that of forced convection analysis for the determination of the convection coefficient. Classical forced convective analyses capture the functional dependence on the working fluid velocity through the Reynolds number. Figs. 5.4 and 5.5 clearly show a strong dependence of both the $\mathrm{CHF}$ and the convection coefficient at CHF upon the droplet velocity. Thus, one might conclude that the droplet velocity may be used to predict heat flux via forced convection analysis using a Nusselt number tailored for spray cooling applications.

\subsection{Spray Cooling Heat Transfer Process}

While spray cooling is known to be a high heat flux technology, full understanding of the process and the heat transfer mechanisms resulting in pronounced heat transfer enhancement (relative to other technologies such as boiling and/or flow boiling) have yet to be fully understood. The growth and expansion of any technology is dependent upon the ability of investigators to fully comprehend the phenomena, as well as the development of predictive models which can be used to facilitate reliable system design. 
A review of the literature shows that the techniques available for spray cooling heat flux prediction are very limited. The convection coefficient for single and multiphase (flow boiling) convective processes has been shown to be predicted reasonably well via the Nusselt number $(\mathrm{Nu})$, where $\mathrm{Nu}$ is a function of parameters such as $\operatorname{Re}, \operatorname{Pr}, \Delta \mathrm{T}_{\text {surf, }}$ and $\mathrm{X}_{\mathrm{tt}}($ Carey, 1992). Estes and Mudawar (1995) have shown that $\mathrm{CHF}$ in spray cooling can be predicted within $\pm 30 \%$ using eqn. 5.3 :

$$
\dot{q}_{C H F}^{\prime \prime}=\left(\frac{\pi}{4}\right) 2.3 \rho_{v} h_{f g} \dot{V}^{\prime \prime}\left(\frac{\rho_{l}}{\rho_{v}}\right)^{0.3}\left(\frac{\rho_{l} \dot{V}^{\prime \prime} d_{32}}{\sigma}\right)^{-0.35}\left(1+0.0019 \frac{\rho_{l} c_{p} \Delta T_{s u b}}{\rho_{v} h_{f g}}\right)
$$

which has a functional dependence of $\dot{q}_{C H F}^{\prime \prime}=q^{\prime \prime}\left(\dot{V}^{\prime \prime}, W e, S u, \rho_{l}, \rho_{v}, h_{f g}\right)$. Internal and external multiphase correlations often incorporate the flow rate and density ratio $\left(\rho_{1} / \rho_{\mathrm{v}}\right)$ for the working fluid (Carey, 1992). While Su is not typically associated with spray cooling heat transfer, application to the process is practical. CHF is the maximum equilibrium point where nucleation is sustained at the heat exchange surface prior to the transition to Leidenfrost phenomena. The spray is produced by a pressure differential between the liquid supply line and the spray chamber. By virtue of the fact that the spray is a pressure driven flow, instabilities present may be considered dynamic instabilities (i.e. flow instabilities). In the context of a multiphase system, these dynamic instabilities present themselves in the form of bubble growth and collapse at the heater surface (and the change in density in the bulk fluid associated with this phenomena) as well as film disturbance at the liquid/vapor interface due to droplet impact. The change in density in the bulk fluid associated with these effects creates density waves through the medium. Changes in the system 
will correspond to changes in the density waves and the flow instability. Previous researchers have shown that stable oscillations in internal multiphase flow systems are highly dependent upon the subcooling number, Su (Saha et al., 1976; Yadigaroglu et al., 1976).

Predictive correlations such as that of eqn. 5.3 raise questions regarding alternate approaches to spray cooling heat flux and/or convective coefficient prediction techniques. One such question is whether or not a forced convection analysis can be applied to spray cooling heat flux, and if so, what is the process for properly determining the functional relationship and the independent variables. The process of investigating this question must begin by defining the problem in terms of the currently understood physical processes via conservation relations. One well studied problem that is highly analogous to that of spray cooling heat transfer phenomena (specifically heat transfer in the liquid film) is external flow over a heated flat plate. The constructs of analysis techniques for the heated flat plate problem applied to spray cooling heat transfer are developed henceforth.

\subsection{Energy Based Correlation}

\subsubsection{Theory}

The multiphase energy conservation equation is often used as a framework to determine the maximum amount of energy available for heat transfer in a multiphase process:

$$
\dot{q}=\dot{m}\left(c_{p} \Delta T_{s u b}+h_{f g}\right)
$$


This relation assumes that all liquid involved in the process undergoes complete phase change. If a non-dimensional convection coefficient model were to be developed (similar to the traditional Nu relations) from the energy equation, it would have to be re-cast in the form of $\mathrm{Nu}$. Given the strong dependence upon $\mathrm{Re}$ and $\mathrm{Pr}$ displayed in traditional correlations, the functional form of the new spray cooling correlation may also include Re and Pr. Other non-dimensional parameters affecting the process would also have to be determined. To start the process of the energy based correlation development, one must determine the functional form for the correlation. This begins with the multiphase energy equation in flux form:

$$
\dot{q}^{\prime \prime}=\rho_{l} \dot{V}^{\prime \prime}\left(c_{p} \Delta T_{s u b}+h_{f g}\right)
$$

$\mathrm{Nu}$ can be written as

$$
N u=\frac{h_{\text {conv }} d_{h}}{k}=\frac{\dot{q}^{\prime \prime}}{\left(T_{\text {surf }}-T_{l}\right)}\left[\frac{d_{h}}{k}\right]
$$

The characteristic length $\left(d_{h}\right)$ is defined as the ratio of surface area to perimeter length (i.e. hydraulic radius) multiplied by a factor of two:

$$
d_{h}=2 \frac{\text { Surface Area }}{\text { Perimeter Length }}
$$

This is analogous to jet impingement modeling, which typically uses a characteristic length (for the Re determination) equal to half the diameter of the heat exchange surface that experiences the pressure distribution from the liquid ( $\mathrm{Tu}$ and Wood, 1996; Phares et al., 2000). Substituting 5.5 into 5.6 yields

$$
N u=\frac{\rho_{l} \dot{V}^{\prime \prime}}{\left(T_{\text {surf }}-T_{l}\right)} h_{f g}[J a+1]\left[\frac{d_{h}}{k}\right]
$$


Multiplying the right hand side numerator and denominator by $\frac{1}{\mu c_{p}}$ yields

$$
N u=\left(\frac{\rho_{l} \dot{V}^{\prime \prime} d_{h}}{\mu}\right)\left(\frac{\mu c_{p}}{k}\right)\left(\frac{h_{f g}}{c_{p}\left(T_{\text {surf }}-T_{l}\right)}\right)(J a+1)
$$

or

$$
N u=\operatorname{Re}_{s p} \operatorname{Pr}\left(\frac{1}{J a_{\text {aug }}}\right)(J a+1)
$$

where $\mathrm{Re}_{\mathrm{sp}}$ is the spray Re and $\mathrm{Ja}_{\mathrm{aug}}$ is the augmented Jakob number defined as:

$$
J a_{\text {aug }} \equiv \frac{c_{p}\left(T_{\text {surf }}-T_{l}\right)}{h_{f g}}
$$

This parameter is considered augmented because the temperature difference includes $\mathrm{T}_{\text {surf }}$ instead of $\mathrm{T}_{\text {sat }}$, which extends the temperature value beyond the sensible heating range. Physically, it is the ratio of the summation of the liquid superheat and sensible heating at the heater surface to the heat of evaporation and is a variant of the superheat ratio (Sr) as defined by Tong and Tang (1997). Chen et al. (2002) showed that heat transfer is not dependent upon the nominal volumetric flux, but on the spray characteristics embodied within the volumetric flux. These spray characteristics include droplet velocity $(\mathrm{U}), \operatorname{SMD}\left(\mathrm{d}_{32}\right)$, and droplet number density $(\Pi)$. Chen et al.'s (2002) work showed that the volumetric flow rate could be approximated from spray characteristics. This was shown in eqn. 5.1. Rewriting eqn. 5.1 in flux form (i.e. dividing by $\mathrm{A}_{\text {surf }}$ ) and substituting for the volume flux in eqn. 5.9 gives:

$$
N u=\left(\frac{\rho_{l} U d_{h}}{\mu}\right) \operatorname{Pr}\left(\frac{1}{J a_{\text {aug }}}\right)(J a+1)\left(\Pi \frac{\pi}{6} d_{32}^{3}\right)
$$




$$
N u=\operatorname{Re} \operatorname{Pr}\left(\frac{1}{J a_{\text {aug }}}\right)(J a+1)(\psi)
$$

where Re has the same form as in traditional developments and the volume fraction is defined as:

$$
\psi=\left(\Pi \frac{\pi}{6} d_{32}^{3}\right)
$$

The volume fraction represents the percent fraction by volume of liquid present in the spray cone. In the current $\mathrm{Nu}$ relation (eqn. 5.13), the velocity for the bulk fluid is assumed as being equal to that of the droplet velocity. The multiphase effects are included in the energy based correlation via the Jakob terms. The final Nu relation is assumed to have the form $\mathrm{Nu}=\mathrm{Nu}\left(\mathrm{Re}, \mathrm{Pr}, \mathrm{Ja}, \mathrm{Ja}_{\text {aug }}, \psi\right)$.

As mentioned previously, CHF has been shown to be highly dependent upon $\mathrm{Su}$ in internal flow boiling systems. Su is defined as:

$$
S u=\left(\frac{\rho_{l}}{\rho_{v}}\right)\left(\frac{c_{p} \Delta T}{h_{f g}}\right)
$$

and was used as a non-dimensional parameter in the correlation developed by Estes and Mudawar (1995). Furthermore, studies have also shown that for a given fluid there is a range for which flow instabilities are feasible while still maintaining equilibrium (this is reviewed in the text by Carey (1992), section 13.1). The stability plane is typically treated as a function of Su and/or the subcooling temperature and the heat flux. One may hypothesize that since CHF is a stability point (i.e. with unstable behavior leading to dry-out), a more appropriate form of the energy correlation may include some variant of $\mathrm{Su}$ in the denominator instead of Ja which takes into account the ratio of the sensible to latent heat. The mass required to transfer 
a given amount of heat will vary with the physical properties of the working fluid. Su assesses the sensible to latent heat ratio on the basis of energy per unit volume as opposed to energy per unit mass. Assuming that heat exchange occurs over a similar fluid volume adjacent to the heat exchange surface, Su may be more applicable. Applying this to the denominator, the energy correlation now takes the form of eqn. 5.16 .

$$
N u=\operatorname{Re} \cdot \operatorname{Pr}\left(\frac{J a+1}{S u_{\text {aug }}}\right)(\psi)
$$

Eqn. 5.16 is not expected to adequately model the spray cooling process at CHF because it does not embody inefficiencies in the spray cooling heat transfer process. One way to account for these inefficiencies, as well as the conclusion by Chen et al. (2002) that spray characteristics other than velocity have a marginal effect upon heat flux, would be to consider values other than unity for the powers of each of the nondimensional terms. A more appropriate form may then be given by:

$$
N u=\operatorname{Re}^{a} \operatorname{Pr}^{b}\left(\frac{Z J a+1}{Y\left(\frac{\rho_{l}}{\rho_{v}}\right)^{K} J a_{\text {aug }}}\right) \psi^{d}
$$

where the constants and powers (a, b, d, Z, Y, and K) must be determined such that the correlation successfully predicts the experimental results of several researchers using different test platforms and multiple fluids. Once the final desired form of $\dot{q}_{C H F}^{\prime \prime}$ is solved for using Newton's Law of Cooling, the constant $\mathrm{Y}$ will be the main scaling constant for the $\mathrm{CHF}$ correlation. The $\mathrm{Ja}$ and $\mathrm{Su}_{\text {aug }}$ terms are primarily comprised of thermophysical properties for the fluid $\left(\rho_{\mathrm{l}}, \rho_{\mathrm{v}}, \mathrm{c}_{\mathrm{p}}, \Delta \mathrm{h}_{\mathrm{fg}}\right)$. A physical interpretation of 
power law scaling applied to these terms has not been attained at this time. Nonetheless, it is expected that some scaling is required for these terms. The scaling has been applied via constant coefficients and power application to the density ratio for $\mathrm{Su}_{\text {aug }}$. The $\mathrm{Ja}_{\text {aug }}$ term included in the $\mathrm{Su}_{\text {aug }}$ term has not been modified. In order to perform the comparison task, several studies were identified for comparison of experimental results to correlation predictions. Table 5.2 is a comprehensive listing of

Table 5.2 Studies Used For Energy Based Nu Correlation Effort

\begin{tabular}{|c|c|c|c|}
\hline $\begin{array}{c}\text { Research } \\
\text { Group/Publication }\end{array}$ & $\begin{array}{l}\text { Working } \\
\text { Fluid }\end{array}$ & $\begin{array}{l}\text { Heater } \\
\text { Surface } \\
\text { Area }\end{array}$ & $\begin{array}{l}\text { Experimental } \\
\text { Conditions }\end{array}$ \\
\hline $\begin{array}{c}{ }^{*} \text { Silk LPS Study } \\
\text { (detailed in Chapter 4) }\end{array}$ & PF-5060 & $1.0 \mathrm{~cm}^{2}$ & Degassed, $\mathrm{T}_{\mathrm{sat}}=56.0^{\circ} \mathrm{C}$ \\
\hline${ }^{*}$ Chen et al. (2002) & Water & $1.0 \mathrm{~cm}^{2}$ & Gassy, $\mathrm{T}_{\mathrm{sat}}=80^{\circ} \mathrm{C}$ \\
\hline "Rini et al. (2002) & FC-72 & $1.0 \mathrm{~cm}^{2}$ & Degassed, $\mathrm{T}_{\mathrm{sat}}=56.0^{\circ} \mathrm{C}$ \\
\hline${ }^{*}$ Horacek et al. (2005) & PF-5060 & $49.0 \mathrm{~mm}^{2}$ & $\begin{array}{c}\text { Variable Gas Content } \\
\text { Variable } \mathrm{T}_{\text {sat }} \\
\end{array}$ \\
\hline \multirow{3}{*}{$\begin{array}{l}\ddagger \S^{*} \text { Lin and Ponnappan } \\
(2003)\end{array}$} & FC-72 & $2.0 \mathrm{~cm}^{2}$ & $\begin{array}{c}\text { Degassed, } \mathrm{T}_{\mathrm{sat}}=36.0^{\circ} \mathrm{C}, \\
54.0^{\circ} \mathrm{C}\end{array}$ \\
\hline & FC-87 & $2.0 \mathrm{~cm}^{2}$ & Degassed, $\mathrm{T}_{\mathrm{sat}}=42.5^{\circ} \mathrm{C}$ \\
\hline & Methanol & $2.0 \mathrm{~cm}^{2}$ & Degassed, $\mathrm{T}_{\mathrm{sat}}=52.0^{\circ} \mathrm{C}$ \\
\hline $\begin{array}{l}\text { *Puterbaugh et al. } \\
(2007)\end{array}$ & FC-72 & $1.4 \mathrm{~cm}^{2}$ & $\begin{array}{c}\text { Variable Gas Content } \\
\text { Variable } \mathrm{T}_{\mathrm{sat}} \\
\end{array}$ \\
\hline $\begin{array}{l}\$ 8^{*} \text { Silk et al. (2005) } \\
\text { Goddard Extended Flat } \\
\text { Surface Studies }\end{array}$ & PF-5060 & $2.0 \mathrm{~cm}^{2}$ & $\begin{array}{c}\text { Partially Degassed, } \\
\mathrm{T}_{\mathrm{sat}}=31.0^{\circ} \mathrm{C} \\
\text { Gassy, } \mathrm{T}_{\mathrm{sat}}=56.0^{\circ} \mathrm{C}\end{array}$ \\
\hline
\end{tabular}

the published and non-published studies used for comparison of the correlation results. Included in Table 5.2 is the author (or research group), working fluid, heat exchange surface area, and saturation conditions. There were a total of 85 test cases modeled in this development. The unknown constants in eqn. 5.17 were determined using a Fortran code written by the author. 


\subsubsection{Fortran Code Energy Based Correlation Results and Discussion}

The Fortran code consists of a series of nested loops (each loop being dedicated to an unknown value) which set the unknown constants and exponents (with exception of the exponent on the Pr) shown in eqn. 5.17 during each iteration (see Appendix D for a listing of the code). After the unknown values were set, the corresponding $\mathrm{Nu}$ was calculated for each comparison case. The exponent on $\operatorname{Pr}$ was set to 0.33 (similar to that used in mixing length theory). In addition to calculation of $\mathrm{Nu}$, the relative error between the predicted and experimental $\mathrm{Nu}$ was calculated along with the average mean error for the comprehensive test cases. Cases with the smallest individual error and average mean error for the entire comparison group were recorded for later comparison and review. Initial values (as well as acceptable ranges for the current study) for the constants and exponents in question were predetermined based on initial trial and error cases previously modeled. The combination of constants that produced the smallest average mean error comprehensively for the study cases used was then selected for use in the calculation of CHF. The final form for the fit of the Nusselt number was:

$$
N u=\operatorname{Re}^{0.55} \operatorname{Pr}^{0.33}\left(\frac{0.8 J a+1}{0.19\left(\frac{\rho_{l}}{\rho_{v}}\right)^{0.4} J a_{\text {aug }}}\right) \psi^{0.09}
$$

Given that $d_{h}$ and the surface to liquid temperature difference is known in each test case, CHF was calculated using eqn. 5.18 and Newton's Law of Cooling. Figs. 5.6 and 5.7 show predicted vs. measured $\mathrm{CHF}$ for the perfluorocarbon and 
water/methanol cases, respectively. Fig. 5.6 shows that the majority of the perfluorocarbon cases (with exception of the Rini et al.(2002) cases as well as a few cases from the LPS study) are predicted within an error band of $\pm 30 \%$. Fig. 5.7 also shows that the correlation predicts water and methanol data within the $\pm 30 \%$ error band (only four data points fall outside the upper error limit). The average mean error for this correlation was $\pm 17.6 \%$. There are a total of ten data points outside of the highlighted error band of $\pm 30 \%$, giving the correlation a prediction accuracy of $88 \%$ for the test group that it was correlated against. Expansion of the error limits to $\pm 35 \%$ would capture four of the predictions currently outside of the $\pm 30 \%$ error band making $92 \%$ of the data predictable to within $\pm 35 \%$.

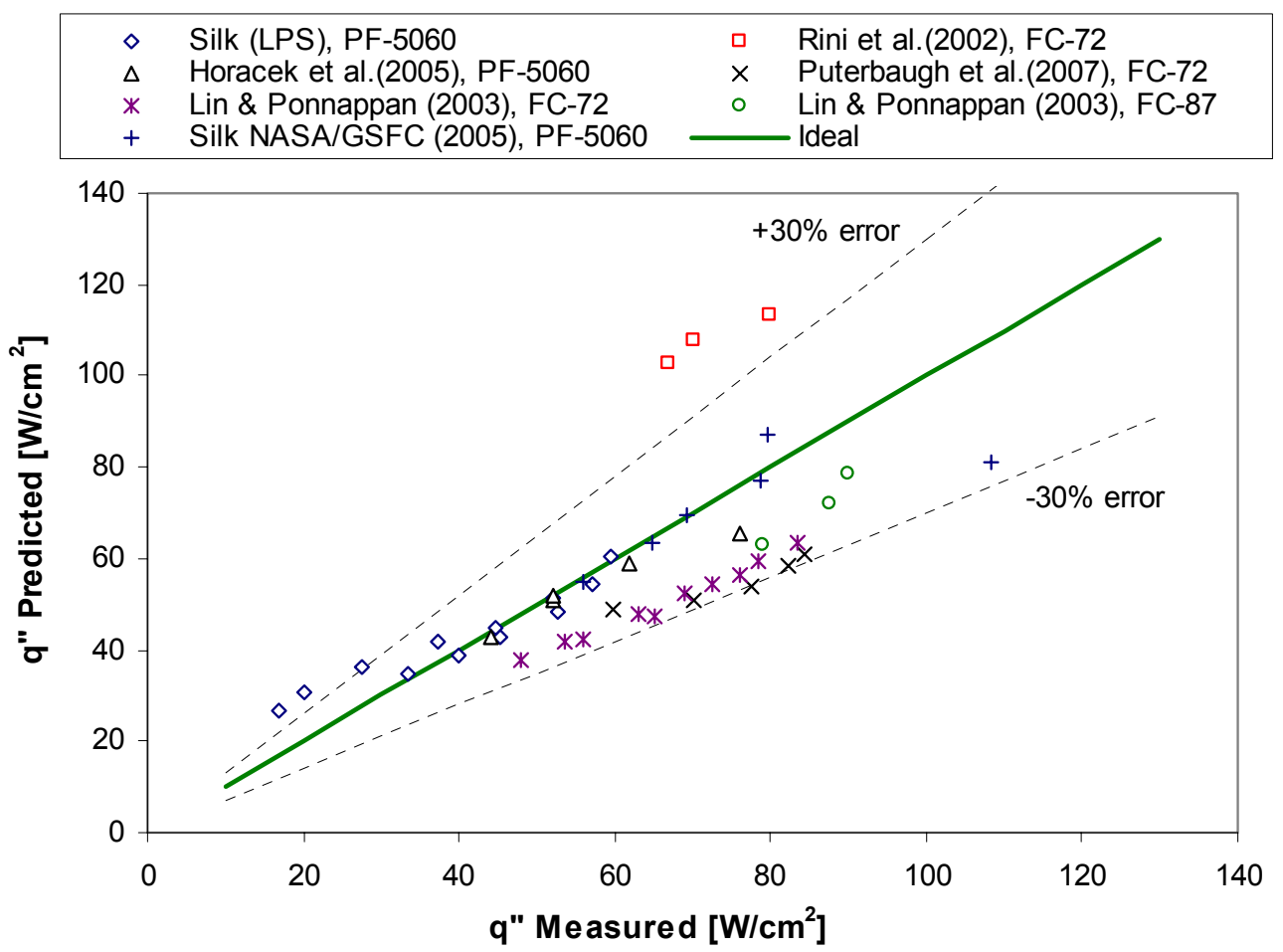

Fig. 5.6 Measured vs. Predicted CHF for Perfluorocarbon Fluids Using Fortran code for determination of Constants and Powers 


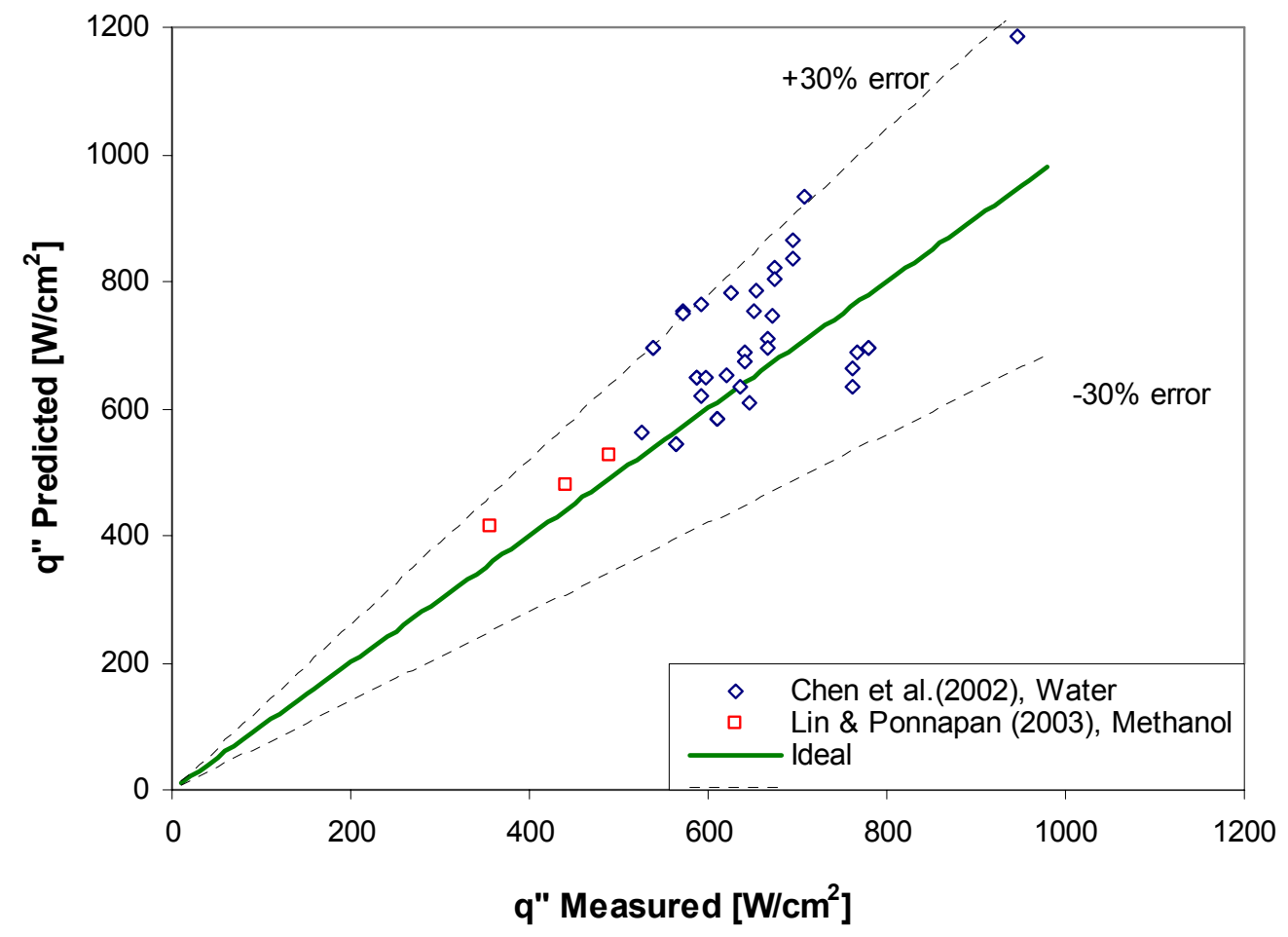

Fig. 5.7 Measured vs. Predicted CHF for Water and Methanol Using Fortran code for determination of Constants and Powers

Beyond performance metrics for the predictive capabilities of the finalized correlation, a review of the final form of the $\mathrm{Nu}$ relation is required for assessment of the validity of the correlation. The final form of the correlation should be consistent with the assumptions made during previous stages of the correlation development. Previous modeling attempts by the author focused on application of power law mixing length models to the spray cooling studies investigated. This approach led to a marginal success due to over-emphasis on the velocity in the Re (power of 0.8 ) and no accounting for volume fraction or phase change. The exponent attributed to the Reynolds number in the current correlation (0.55) is significantly lower than the exponent associated with the one determined from mixing length theory. Since the current correlation includes terms for both volume fraction and phase change, it was 
expected that the Reynolds exponent would scale down. As previously mentioned, the power used for the Prandtl number was fixed at 0.33. This value builds upon previously accepted theory. Given the current understanding and data available on spray cooling heat transfer, an argument for or against the use of this particular value of the exponent cannot be properly validated nor disputed based on the physical process. Execution of the Fortran code with a fixed power for Pr was observed to be very time consuming. Variation of the exponent was not performed due to time constraints. It is unknown at this time whether or not usage of alternate exponents for Pr can create more accurate predictions (i.e. a data set with a lower comprehensive average mean error) using this correlation.

The liquid volume fraction $(\psi)$ is a number whose value is between 0 and 1 . For the range of liquid volume fractions in the comparison data set $(0.0003-0.034)$, the resultant value for $\psi^{\mathrm{d}}$ approaches unity as $\mathrm{d}$ approaches 0 . Plots for the bounding

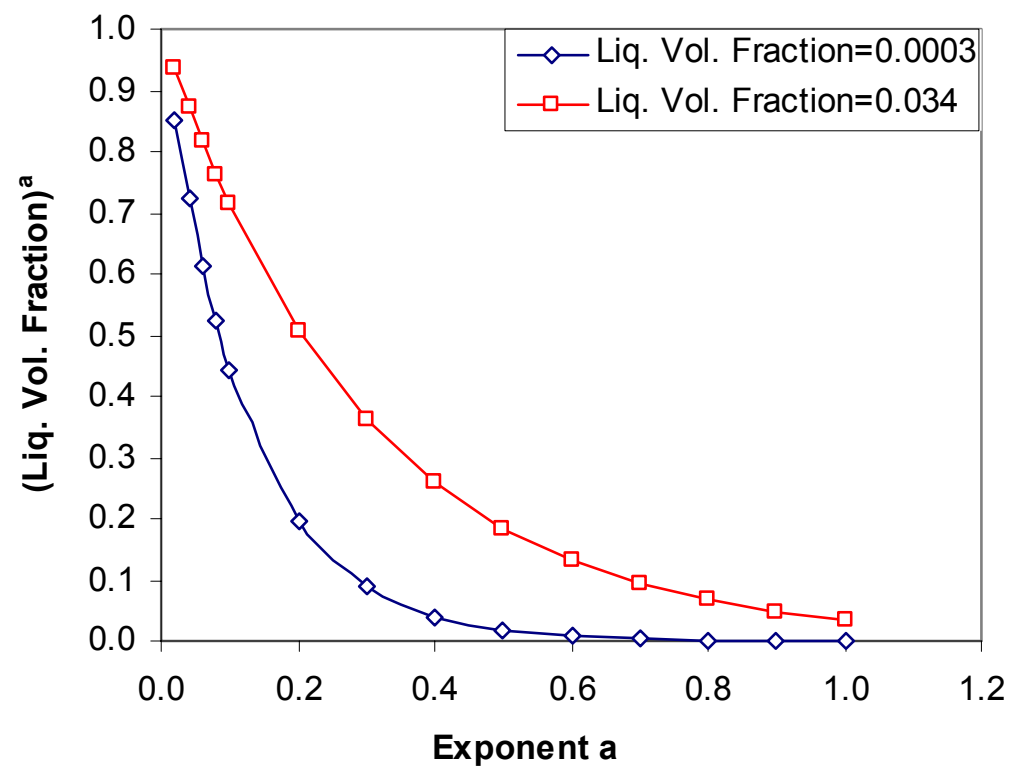

Fig. 5.8. Liquid Volume Fraction term value as a function of exponent a 
liquid volume fractions for the experimental cases are shown in Fig. 5.8. Powers applied that yield values significantly less than unity increase the impact of the $\psi^{\mathrm{d}}$ term on the final $\mathrm{Nu}$. The closer the final $\psi^{\mathrm{d}}$ term is to 1 , the less impact the liquid volume fraction has on $\mathrm{Nu}$, thus making the energy based correlation more aligned with the conclusions of Chen et al. (2002) where $\Pi$ and $d_{32}$ had less of an impact upon heat flux than the droplet velocity. In light of this fact, one would expect the power on $\psi$ to produce a final value close to unity. The liquid volume fraction was determined as having an exponent of 0.09 . While this does not reduce the final liquid volume fraction terms to unity for each of the experimental cases, it does noticeably decrease the effect of this term upon the final $\mathrm{Nu}$. The limited effect of this term is in agreement with the conclusions of Chen et al. (2002). The final form for the heat flux at CHF is shown in eqn. 5.19.

$$
\dot{q}_{C H F}^{\prime \prime}=\operatorname{Re}^{0.55} \operatorname{Pr}^{0.33}\left[\frac{0.8 J a+1}{0.19\left(\frac{\rho_{l}}{\rho_{v}}\right)^{0.4}}\right] \psi^{0.09}\left(\frac{k_{l}}{d_{h}}\right)\left(\frac{h_{f g}}{c_{p}}\right)
$$

\subsection{Estes and Mudawar Correlation}

The energy based correlation development put forth in the current study cannot conclusively be considered an advancement in spray cooling CHF modeling without comparison to previously developed correlations. As mentioned previously, prior heat flux models and correlations have been very limited in quantity. Two heat transfer modeling efforts that standout in the current literature are the works of Ghodbane and Holman (1991) and Estes and Mudawar (1995). The heat transfer correlation developed by Ghodbane and Holman (1991) and later improved upon by Holman and 
Kendall (1993) was based upon and limited to Freon 113 as the working fluid. Due to this fact, their correlations were considered very limited with respect to fluid applicability and not appropriate for use with the comparison studies listed in Table 5.2. However, the CHF correlation developed by Estes and Mudawar (1995) was based on experimental studies using FC-87, FC-72 and water. Each of these fluids are listed in the data set shown in Table 5.2. Furthermore, the Estes and Mudawar correlation (shown in eqn. 5.3) has been validated by several researchers for spray cooling CHF prediction. The Estes and Mudawar (1995) correlation has been selected for performance comparison to the Energy based correlation developed in the present work.

Figs. 5.9 and 5.10 show predicted vs. measured CHF for the perfluorcarbon and water/methanol cases respectively, using the Estes and Mudawar correlation. Fig. 5.9 shows that their correlation over-predicts many of the perfluorocarbon cases. While the Horacek et al. (2005) data set falls within the $\pm 30 \%$ error bands, the Silk (LPS), Puterbaugh et al. (2007) and the Lin and Ponnappan (2003) FC-87 studies are completely outside the error limits. The Silk NASA/GSFC (2005) and Lin and Ponnappan (2003) FC-72 data sets are predominantly outside the error limits as well. While gross inaccuracies in predictions are not occurring for the Rini et al. (2002) data, these predicts are also outside the error limits. Fig. 5.10 shows that the Estes and Mudawar correlation applied to water and methanol predominantly predicts within the $\pm 30 \%$ error band for the water studies (only four data points fall outside the lower error limit). Predictions for the Lin and Ponnappan (2003) methanol study are 


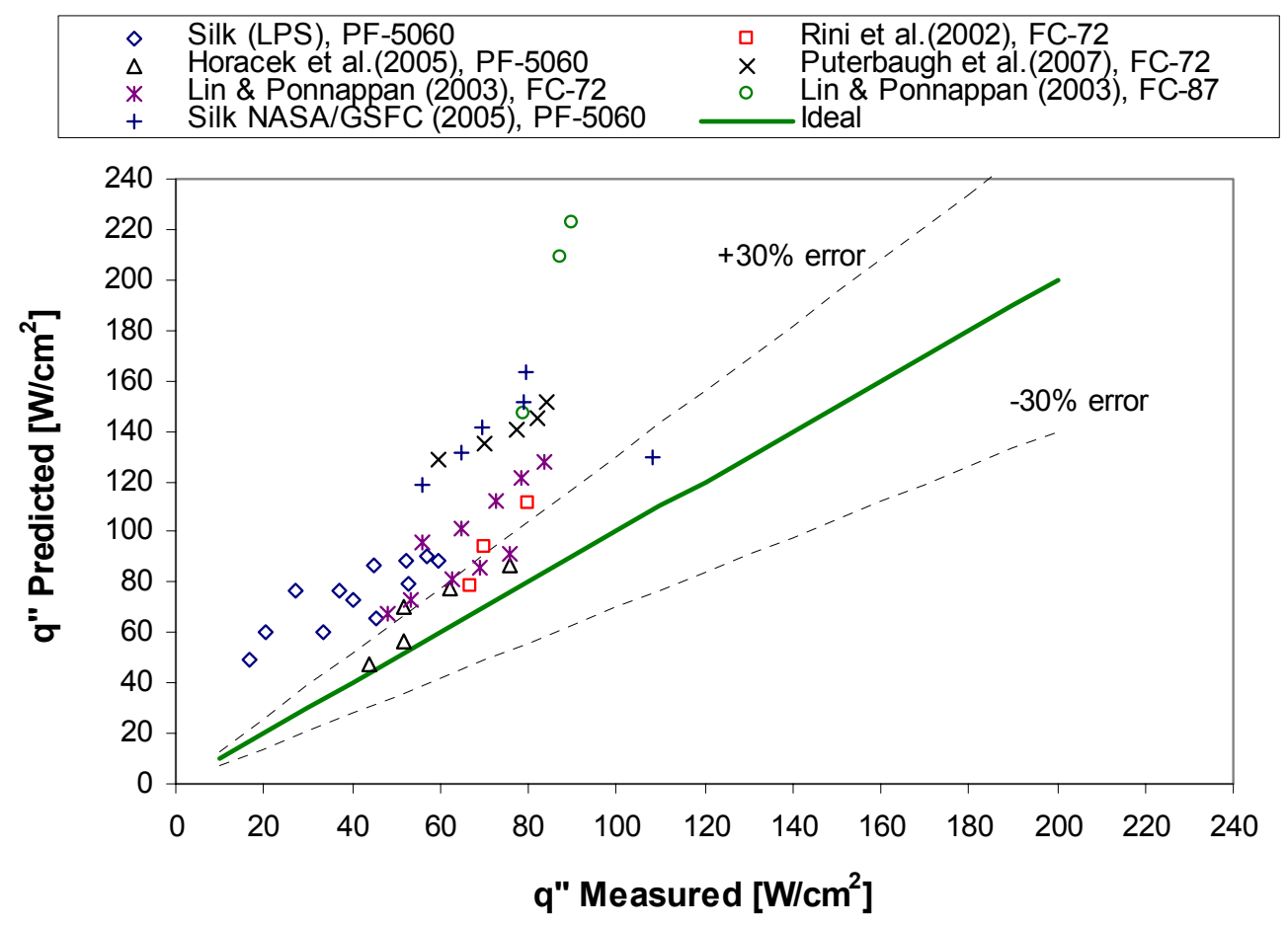

Fig. 5.9 Measured vs. Predicted CHF for Perfluorocarbon Fluids Using Estes and Mudawar (1995) CHF correlation

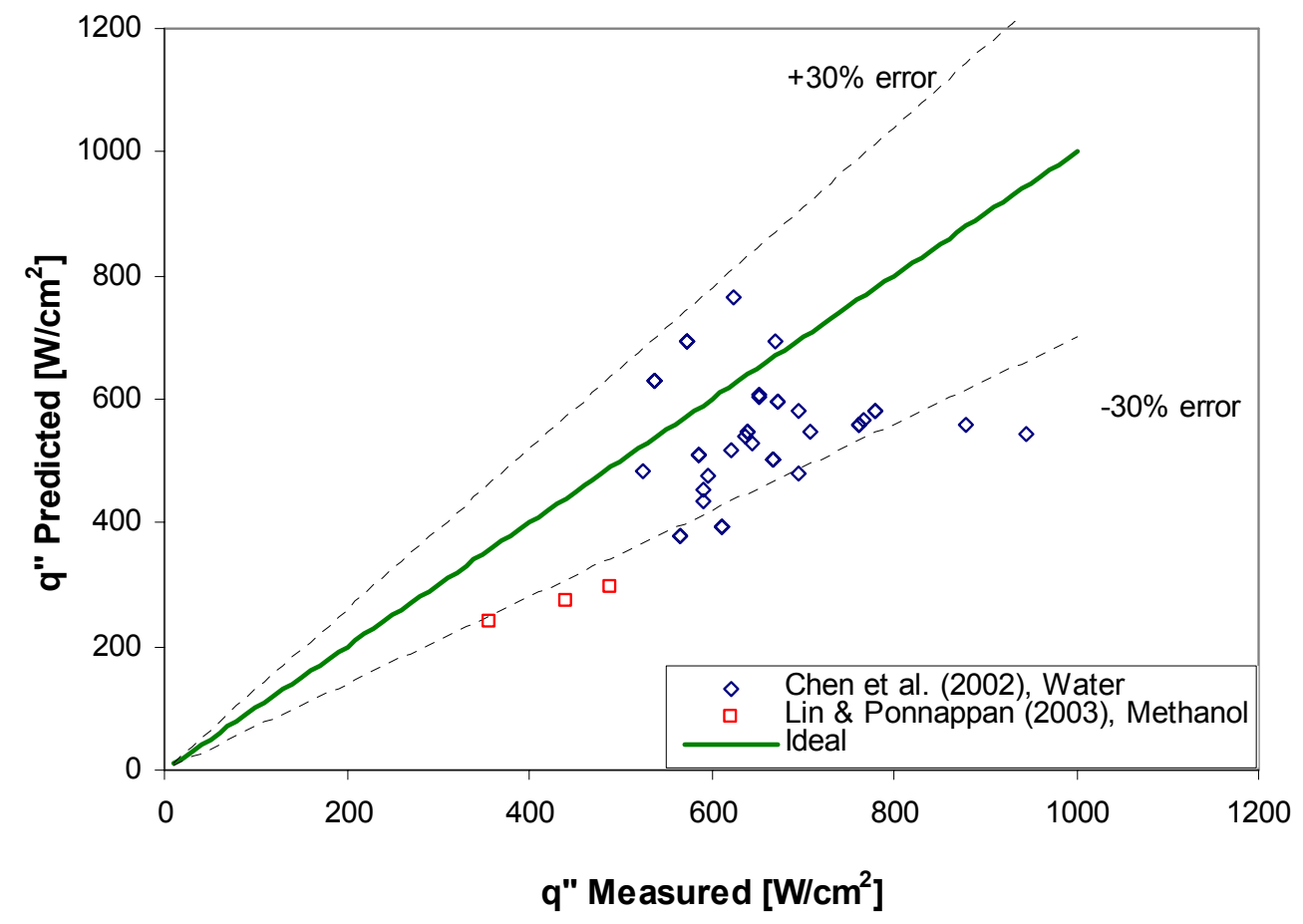

Fig. 5.10 Measured vs. Predicted CHF for Water and Methanol Using Estes and Mudawar (1995) CHF correlation 
predominantly outside the error bounds. However, the data set only includes three comparison cases and the error shown is not gross.

The average mean error for this correlation was $49 \%$ for the entire data set. There were 44 predictions outside of the highlighted error band of $\pm 30 \%$. However, only five predictions were outside the error band in the water/methanol comparison case. This implies that the Estes and Mudawar correlation works best for studies including methanol and/or water. The correlation has a prediction accuracy of $52 \%$ for the data set that it was compared against. At this time, it is not understood why the performance of the Estes and Mudawar correlation had marginal success with the perfluorocarbon studies listed in Table 5.2. The energy based correlation consisted of two additional parameters relative to the total number of parameters included in the Estes and Mudawar correlation. This may have provided an improvement in overall correlation performance. Nonetheless, the results presented in section 5.3 clearly indicate that the energy correlation developed here provides better agreement with the experimental data than the Estes and Mudawar correlation.

\subsection{Energy Based Correlation Scope and Application}

The Energy based correlation developed has shown fair success in two manners. The first is the ability to predict $\mathrm{Nu}$ as a function of Re tailored for spray cooling applications. The second is the accuracy of the heat flux predictions. Both of these items should be reviewed for better understanding of the correlation.

The success in determination of $\dot{q}_{C H F}^{\prime \prime}$ via traditional forced convection analysis (which includes a representation of Re) is based on the type of spray used and the 
selection of the characteristic dimension used for determination of Re. From a fluid dynamics perspective, a dense spray creates a continuously replenished liquid film on the heat exchange surface. The cases used for correlation in this effort had spray liquid volume fractions ranging $0.034 \%$ to $3.4 \%$. The combination of the droplets impinging the film at the liquid/vapor interface and the bulk fluid motion on the heater surface make the liquid film a turbulent flow. At CHF the heater surface is experiencing heat exchange via a turbulent liquid flow with some nucleate boiling. Given sufficient liquid replenishment of the heater surface, this is analogous to the general problem of external flow over a heated flat plate. Forced convection analyses applied to the heated flat plate problem typically use a combination of Re and $\operatorname{Pr}$ to determine $\mathrm{Nu}$ value. The Reynolds number is usually defined using a characteristic length pertinent to the heat exchange surface and the area that the working fluid is in contact with on the heat exchange surface. For internal flows, this would be the hydraulic diameter, whereas for external flows it would be the heat exchange length scale. For the current study, that length scale was defined as $d_{h}$. Prior definitions of Re and We have used either SMD or the nozzle orifice diameter (Estes and Mudawar, 1995; Mudawar and Estes, 1996; Ghodbane and Holman, 1991), in the determination of these non-dimensional parameters. Use of the SMD or nozzle orifice diameter for these parameters removes the heat exchange surface dimensions from the overall problem, and hence neglects the important contribution that liquid convection on the surface of the heater appears to play in this process. When using this approach, the definition of the ratios for the inertia to viscous forces and inertia to surface tension forces is limited to the spray and/or its development during droplet breakup. 
Furthermore, the use of a dense spray significantly diminishes the effect of orifice conditions on the liquid deposition process at the heat exchange surface. The majority of the cases correlated against had dense sprays. Use of a characteristic length defined relative to the heater surface $\left(d_{h}\right)$ in Re incorporates the heat exchange surface into the force ratio, and results in a definition of $\mathrm{Nu}$ that is more aligned with traditional forced convection analyses that use the Nu. Furthermore, since heater surface liquid management is considered highly important in small scale surface area heat exchange, as well as future projected large scale surface area applications, emphasis on the heater surface through $\left(\mathrm{d}_{\mathrm{h}}\right)$ is more appropriate.

The success in accurately predicting CHF also is a function of the experimental conditions that make the correlation appropriate for application. In the early stages of the development, it was assumed that the surface heat transfer phenomena could be accurately modeled as a continuous liquid flow across the heater surface. However, this assumption is only valid for spray cooling scenarios in which the heat exchange surface is continually replenished with liquid. As mentioned previously, this applies to dense sprays and some sparse sprays. However, sparse sprays typically do not have enough liquid supply at CHF to maintain a continually replenished liquid film. This is indicated by the fact that spray cooling curves for sparse sprays typically have a highly non-linear $\dot{q}_{C H F}^{\prime \prime}$ to superheat relationship. In light of this fact, application of the correlation should be directed towards dense sprays in order to attain the most accurate results. 


\section{CHAPTER 6}

\section{CONCLUSIONS AND RECOMMENDATIONS}

\subsection{Concluding Remarks}

The present work has shown that heat flux enhancement when using spray cooling is capable with the addition of surface structures with dimensions greater than the typical liquid film thickness. Heat flux performance for several different extended and embedded enhanced surfaces was investigated and reported using both the AUF and CHF as performance metrics. The have shown that the heat flux enhancement is not due to the addition of surface area alone. However, the amount of the enhancement is a function of the structure geometry and dimensions (surface area being determined by the dimensions used) as well as liquid management on the heater surface. The surface with the highest AUF in both the degassed or gassy cases $\left(\xi_{2-\Phi}=0.74\right.$ and 0.72 respectively) was surface 1s. However, surfaces $1 \mathrm{~s} \_\mathrm{t}$ and $1 \mathrm{pt}$ had the highest CHFs in

the degassed case $\left(144\right.$ and $140 \mathrm{~W} / \mathrm{cm}^{2}$ respectively) and gassy case $\left(175 \mathrm{~W} / \mathrm{cm}^{2}\right.$ for both surfaces).

While numerous test parameters affecting spray cooling heat flux optimum performance (e.g. flowrate optimization) are not addressed in the present study, some conclusions considered good design practices can be made based on lessons learned from this study as well as prior studies by other researchers. The study by Mudawar and Estes (1996) experimentally showed that spray cooling CHF was maximized when the spray footprint was exactly inscribed within the perimeter of the heater surface. The same technique was used in the current study and may be considered a rule for maximizing heat flux performance. 
Spray cone selection is another important parameter that affects liquid management on the heater surface and ultimately CHF. Hollow cone sprays lead to premature dry-out due to liquid deficiency in the center of the heater surface. Multinozzle arrays correct for this liquid deficiency. However, they also produce stagnation zones due to spray cone overlap and positioning. When using a multinozzle array for spray cooling of a flat surface, elimination of the stagnation zone will provide the best heat flux performance. Elimination of the stagnation zone can be performed either through use of an inclined spray or a surface enhancement which provides a structural relief (e.g. porous tunnels) for the excess liquid on the heater surface. However, the enhanced structures that provide the best utilization of area added for heat transfer are radial and straight fins.

\subsection{Recommendations for Future Work}

\subsubsection{Fundamental Work}

Spray cooling heat transfer is a technology currently being investigated by several researchers in industry, academia, and the government sector. Over the past decade these research efforts have lead to numerous insights pertaining to the heat transfer mechanisms involved in the phenomena as well as techniques to optimize and/or enhance heat flux. However, there are many more gains to be made. Despite the current attention being given to spray cooling from the heat transfer community, spray cooling has yet to be fully understood as a process and defined in terms of commonly accepted heat transfer mechanisms. Attempts at definitively describing the process have been met with speculation and partial acceptance. Thus the technology 
has been relegated (predominantly) to experimental studies. Future efforts dedicated to definitively describing the heat transfer process associated with spray cooling will benefit the heat transfer community as a whole and increase the acceptance level of the technology.

Future experimental efforts should seek to expand the benchmark for spray cooling performance and applications. One area which has not been addressed yet is that of large scale surface area spray cooling heat transfer (i.e. $A_{\text {surf }}>3.0 \mathrm{~cm}^{2}$ ) and heat flux scalability. The majority of the published studies to date have been performed using surface areas on the order of $2.0 \mathrm{~cm}^{2}$ or smaller. Surface areas on the order of this size are good for heat flux performance testing. However, real life applications often call for cooling of heat exchange areas that are much larger (i.e. 5.0 to $20.0 \mathrm{~cm}^{2}$ ). Larger heat exchange areas require multi-nozzle arrays for full coverage of the additional heat exchange area. However, large scale surface area spray cooling has significant challenges regarding heat flux reduction and proper drainage of excess liquid from the heater surface. Lin et al. (2004) experimentally showed that a heat flux reduction as large as $30 \%$ can be observed when undergoing scale-up of the heater surface from traditional sizes (i.e. $1.0 \mathrm{~cm}^{2}$ to $3.0 \mathrm{~cm}^{2}$ ). Recent large scale surface area $\left(\mathrm{A}_{\text {surf }} \approx 49.0 \mathrm{~cm}^{2}\right)$ work by Pautsch and Shedd (2005) has experimentally shown that heat flux is limited by the occurrence of $\mathrm{CHF}$ in regions of low fluid momentum (i.e. spray cone intersections and stagnation zones). They also showed that heat transfer is a function of both nozzle spacing and geometry. Future work in the area of large scale surface area spray cooling may include multi-nozzle array design for high heat flux applications. Nonetheless, the establishment of a literature 
base dealing with this subject would make the technology more appealing to a broader range of real life applications.

\subsubsection{Theoretical Development}

As mentioned previously, much of the interest in spray cooling in recent years has manifested itself in the form of experimental studies. A few of these studies have lead to the creation of empirically based models and correlations. However, little work has been dedicated to the creation of analytical models. This is rooted in the fact that a firm understanding of the process is still growing. However, research efforts dedicated to developing modeling techniques as a compliment to the multitude of experimental investigations will benefit the entire heat transfer community. Prior to the creation of the current spray cooling $\mathrm{Nu}$ methodology, it was commonly accepted that traditional $\mathrm{Nu}$ analysis techniques using non-dimensional parameters (such as Re and Pr) could not accurately predict spray cooling CHF. It is the desire of the author that the modeling effort included in this document will serve as a basis for the heat transfer community to revisit its previously accepted dogmas regarding modeling of spray cooling heat transfer and initiate future modeling efforts by additional researchers.

\subsubsection{Enhanced Surfaces}

The present work showed that heat fluxes upwards of $175 \mathrm{~W} / \mathrm{cm}^{2}$ (using PF-5060 with $\mathrm{T}_{\text {sat }}=56^{\circ} \mathrm{C}$ ) can be achieved when using enhanced surface spray cooling. However, the spray cooling studies detailed in this work are not comprehensive with 
respect to the several different types of structures that can be tested. As such, these studies should serve as a basis for future studies which expand the types of structures used for spray cooling heat transfer enhancement. Heat fluxes upwards of $200 \mathrm{~W} / \mathrm{cm}^{2}$ (using PF-5060) may be attainable given some additional study. Furthermore, a greater understanding of the heat transfer mechanisms leading to heat flux enhancement may be attained by computer modeling and/or visualization studies.

Future structured surface spray cooling studies may seek to create heat exchange surfaces that have the ability to determine localized heat flux and surface temperatures. The studies included in the present work used copper surfaces which did not provide the ability to determine such localized values. The ability to determine these values may lead to an increased understanding of the heat transfer process associated with spray cooling with and without enhanced surface structures.

\subsubsection{Space Applications}

NASA's new vision for space exploration encompasses the development of alternative power systems and advanced on-board flight system components which require operational capabilities across a broad range of temperature and heat flux ranges (see Fig. 6.1). Thermal management of flight system components such as Laser-Diode Arrays (LDA's) and Multi-chip modules (MCM's) is critical to mission success. Projected thermal control requirements for the proposed systems include high heat flux cooling capability $\left(\geq 100 \mathrm{~W} / \mathrm{cm}^{2}\right)$, tight temperature control (approx. $\pm 2^{\circ} \mathrm{C}$ ), reliable (on demand) start-up, shut down, and long term stability. Traditional multiphase thermal control flight technologies (loop heat pipes, capillary pumped 


\begin{tabular}{|c|c|c|c|}
\hline $\begin{array}{c}\text { Temperature } \\
\text { Range }\end{array}$ & $\begin{array}{l}\text { Low Heat Flux } \\
\left(<50 \mathrm{~W} / \mathrm{cm}^{2}\right)\end{array}$ & $\begin{array}{c}\text { Intermediate } \\
\text { Heat Flux } \\
\left(50-100 \mathrm{~W} / \mathrm{cm}^{2}\right)\end{array}$ & $\begin{array}{c}\text { High Heat Flux } \\
\left(>100 \mathrm{~W} / \mathrm{cm}^{2}\right)\end{array}$ \\
\hline $\begin{array}{c}\text { Low } \\
\text { Temperatures } \\
(<150 \mathrm{~K})\end{array}$ & $\begin{array}{l}\text { LHPs, } \\
\text { Cryo-C } \\
\text { Spray }\end{array}$ & $\begin{array}{c}\text { LHPs, CPLs, } \\
1-\Phi \text { convection, } \\
\text { Vapor Compression, } \\
\text { Spray Cooling }\end{array}$ & $\begin{array}{r}1-\Phi \text { con } \\
\text { Vapor Con } \\
\text { Spray } C\end{array}$ \\
\hline $\begin{array}{r}\text { Roo } \\
\text { Temper } \\
(150 K-\end{array}$ & $\begin{array}{c}\text { LHPs, CPLs, } \\
1-\Phi \text { convection, } \\
\text { Vapor Compression, } \\
\text { Spray Cooling }\end{array}$ & $\begin{array}{c}\text { LHPs, CPLs, } \\
1-\Phi \text { convection, } \\
\text { Vapor Compression, } \\
\text { Spray Cooling }\end{array}$ & $\begin{array}{r}1-\Phi \text { con } \\
\text { Vapor Con } \\
\text { Spray C }\end{array}$ \\
\hline $\begin{array}{c}\text { High } \\
\text { Temperature } \\
(>400 K)\end{array}$ & $\begin{array}{c}\text { LHPs, } \\
\text { 1-Ф convection, } \\
\text { Vapor Compression, } \\
\text { Spray Cooling? }\end{array}$ & $\begin{array}{c}\text { LHPs, } \\
1-\Phi \text { convection, } \\
\text { Vapor Compression, } \\
\text { Spray Cooling? }\end{array}$ & $\begin{array}{c}\text { LHPs, } \\
1-\Phi \text { convection, } \\
\text { Vapor Compression?, } \\
\text { Spray Cooling? }\end{array}$ \\
\hline
\end{tabular}

Traditional Temperature and Heat Flux Operating Ranges

Exploration Systems Technology Directorate (ESTD) Temperature and Heat Flux Operating Ranges

Fig. 6.1 Space Thermal Control Technology Temperature and Heat Flux Operational Ranges

loops, etc.) satisfy the temperature control and stability requirements, but their heat flux removal capabilities are limited. While the application of spray cooling to microgravity platforms presents significant challenges (microgravity thermophysics, scavenging of excess liquid, environmental temperatures, etc.), spray cooling is one of the most appealing heat transfer techniques for the thermal management needs of tomorrow's high heat flux space and airborne platforms. Technology development efforts dedicated to growing and applying the technology to these environments have included drop tower testing (Golliher et al., 2005), design and flight of KC-135 microgravity airplane test apparatus (Yerkes et al., 2002; Baysinger et al., 2004; Hunnell et al., 2006), and computer modeling tailored for the relevant environment (Selvam et al., 2006). This research is expected to continue and grow over the upcoming years. 


\section{APPENDIX A}

\section{Droplet shape relation}

$$
y=\left[\frac{\left(\frac{1}{\Omega}+\Omega\right)^{2}}{4}-r^{2}\right]^{1 / 2}-\frac{\left(\frac{1}{\Omega}-\Omega\right)}{2}
$$

where $\Omega$ is:

$$
\Omega=S\left\{\left[\frac{4}{\beta^{3}}+\left(1+\frac{16}{\beta^{6}}\right)^{1 / 2}\right]^{1 / 3}+\left[\frac{4}{\beta^{3}}-\left(1+\frac{16}{\beta^{6}}\right)^{1 / 2}\right]^{1 / 3}\right\}
$$

Taken from di Marzo and Evans (1997) 


\section{APPENDIX B}

\section{Spray Cooling Flow Field Governing Equations}

Gas and Liquid Phase densities are defined as:

$$
\begin{gathered}
\bar{\rho}=\Lambda \rho \\
\bar{\rho}_{l}=(1-\Lambda) \rho_{l}
\end{gathered}
$$

The void fraction shall be assigned the variable $\Lambda$. The liquid volume fraction then becomes:

$$
1-\Lambda=\sum_{k} \Xi^{(j)}
$$

where the superscript $j$ denotes a specific droplet size range. The mass vaporization rate is then written:

$$
\dot{B}=\sum_{j} \dot{B}^{(j)}=\sum_{k} \dot{b}^{(j)} n^{(j)}
$$

Gas phase continuity is defined as:

$$
\frac{\partial \bar{\rho}}{\partial t}+\frac{\partial\left(\bar{\rho} u_{j}\right)}{\partial x_{j}}=\dot{B}
$$

Liquid phase continuity is defined as:

$$
\frac{\partial \bar{\rho}_{l}}{\partial t}+\frac{\partial\left(\bar{\rho}_{l} u_{l j}\right)}{\partial x_{j}}=-\dot{B}
$$

The momentum equations (non-conservative form) are defined below.

Gas Phase Momentum:

$$
\left.\bar{\rho}\left[\frac{\partial u_{i}}{\partial t}+u_{j} \frac{\partial u_{i}}{\partial x_{j}}\right]+\theta \frac{\partial P}{\partial x_{i}}-\theta \frac{\partial \tau_{i j}}{\partial x_{j}}=\sum_{k} n^{(j)} \dot{b}^{(j)}\left[u_{l i}^{(j)}-u_{i}\right]-F_{D i}+\bar{\phi} \mathbf{B}_{i i} 7\right)
$$


where $F_{D i}$ and $\tau_{\mathrm{ij}}$ are:

$$
\begin{gathered}
F_{D i}=\sum_{k} n^{(j)} F_{D i}^{(j)} \\
\tau_{i j}=\mu\left(\frac{\partial u_{i}}{\partial x_{j}}+\frac{\partial u_{j}}{\partial x_{i}}\right)-\frac{2}{3} \delta_{i j} \frac{\partial u_{i}}{\partial x_{j}}
\end{gathered}
$$

The Liquid phase momentum is written as:

$$
\bar{\rho}_{l}^{(j)}\left[\frac{\partial u_{l i}^{(j)}}{\partial t}+u_{l j}^{(j)} \frac{\partial u_{l i}^{(j)}}{\partial x_{j}}\right]=n^{(j)} F_{D i}^{(j)}+\bar{\rho}_{l}^{(j)} g_{i}-\Xi^{(j)} \frac{\partial P}{\partial x_{i}}+\Xi^{(j)} \frac{\partial \tau_{i j}}{\partial x_{j}}
$$

The energy equations (non-conservative form) are defined below.

Gas Phase Energy:

$$
\bar{\rho}\left[\frac{\partial h}{\partial t}+u_{j} \frac{\partial h}{\partial x_{j}}\right]-\Lambda \frac{\partial}{\partial x_{j}}\left(\frac{k}{c_{p}} \frac{\partial h}{\partial x_{j}}\right)=\frac{d(\Lambda P)}{d t}-\sum_{k} n^{(j)} \dot{b}^{(j)}\left[h-h_{s}^{(j)}+h_{f g}^{(j)}\right]
$$

Liquid Phase Energy:

$\bar{\rho}_{l}^{(j)}\left[\frac{\partial h_{l}^{(j)}}{\partial t}+u_{l j}^{(j)} \frac{\partial h_{l}^{(j)}}{\partial x_{j}}\right]-\Xi^{(j)} \frac{\partial}{\partial x_{j}}\left(\frac{k}{c_{p}} \frac{\partial h_{l}^{(j)}}{\partial x_{j}}\right)=\frac{d\left(\Xi^{(j)} P\right)}{d t}+n^{(k)} \dot{b}^{(j)}\left[h_{l}^{(j)}-h_{l s}^{(j)}+\frac{\dot{q}_{l}^{(j)}}{\left.\dot{b}^{(\mathrm{B})} \cdot 12\right)}\right.$

where $e$ and $d h$ are:

$$
d h=c_{p} d T
$$




\section{APPENDIX C}

\section{Test Conditions For Model Comparison Cases}

Table C.1 Model Comparison Test data for Silk LPS Study

\begin{tabular}{|c|c|c|c|c|c|c|c|}
\hline \multirow{5}{*}{ Fluid } & $\begin{array}{c}\mathrm{T}_{1} \\
\left({ }^{\circ} \mathrm{C}\right)\end{array}$ & $\begin{array}{c}\mathrm{T}_{\text {sat }} \\
\left({ }^{\circ} \mathrm{C}\right)\end{array}$ & $\begin{array}{c}\mathrm{T}_{\text {surf }} \\
\left({ }^{\circ} \mathrm{C}\right)\end{array}$ & $\begin{array}{c}{ }^{*} \dot{V}^{\prime \prime} \\
\left(\mathrm{m}^{3} / \mathrm{m}^{2}-\mathrm{s}\right)\end{array}$ & $\begin{array}{c}{ }^{\dagger} \mathrm{d}_{32} \\
(\mu \mathrm{m})\end{array}$ & $\begin{array}{c}{ }^{+} \text {Droplet } \\
\text { Velocity } \\
(\mathrm{m} / \mathrm{s})\end{array}$ & $\begin{array}{c}\dot{q}^{\prime \prime} \\
\left(\mathrm{W} / \mathrm{cm}^{2}\right)\end{array}$ \\
\hline \multirow{7}{*}{ PF-5060 } & 23.0 & 56.0 & 95.3 & 0.00094 & 48.3 & 2.77 & 16.9 \\
\cline { 2 - 8 } & 23.0 & 56.0 & 93.5 & 0.00180 & 48.5 & 4.28 & 33.3 \\
\cline { 2 - 8 } & 23.0 & 56.0 & 87.7 & 0.00259 & 51.8 & 6.38 & 45.4 \\
\cline { 2 - 8 } & 23.0 & 56.0 & 96.5 & 0.00165 & 46.2 & 3.42 & 20.2 \\
\cline { 2 - 8 } & 23.0 & 56.0 & 91.2 & 0.00316 & 46.4 & 4.99 & 40.1 \\
\cline { 2 - 8 } & 23.0 & 56.0 & 92.0 & 0.00455 & 49.4 & 7.44 & 52.6 \\
\cline { 2 - 8 } & 23.0 & 56.0 & 93.6 & 0.00333 & 41.4 & 4.28 & 27.5 \\
\cline { 2 - 8 } & 23.0 & 56.0 & 89.6 & 0.00500 & 41.3 & 6.23 & 44.8 \\
\cline { 2 - 8 } & 23.0 & 56.0 & 88.3 & 0.00667 & 46.9 & 8.96 & 57.1 \\
\cline { 2 - 7 } & 23.0 & 56.0 & 84.5 & 0.00333 & 41.3 & 5.74 & 37.2 \\
\cline { 2 - 7 } & 23.0 & 56.0 & 88.1 & 0.00500 & 39.2 & 8.3 & 52.2 \\
\cline { 2 - 7 } & 23.0 & 56.0 & 85.1 & 0.00667 & 50.4 & 11.19 & 59.6 \\
\hline
\end{tabular}

*Calculated using volumetric flow rate relation by Mudawar and Estes (1996)

${ }^{\dagger}$ Calculated using SMD correlation by Estes and Mudawar (1995)

${ }^{\ddagger}$ Calculated using velocity relation by Ghodbane and Holman (1991)

Table C.2 Model Comparison Test data for Horacek et al. (2005) Study

\begin{tabular}{|c|c|c|c|c|c|c|c|}
\hline Fluid & $\begin{array}{c}\mathrm{T}_{1} \\
\left({ }^{\circ} \mathrm{C}\right)\end{array}$ & $\begin{array}{c}\mathrm{T}_{\text {sat }} \\
\left({ }^{\circ} \mathrm{C}\right)\end{array}$ & $\begin{array}{c}\mathrm{T}_{\text {surf }} \\
\left({ }^{\circ} \mathrm{C}\right)\end{array}$ & $\begin{array}{c}{ }^{*} \dot{V}^{\prime \prime} \\
\left(\mathrm{m}^{3} / \mathrm{m}^{2}-\mathrm{s}\right)\end{array}$ & $\begin{array}{c}{ }^{\dagger} \mathrm{d}_{32} \\
(\mu \mathrm{m})\end{array}$ & $\begin{array}{c}{ }^{+} \text {Droplet } \\
\text { Velocity } \\
(\mathrm{m} / \mathrm{s})\end{array}$ & $\begin{array}{c}\dot{q}^{\prime \prime} \\
\left(\mathrm{W} / \mathrm{cm}^{2}\right)\end{array}$ \\
\hline \multirow{5}{*}{ FC-72 } & 25.0 & 27.1 & 65.0 & 0.00189 & 38.0 & 8.0 & 44.0 \\
\cline { 2 - 8 } & 1.4 & 27.1 & 65.0 & 0.00189 & 38.0 & 8.0 & 52.0 \\
\cline { 2 - 8 } & 25.0 & 45.5 & 75.0 & 0.00189 & 38.0 & 8.0 & 52.0 \\
\cline { 2 - 8 } & 25.0 & 57.6 & 85.0 & 0.00189 & 38.0 & 8.0 & 62.0 \\
\cline { 2 - 8 } & 25.0 & 68.1 & 90.0 & 0.00189 & 38.0 & 8.0 & 76.0 \\
\hline
\end{tabular}

*Calculated using volumetric flow rate relation by Mudawar and Estes (1996)

Table C.3 Model Comparison Test data for Rini et al. (2002) Study

\begin{tabular}{|c|c|c|c|c|c|c|c|}
\hline Fluid & $\begin{array}{c}\mathrm{T}_{1} \\
\left({ }^{\circ} \mathrm{C}\right)\end{array}$ & $\begin{array}{c}\mathrm{T}_{\text {sat }} \\
\left({ }^{\circ} \mathrm{C}\right)\end{array}$ & $\begin{array}{c}\mathrm{T}_{\text {surf }} \\
\left({ }^{\circ} \mathrm{C}\right)\end{array}$ & $\begin{array}{c}{ }^{*} \dot{V}^{\prime \prime} \\
\left(\mathrm{m}^{3} / \mathrm{m}^{2}-\mathrm{s}\right)\end{array}$ & $\begin{array}{c}{ }^{\dagger} \mathrm{d}_{32} \\
(\mu \mathrm{m})\end{array}$ & $\begin{array}{c}{ }^{\ddagger} \text { Droplet } \\
\text { Velocity } \\
(\mathrm{m} / \mathrm{s})\end{array}$ & $\begin{array}{c}\dot{q}^{\prime \prime} \\
\left(\mathrm{W} / \mathrm{cm}^{2}\right)\end{array}$ \\
\hline \multirow{2}{*}{ FC-72 } & 50.0 & 56.0 & 70.0 & 0.0166 & 113 & 35.0 & 67.0 \\
\cline { 2 - 8 } & 50.0 & 56.0 & 68.0 & 0.0308 & 104 & 35.0 & 70.0 \\
\cline { 2 - 8 } & 50.0 & 56.0 & 69.0 & 0.0563 & 102 & 35.0 & 80.0 \\
\hline
\end{tabular}


Table C.4 Model Comparison Test data for Lin and Ponnappan (2003) Study

\begin{tabular}{|c|c|c|c|c|c|c|c|}
\hline Fluid & $\begin{array}{c}\mathrm{T}_{1} \\
\left({ }^{\circ} \mathrm{C}\right)\end{array}$ & $\begin{array}{c}\mathrm{T}_{\text {sat }} \\
\left({ }^{\circ} \mathrm{C}\right)\end{array}$ & $\begin{array}{c}\mathrm{T}_{\text {surf }} \\
\left({ }^{\circ} \mathrm{C}\right)\end{array}$ & $\begin{array}{c}\dot{V}^{\prime \prime} \\
\left(\mathrm{m}^{3} / \mathrm{m}^{2}-\mathrm{s}\right)\end{array}$ & $\begin{array}{c}\dagger \\
(\mu \mathrm{d})\end{array}$ & $\begin{array}{c}\text { 'Droplet } \\
\text { Velocity } \\
(\mathrm{m} / \mathrm{s})\end{array}$ & $\begin{array}{c}\dot{q}^{\prime \prime} \\
\left(\mathrm{W} / \mathrm{cm}^{2}\right)\end{array}$ \\
\hline \multirow{5}{*}{ FC-72 } & 53.0 & 54.0 & 93.0 & 0.0123 & 52.4 & 9.3 & 56.0 \\
\cline { 2 - 8 } & 53.0 & 54.0 & 91.9 & 0.0144 & 52.1 & 11.4 & 65.0 \\
\cline { 2 - 8 } & 53.0 & 54.0 & 90.4 & 0.0175 & 45.2 & 14.7 & 72.5 \\
\cline { 2 - 8 } & 53.0 & 54.0 & 90.0 & 0.0201 & 41.4 & 17.4 & 78.5 \\
\cline { 2 - 7 } & 53.0 & 54.0 & 90.4 & 0.0222 & 38.7 & 19.8 & 83.5 \\
\cline { 2 - 7 } & 34.5 & 36.0 & 75.0 & 0.0122 & 61.3 & 9.1 & 48.0 \\
\cline { 2 - 8 } & 34.5 & 36.0 & 75.0 & 0.0137 & 55.3 & 11.2 & 53.5 \\
\cline { 2 - 8 } & 34.5 & 36.0 & 73.0 & 0.0167 & 48.4 & 14.5 & 63.0 \\
\cline { 2 - 8 } & 34.5 & 36.0 & 72.0 & 0.0183 & 44.4 & 17.1 & 69.0 \\
\cline { 2 - 8 } & 34.5 & 36.0 & 73.0 & 0.0212 & 41.6 & 19.5 & 76.0 \\
\hline \multirow{7}{*}{ Methanol } & 46.0 & 52.0 & 122.4 & 0.0246 & 79.6 & 14.1 & 357.5 \\
\cline { 2 - 8 } & 46.0 & 52.0 & 122.9 & 0.0308 & 68.6 & 18.3 & 440.0 \\
\cline { 2 - 8 } & 46.0 & 52.0 & 121.9 & 0.0363 & 62.3 & 21.8 & 490.0 \\
\hline \multirow{7}{*}{ FC-87 } & 41.0 & 42.0 & 97.0 & 0.0147 & 45.3 & 11.9 & 79.0 \\
\cline { 2 - 8 } & 41.0 & 42.0 & 97.0 & 0.0181 & 39.6 & 15.4 & 87.5 \\
\cline { 2 - 8 } & 41.0 & 42.0 & 85.0 & 0.0204 & 36.5 & 18.3 & 90.0 \\
\hline
\end{tabular}

${ }^{\dagger}$ Calculated using SMD correlation by Estes and Mudawar (1995)

Calculated using velocity relation by Ghodbane and Holman (1991)

Table C.5 Model Comparison Test data for Puterbaugh et al. (2007) Study

\begin{tabular}{|c|c|c|c|c|c|c|c|}
\hline Fluid & $\begin{array}{l}\mathrm{T}_{1} \\
\left({ }^{\circ} \mathrm{C}\right)\end{array}$ & $\begin{array}{l}\mathrm{T}_{\mathrm{sat}} \\
\left({ }^{\circ} \mathrm{C}\right)\end{array}$ & $\begin{array}{l}\mathrm{T}_{\text {surf }} \\
\left({ }^{\circ} \mathrm{C}\right)\end{array}$ & $\begin{array}{c}\dot{V}^{\prime \prime} \\
\left(\mathrm{m}^{3} / \mathrm{m}^{2}-\mathrm{s}\right)\end{array}$ & $\begin{array}{c}\mathrm{d}_{32} \\
(\mu \mathrm{m})\end{array}$ & $\begin{array}{l}\text { Droplet } \\
\text { Velocity } \\
(\mathrm{m} / \mathrm{s})\end{array}$ & $\begin{array}{c}\dot{q}^{\prime \prime} \\
\left(\mathrm{W} / \mathrm{cm}^{2}\right)\end{array}$ \\
\hline \multirow{5}{*}{ FC-72 } & 35.5 & 46.5 & 62.4 & 0.04506 & 48 & 8.5 & 59.8 \\
\hline & 35.5 & 46.5 & 64.6 & 0.05258 & 48 & 9.0 & 70.1 \\
\hline & 35.5 & 46.5 & 65.7 & 0.06009 & 48 & 10.0 & 77.6 \\
\hline & 35.5 & 46.5 & 65.5 & 0.06760 & 48 & 11.5 & 82.3 \\
\hline & 35.5 & 46.5 & 64.2 & 0.07511 & 48 & 12.5 & 84.2 \\
\hline
\end{tabular}

Table C.6 Model Comparison Test data for Silk et al. (2005) GSFC Extended Studies

\begin{tabular}{|c|c|c|c|c|c|c|c|}
\hline Fluid & $\begin{array}{c}\mathrm{T}_{1} \\
\left({ }^{\circ} \mathrm{C}\right)\end{array}$ & $\begin{array}{c}\mathrm{T}_{\text {sat }} \\
\left({ }^{\circ} \mathrm{C}\right)\end{array}$ & $\begin{array}{c}\mathrm{T}_{\text {surf }} \\
\left({ }^{\circ} \mathrm{C}\right)\end{array}$ & $\begin{array}{c}\dot{V}^{\prime \prime} \\
\left(\mathrm{m}^{3} / \mathrm{m}^{2}-\mathrm{s}\right)\end{array}$ & $\begin{array}{c}{ }^{\dagger} \mathrm{d}_{32} \\
(\mu \mathrm{m})\end{array}$ & $\begin{array}{c}\text { "Droplet } \\
\text { Velocity } \\
(\mathrm{m} / \mathrm{s})\end{array}$ & $\begin{array}{c}\dot{q}^{\prime \prime} \\
\left(\mathrm{W} / \mathrm{cm}^{2}\right)\end{array}$ \\
\hline \multirow{5}{*}{ FC-72 } & 20.5 & 31.0 & 67.1 & 0.01000 & 53.2 & 9.0 & 55.9 \\
\cline { 2 - 8 } & 20.5 & 31.0 & 70.9 & 0.01167 & 45.7 & 12.1 & 64.9 \\
\cline { 2 - 8 } & 20.5 & 31.0 & 67.0 & 0.01333 & 41.9 & 14.3 & 69.4 \\
\cline { 2 - 8 } & 20.5 & 31.0 & 69.0 & 0.01500 & 37.9 & 17.4 & 78.7 \\
\cline { 2 - 8 } & 20.5 & 31.0 & 69.9 & 0.01667 & 33.4 & 22.2 & 79.6 \\
\cline { 2 - 8 } & & & & & & & \\
\cline { 2 - 8 } & 20.5 & 56.0 & 87.5 & 0.016 & 33.4 & 22.1 & 108.3 \\
\hline
\end{tabular}

${ }^{\dagger}$ Calculated using SMD correlation by Estes and Mudawar (1995)

Calculated using velocity relation by Ghodbane and Holman (1991) 
Table C.7 Model Comparison Test data for Chen et al. (2002) Study

\begin{tabular}{|c|c|c|c|c|c|c|c|}
\hline Fluid & $\begin{array}{l}\mathrm{T}_{1} \\
\left({ }^{\circ} \mathrm{C}\right)\end{array}$ & $\begin{array}{l}\mathrm{T}_{\text {sat }} \\
\left({ }^{\circ} \mathrm{C}\right)\end{array}$ & $\begin{array}{l}T_{\text {surf }} \\
\left({ }^{\circ} \mathrm{C}\right)\end{array}$ & $\begin{array}{c}\dot{V}^{\prime \prime} \\
\left(\mathrm{m}^{3} / \mathrm{m}^{2}-\mathrm{s}\right)\end{array}$ & $\begin{array}{c}\mathrm{d}_{32} \\
(\mu \mathrm{m})\end{array}$ & $\begin{array}{c}\text { Droplet } \\
\text { Velocity } \\
(\mathrm{m} / \mathrm{s})\end{array}$ & $\begin{array}{c}\dot{q}^{\prime \prime} \\
\left(\mathrm{W} / \mathrm{cm}^{2}\right)\end{array}$ \\
\hline \multirow{37}{*}{ \& } & 25.0 & 80.0 & 102.8 & 0.0072 & 57.3 & 6.9 & 610.7 \\
\hline & 25.0 & 80.0 & 108.7 & 0.0224 & 55.4 & 7.3 & 761.9 \\
\hline & 25.0 & 80.0 & 109.1 & 0.0248 & 54.7 & 8.0 & 780.2 \\
\hline & 25.0 & 80.0 & 100.9 & 0.0146 & 79.7 & 10.8 & 591.2 \\
\hline & 25.0 & 80.0 & 104.2 & 0.0348 & 72.6 & 11.1 & 694.6 \\
\hline & 25.0 & 80.0 & 103.9 & 0.0376 & 72.6 & 10.1 & 673.2 \\
\hline & 25.0 & 80.0 & 100.9 & 0.0172 & 79.7 & 6.9 & 591.2 \\
\hline & 25.0 & 80.0 & 106.7 & 0.0213 & 71.7 & 8.2 & 667.8 \\
\hline & 25.0 & 80.0 & 107.1 & 0.0319 & 79.6 & 7.1 & 640.6 \\
\hline & 25.0 & 80.0 & 107.4 & 0.0243 & 70.2 & 6.0 & 645.1 \\
\hline & 25.0 & 80.0 & 104.2 & 0.0665 & 75.9 & 8.7 & 671.2 \\
\hline & 25.0 & 80.0 & 108.7 & 0.0224 & 55.4 & 7.3 & 761.9 \\
\hline & 25.0 & 80.0 & 108.9 & 0.0235 & 55.7 & 7.9 & 767.1 \\
\hline & 25.0 & 80.0 & 109.1 & 0.0248 & 54.7 & 8.0 & 780.2 \\
\hline & 25.0 & 80.0 & 99.2 & 0.007 & 62.2 & 6.0 & 565.2 \\
\hline & 25.0 & 80.0 & 106.0 & 0.0343 & 105.0 & 6.4 & 586.7 \\
\hline & 25.0 & 80.0 & 104.2 & 0.1184 & 163.8 & 5.9 & 537.6 \\
\hline & 25.0 & 80.0 & 108.3 & 0.1957 & 191.4 & 6.3 & 572.6 \\
\hline & 25.0 & 80.0 & 102.8 & 0.0072 & 57.3 & 6.9 & 610.7 \\
\hline & 25.0 & 80.0 & 102.8 & 0.0291 & 86.5 & 6.7 & 621.6 \\
\hline & 25.0 & 80.0 & 108.3 & 0.0687 & 115.7 & 7.8 & 651.1 \\
\hline & 25.0 & 80.0 & 102.8 & 0.0072 & 57.3 & 6.9 & 610.7 \\
\hline & 25.0 & 80.0 & 99.2 & 0.0069 & 62.2 & 6.0 & 565.2 \\
\hline & 25.0 & 80.0 & 100.9 & 0.0249 & 92.7 & 5.0 & 524.6 \\
\hline & 25.0 & 80.0 & 106.0 & 0.0343 & 105.0 & 6.4 & 586.7 \\
\hline & 25.0 & 80.0 & 106.4 & 0.0282 & 107.6 & 6.7 & 596.2 \\
\hline & 25.0 & 80.0 & 108.6 & 0.1800 & 135.2 & 7.9 & 625.4 \\
\hline & 25.0 & 80.0 & 104.2 & 0.1184 & 163.8 & 5.9 & 537.6 \\
\hline & 25.0 & 80.0 & 108.3 & 0.1957 & 191.4 & 6.3 & 572.6 \\
\hline & 25.0 & 80.0 & 112.8 & 0.026 & 68.7 & 24.1 & 945.7 \\
\hline & 25.0 & 80.0 & 107.2 & 0.026 & 70.2 & 6.0 & 636.7 \\
\hline & 25.0 & 80.0 & 107.7 & 0.034 & 83.7 & 13.6 & 708.1 \\
\hline & 25.0 & 80.0 & 107.1 & 0.032 & 79.6 & 7.1 & 640.6 \\
\hline & 25.0 & 80.0 & 104.2 & 0.014 & 57.4 & 13.7 & 695.8 \\
\hline & 25.0 & 80.0 & 110.7 & 0.039 & 90.3 & 22.1 & 880.2 \\
\hline & 25.0 & 80.0 & 103.9 & 0.038 & 72.6 & 10.1 & 673.2 \\
\hline & 25.0 & 80.0 & 106.7 & 0.021 & 71.9 & 8.2 & 667.8 \\
\hline
\end{tabular}




\section{APPENDIX D}

\section{Fortran Code}

$\mathrm{c}$

c

c

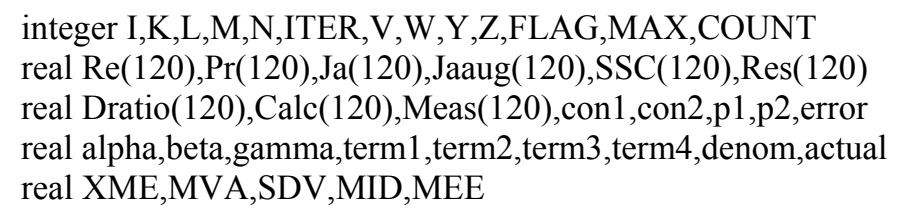


C

c

c

c

c

c

c

c

c

c

c

c

c

c

$\mathrm{C}$

Liquid Volume Fraction Loop Section

beta $=0.0$

do $40 \mathrm{~L}=1,15$

beta $=$ beta +0.01

Density Ratio 1 Loop

$\mathrm{p} 1=0.0$

do $50 \mathrm{M}=1,100$

$$
\mathrm{p} 1=\mathrm{p} 1+0.01
$$

Density Ratio 2 Loop

$$
\mathrm{p} 2=0.0
$$

$$
\text { do } 60 \mathrm{~N}=1,100
$$

$$
\mathrm{p} 2=\mathrm{p} 2+0.01
$$

Constant Factor 1

$$
\operatorname{con} 1=0.0
$$

do $70 \mathrm{~V}=1,100$

con $1=$ con $1+0.01$

Constant Factor 2

con $2=0.0$

do $80 \mathrm{~W}=1,100$

$\operatorname{con} 2=\operatorname{con} 2+0.01$

\section{$\mathrm{FLAG}=0$}

$\mathrm{XME}=0.0$

$$
\begin{aligned}
\text { do } 90 \mathrm{Z} & =1, \mathrm{MAX} \\
\text { term } 1 & =\operatorname{Re}(\mathrm{Z})^{* *} \text { alpha } \\
\text { term } 2 & =\operatorname{Pr}(\mathrm{Z})^{* *} 0.33 \\
\text { term } 3 & =\mathrm{SSC}(\mathrm{Z})^{* *} \text { beta } \\
\text { term } 4 & =\operatorname{con} 2 *\left(\operatorname{Dratio}(\mathrm{Z})^{* *} \mathrm{p} 1\right)^{*} \operatorname{Ja}(\mathrm{Z})+1.0 \\
\text { denom } & =\operatorname{con} 1 *\left(\operatorname{Dratio}(\mathrm{Z})^{* *} \mathrm{p} 2\right)^{*} \operatorname{Jaaug}(\mathrm{Z})
\end{aligned}
$$

$\operatorname{Calc}(Z)=$ term $1 *$ term $2 *$ term $3 *$ term $4 /$ denom

$\operatorname{Res}(Z)=100.0 *(\operatorname{ABS}(\operatorname{Meas}(Z)-\operatorname{Calc}(Z))) / \operatorname{Meas}(Z)$

$\mathrm{XME}=\mathrm{XME}+\operatorname{Res}(\mathrm{z})$

$$
\text { write }\left(6,{ }^{*}\right) \text { MAX, XME, Res(Z) }
$$

write $\left(6,{ }^{*}\right)$ alpha, beta, p1, p2, con1,con2

IF (Res(Z).GE.error) THEN

$\mathrm{FLAG}=1$

END IF 


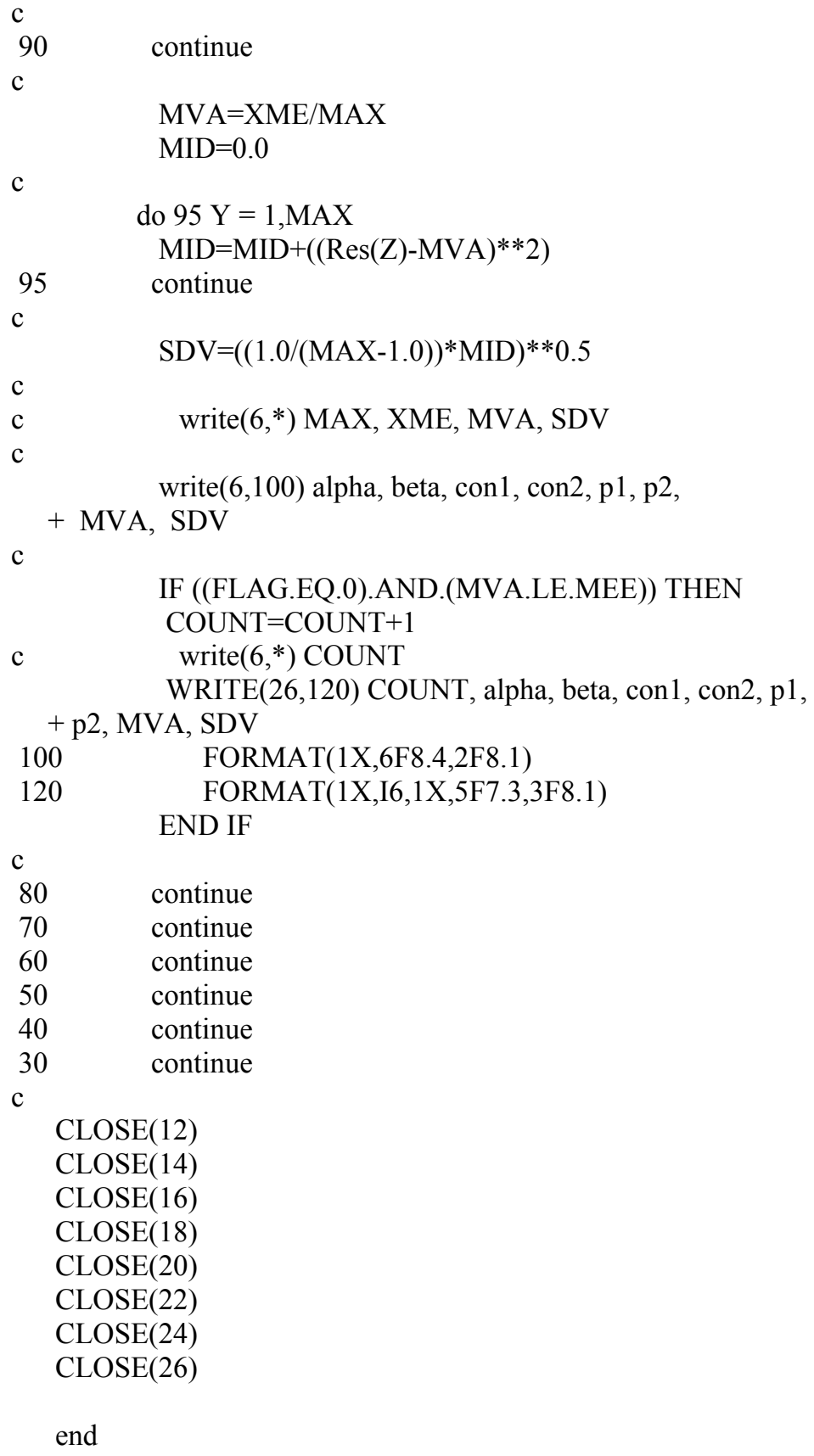




\section{APPENDIX E}

\section{List of Publications and Presentations}

Silk, E.A., Kim, J., and Kiger, K., 2004, "Investigation of Enhanced Surface Spray Cooling," ASME International Mechanical Engineering Congress, Anaheim, CA, Nov.13-19, IMECE2004 Conference Proceedings

Silk, E.A., Kim, J., and Kiger, K., 2005, "Impact of Cubic Pin Finned Surface Structure Geometry Upon Spray Cooling Heat Transfer," ASME International Electronic Packaging and Technical Conference, San Francisco, CA, July. 17-22, InterPACK 2005 Conference Proceedings

Silk, E.A., Kim, J., Kiger, K., 2005, "Effect of Spray Cooling Trajectory angle on Heat Flux for a Straight Finned Enhanced Surface," ASME International Summer Heat Transfer Conference, July 17-22, 2005, San Francisco, CA.

Rowden, B., Selvam, R.P., and Silk, E.A., 2006, "Spray Cooling Development Effort for Microgravity Environments," Space Technology and Applications International Forum, Albuquerque, NM., February 13-17.

Silk, E.A., Kim, J., Kiger, K., 2006, "Enhanced Surface Spray Cooling with Embedded and Compound Extended Surface Structures," Tenth Intersociety Conference on Thermal and Thermomechanical Phenomena in Electronic Systems, May 30 - June 3, 2006, San Diego, CA. 


\section{Presentations}

Yerkes, K., Michalak, T., Silk, E.A., Swanson, T., McQuillen, J., and Golliher, E., 2002, "Investigation into the Micro-Gravity Effects on Two-Phase Spray Thermophysics," International Two-Phase Thermal Control Technology Workshop, Greenbelt, MD., September 24-26.

Silk, E.A., 2005, "Spray Cooling and the next Generation of NASA Space Flight," Space Technology and Applications International Forum, February 13, 2005, Albuquerque, NM.

Silk, E.A., Kim, J., and Kiger, K., 2005, "Spray Cooling Heat Transfer Development," Interagency Advanced Power Group (IAPG) Mechanical Working Group Meeting, May 24-25, Dayton, OH., IAPG Conference Proceedings

Silk, E.A., 2005, "NASA GSFC Thermal Research Initiatives," ONR (Office of Naval Research) Thermal Management PI Meeting, October 27-28, Orlando, FL.

Silk, E.A., Kim, J., Kiger, K., 2006, “Overview of Enhanced Surface Spray Cooling with Embedded and Extended Surface Structures," International Two-Phase Thermal Control Technology Workshop, Applied Physics Laboratory, Baltimore, MD., September 19-21. 


\section{REFERENCES}

Baysinger, K., Yerkes, K., Michalak, T., Harris, R., and McQuillen, J., 2004, “Design of a Microgravity Spray Cooling Experiment," $42^{\text {nd }}$ Annual Aerospace Sciences Conference and Exhibit, Reno, NV., January 5-8.

Baysinger, K., Yerkes, K., Michalak, T., Harris, R., and McQuillen, J., 2005, "Variable Gas Content Terrestrial Experiments using FC-72," unpublished

Bird, R.B, Stewart, W.E, and Lightfoot, E.N., Transport Phenomena, John Wiley \& Sons Inc., New York, 1960

Bernadin, J.D., and Mudawar, I., 1999, “The Leidenfrost Point: Experimental Study and Assessment of Existing Models," Journal of Heat Transfer, Vol. 121, pp.894-903

Carey, V., Liquid-Vapor Phase Change Phenomena, Taylor and Francis, Bristol, PA., 1992

Chandra, S., di Marzo, M., Qiao, Y.M., and Tartarini, P., 1996, “ Effect of Liquid Solid Contact Angle on Droplet Evaporation," Fire Safety Journal, Vol. 27, pp. 141148

Chen, R-H., Chow, L., and Navedo, J., 2002, "Effects of spray characteristics on critical heat flux in subcooled water spray cooling," International Journal of Heat and Mass Transfer, Vol. 45, pp. 4033-4043 
Chien, L.H., and Webb, R.L., 1998a, "A Parametric Study of Nucleate Boiling on Structured Surfaces, Part I: Effect of Tunnel Dimensions," Journal of Heat Transfer, Vol. 120, pp. 1042-1048

Chien, L.H., and Webb, R.L., 1998b, "A Parametric Study of Nucleate Boiling on Structured Surfaces, Part II: Effect of Pore Diameter and Pore Pitch," Journal of Heat Transfer, Vol. 120, pp. 1049-1054

Chilton, T.H., and Colburn, A.P., 1934, "Mass Transfer (Absorption) Coefficients," Industrial and Engineering Chemistry, Vol. 26, No. 11, pp. 1183-1187

di Marzo, M., and Evans, D., 1987, “ Dropwise Evaporative Cooling Of High Thermal Conductivity Materials," Heat and Technology, Vol. 5, No. 1-2, pp. 126-136

di Marzo, M., and Evans, D., 1989, “Evaporation of a Water Droplet Deposited on a Hot High Thermal Conductivity Surface," Journal of Heat Transfer, Vol. 111, pp. $210-213$

di Marzo, M., Tartarini, P., Laio, Y., Evans, D., and Baum, H., 1993, "Evaporative cooling due to a gently deposited droplet," International Journal of Heat and Mass Transfer, Vol. 36, No. 17, pp. 4133-4139 
Estes, K.A., and Mudawar, I., 1995, “Correlation of Sauter mean diameter and critical heat flux for spray cooling of small surfaces," International Journal of Heat and Mass Transfer, Vol.38, No.16, pp. 2985-2996

Fukai, J., Zhao, Z., Poulikakos, D., Megaridis, C., and Miyatake, O., 1993, “Modeling of the deformation of a liquid droplet impinging upon a flat surface," Physics Fluid A, Vol.5, No.11, pp. 2588-2599

Ghodbane, M., and Holman, J.P., 1991, "Experimental study of spray cooling with Freon-113," International Journal of Heat and Mass Transfer, Vol.34, No. 4/5, pp. $1163-1174$

Golliher, E., Zivich, C., and Yao, S.C., 2005, "Exploration of Unsteady Spray Cooling for High Power Electronics at Microgravity Using NASA Glenn's Drop Tower," 2005 ASME Summer Heat Transfer Conference, San Francisco, CA., July $17-22$.

Halvorson, P.J., On the heat transfer characteristics of spray cooling. Ph.D. Thesis, Georgia Institute of Technology, Atlanta, GA, 1993

Halvorson, P., Carson, R., Jeter, S., and Abdel-Khalik, S., 1994, “ Critical heat flux limits for a heated surface impacted by a stream of liquid droplets," Journal of Heat Transfer, Vol. 116, pp. 679-685 
Healy, W., Halvorson, P., Hartley, J., and Abdel-Khalik, S., 1998, “A critical heat flux correlation for droplet impact cooling at low Weber numbers and various ambient pressures," International Journal of Heat and Mass Transfer, Vol. 41, pp. $975-978$

Holman, J.P., and Kendell, C.M. 1993, "Extended studies of spray cooling with Freon-113," International Journal of Heat and Mass Transfer, Vol.36, No. 8, pp.2239-2241

Honda, H., Takamastu, H., and Wei, J.J., 2002, "Enhanced Boiling of FC-72 on Silicon Chips With Micro-Pin-Fins and Submicron-Scale Roughness," Journal of Heat Transfer, Vol. 124, pp. 383-390

Horacek, B., Kiger, K., Kim, J., “Single Nozzle Spray Cooling Heat Transfer Mechanisms", International Journal of Heat and Mass Transfer, Vol. 48, No. 8, pp. $1425-1438,2005$

Horacek, B., Kim, J., and Kiger, K., 2005, “Spray Cooling Using Multiple Nozzles: Visualization and Wall Heat Transfer Measurements," IEEE Transactions on Device and Materials Reliability, Vol. 4, No. 4, pp. 614-625 
Hunnell, A., Kuhlman, J., and Gray, J., 2006, "Spray Cooling in Terrestrial and Simulated Reduced Gravity," Space Technology and Applications International Forum, Albuquerque, NM., February 13-17.

Hsieh, S.S., and Weng, C.J., 1997, "Nucleate pool boiling from coated surfaces in saturated R-134a and R-407c," International Journal of Heat and Mass Transfer, Vol. 40, No. 3, pp. 519-532

Incropera, F., and DeWitt, D., 1990, Fundamentals of Heat and Mass Transfer, John Wiley \& Sons, New York, NY.

Kato, M., Yoshiyuki, A., Toshiharu, O., and Akira, Nagashima, 1994, “Spray Cooling Characteristics Under Reduced Gravity,” Journal of Thermophysics, Vol. 9, No. 2

Kays, W.M. and Crawford, M.E., Convective Heat and Mass Transfer, McGraw-Hill, New York, 1993

Kearns, D., Du, J.H., Chen, R.H., Chow, L., 2002, “A Parametric Study of Dielectric Spray Cooling of a Row of Heaters in a Narrow Channel," $18^{\text {th }}$ IEEE SEMI-THERM Symposium, San Jose, CA, Mar.12-14, 2002, Conference Proceedings

Krause, A.D., and Bar-Cohen, A., Design and Analysis of Heat Sinks, pp. 11-28, John Wiley \& Sons Inc., New York, 1995 
Lee, J., Kim, J., Kiger, K., and Horacek, B., 2000, "Heat Transfer characteristics of single droplet cooling using a microscale heater array," Proceedings of the 2000 International Mechanical Engineering Congress and Exposition (Transport Phenomena in Spray and Coating Processes), Orlando, Fl, Nov., ASME Publications, Vol. 366, no.3

Lee, J., Kim, J., and Kiger, K., "Droplet Cooling Heat Transfer Model Validation”, 2000 SAE Power Systems Conference, San Diego, CA., Oct., SAE Conference Proceedings no. 359

Lee, W.H., 1979, “A Pressure Iteration Scheme for Two-Phase Flow Modeling, Los Alamos National Laboratory Report on Mathematical Modeling, pp. 407-431

Lide, D., and Kehiaian, H., 1994, CRC Handbook of Thermophysical and Thermochemical Data, CRC Press, Boca Raton, Fl.

Lin, L., and Ponnappan, R., 2003, "Heat Transfer Characteristics of Evaporative Spray Cooling in a Closed Loop," International Journal of Heat Transfer, Vol. 46, pp. $3737-3746$

Lin, L., Ponnappan, R., Yerkes, K., and Hager, B., 2004, “Large area spray cooling”, Proceedings of the $42^{\text {nd }}$ AIAA Aerospace Sciences meeting and Exhibit, Reno, Nevada, 2004, pp. 10838-10843 
Mesler, R., and Mailen, G., 1977, "Nucleate Boiling in Thin Liquid Films," AIChE Journal, Vol. 23, No. 6, pp. 954-957

Mesler, R., 1993, "Surface Roughness and It's Effects on the Heat Transfer Mechanism of Spray Cooling," Journal of Heat Transfer, Vol. 115, pp. 1083-1085

Milke, J., Tinker, S., and di Marzo, M., 1997, "Effect of Dissolved Gases on Spray Evaporative Cooling with Water," Fire Technology, Vol. 33, Second Quarter, pp. 99114

Mudawar, I., and Estes, K., 1996, “Optimizing and Predicting CHF in Spray Cooling of a square surface,” Journal of Heat Transfer, Vol. 118, pp. 672-679

Nason, J.R., Wierum, F., and Yanosy, J., 1985, "Challenges in the Development of the Orbiter Active Thermal Control Subsystem," NASA Johnson Space Center Space Shuttle Technical Conference Proceedings, Houston, TX, Jan., pp. 450-464

Nishikawa, K., and Fidgety, Y., 1990, "Nucleate Boiling Heat Transfer and It's Augmentation," Advances in Heat Transfer, Vol. 20, pp. 1-82

Nishio, S., and Kim, Y-C., 1997, "Heat transfer of dilute spray impinging on hot surface (simple model focusing on rebound motion and sensible heat of droplets)," International Journal of Heat and Mass Transfer, Vol. 41, pp. 4113-4119 
O’Connor, J.P., and You, S.M., 1995, “A Painting Technique to Enhance Pool Boiling Heat Transfer in Saturated FC-72," Journal of Heat Transfer, Vol. 117, pp. $387-393$

O’Connor, E.W., Zampiceni, J.J., Cerna, N.F., and Fuller, M.J., 1997, “Orbiter Flash Evaporator: Flight Experience and Improvements," International Conference on Environmental Systems, Lake Tahoe, NV., July

Pais, M., Chow, L., and Mahefkey, E., 1992, "Surface Roughness and Its Effects on the Heat Transfer Mechanism of Spray Cooling," Journal of Heat Transfer, Vol. 114, No. 1, pp. 211-219

Panton, R.L., Incompressible Flow, John Wiley \& Sons Inc., New York, 1996

Pasandideh-Fard, M., Qiao, Y.M., Chandra, S., and Mostaghimi, J., 1995, “Capillary effects during droplet impact on a solid surface," Physics of Fluids, Vol. 8, No. 3, pp. $650-659$

Pautsch, G., and Bar-Cohen, A., 1999, “Thermal management of multichip modules with evaporative spray cooling," ASME International Intersociety Electronics and Photonic Packaging Conference, Maui, HI., June 13-19., Vol. 26-2, pp. 1453-1461 
Pautsch, A.G., and Shedd, T.A., 2005, "Spray Impingement Cooling with Singles-and Multiple-Nozzle Arrays Part I: Heat Transfer Data Using FC-72”, International Journal of Heat and Mass Transfer, Vol. 48, pp. 3167-3175

Phares, D.J., Smedley, G.T., and Flagan, R.C., 2000, “The wall shear stress produced by the normal impingement of a jet on a flat surface," Journal of Fluid Mechanics, Vol. 418, pp. 351-375

Potash, M., Jr., and Wayner, P.C., Jr., 1972, “Evaporation From A Two-Dimensional Extended Meniscus," International Journal of Heat and Mass Transfer, Vol. 15, pp. $1851-1863$

Puterbaugh, R., Yerkes, K., Michalak, T., and Thomas, S., 2007, "Cooling Performance of a Partially-Confined FC-72 Spray: The Effect of Dissolved Air", $45^{\text {th }}$ Annual AIAA Aerospace Sciences Meeting and Exhibit, Jan. 8-11, 2007, Reno, Nevada

Qiao, Y.M., and Chandra, S., 1997, "Experiments on adding a surfactant to water drops boiling on a hot surface," Proceedings of the Royal Society of London, Vol. 453, pp. 673-689

Qiao, Y., and Chandra, S., 1998, "Spray Cooling Enhancement by Addition of a Surfactant," Journal of Heat Transfer, Vol. 120, pp. 92-98 
Rini, D., Chen, R.-H., Chow, L., "Bubble Behavior and Nucleate Boiling Heat Transfer in Saturated FC-72 Spray Cooling," Journal of Heat Transfer, Vol. 124, pp. $63-72$

Rainey, K.N., Li, G., and You, S.M., 2001," Flow Boiling Heat Transfer From Plain and Microporous Coated Surfaces in Subcooled FC-72," Journal of Heat Transfer, Vol. 123, pp. 918-925

Rowden, B., Selvam, R.P., and Silk, E., 2006, "Spray Cooling Development Effort for Microgravity Environments," Space Technology and Applications International Forum, Albuquerque, NM., February 13-17.

Sadhal, S.S., Ayyaswamy, P.S., and Chung, J.N., Transport Phenomena with Drops and Bubbles, Springer., New York, 1996

Saha, P., Ishii, M., and Zuber, N., 1976, "An experimental investigation of the thermally induced flow oscillations in two-phase systems," ASME Journal of Heat Transfer, Vol. 98, pp.612-622

Sawyer, M., Jeter, S., and Abdel-Khalik, S., 1997, “A critical heat flux correlation for droplet impact cooling," International Journal of Heat Transfer, Vol. 40, No. 9, pp. $2123-2131$ 
Schwarzkopf, J., Sovar, G., Cader, T., Okamoto, K., Li, B.Q., and Ramaprian, B., 2004, "Effect of Spray Angle in Spray Cooling Thermal Management of Electronics," ASME Heat Transfer/Fluids Engineering Summer Conference, Charlotte, NC, July 11-15, 2004, Conference Proceedings

Scurlock, R.G., 1995, “Enhanced boiling heat transfer surfaces," Cryogenics, Vol. 35, No. 4, pp. 233-237

Sehmbey, M., Pais, M., and Chow, L., 1992, “A study of diamond laminated surfaces in evaporative spray cooling," Thin Solid Films, Vol. 212, pp. 25-29

Sehmbey, M., Chow, L., Pais, M., and Mahefkey, T., 1995, "High heat flux spray cooling of electronics," $12^{\text {th }}$ Symposium on Space Nuclear Power and propulsion, Albuquerque, NM, Jan., AIP Conference Proceedings no. 324, pp. 903-909

Sehmbey, M., Chow, L., Hahn, O., and Pais, M., 1995, "Spray Cooling of Power Electronics at Cryogenic Temperatures," Journal of Thermophysics and Heat Transfer, Vol. 9, No. 1, pp. 123-128

Selvam, R.P., Sarkar, M., Sarkar, S., and Ponnappan, R., 2006, "Effect of Vapor Bubble Size on Heat Transfer In Spray Cooling," Space Technology and Applications International Forum, Albuquerque, NM., February 13-17. 
Shedd, T.A., and Pautsch, A.G., 2005, "Full Coverage Spray Drainage System And Method For Orientation- Independent Removal Of High Heat Flux,” U.S. Patent Pending

Silk, E.A., Kim, J., and Kiger, K., 2004, "Investigation of Enhanced Surface Spray Cooling," ASME International Mechanical Engineering Congress, Anaheim, CA, Nov.13-19, IMECE2004 Conference Proceedings

Silk, E.A., Kim, J., and Kiger, K., 2005, "Impact of Cubic Pin Finned Surface Structure Geometry Upon Spray Cooling Heat Transfer," ASME International Electronic Packaging and Technical Conference, San Francisco, CA, July. 17-22, InterPACK 2005 Conference Proceedings

Silk, E.A., Kim, J., and Kiger, K., 2005, "Extended Flat Surface Studies Using PF5060," Greenbelt, MD, unpublished

Sirignano, W., 1999, Fluid Dynamics and Transport of Droplets and Sprays, Cambridge University Press, New York, NY.

Toda, S., 1972, “ A study of Mist Cooling ( $1^{\text {st }}$ Report: Investigation of Mist Cooling)," Transactions for the Japanese Society of Mechanical Engineering, Vol. 38, pp. $581-588$ 
Toda, S., 1973, “ A Study of Mist Cooling ( $2^{\text {nd }}$ Report: Theory of Mist Cooling and Its Fundamental Experiments )," Transactions of the Japanese Society of Mechanical Engineering, Vol. 39, pp. 2160-2193

Tong, L.S., and Tang, Y.S., Boiling Heat Transfer and Two-Phase Flow, Taylor and Francis, Washington, DC., 1997

Tu, C.V., and Wood, D.H., 1996, "Wall Pressure and Shear Stress Measurements Beneath an Impinging Jet," Experimental Thermal and Fluid Science, Vol. 13, pp. $364-373$

White, F. , Viscous Fluid Flow, McGraw-Hill, New York, 1991

Yadigaroglu, G., and Bergles, A.E., 1972, "Fundamental and higher-mode density wave oscillation in two-phase flow," ASME Journal of Heat Transfer, Vol. 94, pp. $189-195$

Yang, J., Pais, M., and Chow, L., 1993, “Critical Heat Flux Limits In Secondary Gas Atomized Liquid Spray Cooling,” Experimental Heat Transfer, Vol. 6, pp. 55-67

Yang, J.D., Chow, L.C., and Pais, M.R., 1996a, “An Analytical Method to Determine the Liquid Film Thickness Produced by Gas Atomized Sprays," ASME Journal of Heat Transfer, Vol. 118, pp. 255-258 
Yang, J., Chow, L., and Pais, M., 1996b, "Nucleate Boiling Heat Transfer in Spray Cooling," Journal of Heat Transfer, Vol. 118, pp. 668-671

Yerkes, K., Michalak, T., Silk, E., Swanson, T., McQuillen, J., and Golliher, E., 2002, "Investigation into the Micro-Gravity Effects on Two-Phase Spray Thermophysics," International Two-Phase Thermal Control Technology Workshop, Greenbelt, MD., September 24-26.

Yoshida, K., Yoshiyuki, A., Toshiharu, O., Yasuhiko, M., and Akira, Nagashima, 2001, "Spray Cooling Under Reduced Gravity," ASME Journal of Heat Transfer, Vol. 123, pp. 309-318 